
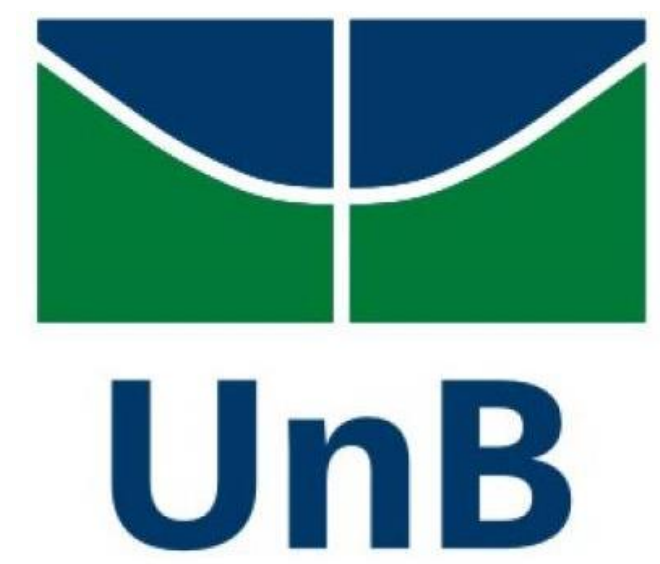

Instituto de Química

Programa de Pós-Graduação em Química

DISSERTAÇÃO DE MESTRADO

ESTUDO DA APLICABILIDADE DE MARCADORES LUMINESCENTES DE DISPAROS DE ARMAS DE FOGO

\author{
ALUNA: ALINE MARCELINO AROUCA \\ ORIENTADORA: INGRID TAVORA WEBER \\ CO-ORIENTADOR: MÁRCIO TALHAVINI
}

Brasília, DF

2016 


\author{
UNIVERSIDADE DE BRASÍLIA \\ INSTITUTO DE QUÍMICA \\ PROGRAMA DE PÓS-GRADUAÇÃO EM QUÍMICA \\ LABORATÓRIO DE INORGÂNICA E MATERIAIS - LIMA
}

\title{
ESTUDO DA APLICAÇÃO DOS MARCADORES LUMINESCENTES DE DISPAROS DE ARMAS DE FOGO
}

\author{
Dissertação de Mestrado apresentado ao \\ Programa de Pós-Graduação em Química.
}

\begin{abstract}
Aluna: Aline Marcelino Arouca
Orientadora: Ingrid Tavora Weber

Co-Orientador: Márcio Talhavini
\end{abstract}

Brasília

2016 


\section{FOLHA DE APROVAÇÃO}

Universidade de Brasília

Instituto de Química (IQ)

\section{FOLHA DE APROVAÇÃO}

Comunicamos a aprovação da Defesa de Dissertação de Mestrado do (a) aluno (a) Aline Marcelino Arouca, matrícula no 15/0103077, intitulada "Estudo da Aplicabilidade de Marcadores Luminescentes de Disparos de Arma de Fogo", apresentada no (a) Auditório Azul do Instituto de Química (IQ) da Universidade de Brasília (UnB) em 6 de dezembro de 2016.

Prof.a Dra. Ingrid Távora Weber

Presidente de Banca $(\mathrm{IQ} / \mathrm{UnB})$

Dr. Jorge Jardim Zacca

Membro Titular (INC/DPF)

Prof. Dr. Leonardo Giordano Paterno

Membro Titular (IQ/UnB)

Dra. Luciana Diniz Borges

Membro Suplente (IQ/UnB)

Em 6 de dezembro de 2016.

4 Caixa Postal 4478 - CEP: 70904-970 - Brasilia - DF - BRASIL

\% (61) $3107-3805$

a www.unb.brliq/pg posgiq@unb.br 
Aos meus pais, avô, esposo e

à minha eterna companheira de estudo Biga. 


\section{AGRADECIMENTOS}

Em primeiro lugar agradeço a Deus, por me conceder força e esperança para continuar a caminhada sempre. Sem Ele, nada faria sentido.

Gostaria de agradecer aos meus pais, que sempre me incentivaram a seguir os meus sonhos, sempre instigando e mostrando o caminho certo. Agradeço pela motivação e inspiração que sempre me forneceram.

Ao meu esposo e companheiro de vida, Felipe, que compartilhou todos os momentos importantes ao meu lado, sempre me ajudando e me tranquilizando. Você sempre será meu modelo. Te amo.

Agradeço também à minha família, em especial meu avô Marcelino e minha avó Odette (in memorian), que sempre irá me acompanhar em mente e coração. Às minhas irmãs caninas, Bia (in memorian) e Biga (in memorian), que sempre estiveram ao meu lado.

À Profa. Ingrid pela paciência, confiança e amizade. Obrigada por permitir que eu entrasse no mundo da Química Forense.

Ao Márcio, pelo apoio, ensinamentos e discussões. Obrigada pela dedicação na co-orientação e por sua amizade.

Aos Peritos Dr. Eduardo Sato, Maurício Leite Vieira e Ronei Maia Salvatori do Instituto Nacional de Criminalística da Polícia Federal Brasileira por me receberem e auxiliarem na pesquisa.

Aos colegas e amigos do LIMA e BSTR, por todos os momentos de descontração e de estudo que compartilhamos.

Aos amigos André e Rafael, pela colaboração na pesquisa.

À Marcella, pelas correções e dicas.

Aos professores e funcionários do IQ, que me ajudaram.

Ao Instituto Federal de Brasília-IFB, por permitir que eu realizasse minha pesquisa.

À CAPES, CNPq e FAP-DF, pelo apoio financeiro

For fim, agradeço a todos que contribuíram direta ou indiretamente nesse trabalho. 


\section{ÍNDICE}

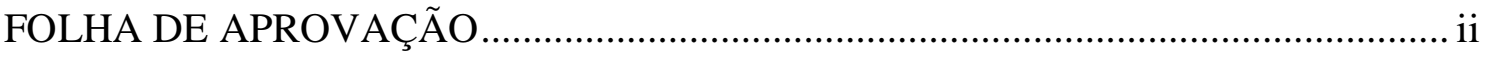

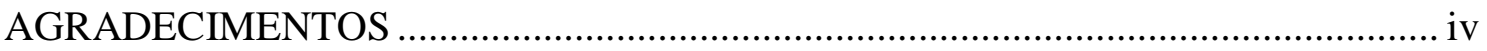

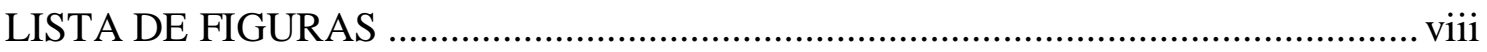

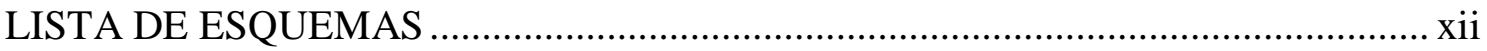

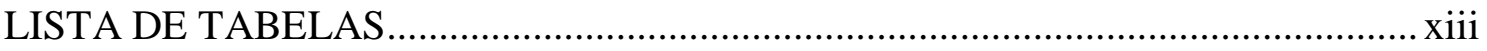

ABREVIATURAS E ACRÔNIMOS ................................................................... xiv

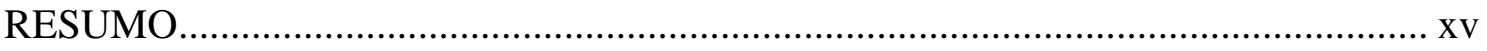

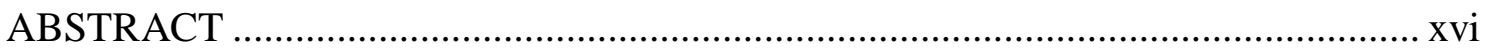

1. Introdução e objetivos ................................................................................. 1

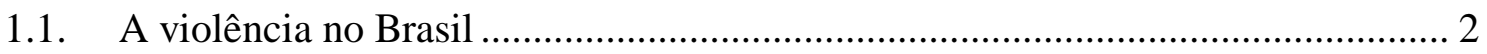

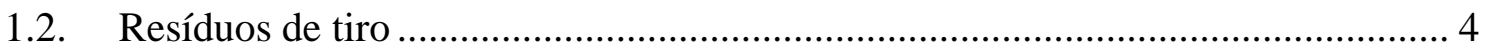

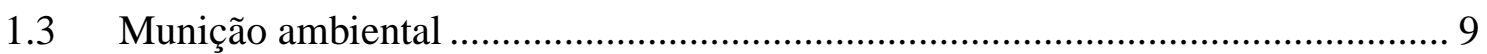

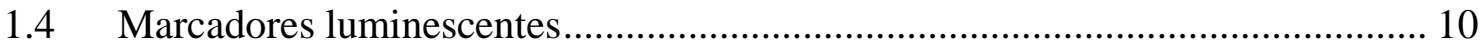

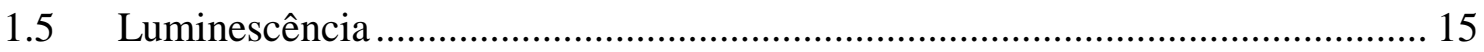

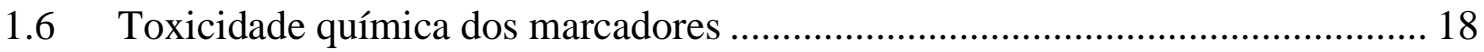

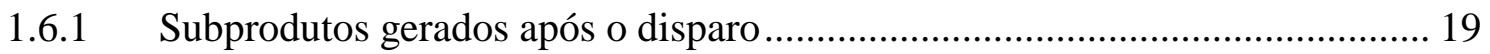

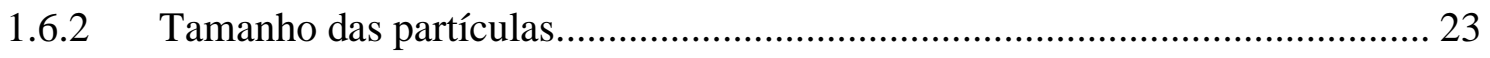

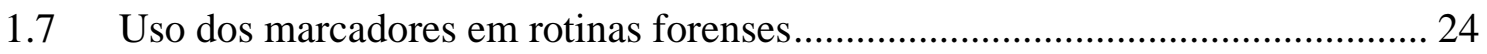

1.7.1 Influência da arma na produção do resíduo ................................................. 25

1.7.2 Estimativa da distância do disparo...................................................... 28

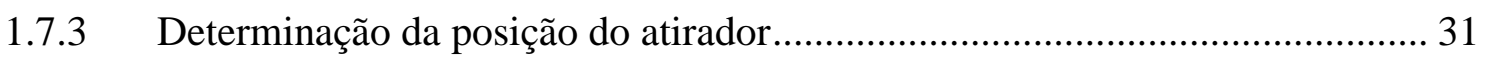

1.7.4 Transferência secundária e terciária de GSR ….............................................. 31

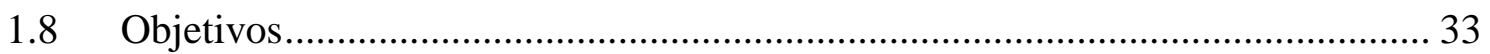

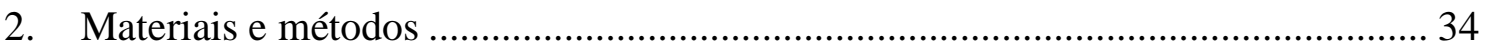

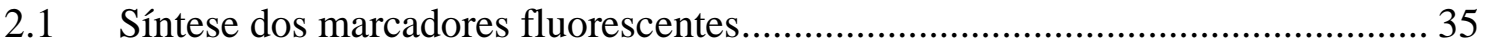

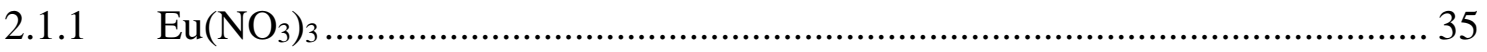




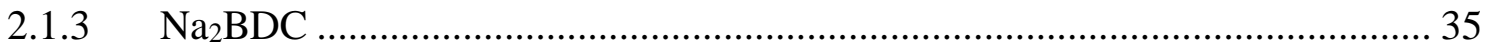

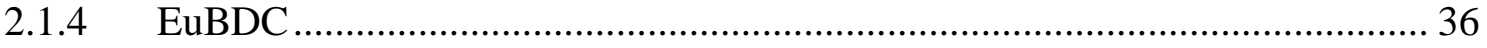

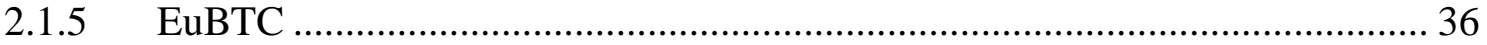

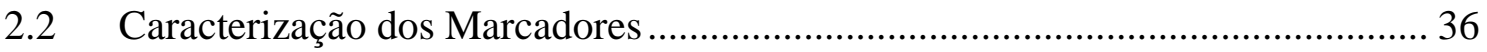

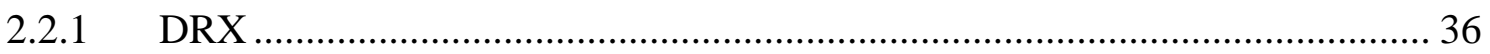

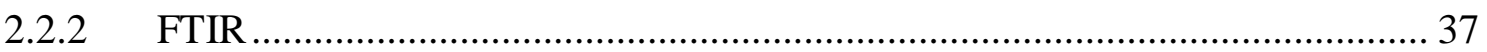

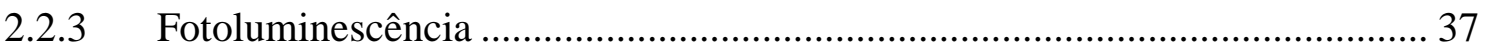

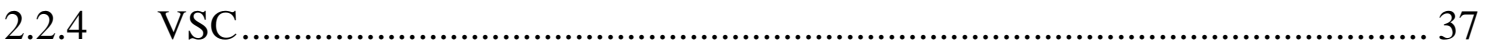

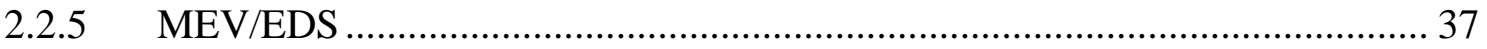

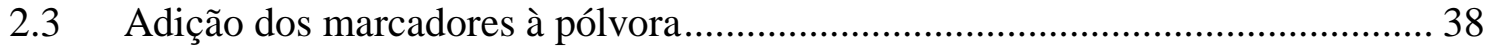

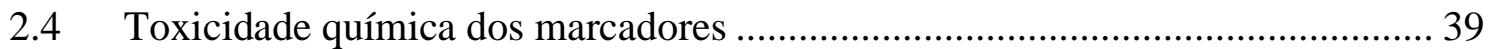

2.4.1 Subprodutos gerados após o disparo ............................................................... 39

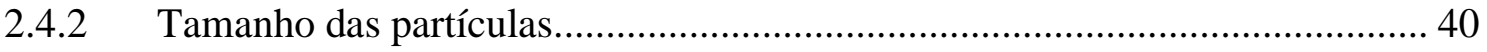

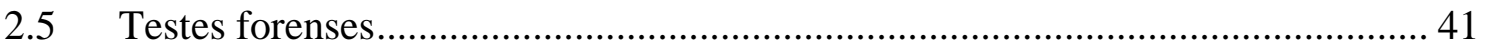

2.5.1 Influência do tipo da arma na produção do LGSR ....................................... 42

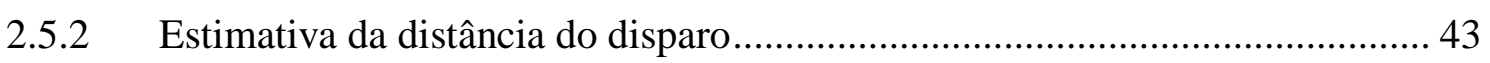

2.5.3 Determinação da posição do atirador/teste cego.............................................. 44

2.5.4 Transferência secundária e terciária........................................................... 45

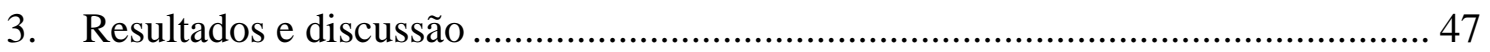

3.1 Caracterização dos marcadores luminescentes ................................................ 48

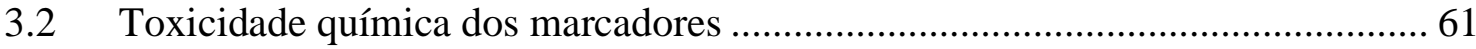

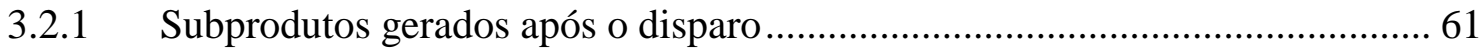

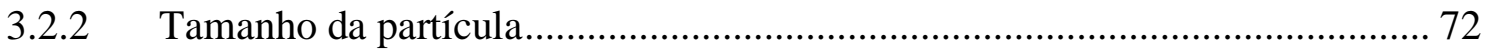

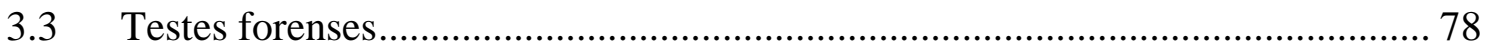

3.3.1 Influência do tipo de arma na produção do LGSR ........................................ 78

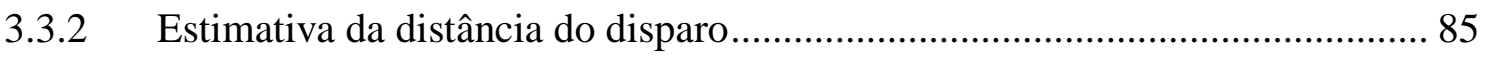


3.3.3 Determinação da posição do atirador/teste cego............................................ 94

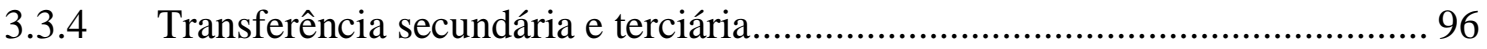

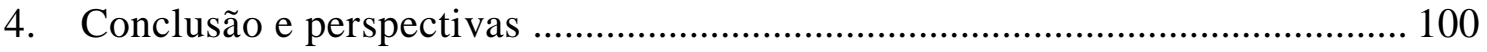

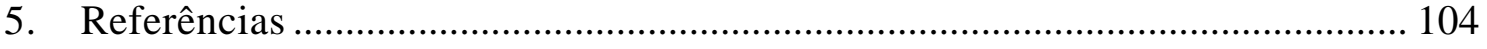

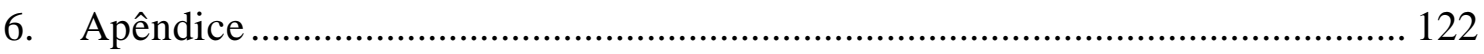




\section{LISTA DE FIGURAS}

Figura 1. EVOLUÇÃO DA TAXA DE MORTALIDADE (EM 100 MIL HABITANTES) POR ARMAS DE FOGO.

FIGURA 2. IMAGEM DA NUVEM FORMADA APÓS O DISPARO DE UMA ARMA DE FOGO. ......... 4

FIGURA 3. PARTES QUE COMPÕEM UMA MUNIÇÃO.......................................................... 5

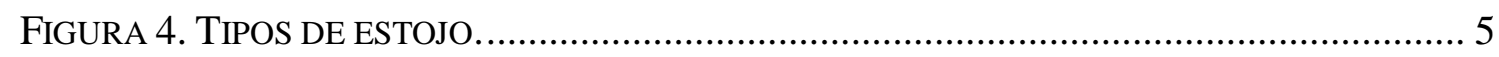

FIGURA 5. TIPOS DE PROJETEIS PRODUZIDOS PELA CBC ${ }^{\circledR}$ PARA PISTOLAS.......................... 5

FiguRA 6. BASES ENERGÉTICAS DOS PROPELENTES UTILIZADOS ATUALMENTE: (A) NITROCELULOSE, (B) NITROGLICERINA E (C) NITROGUANIDINA............................... 6

FiguRA 7. REGiÕES DA MÃO DE ATIRADORES SUBMETIDAS À COLETA: A) PALMA; B) DORSO;

C) REgião da PinÇA (PALMAR); D) REGIÃo dA PinÇA (DORSAL) ............................. 8

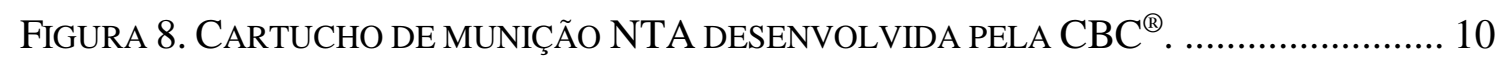

FIGURA 9. ESTRUTURAS COMUMENTE UTILIZADAS NA SÍNTESE DAS LMOFS. .................. 12

FIGURA 10. LIGANTES UTILIZADOS NA SÍNTESE DOS MARCADORES DE MUNIÇÕES NTA.. 12

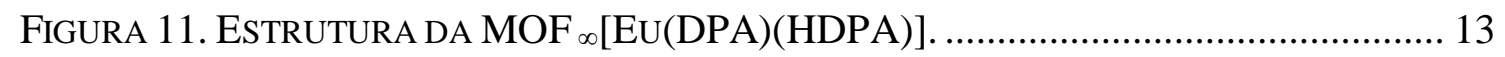

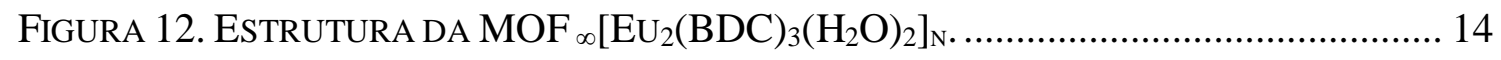

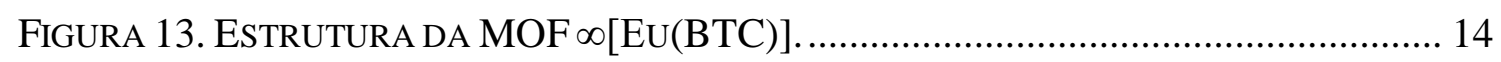

FIGURA 14. DiAGRAMA DE JABLONSKI ILUSTRANDO O EFEITO ANTENA. .......................... 17

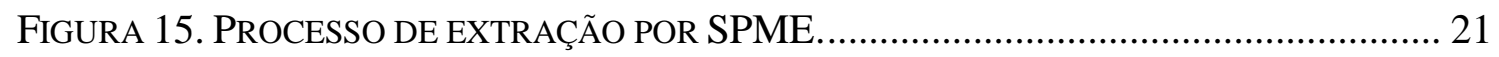

FIGURA 16. PADRÕES DE DISPERSÃO DO GSR OBTIDOS DE DIFERENTES DISTÂNCIAS EM QUE

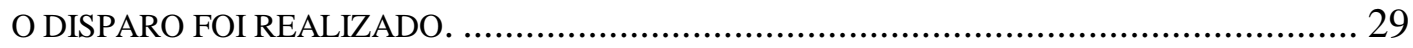

Figura 17. Stand de tiros do Setor de Balística do Instituto Nacional de CRIMINALÍSTICA DA PoLÍCIA FEDERAL BRASILEIRA. ................................................ 42

Figura 18. Armas testadas: (A) Browning, (B) Jericho (C) SMith \& Wesson, (D)

TAurus, (E) GLOCK G17 E (F) GLOCK G26. ..................................................... 42

FIGURA 19. LAYOUT DA CENA DO CRIME SIMULADA PARA REALIZAÇÃO DO TESTE CEGO. 45

FIGURA 20. DIFRATOGRAMA DE RAIOS X DO MARCADOR EUDPA. .................................. 48

FIGURA 21. DIFRATOGRAMA DE RAIOS X DO MARCADOR EUBDC................................ 49

FIGURA 22. DIFRATOGRAMA DE RAIOS X DO MARCADOR EUBTC................................... 49

Figura 23. ESTRUtura dos MARCADORES (A) $\infty_{\infty}[\mathrm{EU}(\mathrm{DPA})-(\mathrm{HDPA})], \quad$ (B)

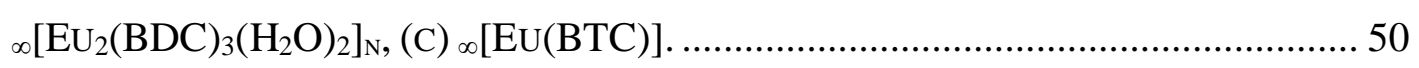

FIGURA 24. ESPECTRO NO INFRAVERMELHO DO MARCADOR EUDPA.............................. 50

FIGURA 25. ESPECTRO DE INFRAVERMELHO DO MARCADOR EUBDC............................. 51 
FIGURA 26. ESPECTRO DE INFRAVERMELHO DO MARCADOR EUBTC.

Figura 27. ESPECTROS DE EXCITAÇÃO dOS MARCADORES (A) EUDPA, (B) EuBDC E (C) EUBTC.

Figura 28. Espectros de EMissÃo dos MARCADORES (A) EuDPA, (B) EuBDC E (C) EUBTC. 56

FIGURA 29. IMAGENS ADQUIRIDAS POR VSC DOS MARCADORES (A) EUDPA, (B) EUBDC E

(C) EUBTC COM LUZ BRANCA E LUZ UV $(\Lambda=254 \mathrm{NM})$. 57

Figura 30. DiagRAMA DE CROMATICIDADE CIE 1931 OBTIDO POR VSC SOB RADIAÇÃO UV $(\Lambda=254 \mathrm{NM})$ DOS MARCADORES EUDPA(+1), EuBDC(+2) E EUBTC(+3)...... 58

Figura 31. Micrografias dOS MARCADORES EuDPA, EUBDC E EUBTC. 59

FIGURA 32. ESPECTROS DE DISPERSÃO DE ENERGIA DOS MARCADORES EUDPA, EUBDC E EUBTC 60

Figura 33. CROMATOGRAMAS DOS CARTUCHOS DEFLAGRAdOS COM OS MARCADORES EUDPA (A), EUBDC (B), EUBTC (C), E MUNIÇÃO NTA. 64

FIGURA 34. COMPARAÇÃO ENTRE OS CROMATOGRAMAS DOS MARCADORES (A) EUDPA, (B) EuBDC E (C) EuBTC COM O CROMATOGRAMAS DA MuniçÃo NTA. O TEMPO DE RETENÇÃO DOS COMPOSTOS PIRIDINA E BENZENO ESTÃO DEMARCADOS COM (*)..... 66

FIGURA 35. COMPARAÇÃO ENTRE OS ESPECTROS DE MASSAS DOS COMPOSTOS PIRIDINA E BENZENO OBTIDOS NOS EXPERIMENTOS COM OS ESPECTROS DE MASSAS PADRÕES FORNECIDOS PELA BIBLIOTECA DIGITAL 67

FiguRA 36. HistogRAMA CONSOLIDADO DE TODAS AS PARTÍCULAS COLETADAS DA MUNIÇÃO NTA. 74

FiguRA 37. HistOGRAMAS CONSOLIDADOS DAS PARTÍCULAS COLETADAS DA MUNIÇÃO MARCADA, SENDO: (A) TODAS AS PARTÍCULAS, (B) PARTÍCULAS QUE CONTÉM EURÓPIO (CLASSIFICADAS) E (C) PARTÍCULAS QUE NÃO CONTEM EURÓPIO (NÃO CLASSIFICADAS).

FigURA 38. MiCROGRAFIAS DOS RESÍDUOS ENCONTRADOS NAS MÃO E ARMAS: (A) Browning, (B) Jericho (C) SMith \& Wesson, (D) TAurus, (E) Glock G17 E (F) GLOCK G26. 80

FIGURA 39. ESPECTROS DE DISPERSÃO DE ENERGIA RESÍDUOS ENCONTRADOS NAS MÃO E ARMAS: (A) BROWNING, (B) JERICHO (C) SMITH \& Wesson, (D) TAURUS, (E) GlOCK G17 E (F) GLOCK G26. 81

FIGURA 40 IMAGENS DAS PARTÍCULAS OBSERVADAS SOBRE AS ARMAS OBTIDAS NO VSC SOB RADIAÇÃO UV ( $\Lambda=254$ NM) APÓS OS DISPAROS COM NTA MARCADA: (A) 
Browning, (B) Jericho (C) Smith \& Wesson, (D) TAurus, (E) Glock G17 E (F)

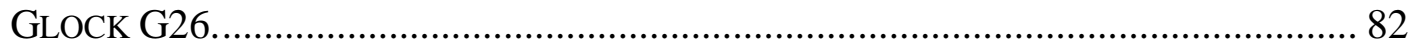

FIGURA 41. IMAGENS VSC DAS MÃOS DOS ATIRADORES OBTIDO SOB RADIAÇÃO UV $(\Lambda=$ 254 NM) USANdo AS ARMas: (A) DE Browning, (B) Jericho (C) SMith \& WeSSON, (D) TAurus, (E) GLOCK G17 E (F) GLOCK G26. 83

FIGURA 42. IMAGEM OBTIDA SOB RADIAÇÃO UV $(\Lambda=254$ NM) DA PARTÍCULA DE LGSR DEPOSITADA NO ROSTO DO ATIRADOR UTILIZANDO A ARMA TAURUS. 84

FIGURA 43. IMAGENS DO ALVO (TECIDO DE ALGODÃO) OBTIDAS NO VSC SOB IRRADIAÇÃO UV $(\Lambda=254 \mathrm{NM})$ COM O MARCADOR EUDPA EM FUNÇÃO DAS DISTÂNCIAS DO ATIRADOR: (A) DE 6 CM, (B) 30 CM, (C) 60 CM E (D) 120 CM. A LOCALIZAÇÃO DO ORIFÍCIO DE ENTRADA DO PROJÉTIL FOI MARCADA COMO UM CÍRCULO BRANCO NA FOTOGRAFIA. 86

FIGURA 44 IMAGENS DO ALVO (TECIDO DE ALGODÃO) OBTIDAS NO VSC SOB IRRADIAÇÃO UV $(\Lambda=254 \mathrm{NM})$ COM O MARCADOR EUBDC EM FUNÇÃO DAS DISTÂNCIAS DO ATIRADOR: (A) DE 6 CM, (B) 30 CM, (C) 60 CM E (D) 120 CM. A LOCALIZAÇÃO DO ORIFÍCIO DE ENTRADA DO PROJÉTIL FOI MARCADA COMO UM CÍRCULO BRANCO NA FOTOGRAFIA. 86

FIGURA 45. IMAGENS DO ALVO (TECIDO DE ALGODÃO) OBTIDAS NO VSC SOB IRRADIAÇÃO UV $(\Lambda=254 \mathrm{NM})$ COM O MARCADOR EUBTC EM FUNÇÃO DAS DISTÂNCIAS DO ATIRADOR: (A) DE 6 CM, (B) 30 CM, (C) 60 CM E (D) 120 CM. A LOCALIZAÇÃO DO ORIFÍCIO DE ENTRADA DO PROJÉTIL FOI MARCADA COMO UM CÍRCULO BRANCO NA FOTOGRAFIA.

FIGURA 46. IMAGENS DE VSC $(\Lambda=254$ NM) DOS TECIDOS DE ALGODÃO DISPARADOS ANTES E DEPOIS DE SEREM CHACOALHADOS, ATIRADOS NAS DISTÂNCIAS: (A) 6 CM (B) 30 CM (C) $60 \mathrm{CM} \mathrm{E}$ (D) $120 \mathrm{CM}$. 88

FiguRA 47. IMAGENS DA ZONA DE ENXUGO DAS AMOSTRAS DE TECIDO, OBTIDAS POR DE VSC ( $\Lambda=254$ NM), QUANDO O DISPARO É REALIZADO NAS DISTÂNCIAS: (A) 6 CM, (B) $30 \mathrm{CM}$, (C) 60 CM E (D) 120 CM DO ALVO, UTILIZANDO O MARCADOR EUDPA. 89

FiguRA 48. IMAGENS DO ALVO (TECIDO DE ALGODÃO COM SANGUE) OBTIDOS NO VSC SOB IRRADIAÇÃO UV $(\Lambda=254 \mathrm{NM})$ COM O MARCADOR EUBDC EM FUNÇÃO DAS DistÂNCIAS DO ATIRADOR: (A) DE 6 CM, (B) $30 \mathrm{CM}$, (C) $60 \mathrm{CM}$ E (D) $120 \mathrm{CM}$. A LOCALIZAÇÃO DO ORIFÍCIO DE ENTRADA DO PROJÉTIL FOI MARCADA COMO UM CÍRCULO BRANCO NA FOTOGRAFIA. 90 
FIGURA 49. IMAGENS DE VSC COM LUZ BRANCA DAS PARTÍCULAS LUMINESCENTE COLETADAS DOS TECIDOS ENSANGUENTADOS DISPARADOS NAS DISTÂNCIAS DE 6, 30, 60 E 120 CM DO ALVO. 91

FIGURA 50. IMAGENS DE VSC $(\Lambda=254 \mathrm{NM})$ DAS PARTÍCULAS LUMINESCENTE COLETADAS DOS TECIDOS ENSANGUENTADOS DISPARADOS NAS DISTÂNCIAS DE 6, 30, 60 E 120 CM DO ALVO 91

FIGURA 51. MICROGRAFIAS DOS RESÍDUOS DEPOSITADOS NOS TECIDOS ENSANGUENTADOS DISPARADOS NAS DISTÂNCIAS DE 6, 30, 60 E 120 CM DO ALVO 92

FIGURA 52. ESPECTROS DE DISPERSÃO DE ENERGIA RESÍDUOS DEPOSITADOS NOS TECIDOS ENSANGUENTADOS DISPARADOS NAS DISTÂNCIAS DE 6, 30,60 E 120 CM DO ALVO... 93

Figura 53. IMAGENS DO ALVO (TECIDO DE ALGODÃO) DISPARADO A UMA DISTÂNCIA DESCONHECIDA E UMA DISTÂNCIA CONHECIDA DO (A) PRIMEIRO, (B), SEGUNDO E (C) TERCEIRO TESTE CEGO REALIZADO, OBTIDOS NO VSC SOB IRRADIAÇÃO UV $(\Lambda=254 \mathrm{NM})$ 94

FIGURA 54. IMAGEM DO LGSR ENCONTRADO NO LOCAL DO DISPARO NA CENA DO CRIME SIMULADA (POSIÇÃO 3B) VISUALIZADOS COM UMA LÂMPADA UV PORTÁTIL $(\Lambda=254 \mathrm{NM})$ 95

FIGURA 55. IMAGENS DE VSC (254 NM) DAS PARTÍCULAS COLETADAS DO (A) ATIRADOR (1), (B) INDIVÍDUO \#2 E (C) INDIVÍDUO \#3. 97

FIGURA 56. INTERFACE DO PROGRAMA INCAGSR@. 97 


\section{LISTA DE ESQUEMAS}

ESQUEMA 1. FORMAÇÃO DA NUVEM DE GSR APÓS O DISPARO DE UMA ARMA DE FOGO.. 26

ESQUEMA 2. CLASSIFICAÇÃO DE UMA ARMA DE FOGO.................................................. 27

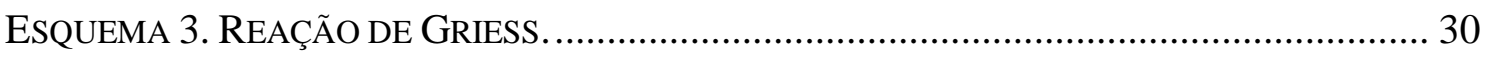

ESQUEMA 4. ESQUEMA REPRESENTATIVO DA TRANSFERÊNCIA PRIMÁRIA E SECUNDÁRIA DE GSR. 31

ESQUEMA 5. PROCESSO DE ADIÇÃO DOS MARCADORES À PÓLVORA DE UMA MUNIÇÃO NTA 9 MM. 38

ESQUEMA 6. CARTUCHO DE UMA MUNIÇÃO 9MM EM UM CG VIAL PARA EXTRAÇÃO DOS VOLÁTEIS APÓS O DISPARO. 39

ESQUEMA 7: CADEIA DE APERTOS DE MÃO E ANÁLISES REALIZADAS NO EXPERIMENTO. . 46 


\section{LISTA DE TABELAS}

TABELA 1. TEMPOS CARACTERÍSTICOS PARA OS VÁRIOS PROCESSOS DE DESATIVAÇÃO. . 16

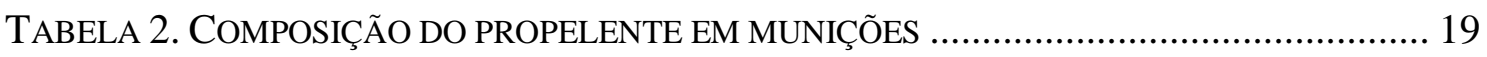

TABELA 3. VANTAGENS E DESVANTAGENS DA TÉCNICA DE SPME................................. 22

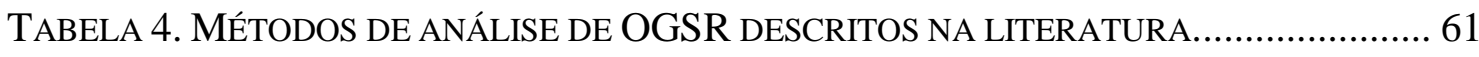

TABEla 5. COMPOSTOS ENCONTRADOS APENAS NOS CARTUCHOS DAS MUNIÇÕES MARCADAS COM EUDPA, EUBDC E EUBTC. OS COMPOSTOS EM NEGRITO APRESENTARAM UMA ÁREA DE INTEGRAÇÃO MAIOR QUE A DO COMPOSTO N,N'-

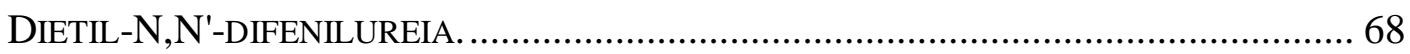

TABELA 6. DAdOS DAS PARTíCULAS COLETADAS DA MUNIÇÃO NTA................................ 75

TABELA 7. DADOS DAS PARTíCULAS COLETADAS DA MUNIÇÃO MARCADA....................... 77

TABELA 8. ARMAS UTILIZADAS NO EXPERIMENTO E SUAS CARACTERÍSTICAS. ................. 79

TABELA 9. POSIÇÕES INDICADAS PELOS ATIRADORES E IDENTIFICADAS PELOS PERITOS.. 96 TABELA 10. NÚMERO DE PARTíCULAS LGSR ENCONTRADOS NAS MÃOS APÓS APERTOS DE

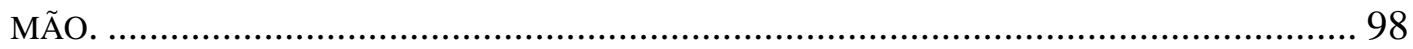

TABELA 11. EFICIÊNCIA DA TRANSFERÊNCIA SECUNDÁRIA E TERCIÁRIA.......................... 99 


\section{ABREVIATURAS E ACRÔNIMOS}

ASTM - Sociedade Americana de Testes e Materiais (do inglês American Society for Testing and Materials)

ATR - Refletância total atenuada (do inglês Attenuated Total Reflectance)

$\mathrm{CBC}^{\circledR}$ - Companhia Brasileira de Cartuchos

CG - Cromatografia Gasosa

EDS - Espectroscopia por Dispersão de Energia

EM - Espectrometria de Massas

EPA - Agência de Proteção Ambiental (do inglês Environmental Protection Agency)

FLASCO - Faculdade Latino-americana de Ciências Sociais (do espanhol Facultad Latinoamericana de Ciencias Sociale)

GSR - Resíduo de Disparo de Arma de Fogo ou Resíduo de Tiro (do inglês GunShot Residue)

$\mathrm{H}_{2} \mathrm{DPA}$ - Ácido dipicolínico

$\mathrm{H}_{2} \mathrm{BDC}$ - Ácido benzeno-1,4-dicarboxílico

$\mathrm{H}_{3} \mathrm{BTC}$ - Ácido benzeno-1,3,5-tricarboxílico

IGSR - Resíduo de Tiro Inorgânico (do inglês Inorganic GunShot Residue)

INC/PF - Instituto Nacional de Criminalística da Polícia Federal

LGSR - Resíduo de Tiro Luminescente (do inglês Luminescent Gunshot Residue)

LIMA - Laboratório de Inorgânica e Materiais

LMOF - Redes Metalorgânicas com Lantanídeos (do inglês Lanthanide Metal-Organic

Framework)

Ln - Lantanídeo

MEV - Microscopia Eletrônica de Varredura

Micro-XRF - Espectrometria de fluorescência de Micro Raios X

MIL - Materiais do Instituto Lavoisier (do inglês Material of Institute Lavoisier)

MOF - Redes Metalorgânicas (do inglês Metal-Organic Framework)

MP - Material Particulado

$\mathrm{NC}$ - Nitrocelulose

$\mathrm{NG}$ - Nitroglicerina

NIOSH - Instituto Nacional de Segurança e Saúde Ocupacional (do inglês National Institute for Occupational Safety and Health

NQ - Nitroguanidina

NTA - Munição não Tóxica (do inglês Non Toxic Ammunition)

OGSR - Resíduo de Tiro Orgânico (do inglês Organic GunShot Residue)

OSHA - Administração de Saúde Ocupacional e Segurança (do inglês Occupational

Safety and Health Administration)

PF - Polícia Federal Brasileira

SPME - Microextração por Fase Sólida (do inglês Solid Phase Micro Extration)

VSC - Vídeo Espectral Comparador (do inglês Video Spectral Comparator) 


\section{RESUMO}

Com o desenvolvimento da munição não-tóxica (NTA), a identificação do de resíduos de tiro (GSR) por Microscopia Eletrônica de Varredura acoplada à Espectroscopia de Raios X por Dispersão de Energia (MEV/EDS) foi prejudicada, sendo que adição de um marcador luminescente à munição tornou-se uma alternativa para identificar resíduos de tiro provenientes de munições NTA. Apesar dos marcadores apresentarem excelentes resultados na identificação de resíduos provenientes da munição NTA, pouco se sabe acerca da sua toxicidade, sendo desejável que esses sejam atóxicos. Dois fatores são avaliados nesse trabalho: os subprodutos formados pelo disparo de uma arma de fogo municiada com NTA marcada e o tamanho das partículas dos marcadores formadas após o disparo. Foi possível determinar uma variedade de compostos orgânicos que apresentam uma toxicidade relativa, contudo, muitos deles estão ligados à degradação da pólvora utilizada. Com relação ao tamanho das partículas, foi possível determinar que tanto a munição NTA, quanto a munição NTA marcada apresentam uma maior quantidade de partículas menores que 2,5 micrômetros, indicando uma certa toxicidade. Contudo, como a adição do marcador não alterou, de forma significativa, os padrões de dispersão das partículas, quando comparados com os padrões de dispersão da NTA, podese inferir que a toxicidade da munição marcada não foi alterada. A segunda parte desse trabalho consiste na aplicação dos marcadores desenvolvidos pelo nosso grupo em uma série de experimentos para simular rotinas forenses, para avaliarmos o comportamento dos resíduos de tiro luminescentes (LGSR). Foi testada a viabilidade do uso do padrão de dispersão do LGSR para estimar a distância de disparo e identificar a posição do atirador, com a realização de testes cegos. Em todos os casos testados, a posição do atirador e a distância em que o tiro foi deflagrado foi determinada com precisão, mesmo para tiros distantes. Além disso, foi avaliada a influência do tipo de arma (diferentes pistolas) no padrão de dispersão LGSR, no qual foi possível verificar que os diferentes tipos de mecanismos não alteram a formação do resíduo luminescente. Finalmente, também foi avaliado se as partículas luminescentes podem ser transferidas por contato direto (aperto de mão). Determinou-se que elas podem ser submetidas à transferência secundária e terciária, influenciando o modo que esta evidência deve ser interpretada na análise de uma cena de crime

Palavras Chave: Resíduo de tiro, marcador luminescente, munição não tóxica, munição livre de chumbo, investigação forense. 


\begin{abstract}
With the introduction of non-toxic ammunition (NTA), gunshot residue (GSR) identification by Scanning Electron Microscopy/Energy Dispersive X ray analysis (SEM/EDS) was impaired, in which, the use of a luminescent marker has become an alternative to identify shooting residue. Despite the markers present excellent results in GSR from NTA ammunition, little is known about its toxicity, requiring that these are non-toxic. Two factors are evaluated in this work: the by-products formed by firing a firearm loaded with marked NTA ammunition and the particle size formed after the shot. It was possible to determine a variety of organic compounds which have a relative toxicity, however, many of them are connected to the degradation of the gunpowder used. The particle size, it was determined that both NTA ammunition marked as NTA ammunition have a greater amount of particles smaller than 5 microns, indicating a degree of toxicity. However, since the addition of the marker did not alter significantly the dispersion patterns compared to NTA, the toxicity of ammunition marked was considered the same as the NTA. The second part of this work consists of applying the markers developed by our group in a series of experiments to simulate forensic routines to evaluate the behavior of luminescent GSR (LGSR) To determinate the performance of the markers developed by our group, a series of experiments were conduct to mimic forensic routines and determinate the luminescent gunshot residue (LGSR) behavior. It was evaluated the viability of the use of LGSR dispersion pattern to estimate the shooting distance and identify the position of the shooter, as the realization of blind tests. In all cases, the position of the shooter and the distance at which the shot was triggered was accurately determined, even for distant shots. Furthermore, the influence of the type of weapon (different pistols) in LGSR dispersion pattern was evaluated, in which it was possible to verify that different types of mechanisms do not alter the formation of the luminescent residue. Finally, it was also evaluated if the luminescent particle can be transferred by direct contact (handshake). It was determined that the luminescent particle can undergo secondary and tertiary transfer, influencing the way which this evidence should be interpreted in the analysis of a crime scene.
\end{abstract}

Keywords: Gunshot residue, luminescent marker, non-toxic ammunition, lead free ammunition, forensic investigation. 


\section{INTRODUÇÃO E OBJETIVOS}




\subsection{A violência no Brasil}

No período de 1980 a 2012, o número de vítimas fatais por armas de fogo na população brasileira total foi de 880.386, segundo estudo intitulado Mapa da Violência realizado pela FLASCO (do espanhol Facultad Latinoamericana de Ciencias Sociales) e publicado anualmente pelo governo brasileiro. ${ }^{1}$ Do referido quantitativo de vítimas, 747.760 (85\%) são de homicídios, 35.957 (4\%) de suicídios, 15.312 (2\%) de acidentes e 81.357 (9\%) de causas indeterminadas. Somente no ano de 2012, houve 42.416 vítimas fatais de armas de fogo em todo o Brasil.

No caso da região Centro-Oeste, considerando os anos 2002-2012, houve um forte crescimento da mortalidade $(44,9 \%)$ causada por armas de fogo. ${ }^{1}$ Em 2012, a região apresentou 3.822 vítimas, sendo 803 do Distrito Federal, 1.951 de Goiás, 790 do Mato Grosso e 358 do Mato Grosso do Sul. ${ }^{1}$ Comparando as taxas de óbito (por 100 mil) por arma de fogo na população total, o DF fica em segundo lugar com uma taxa de 30,3, ficando atrás de Goiás que possui a maior taxa $-31,3$.

No Brasil, a taxa de mortalidade (por 100 mil) na população total por armas de fogo no ano de 2012 foi de 21,9 e, especificamente nos casos de homicídios, 20,7. ${ }^{1}$ No mundo, segundo estudo publicado pela $\mathrm{ONU},{ }^{2}$ a taxa média de homicídios é de 6,2 para cada 100 mil pessoas, mas o sul da África e a América Central têm taxas quatro vezes maiores.

O Estatuto do Desarmamento, aprovado pela Lei $n^{\circ} 10.826$ de 22 de dezembro de 2003, que dispõe sobre registro, posse e comercialização de armas de fogo e munição, foi um passo no controle de mortes envolvendo armas de fogo. Segundo o estudo publicado em 2015, ${ }^{1}$ após a promulgação da Lei, a taxa de mortalidade (em 100 mil habitantes) por armas de fogo apresentou uma sutil queda conforme demonstrado na Figura 1. Contudo, em 2012, a taxa aproximou-se do valor observado em 2003, indicando a necessidade de uma revisão na política de desarmamento ou no desenvolvimento de uma nova política pública direcionada para a redução do número de mortes envolvendo armas de fogo. 


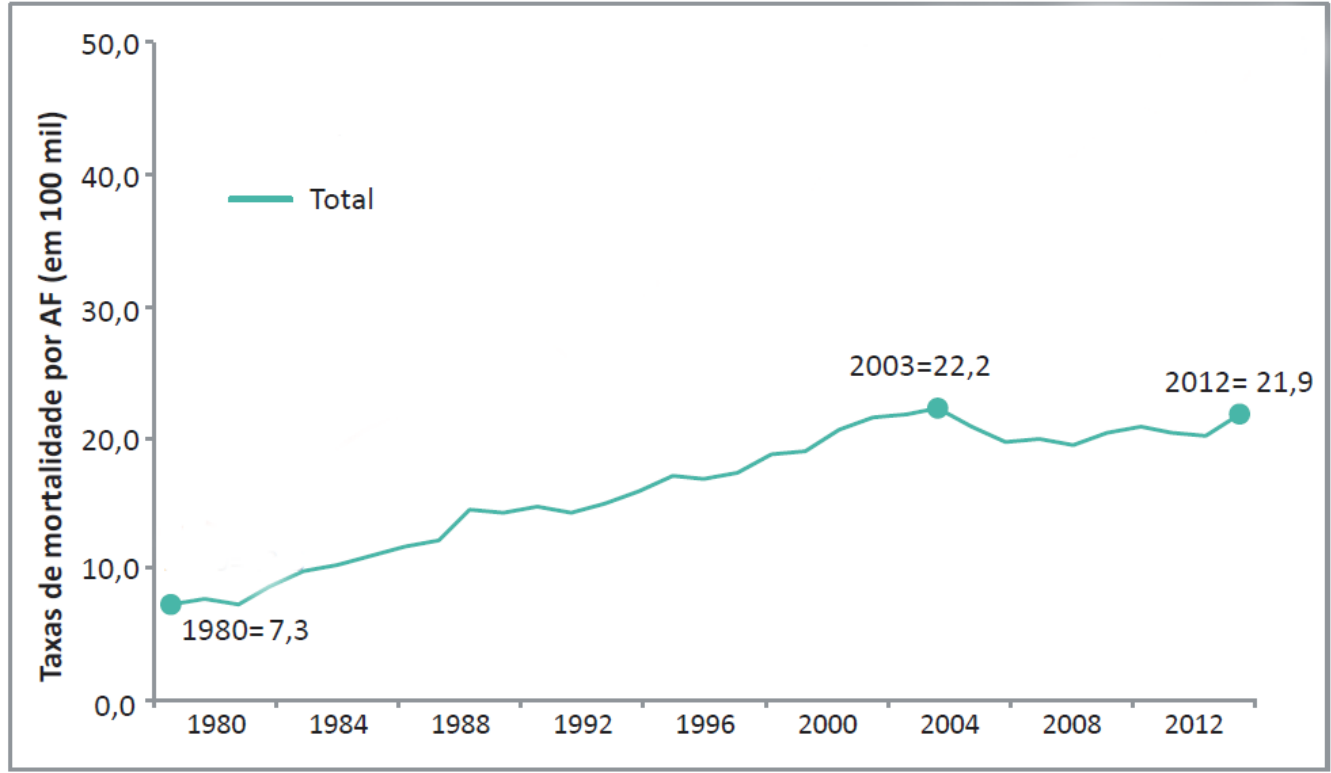

Figura 1. Evolução da taxa de mortalidade (em 100 mil habitantes) por armas de fogo. Adaptada da referência 1.

Apesar da política iniciada em 2003, a qual incluía a entrega espontânea da arma com direito à indenização, o Brasil ainda apresenta um vasto arsenal de armas de fogo. Dreyfus $^{3}$ estima que existam no Brasil cerca de 30,5 milhões de armas, das quais 15,3 milhões são privadas, 6,8 milhões registradas, 8,5 milhões não registradas e aproximadamente 3,8 milhões dessas estão em mão de criminosos. De acordo com o estudo Armas de Pequeno Porte no Brasil, Produção, Comércio e Porte ( do inglês Small Arms in Brazil: Production, Trade, and Holdings), publicado em 2010, ${ }^{4}$ o Brasil é o maior produtor de armas de pequeno porte e equipamentos militares da América do Sul, além de ser o produtor com a distribuição mais diversificada do mundo, com exceção dos Estados Unidos da América.

A magnitude dos números expostos evidencia a gravidade da situação e a necessidade de um controle mais rígido sobre a disseminação dessas armas e a sua utilização. Vale destacar que a simples questão sobre a disponibilidade de armas de fogo não deve esgotar a questão da violência. Análises científicas mais profundas são requeridas, tanto com um viés político-social, quanto técnico-científico.

Além disso, sociedades que apresentam altas taxas de homicídios cometidos com o uso de armas de fogo são aquelas que também apresentam as maiores taxas globais de homicídio. Isso está relacionando diretamente com o baixo poder coercitivo e com a fraca capacidade dos Estados no cumprimento da lei, o baixo investimento na educação e o alto número de casos não resolvidos, gerando uma sensação de impunidade. 
Nesse sentido, a ciência pode fornecer ferramentas que auxiliem o trabalho das autoridades policiais, de forma que estas possam trabalhar de forma mais rápida e precisa, solucionando crimes e imputando responsabilidades. Umas das ferramentas de grande importância são os Resíduos de Tiro (GSR), que permitem relacionar atirador, vítima e arma em uma cena de crime.

\subsection{Resíduos de Tiro}

No momento do disparo de uma arma de fogo, gases provenientes da queima da massa iniciadora e da pólvora são expelidos pelo cano (Figura 2) formando partículas sólidas chamadas de Resíduos de Tiro (GSR). ${ }^{5-10}$ O resíduo formando pode ser classificado como resíduo de tiro orgânico (OGSR) e resíduo de tiro inorgânico (IGSR), também conhecido somente como GSR. ${ }^{11}$ O OGSR é composto principalmente por compostos orgânicos provenientes do propelente, massa iniciadora e lubrificantes. ${ }^{6}$ Já o $^{\circ}$ IGSR consiste em uma mistura de compostos inorgânicos, como óxidos, nitratos, nitritos e partículas metálicas. ${ }^{6}$

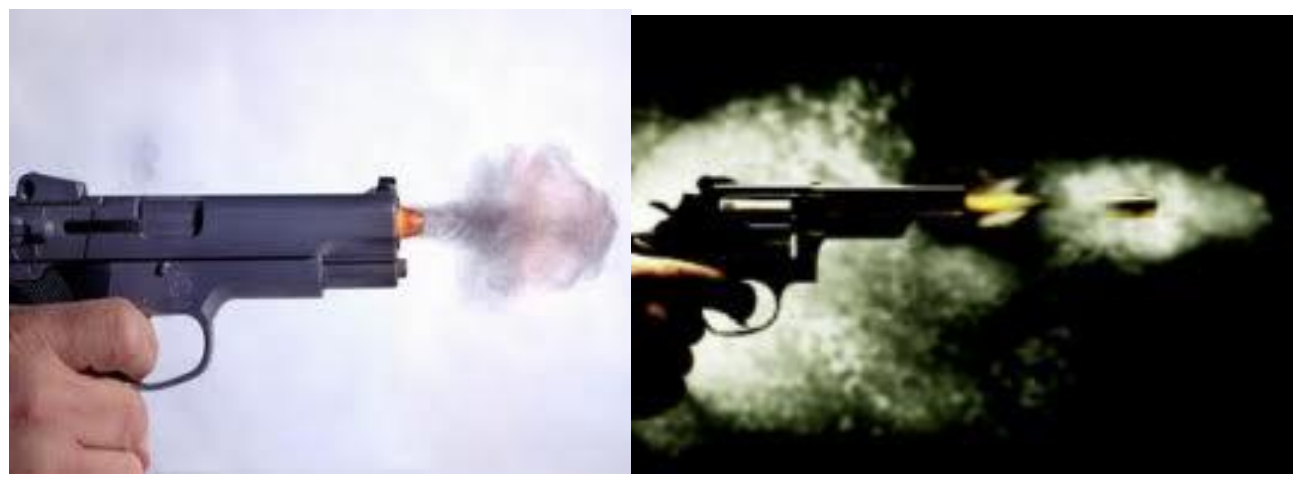

Figura 2. Imagem da nuvem formada após o disparo de uma arma de fogo.

A análise de GSR, em cenas de crime, pode ajudar a solucionar diversos casos, criando uma ligação entre o atirador, a vítima e a arma do crime. ${ }^{7}$ Ela produz evidências que podem incluir ou excluir pessoas da cena do crime, diferenciar entre suicídio e homicídio e até mesmo auxiliar na estimativa da distância em que a arma foi disparada. ${ }^{6}$

A munição (Figura 3) pode ser dividida nas seguintes partes: projétil, estojo, pólvora (propelente) e a espoleta, onde está acondicionada a massa iniciadora. 


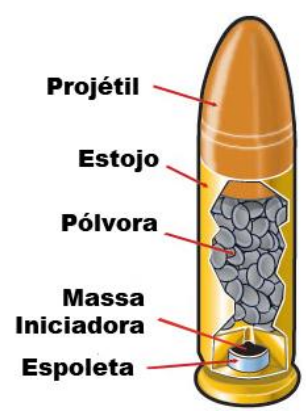

Figura 3. Partes que compõem uma munição. Adaptada da referência 12.

O estojo ou cartucho, geralmente é fabricado de latão (liga contendo $70 \%$ de cobre e 30\% de zinco). Sua função é unir o projetil com o propelente e a massa iniciadora, dando sustentação à munição. Os estojos podem ser encontrados em diversos formatos e tamanho, dependendo da sua aplicação (Figura 4). ${ }^{13}$
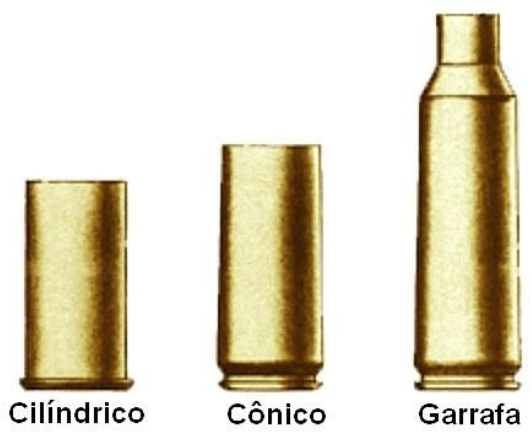

Figura 4. Tipos de estojo. Adaptada da referência 14.

O projétil é a parte que será efetivamente expelida durante o disparo. Seu formato e o material de sua fabricação dependem do seu propósito, podendo ser de ponta plana, expansivo ponta oca, expansivo ponta plana, dentre outros. Além disso, os projéteis podem ser totalmente, parcialmente ou não encamisados. A Figura 5 demonstra alguns tipos de projéteis produzidos pela $\mathrm{CBC}^{\circledR}$ (Companhia Brasileia de Cartuchos) para pistolas.
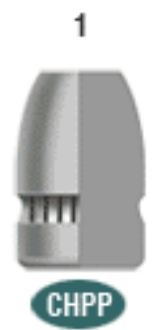

Chumbo ponta plana

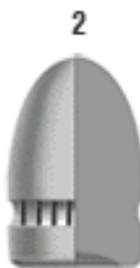

CHOG

Chumbo ogival
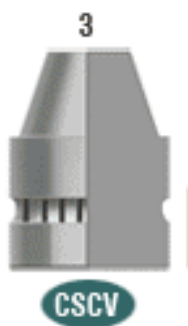

Chumbo semi
canto vivo
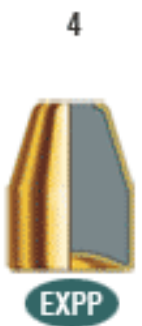

Expansivo Encamisado Encamisado ponta plana total total ponta plana ogival
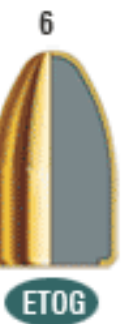

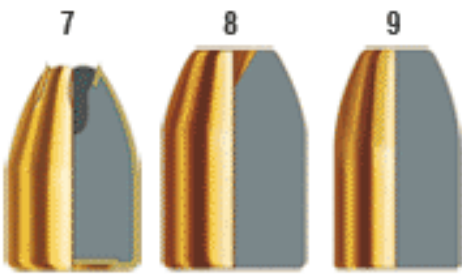

FRANGIVEIS

$.40 \mathrm{~S} \& \mathrm{~W} \quad 9 \mathrm{~mm}$ Luger

Figura 5. Tipos de projeteis produzidos pela $\mathrm{CBC}^{\circledR}$ para pistolas. Adaptada da referência 15. 
O propelente pode ser definido como o material explosivo que tem como função produzir grandes volumes de gases, por meio de sua queima. Estes gases impulsionam o projétil para fora do cano da arma. ${ }^{16}$ Antigamente, era utilizado como propelente a pólvora negra, que consiste em uma mistura de carvão, nitrato de potássio (salitre) e enxofre, na proporção de 15:75:10. ${ }^{13}$ Atualmente, nitrocompostos são utilizados por possuírem maior eficiência e segurança (também conhecida como pólvora sem fumaça, Figura 6). Os propelentes atuais são divididos em base simples, base dupla ou base tripla. Propelentes base simples são aqueles que possuem como base energética apenas a nitrocelulose (NC), já os propelentes que contêm nitrocelulose e nitroglicerina (NG) são nomeados de base dupla. Os propelentes base tripla são compostos por nitroglicerina, nitrocelulose e nitroguanidina (NQ). ${ }^{17,18}$ Os propelentes base simples e base dupla são mais utilizados na confecção de munições. Além do propelente propriamente dito, alguns $\operatorname{aditivos}^{7,19,20}$ são adicionados à pólvora, como estabilizantes, plastificantes, supressores de chama, etc.

(a)

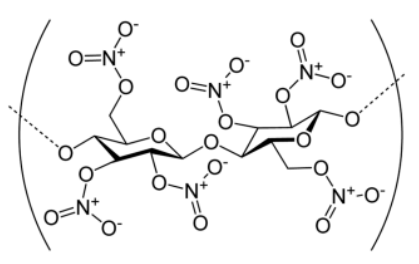

NC<smiles>O=[N+]([O-])OCC(CO[N+](=O)[O-])O[N+](=O)[O-]</smiles>

NG (b)

(c)

Figura 6. Bases energéticas dos propelentes utilizados atualmente: (a) nitrocelulose, (b) nitroglicerina e (c) nitroguanidina.

A massa iniciadora, também conhecida como primer, é acondicionada dentro da espoleta e é a responsável por provocar a queima da pólvora. Por ser sensível ao choque mecânico, após o contato com o pino percursor da arma, ela entra em combustão, fornecendo energia para a queima da pólvora. ${ }^{21}$ A massa iniciadora é composta por diversos componentes, sendo os principais: explosivos, agentes oxidantes, combustível, sensibilizadores e ligantes. ${ }^{13}$ Tradicionalmente, os agentes oxidantes encontrados na massa iniciadora são nitrato de bário $\left[\mathrm{Ba}\left(\mathrm{NO}_{3}\right)_{2}\right]$, dióxido de chumbo $\left[\mathrm{PbO}_{2}\right]$, nitrato de chumbo $\left[\mathrm{Pb}\left(\mathrm{NO}_{3}\right)_{2}\right]$, estifinato de chumbo $\left[\mathrm{C}_{6} \mathrm{HN}_{3} \mathrm{O}_{8} \mathrm{~Pb}\right]$ e trissulfeto de antimônio $\left[\mathrm{Sb}_{2} \mathrm{~S}_{3}\right]$. Por conta da presença dos metais antimônio $(\mathrm{Sb})$, bário( $\left.\mathrm{Ba}\right)$ e chumbo $(\mathrm{Pb})$ na massa iniciadora, o GSR tradicional é caracterizado pela presença simultânea destes três metais nas partículas expelidas. ${ }^{5}$ 
O mecanismo de disparo de uma arma de fogo pode ser resumido da seguinte forma: após a ignição da massa iniciadora, a energia é transferida para pólvora, provocando sua queima. $\mathrm{O}$ aumento de pressão oriundo dos gases produzidos na queima impulsiona o projétil para fora da arma. Com isso, tanto os compostos presentes na massa iniciadora, quanto na pólvora são vaporizados, formando uma nuvem em torno da arma. Os gases expelidos da arma resfriam em contato com o ar e condensam, formando partículas de forma predominantemente esferoide, da a condição de alta temperatura e pressão. Dessa maneira, partículas esferoides contendo simultaneamente os elementos antimônio, bário e chumbo, formam o resíduo de tiro característico. 5,6,10

Esses resíduos de tiro podem ser divididos em duas classes, GSR característico e GSR consistente, de acordo com a sua composição. ${ }^{5,6,10}$ GSR característico são aqueles que apresentam, em uma mesma partícula, os elementos $\mathrm{Sb}, \mathrm{Ba} \mathrm{e} \mathrm{Pb}{ }^{22}$ Além disso, metais provenientes da arma e demais elementos da munição podem ser encontrados, tais como, alumínio, chumbo, cálcio, potássio, cloro, etc. São classificadas como GSR consistente ${ }^{22}$ as partículas que possuam a seguinte combinação de elementos:

- Bário, cálcio, silício (com traços de enxofre)

- Antimônio, bário (com traços de enxofre e ferro)

- Ferro e antimônio

- Bário e alumínio (na ausência de enxofre)

- Chumbo e bário

- Chumbo

- Antimônio

- Bário (na ausência de enxofre)

A variação na composição das partículas de GSR são oriundas da baixa homogeneidade do primer.

Diversas técnicas podem ser utilizadas na identificação e caracterização do GSR. Dentre os métodos descritos na literatura ${ }^{8,9,11,23-27}$ são largamente citados aqueles de via úmida: reativo de Griess modificado ${ }^{28-30}$ - para a detecção de nitritos - e testes com Rodizonato de sódio ${ }^{31-33}$ para a detecção de chumbo. Adicionalmente, métodos espectroscópicos também podem ser utilizados como Espectroscopia de Massas ${ }^{27}$, Espectrometria de Emissão Atômica por Plasma Indutivamente Acoplado, ${ }^{34}$ dentre outros. 
Entretanto, a técnica mais aceita atualmente na análise dos GSR é a Microscopia Eletrônica de Varredura acoplada à Espectroscopia por Dispersão de Energia (MEV/EDS). ${ }^{22,35,36} \mathrm{O}$ uso de MEV/EDS fornece informações tanto relativas à morfologia quanto à composição química. ${ }^{36-38} \mathrm{~A}$ importância da avaliação simultânea da composição e da morfologia dos GSR deve-se ao fato dos elementos $\mathrm{Pb}$, Ba e $\mathrm{Sb}$ poderem ser encontrados em diversos produtos (fogos de artifícios, pastilhas de freio, tintas, ligas, etc), ${ }^{39}$ mas eles somente são encontrados juntos e em partículas esferoides provenientes do disparo de uma arma de fogo.

Uma norma da ASTM (American Society for Testing and Materials) ${ }^{35}$ preconiza o uso de MEV/EDS para identificação inequívoca de GSR, considerando para tal partículas esferoides que contenham simultaneamente os elementos antimônio, bário e chumbo. Esta norma é adotada por diversos departamentos de polícia de todo mundo como, por exemplo, a Polícia Federal Brasileira (PF), o Federal Bureau of Investigation (EUA) e a Bundespolizei (Alemanha).

A coleta dos resíduos pode ser realizada em diversas superfícies próximas ao local do disparo, como paredes, cadeiras, vidros de carro etc., ou em qualquer parte da vítima ou suspeito: mãos, cabelos, braços e roupas. A forma da coleta depende de qual método de análise será utilizado, podendo ser usados swabs (haste com algodão na ponta para coleta de material), fitas adesivas, aspiradores, colas, etc. 5,6,40,41 Para a análise por MEV/EDS, o procedimento padrão consiste na coleta das partículas pressionando stubs metálicos cobertos com fitas adesivas de carbono na superfície de interesse. ${ }^{42-44} \mathrm{Na}$ maioria das vezes, a coleta de GSR é realizada nas mãos do suspeito, principalmente na palma, dorso, região da pinça (palmar e/ou dorsal), conforme Figura 7, por serem regiões com maior probabilidade do GSR ser depositado. ${ }^{27}$

a)

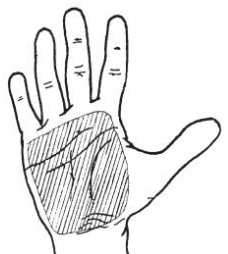

c)

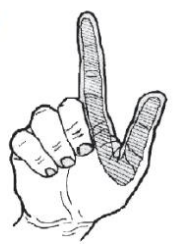

b)
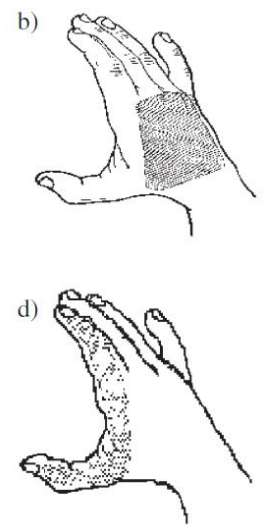

Figura 7. Regiões da mão de atiradores submetidas à coleta: a) Palma; b) Dorso; c) Região da Pinça (Palmar); d) Região da Pinça (Dorsal). Adaptada da referência 27. 


\subsection{Munição ambiental}

O Instituto Nacional de Segurança Operacional e Saúde, NIOSH (do inglês National Institute for Occupational Safety and Health) estudou a exposição de atiradores frequentes (instrutores de tiros, policiais, etc.) a metais pesados, principalmente ao chumbo. ${ }^{45-47}$ Em 2010, o NIOSH ${ }^{48}$ publicou um estudo no qual constatou que instrutores de tiro apresentavam a taxa de chumbo no sangue acima da taxa permitida pela Administração de Segurança e Saúde Ocupacional, OSHA (do inglês Occupational Safety and Health Administration), a qual corresponde à $60 \mu \mathrm{g} . \mathrm{dL}^{-1} \cdot 49$

O chumbo, que não apresenta nenhuma função fisiológica no corpo humano, causa uma intoxicação chamada de saturnismo. ${ }^{50}$ A principal via de contaminação por chumbo é oral, contudo, o contato por via inalatória ou cutânea também podem levar à intoxicação. No caso dos atiradores, o contato com o metal depositado em superfícies e na arma, a inalação dos gases e a ingestão de partículas retidas no trato aéreo superior são fontes de contaminação de atiradores frequentes ${ }^{51} \mathrm{Um}$ problema que agrava os casos de intoxicação é fato de o chumbo não ser metabolizado, sendo complemente absorvido e depositado nos ossos, tecidos, causando diversas alterações fisiológicas. Os sintomas da intoxicação estão relacionados com o nível de chumbo presente no sangue, podendo se manifestar quando concentrações estão acima de $25 \mu \mathrm{g} \cdot \mathrm{dL}^{-1} .^{50}$

No Brasil, a quantidade máxima permitida de chumbo no sangue, segundo a Norma Regulamentadora 7 do Programa de Controle Médico de Saúde Ocupacional, ${ }^{52}$ é $60 \mu \mathrm{g} . \mathrm{dL}^{-1}$. Em 2014, Rocha et al. ${ }^{53}$ publicaram um estudo realizado em São Paulo com 20 policiais e 21 instrutores de tiros. O teste tinha como objetivo avaliar a taxa de chumbo no sangue dos participantes antes e após um curso de Autoproteção e Preservação da Vida, no qual situações da rotina de um policial da cidade de São Paulo foram simuladas. No grupo não foi detectado nenhum participante com a taxa acima da recomendada pelo Ministério do Trabalho e Emprego, contudo, o aumento no nível de chumbo no sangue de alguns participantes foi considerável (aumento da taxa para $20 \mu \mathrm{g} \cdot \mathrm{dL}^{-1}$ ) tendo em vista o curto período de tempo ( 3 dias) do curso. ${ }^{53}$

Com o intuito de diminuir a contaminação de chumbo em policiais, assim como a do meio ambiente, foi desenvolvida uma munição isenta desse metal, conhecida como NTA (do inglês Non Toxic Ammunition), munição livre de chumbo, munição limpa, ou munição ambiental. Nela, a mistura iniciadora não contém chumbo, assim como outros metais pesados. No Brasil, a $\mathrm{CBC}^{\circledR}$ é responsável pela fabricação e distribuição das 
munições ambientais, porém, essas somente estão disponíveis para uso em treinamento da Polícia Federal. Segundo a empresa, "a munição NTA $\mathrm{CBC}^{\circledR}$ não gera gases ou resíduos tóxicos durante o tiro, pois possui projétil totalmente encapsulado (Figura 8), pólvora química sem fumaça e mistura iniciadora livre de metais pesados, protegendo a saúde do policial". ${ }^{15}$

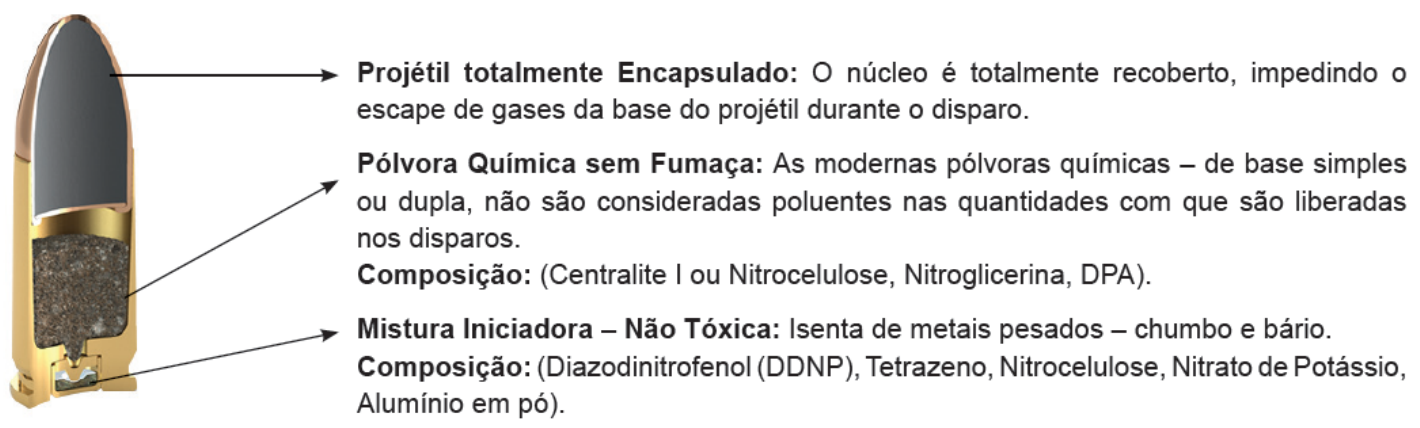

Figura 8. Cartucho de munição NTA desenvolvida pela $\mathrm{CBC}^{\circledR}$. Adaptada da referência 15.

Apesar do benefício ambiental e à saúde dos profissionais, a introdução dessa nova munição dificultou a identificação dos GSR. Estudos realizados com munições NTA produzidas no Estados Unidos ${ }^{54}$ e pela $\mathrm{CBC}^{\circledR 55}$ demonstraram uma grande variedade de composição dos GSR produzidos por este tipo de munição, sem que nenhum elemento característico fosse encontrado. Diversas combinações de $\mathrm{Al}, \mathrm{Si}, \mathrm{Cu}$ e $\mathrm{Zn}$, com traços de $\mathrm{S}$ e Ca foram obtidas. Além disso, apesar de partículas de forma esferoides terem sido encontradas, diversas outras formas estavam presentes.

Diante da grande variedade de composição e morfologia das partículas, a identificação do GSR-NTA tornou-se uma tarefa quase impossível e um novo padrão para identificação de GSR ainda precisa ser definido.

\subsection{Marcadores Luminescentes}

Para resolver o problema na identificação por MEV/EDS dos resíduos de tiro provenientes do disparo de uma munição NTA, autores, como Martiny et al., ${ }^{55}$ sugeriram a inclusão de marcadores externo às munições. A marcação de munições já é uma realidade na Alemanha, onde gadolínio e gálio ${ }^{56}$ foram adicionados à munição NTA. Outras propostas, como a de Brandone et al., ${ }^{57}$ envolvem a adição de óxido de samário como marcador químico de pólvora NTA. Em todos os casos, utilizam-se elementos que 
não são encontrados rotineiramente em atividades ocupacionais e no meio ambiente para fazer a marcação química do GSR.

A forma de marcação proposta pelo nosso grupo foi a adição de um marcador luminescente à munição, com isso, no momento do disparo seriam produzidos resíduos luminescentes, LGSR (Luminescent Gunshot Residue). O fato do resíduo apresentar luminescência permite a sua identificação visual na própria cena do crime, facilitando a coleta e permitindo testes de contraprova por outras técnicas analíticas, sem a necessidade da utilização de equipamentos sofisticados e que demandam demasiado tempo de análise. Essa nova classe de resíduo pode ser facilmente detectada nas mãos, roupas, armas e objetos pessoais do atirador, bem como no local do disparo e na vítima, usando apenas uma lâmpada UV portátil. Os marcadores testados apresentaram alto desempenho em todas as experiências realizadas e forneceram informações importantes para as investigações forenses.

As estruturas e a utilização desses sistemas luminescentes foram descritas em $\operatorname{artigos}^{58-62}$ e trabalhos ${ }^{63}$ publicados pelo grupo. Alguns dos marcadores desenvolvidos são baseados em polímeros de coordenação, chamados de LMOF, Lanthanide MetalOrganic Framework. A introdução deste material acarretaria em um aumento de US $\$ 0,02$ a US\$0,05 em cada munição de $0.38 \mathrm{~mm}^{58}$

LMOFs podem ser definidas como estruturas metalorgânicas constituídas por um íon lantanídeo contendo ligantes orgânicos. ${ }^{64-66}$ Possuem alta organização molecular e luminescência, formando estruturas em uma, duas ou três dimensões (1D, 2D e 3D). Quando possuem na estrutura íons lantanídeos emissores podem apresentar propriedades de luminescência características, tais como alto rendimento quântico, longo tempo de meia-vida, bandas de Stokes largas e espectros de emissões definidos. ${ }^{67}$ As LMOFs são aplicadas como lasers ajustáveis, sensores fluorescentes, catalisadores, ${ }^{68}$ sensores biológicos e em imageamento biomédico. ${ }^{65,69}$

Em geral, as LMOFs apresentam alta estabilidade térmica e química, característica que as tornaram excelentes candidatas para aplicação como marcadores de munição. Durante o disparo de uma arma de fogo, a temperatura sobe rapidamente, até cerca de $2000{ }^{\circ} \mathrm{C},{ }^{37}$ sendo, assim, necessário um composto estável em altas temperaturas.

Diversos compostos orgânicos podem ser utilizados como ligantes em uma LMOF, sendo os mais comuns aqueles com anéis aromáticos com duplas conjugadas, tais como policarboxilatos, bipiridinas e moléculas poliazoheterocíclicas (imidazol, triazol, tetrazol, pirimidina, pirazinas, etc),${ }^{70}$ conforme descrito na Figura 9. 
<smiles>O=C(O)c1ccc(C(=O)O)cc1</smiles>

Ácido tereftálico<smiles>c1cc(-c2ccncc2)ccn1</smiles>

4,4'-Bipiridina<smiles>O=C(O)c1cc(C(=O)O)cc(C(=O)O)c1</smiles>

Ácido trimésico

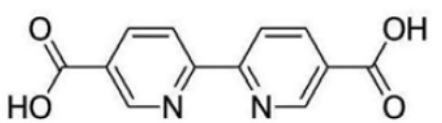

Ácido 2,2'-bipiridina-5,5'-dicarboxílico<smiles>O=C(O)c1ccc(-c2cc(-c3ccc(C(=O)O)cc3)c(-c3ccc(C(=O)O)cc3)cc2-c2ccc(C(=O)O)cc2)cc1</smiles>

1,2,4,5-Tetraquis(4-carboxifenil)benzeno<smiles>O=C(O)c1ccc(-c2nc(-c3ccc(C(=O)O)cc3)nc(-c3ccc(C(=O)O)cc3)n2)cc1</smiles>

Ácido 4,4',4"-s-Triazina-2,4,6-triil-tribenzóico

Figura 9. Estruturas comumente utilizadas na síntese das LMOFs. Adaptada da referência 70.

Dentro do grupo de ligantes descritos acima, três deles foram utilizados na síntese de LMOFs e aplicados na marcação de munições NTA pelo grupo: ácido dipicolínico ( $\left.\mathrm{H}_{2} \mathrm{DPA}\right)$, ácido benzeno-1,4-dicarboxílico $\left(\mathrm{H}_{2} \mathrm{BDC}\right)$ e o ácido benzeno-1,3,5tricarboxílico ( $\left.\mathrm{H}_{3} \mathrm{BTC}\right)$, conforme descrição na Figura 10. O ligante DPA foi utilizado na síntese de dois marcadores, nomeados de R-Marker e G-Marker, sendo o primeiro com o íon $\mathrm{Eu}^{3+}$ e, o segundo, com $\mathrm{Tb}^{3+}$. Sua aplicação como marcador luminescente foi demonstrada em um artigo publicado em 2011. ${ }^{58}$ O ligante BTC foi utilizado na síntese de um marcador isoestrutural à MOF isoestrutural MIL-78, contendo o íon $\mathrm{Eu}^{3+}$ como metal cental. ${ }^{63}$<smiles>O=C(O)c1cccc(C(=O)O)n1</smiles>

$\mathrm{H}_{2}$ DPA<smiles>O=C(O)c1ccc(C(=O)O)cc1</smiles>

$\mathrm{H}_{2} \mathrm{BDC}$<smiles>O=C(O)c1cc(C(=O)O)cc(C(=O)O)c1</smiles>

$\mathrm{H}_{3} \mathrm{BTC}$

Figura 10. Ligantes utilizados na síntese dos marcadores de munições NTA.

Neste trabalho, três redes metalorgânicas (MOFs, do inglês Metal-Organic Framework) foram sintetizadas e aplicadas como marcadores munições NTA: ${ }_{\infty}[\mathrm{Eu}(\mathrm{DPA})(\mathrm{HDPA})],{ }_{\infty}\left[\mathrm{Eu}_{2}(\mathrm{BDC})_{3}(\mathrm{H} 2 \mathrm{O})_{2}\right]_{\mathrm{n}}$, e ${ }_{\infty}[\mathrm{Eu}(\mathrm{BTC})]$, nomeados de EuDPA, EuBDC e EuBTC, respectivamente. 
Na MOF EuDPA, o íon $\mathrm{Eu}^{3+}$ está coordenado com duas moléculas do ligante, sendo uma parcialmente protonada (HDPA) e outra totalmente desprotonada (DPA). Os ligantes coordenam-se ao metal central através dos átomos de nitrogênio, dos anéis heterocíclicos e pelos oxigênios das carbonilas, atuando como uma espécie de ligante tridentado, conforme demonstrado na Figura 11.69,71 $\mathrm{O} \mathrm{Eu}^{3+}$ possui número de coordenação 8, e geometria antiprisma quadrado distorcido.

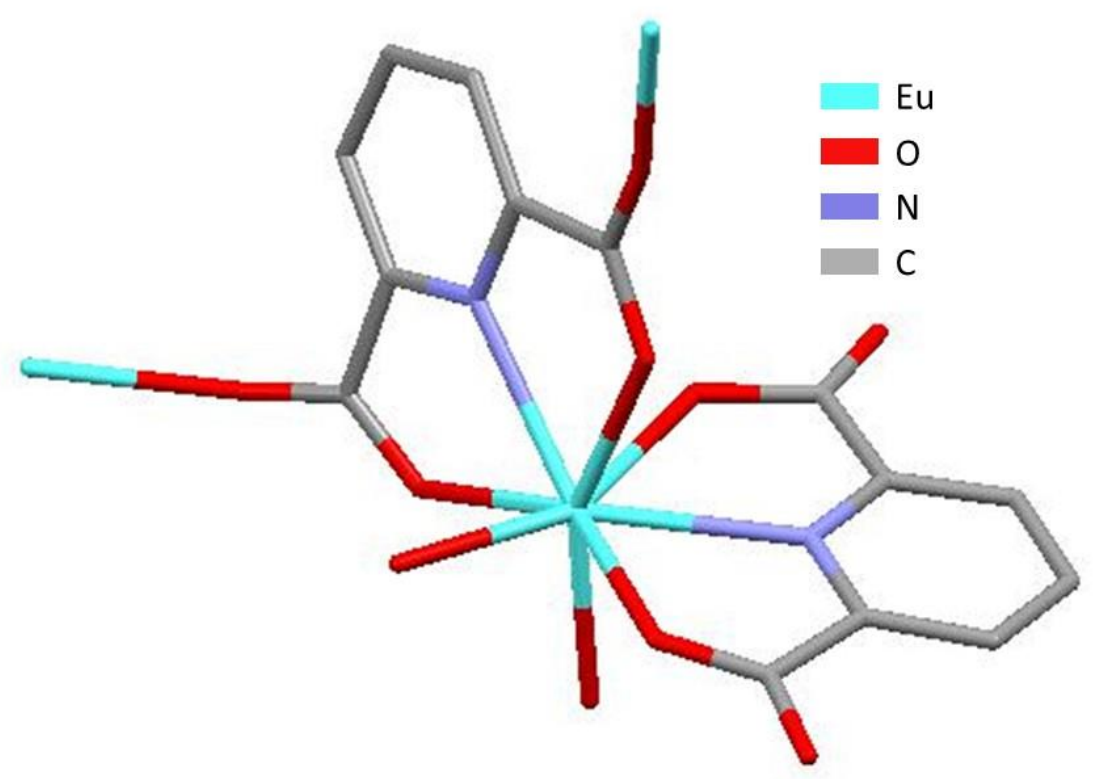

Figura 11. Estrutura da $\mathrm{MOF}_{\infty}[\mathrm{Eu}(\mathrm{DPA})(\mathrm{HDPA})] .{ }^{69}$

A rede ${ }_{\infty}\left[\mathrm{Eu}_{2}(\mathrm{BDC})_{3}\left(\mathrm{H}_{2} \mathrm{O}\right)_{2}\right]_{\mathrm{n}}$ apresenta como metal central o íon $\mathrm{Eu}^{3+}$ e como ligantes o ácido bezeno-1,3-dicaboxílico, sendo que todas as moléculas dos ligantes estão desprotonadas. Os ligantes coordenam-se ao metal através dos íons carboxílicos. Há duas esferas de coordenação para o $\mathrm{Eu}$, sendo que na primeira, o íon apresenta um número de coordenação igual a 7 e uma geometria de bipirâmide pentagonal, composta por 6 oxigênios provenientes do ligante carboxílico e uma molécula de água. ${ }^{72}$ 


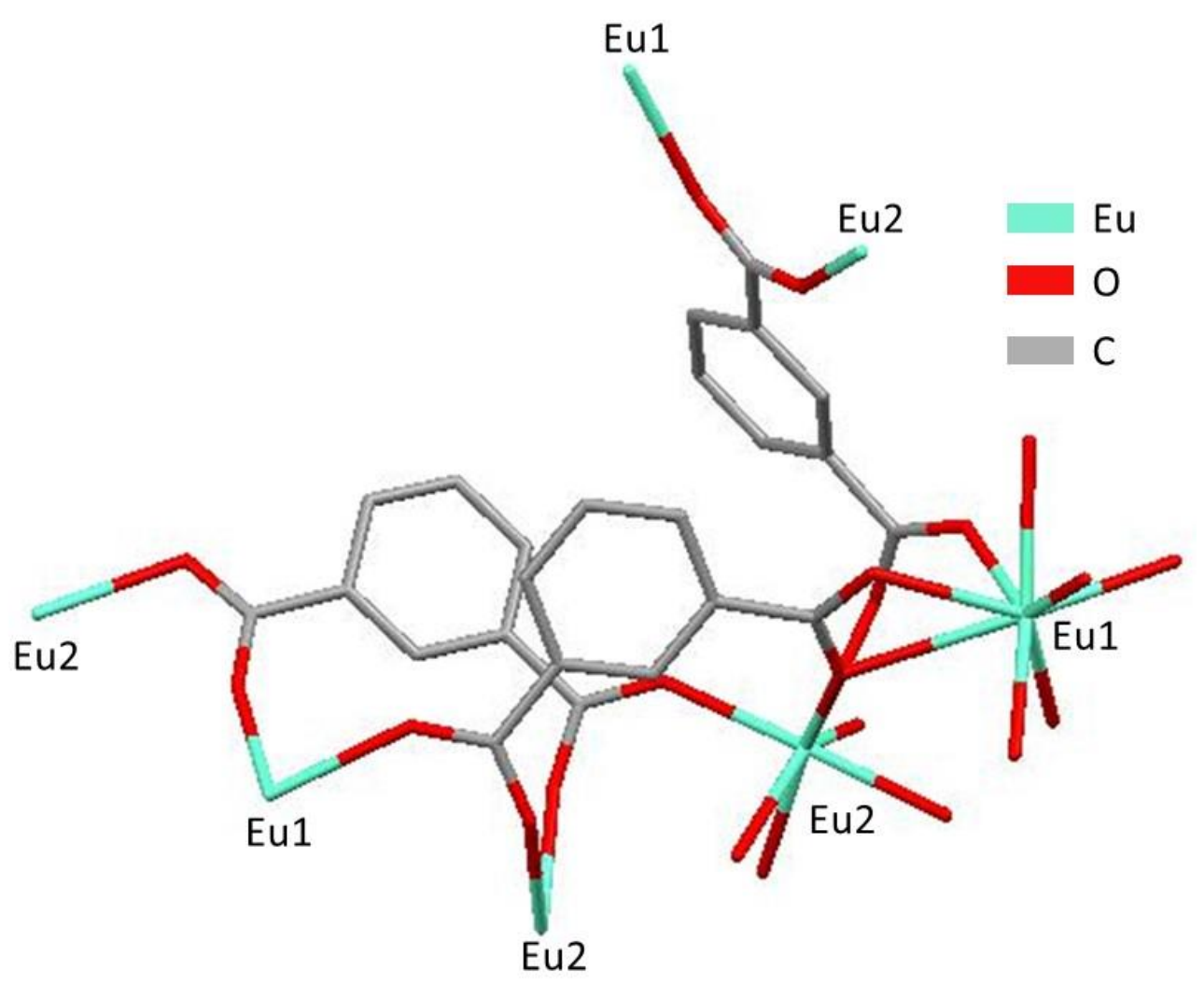

Figura 12. Estrutura da $\mathrm{MOF} \infty\left[\mathrm{Eu}_{2}(\mathrm{BDC})_{3}\left(\mathrm{H}_{2} \mathrm{O}\right)_{2}\right]_{\mathrm{n}}{ }^{72}$

Por fim, a MOF $\alpha_{\infty}[\mathrm{Eu}(\mathrm{BTC})]$, Figura 13, também conhecida como MIL-78, apresenta uma estrutura na qual cada íon $\mathrm{Eu}^{3+}$ está ligado a oito oxigênios provenientes, exclusivamente, do ácido trimésico, formando um arranjo tridimensional. ${ }^{73}$ Nesta estrutura não há nenhuma molécula de água coordenada ao $\mathrm{Eu}^{3+}$.

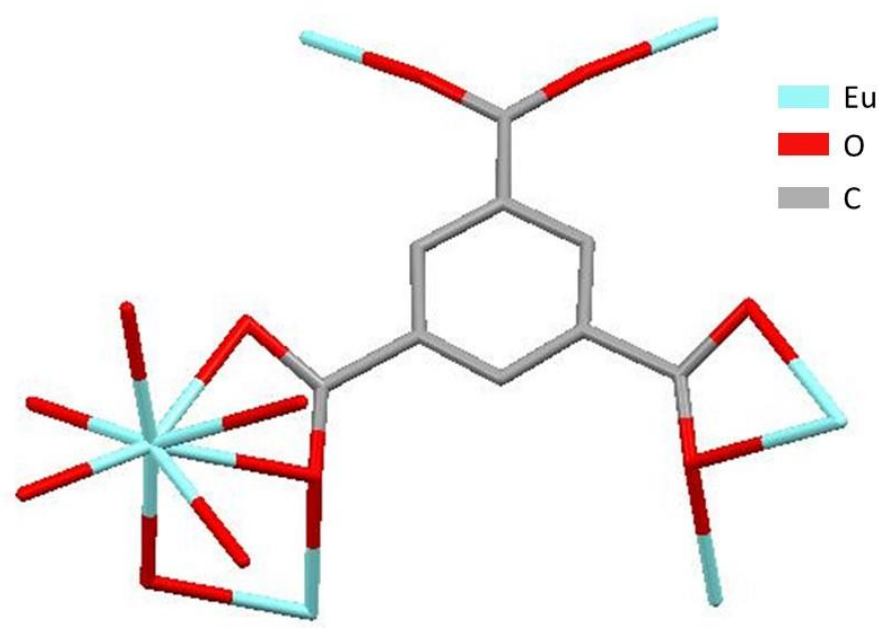

Figura 13. Estrutura da $\mathrm{MOF} \infty[\mathrm{Eu}(\mathrm{BTC})]^{73}$ 
Os três compostos possuem propriedades ópticas similares, apresentando emissão vermelha-alaranjada quando excitados a um comprimento de onda de $254 \mathrm{~nm}$.

\subsection{Luminescência}

Em condições normais, as moléculas estão no menor estado de energia, ou seja, no estado fundamental. Com o fornecimento de energia à uma molécula, os elétrons podem passar do estado eletrônico fundamental para um estado eletrônico excitado. No estado excitado, a molécula torna-se instável e a tendência natural é que por algum processo, seja físico ou químico, libere energia, indo para um estado energeticamente inferior (normalmente o estado fundamental). Ao retornar ao seu estado fundamental, por um processo de relaxação radioativa, a energia absorvida é dissipada na forma de luz, denominando-se esse fenômeno de luminescência. ${ }^{74}$

A energia pode ser dissipada de duas maneiras: mecanismos radioativos e por mecanismos não-radioativos. No primeiro caso, a energia absorvida é dissipada como energia luminosa, mas com uma frequência diferente da energia incidente. Já no segundo, a energia de excitação é dissipada, principalmente, por meio de vibrações e liberação de calor (processos que não envolvem a emissão de fótons). Os processos radioativos podem ser divididos em fluorescência e fosforescência:

1. Fluorescência: o decaimento ocorre de um estado excitado singleto para um estado fundamental também singleto (transição entre estados de mesma multiplicidade)

2. Fosforescência: o decaimento ocorre de um estado excitado tripleto para o estado fundamental singleto (transição entre estados multiplicidades diferentes)

A absorção de um fóton de luz e a passagem para o estado excitado é um processo muito rápido $\left(10^{-14}\right.$ a $\left.10^{-15} \mathrm{~s}\right)$. A velocidade de desativação, entretanto, dependerá do tipo de emissão da molécula. Na Tabela 1, estão indicados os tempos médios para os mecanismos de absorção, fluorescência e fosforescência. ${ }^{75}$ 
Tabela 1. Tempos característicos para os vários processos de desativação.

\begin{tabular}{lcl}
\hline Processo & Variação da Multiplicidade de Spin & Tempo (s) \\
\hline Absorção & $1 \rightarrow 1$ & $10^{-15}$ \\
Fluorescência & $1 \rightarrow 1$ & $10^{-9}$ a $10^{-6}$ \\
Fosforescência & $3 \rightarrow 1$ & $10^{-3} \mathrm{a} 1$ \\
\hline
\end{tabular}

A energia emitida não necessariamente é igual a energia absorvida. Quando a energia emitida é menor que a energia absorvida, esse mecanismo é chamado de downconversion ou Deslocamento Stokes. Tal processo acontece porque ambos os mecanismos (radioativos e não radioativos) ocorrem quando uma molécula é excitada.

A maioria dos íons do grupo dos lantanídeos apresentam propriedade luminescentes. Pertencem ao grupo dos lantanídeos (Ln) os elementos que ocupam o sexto período da tabela periódica, do elemento lantânio ao elemento lutécio. Em sua maioria, os átomos livres apresentam a configuração eletrônica [Xe], $6 s^{2}, 5 \mathrm{f}^{\mathrm{n}}$, onde $\mathrm{n}=0$ - 14. A maior parte dos compostos apresentam número de oxidação +3 , decorrente do fato que os elétrons da camada $4 \mathrm{f}$ estão blindados pelas camadas $5 \mathrm{~s}$ e $5 \mathrm{p}$, indisponíveis para uma ligação covalente. ${ }^{76}$

O fenômeno da luminescência observada nos elementos desse grupo está relacionada às transições f-f. Outras característica destes materiais é que eles apresentam tempos de vida longos (microsegundos a milissegundos), devido ao fato das transições $f$ - f serem proibidas de acordo com a regra de Laporte. ${ }^{77}$ Contudo, devida a influência do campo ligante, quando coordenado o íon lantanídeo, há relaxação na regra de seleção é suficiente para provocar mudança de paridade, fazendo com que as transições f-f ocorram. $^{78}$

O íon trivalente európio, configuração eletrônica [Xe], $4 \mathrm{f}^{6}$, quando irradiado com luz UV, apresenta uma luminescência na região do vermelho, geram linhas espectrais bastante estreitas e espectros de luminescência característicos. Ao ser coordenado com ligantes orgânicos carboxilados com duplas conjugadas é possível intensificar as propriedades luminescentes desses compostos, ${ }^{78,79}$ uma vez que os íons lantanídeos não apresentam absortividades molares altas ${ }^{80}$ Esse efeito é chamado de efeito antena e foi primeiramente descrito por Weissman. ${ }^{81}$ Nele, os ligantes atuam como uma espécie de antena, absorvendo a energia de um fóton e, posteriormente, transferindo essa energia para o íon lantanídeo, o qual emite sua luminescência. ${ }^{80}$ 


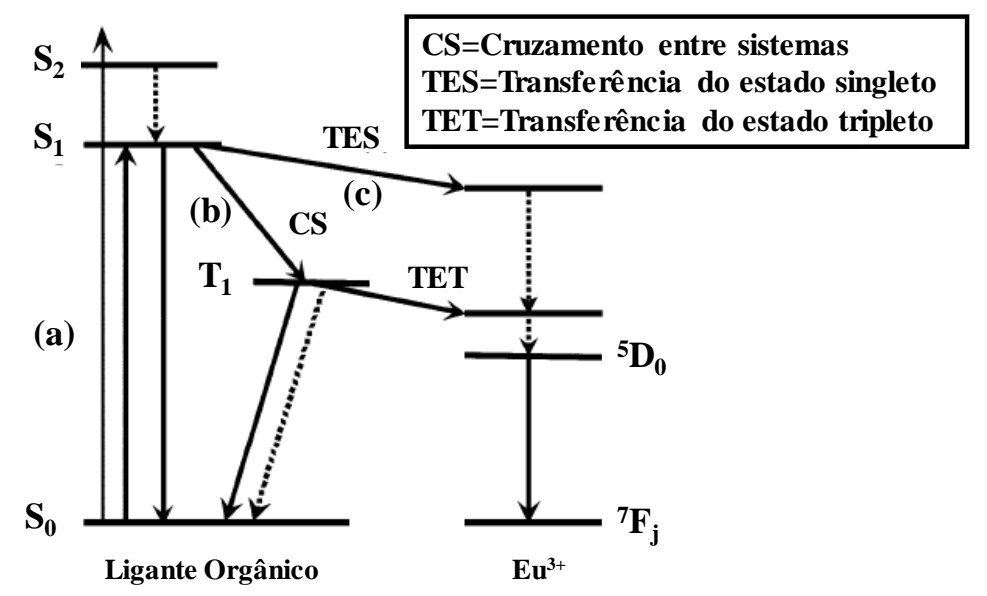

Figura 14. Diagrama de Jablonski ilustrando o efeito antena. ${ }^{82}$

Ao receber um fóton, os elétrons do ligante passam a popular níveis vibracionais do estado excitado singleto $S_{1}$, conforme ilustra a Figura 14. Quando a molécula absorve energia, passando para o estado excitado, essa transição, normalmente, ocorre com conservação do momento de spin. Assim, uma molécula em um estado fundamental singleto $\left(\mathrm{S}_{0}\right)$, passará para um estado excitado também singleto $\left(\mathrm{S}_{1}\right){ }^{83}$

Conforme a Figura, este estado singleto pode ser desativado por três mecanismos: ${ }^{84}$

a) Transições radioativas para um estado fundamental $\left(\mathrm{S}_{0}\right)$ singleto do próprio ligante (fluorescência molecular);

b) Cruzamento entre sistemas (TS), em que a transição entre estados não é radioativa e ocorre do estado singleto do ligante para o seu estado tripleto $\left(\mathrm{T}_{1}\right)$. Com o aumento do número de átomos da molécula, estados eletrônicos podem começar a sobrepor-se (interações spin-órbita). Nessas condições, outras transições, em que a variação do momento de spin é diferente de zero, passam a ser permitidas. Assim, a molécula pode sair de um estado singleto e passar para um estado tripleto. ${ }^{85}$

c) Transferência para o estado singleto do metal (TES), que pode emitir energia na forma de luz (efeito antena).

Portanto, o ligante pode transferir energia para o íon lantanídeo de duas maneiras. Uma transferência singleto-singleto (TES) e/ou por meio do cruzamento entre sistemas do estado tripleto T1 do ligante para o estado singleto do lantanídeo (TET). Essa transferência é permitida devido à sobreposição dos níveis energéticos do ligante e do íon 
lantanídeo, que permite que a conversão seja mais favorável cineticamente do que a fosforescência do ligante. ${ }^{80,86,87}$. Uma vez no estado excitado, o íon lantanídeo libera energia, retornando ao estado fundamental.

\subsection{Toxicidade química dos marcadores}

A estrutura e a utilização dos marcadores luminescentes foi descrita em diversos $\operatorname{artigos}^{58-62}$ e trabalhos ${ }^{63,88}$ e publicados pelo grupo, contudo, pouco se sabe acerca da toxicidade química de tal material. Como estes marcadores se destinam principalmente a munições do tipo NTA, é esperado que sejm atóxicos.

$\mathrm{O}$ primeiro estudo acerca da toxicidade aguda oral in vivo de uma MOF luminescente foi realizado pelo grupo. ${ }^{63}$ Trata-se da $\mathrm{MOF}{ }_{\infty}[\mathrm{Eu}(\mathrm{BTC})]$, a qual também foi usada como marcador luminescente para GSR. Foi observado que a DL50 da sustância era de $5000 \mathrm{mg} / \mathrm{kg}$ o que resultou em um enquadramento na classe 5 , ou seja, o material foi classificado na categoria menos tóxica do protocolo utilizado. Também foi avaliada a toxicidade de um complexo luminescente contendo $\mathrm{Eu}^{3+}$, o qual foi usado como marcador de GSR ${ }^{89} \mathrm{O}$ grupo classificou o material em uma classe 4, apresentando uma toxicidade média. Além desses trabalhos, não há relatos de outros estudos da avalição de toxicidade de marcadores para resíduos de tiro.

Alguns estudos acerca da toxicidade biológica de MOFs foram realizados..$^{90-92} \mathrm{~A}$ maior parte deles visa a aplicação destas MOFs como carreador de fármacos e as análises baseiam-se na avaliação da citotoxicidade, toxicidade aguda e degradação em meio fisiológico desses compostos. ${ }^{92}$ Por exemplo, Horcajada et al. ${ }^{90}$ estudaram a toxicidade de MOFs de ferro com ligantes carboxílicos (conhecidas como MIL - do inglês Material of Institute Lavoisier, dentre elas a MIL-78 a qual tem estrutura similar à $\infty_{\infty}[\mathrm{Eu}(\mathrm{BTC})]$ ). O grupo avaliou a citotoxicidade, a degradação em meio biológico, a toxicidade aguda por via oral e toxicidade em doses repetidas das MOFs de ferro (III) com ligantes carboxílicos: ácido mucônico, ácido fumárico, ácido trimésico, ácido amino-tereftálico e ácido tereftálico. Nos testes realizados, foi possível identificar que o material não é tóxico.

Outra forma de se inferir sobre uma possível toxicidade destes materiais é através do estudo dos subprodutos gerados pelo disparo de uma arma de fogo municiada com NTA marcada. No momento do disparo, uma parte do marcador pode ser degradada, enquanto outra parte da rede permanecerá intacta. Diante desse fato, é necessário investigar os possíveis subprodutos formados, além da toxicidade do marcador puro. 
Outro aspecto importante é o estudo do tamanho das partículas dos marcadores formadas após o disparo.

\subsubsection{Subprodutos gerados após o disparo}

O OGSR consiste em uma mistura proveniente da queima do propelente, massa iniciadora, lubrificante da arma e outros hidrocarbonetos presentes. ${ }^{93-95}$ A composição básica da pólvora sem fumaça consiste de um propelente (nitroglicerina e/ou nitrocelulose e/ou nitroguanidina), estabilizantes, plastificantes, inibidores de chama, lubrificantes, corantes, dentre outros compostos. ${ }^{93}$ A Tabela 2 lista alguns compostos encontrados na composição do OGSR.

Além dos compostos citados na Tabela 2, Goudsmits et al. ${ }^{94}$ reuniram uma extensa lista de compostos descritos na literatura como componentes presentes no OGSR.

Tabela 2. Composição do propelente em munições.$^{93}$

\begin{tabular}{cc}
\hline Função & Composto \\
\hline Explosivos & Nitrocelulose (NC), Nitroglicerina (NG), Nitroguanidina (NQ), \\
& Ciclonita (RDX), Octogeno (HMX), 2,4-Dinitroanisol (DNAN) \\
\hline Sensibilizadores & Trinitrotolueno (TNT), Tetranitrato de Pentraeritrina \\
\hline Estabilizadores & Difenilamina (DPA), Metil Centralita (MC), Etil Centralita (EC) \\
\hline Inibidores de chama & 2,4-Dinitrotolueno (2,4-DNT), Nitroguanidina (NQ) \\
\hline Plastificante & Dietilftalato (DEP), Dimetilftalato (DMP) \\
\hline Produtos da degradação & 2-Nitrodifenilamina (2-NDPA), 4-Nitrodifenilamina (4-NDPA), \\
& 2,-Nitroso-Dinitrofenilamina (2,4-DNDPA), \\
& (2-ADNT), 4-amina-2,6-Dinitrolueno (4-ADNT) \\
\hline
\end{tabular}

Ao contrário do IGSR, o qual já possui uma técnica de análise e identificação por MEV/EDS estabelecida, para o OGSR ainda não foi estabelecida uma rotina analítica para análise e coleta. Dentre as técnicas descritas na literatura, as mais aplicadas são: espectrometria de mobilidade iônica, ${ }^{96}$ espectroscopia Raman, ${ }^{95,97}$ espectroscopia no infravermelho por transformada de Fourier, ${ }^{98}$ espectrometria de massas ${ }^{11}$ e cromatografia gasosa $^{99-103}$ e líquida ${ }^{24,93,104,105}$. A utilização da cromatografia gasosa é uma das técnicas mais descritas para análise do OGSR, pois ela apresenta uma alta seletividade para os compostos característicos e uma variedade de detectores podem ser utilizados, aumentando a variedade de métodos de análises. 
Para a análise de cartuchos deflagrados, a técnica mais comumente aplicada é a cromatografia gasosa com coleta por microextração por fase sólida (SPME, do inglês, Solid Phase Micro Extration), ${ }^{94,106-108}$ pois essa extração dos compostos ocorrerá sem a utilização de solventes, preservando a evidência.

Além dos compostos encontrados provenientes da queima da pólvora e da massa iniciadora, com a adição dos marcadores luminescentes, outros compostos poderão ser identificados. Durante o disparo de uma arma de fogo, a temperatura sobe rapidamente, até cerca de $2000^{\circ} \mathrm{C} .{ }^{37}$ Devido ao fato dos marcadores utilizados terem como ligantes moléculas orgânicas (ácido dipicolínico, ácido benzeno-1,4-dicarboxílico e ácido benzeno-1,3,5-tricarboxílico), com o aumento da temperatura, pode haver uma decomposição dessas estruturas, gerando como subprodutos compostos como piridina e benzeno, o que pode ser um risco à saúde ao atirador.

Dessa forma, é necessário investigar os compostos formados pela decomposição dos marcadores após a deflagração de um tiro marcado, relacionando assim, com a toxicidade dos compostos formados, sendo a técnica de microextração por fase sólida com a análise por cromatografia gasosa uma alternativa para a análise dos resíduos orgânicos produzidos pelo disparo de uma munição marcada.

\section{SPME}

A microextração por fase sólida consiste em uma técnica de micro extração e préconcentração de analitos contidos em uma matriz, líquida, sólida ou gasosa, sem a utilização de solventes. ${ }^{109,110}$ É uma importante ferramenta na análise de vestígios em níveis de traços e ultra traços, contidos em uma matriz complexa. Uma fibra de sílica fundida revestida com um polímero não volátil é utilizada para extrair os analitos contidos na matriz ou do headspace. Primeiramente, a fibra é inserida no recipiente em que se encontra a matriz (Figura 15a), na qual os analitos são extraídos (Figura 15b) e adsorvidos na fibra (Figura 15c). Posteriormente, os analitos são dessorvidos termicamente no injetor do cromatógrafo (Figura 15d). ${ }^{109} \mathrm{O}$ princípio da extração é baseado no equilíbrio de partição dos analitos entre a matriz e a fase adsorvente, sendo que a massa do analito adsorvida, em $\mu g$, na fibra pode ser expressada pela equação 1 , em que $\mathrm{V}_{\mathrm{f}}$ é o volume de filme na fibra, $\mathrm{V}_{\mathrm{s}}$ é o volume de solução extraído, $\mathrm{C}_{0}$ é a concentração inicial do analito que está sendo extraído e K é o coeficiente de partição. 


$$
m=\frac{K V_{f} C_{0} V_{s}}{K V_{f}+V_{s}}
$$

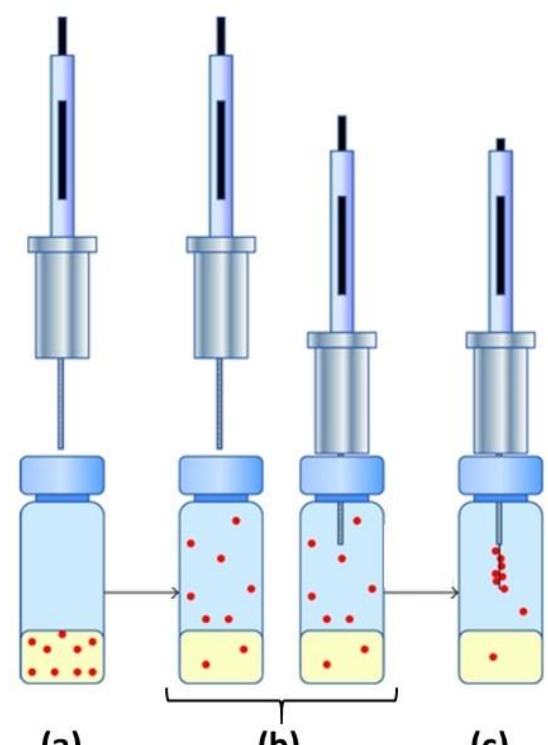

(a)

(b)

(c)

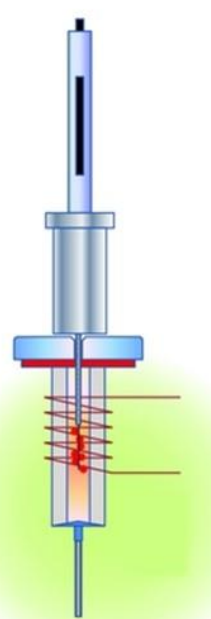

(d)

Figura 15. Processo de extração por SPME.

Dentre os polímeros de recobrimento, pode-se destacar polidimetilsiloxano (PDMS), poliacrilato (PA), Carbowax (Cwx) e Carvão Ativo Microparticulado (Carboxen). As espessuras dos recobrimentos das fibras podem variar de $7 \mathrm{~mm}$ a $100 \mathrm{~mm}$, com volumes de $0,03 \mathrm{~mL}$ a $0,7 \mathrm{~mL} .{ }^{111}$

A técnica foi desenvolvida em 1990 por Janusz Paeliszy e Catherine Arthur, ${ }^{112}$ com o desenvolvimento de uma fibra de SPME utilizando uma microseringa Hamilton série 7000. Fibras de sílica fundidas foram revestidas com Poliimida e utilizadas na detecção de compostos orgânicos voláteis que são contaminantes da água subterrânea: 1,1,1-Tricloroetano (TCEA), Tricloroeteno (TCEY) e Percloroetileno (PCE).

O método de SPME possui diversas vantagens (Tabela 3), o que a torna muito utilizada nas análises forenses, tendo em vista que, na maioria das vezes, evidências traços são encontradas em uma cena do crime. A técnica já foi descrita para a análise de cabelo, ${ }^{113,114}$ tintas de caneta, ${ }^{115}$ odor humano, ${ }^{116,117}$ explosivos, ${ }^{106,118-120}$ resíduo de tiro, ${ }^{25,94,100-102,106}$ dentre outros. ${ }^{121-123}$ 
Tabela 3. Vantagens e desvantagens da técnica de SPME. ${ }^{94}$

\section{Vantagens}

Não é necessário a utilização de solventes

Método de análise simples

Extração e concentração simultânea

Para analitos sólidos, líquidos e gasosos

\section{Desvantagens}

Técnica lenta

Somente aplicável para compostos voláteis

$\mathrm{Na}$ identificação de resíduos de tiro, a técnica é aplicada principalmente na identificação do OGSR, por meio da análise de cartuchos deflagrados e na determinação do tempo após o disparo da arma. As análises baseiam-se principalmente no exame do cartucho, sendo possível extrair os compostos orgânicos voláteis do headspace por cromatografia gasosa.

Para identificação do GSR, Dalby e Birkett ${ }^{107}$ realizaram um estudo por CG/EM em que avaliaram sete tipo de fibras de SPME (PDMS 100 $\mu \mathrm{m}$, PDMS 30 $\mu \mathrm{m}$, PDMS $7 \mu \mathrm{m}$, Poliacrilato $85 \mu \mathrm{m}$ [PA], DVB/CAR/PDMS 50/30 $\mu \mathrm{m}, \mathrm{PDMS} / \mathrm{DVB} 65 \mu \mathrm{m}$ e CAR/PDMS $85 \mu \mathrm{m})$ com diferentes tamanhos e polaridades, para identificar qual a melhor fibra para extrair compostos característicos da pólvora sem fumaça. Os compostos estudados foram: Dietilftalato, Carbazol, Monoetilftalato, Triacetino, Resorcinol, 3,4-Dinitrotolueno, 3Nitrotolueno, 2,4-Dinitrotolueno, 2,6-Dinitrotolueno, 2,3-Dinitrotolueno, Difenilamina, N-Nitroso-Difenilamina, 4-Nitrodifenilamina, 2-Nitrofenilamina, Nitroguanidina, MCresol, O-Cresol, P-Cresol, Dimetilftalato, Dibutilftalato, 2-Nitrotolueno, Dimetilsebacato, 2,4-Dinitrofenilamina, Uretana, Canfora, 2,3,-Dimetil-2,3,Dinitrobutano, 2,4-Dinitrotolueno, Nitroglicerina e Etil Centralita. A fibra de PDMS/DVB apresentou o melhor resultado para os compostos analisados, contudo, não foi possível determinar um tempo de extração ideal para todos os compostos.

Weyermann et al. ${ }^{100}$ realizaram um estudo com objetivo de determinar a composição do resíduo de tiro orgânico de uma munição $9 \mathrm{~mm}$. Para isso, eles testaram incialmente diferente métodos de SPME com CG/EM, avaliando o desempenho de três fibras: poliacrilato $85 \mu \mathrm{m}$ (PA), PDMS $100 \mu \mathrm{m}$ e $75 \mu \mathrm{m}$ carboxen/PDMS (carboxen). Após a análise dos cromatogramas, o grupo determinou que a fibra poliacrilato apresentou um resultado melhor do que as demais.

Chang et al. ${ }^{124}$ investigaram a composição do OGSR presente em um cartucho deflagrado durante 2 meses, utilizando uma fibra de poliacrilato $85 \mu \mathrm{m}$ (PA) e um cromatógrafo FID. Com isso, foi possível estimar o tempo após o disparo pelo comportamento dos compostos orgânicos presentes no cartucho. Foram monitorados os 
seguintes compostos: Difenil amina (DPA), Etil Centralita (EC), Metil Centralita (MC), Naftaleno, 2,4-Dinitrotolueno (2,4-DNT), Dibutilftalato, (DBP) e 2,6-Dinitrotolueno. Através das curvas geradas dos compostos DPA, DBP e naftaleno, foi possível determinar o tempo após o disparo com o método desenvolvido.

Diante do vasto número de técnicas descritas nos artigos, utilizando diferentes parâmetros do método de SMPE (tipo de fibra, tempo e temperatura de amostra/extração, tempo e temperatura de dessorção), não é possível indicar um método único para análise do OGSR, sendo necessário avaliar qual composto deseja-se identificar.

\subsubsection{Tamanho das partículas}

O tamanho de uma partícula possui estreita relação com a toxicidade. Durante os últimos anos, diversos pesquisadores estudaram a toxicidade de nanopartículas e de micropartículas. ${ }^{125-127}$

As partículas sólidas suspensas no ar são denominadas Material Particulado (MP) e são classificadas de acordo com o seu tamanho, em micrômetros, podendo ser divididas em $\mathrm{MP}_{2,5}$ - partículas menores de 2,5 micrômetros - e $\mathrm{MP}_{10}$ - partículas menores de 10 micrômetros.

Segundo a EPA (do inglês Environmental Protection Agency), ${ }^{128}$ partículas maiores que 2,5 e menores que 10 micrômetros são consideradas partículas grossas inaláveis, enquanto as partículas menores que 2,5 micrômetros são consideradas partículas finas. As menores que 2,5 $\mu \mathrm{m}$ são mais prejudiciais à saúde, podendo alcançar o pulmão e o coração. No Brasil, a quantidade de material particulado (MP) permitida está regulamentada pela Resolução do Conselho Nacional do Meio Ambiente CONAMA, $\mathrm{N}^{\circ}$ 003/1990, ${ }^{129}$ sendo a concentração de partículas totais em suspensão permitidas é de 80 microgramas por metro cúbico de ar em um ano, ou, uma concentração média de 24 horas de 150 microgramas por metros cúbicos de ar, que não deve ser excedida mais de uma vez por ano.

Nanopartículas, materiais aplicados principalmente nas áreas biomédica para diagnóstico e tratamentos clínicos, ${ }^{130}$ tornaram-se alvos de pesquisa acerca dos seus possíveis efeitos toxicológicos. A principal, e mais comum, fonte de entrada desses materiais no corpo se dá através da via respiratória, podendo chegar aos pulmões e entrar na corrente sanguínea, onde podem alcançar outros órgãos. ${ }^{130}$ Os efeitos toxicológicos 
destes materiais estão relacionados à sua composição, formato e, principalmente, ao seu tamanho.

Chen et. al. ${ }^{131}$ analisaram os efeitos biológicos de nanopartículas de $\mathrm{NaYF}_{4}$ dopadas com európio em três diâmetros: 50, 150 e 350 nm. Os estudos de citotoxicidade das nanopartículas analisadas pelo grupo demonstraram que os efeitos toxicológicos são fortemente dependentes do tamanho, sendo que as partículas maiores possuíam maior efeito tóxico quando comparadas às menores.

Segundo Zoroddu et. al, ${ }^{130}$ materiais de tamanho nanométrico podem ser encontrados em zonas de treinamento militar, principalmente como resultado da explosão de bombas que provocam a pulverização de rochas e objetos próximos, que são facilmente transportados como uma fina suspensão no ar, assim como em água.

O estudo da toxicidade, relacionada ao tamanho do material, de partículas encontradas em stands de tiro, provenientes do disparo de uma arma de fogo ainda não foi descrito na literatura. No caso do disparo de uma arma de fogo, uma nuvem de partículas combustas e não combustas é formada e ficam suspensas no ar. Essa nuvem de partículas formadas pode ser inalada pelo atirador ou por pessoas próximas no momento de disparo, ou podem ser depositas em superfícies e penetrarem por via dérmica. Este trabalho tem como objetivo determinar o efeito da adição do marcador à pólvora na distribuição do tamanho partícula do material particulado formado no momento do disparo, correlacionando com a sua possível toxicidade.

\subsection{Uso dos marcadores em rotinas forenses}

Em trabalho publicado em $2014,{ }^{61}$ nosso grupo testou 2 marcadores luminescentes desenvolvidos em diversas situações de interesse forense, com o intuito o de avaliar a adequação da luminescência em cenários reais. Foram avaliadas as seguintes situações: alteração na velocidade do projétil e taxa de falha do disparo em função do teor de marcador adicionado; coleta dos LGSR em locais pouco explorados (ex. narinas, orelhas, etc); tempo de permanência do LGSR nas mãos do atirador e a influência do processo de lavagem das mãos nesse tempo; transferência do LGSR para objetos manuseados pelo atirador; dispersão do LGSR em uma cena do crime e dispersão do LGSR na vítima. O LGSR apresentou um excelente tempo de permanência, cerca de 9 horas, e ainda era visível nas mãos do atirador após 16 lavagens. No que diz respeito à alteração na velocidade do projétil e na taxa de falha do disparo, não foram observados efeitos 
significativos para quantidades de até $2 \%$ em massa. Com relação à cena do crime, partículas foram encontradas em uma "linha reta" entre o atirador e o alvo, indicando a direção do tiro. Em todos os testes realizados, o marcador apresentou excelentes resultados, demonstrando ser uma ferramenta crucial na análise de uma cena do crime.

Em virtude dos bons resultados obtidos com o uso de marcadores luminescentes, outras questões, também relativas a situações de interesse forense e que podem auxiliar na perícia de uma cena de crime, foram levantadas. Algumas destas questões são:

(i) Qual a influência da arma na produção e dispersão do resíduo?;

(ii) É possível estimar a distância do tiro por meio da análise do padrão de dispersão do resíduo?;

(iii) É possível determinar a posição do atirador também com base no padrão de dispersão do resíduo?;

(iv) Existem transferências secundária e terciárias das partículas de GSR?;

(v) Como elas podem influenciar a identificação de um suspeito?

Todas estas questões refletem aspectos importantes relacionados à investigação de cenas do crime envolvendo o uso de armas de fogo.

\subsubsection{Influência da arma na produção do resíduo}

No momento em que a arma é acionada, partículas e gases são ejetados do cano formando uma espécie de cone, o qual posteriormente torna-se mais turbulento formando um tipo de vórtice na periferia (Esquema 1a). Após essa etapa, o projétil penetra essa nuvem (Esquema 1b) acompanhada de um novo jato de gases e partículas (Esquema 1c), o qual permanece por um período mais longo. Com isso, há a formação de duas espécies de nuvens esféricas (Esquema 1d) que permanecem suspensas no ar mesmo após o término da emissão de gases do cano. A forma do cone depende principalmente do tamanho do cano da arma, calibre da arma e da velocidade do projétil. ${ }^{132}$ Dessa forma, estes 3 fatores (calibre, tamanho do cano e velocidade do projétil) estão relacionados com o número de partículas de GSR depositadas no atirador e no local. 

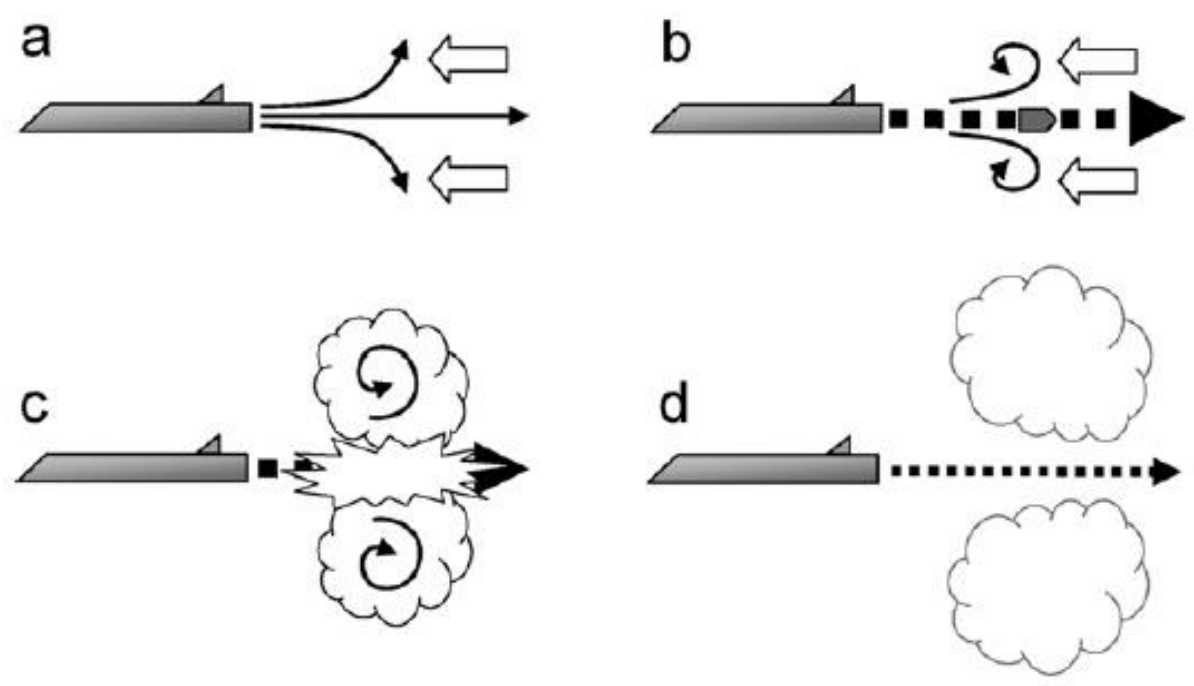

Esquema 1. Formação da nuvem de GSR após o disparo de uma arma de fogo. Adaptada da referência ${ }^{132}$.

A região em que as partículas de GSR são encontradas no atirador dependem do tipo de arma e de munição utilizados, do seu mecanismo de disparo e do sistema de acionamento, assim como formação. O GSR pode ser proveniente de 3 fontes de escape: folgas na arma, janela de ejeção e cano. ${ }^{37}$

As armas podem ser classificadas de acordo com suas características, tais como: alma, tamanho, sistema de carregamento, sistema de funcionamento e sistema de acionamento (Esquema 2).

A alma de uma arma consiste na região interna do cano da arma, podendo ser lisa ou raiada. No caso de armas com alma raiada, suas estrias são aquelas que conferem uma rotação no projétil.

Com relação ao tamanho das armas, estas podem ser divididas em curtas e longas. Armas curtas são aquelas de pequeno porte, que podem ser carregadas somente com uma mão (do inglês Handgun). Já as armas longas, são aquelas que possuem médio e grande porte e necessitam das duas mãos para realizar o disparo.

Armas com sistema de carregamento antecarga são aquelas que o carregamento é realizado na parte anterior, mesmo local da saída do projétil. As armas com sistema de carregamento retrocarga, mais comuns atualmente, são alimentadas pela parte posterior da arma. 


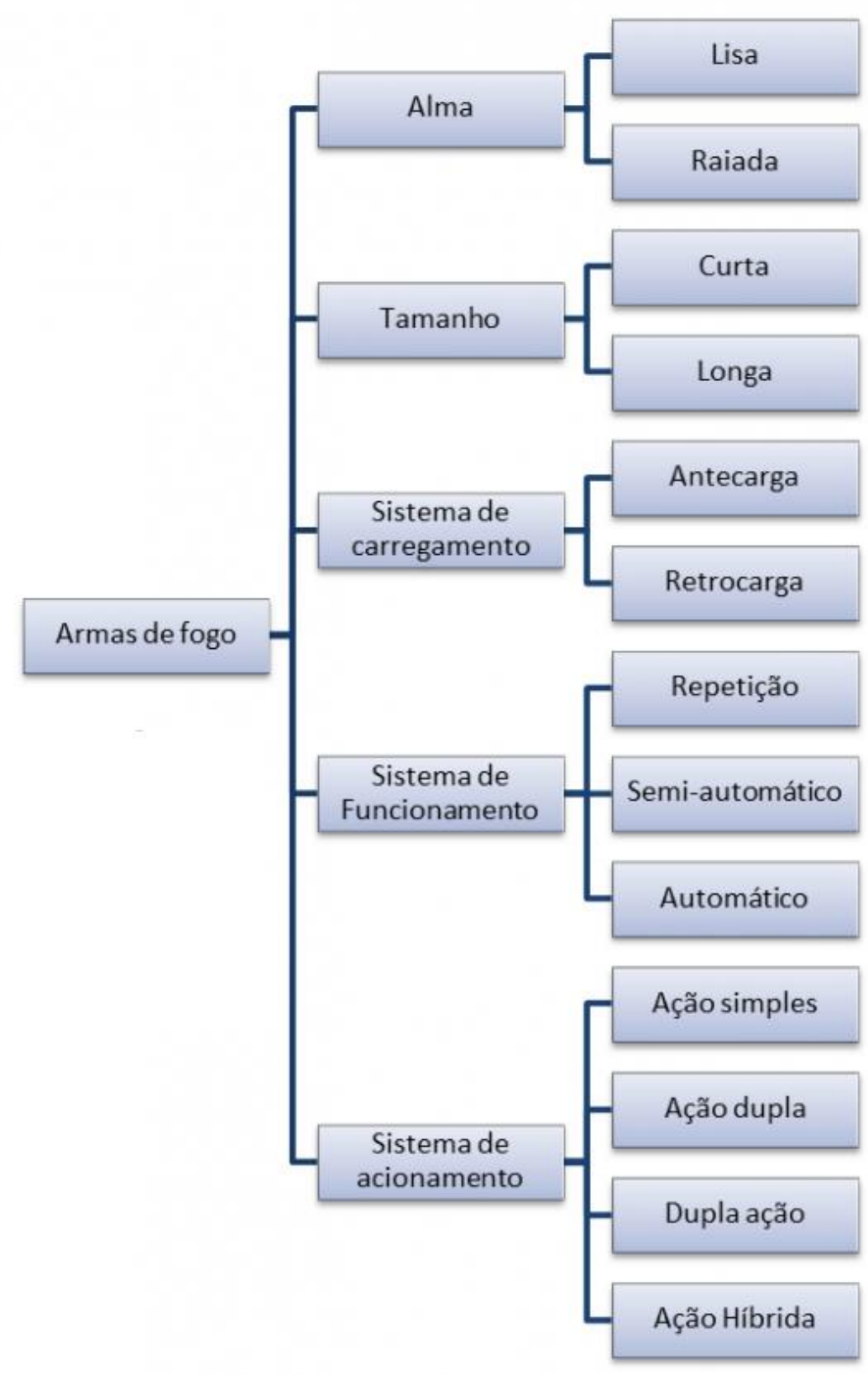

Esquema 2. Classificação de uma arma de fogo. ${ }^{133}$

Quanto ao tipo de funcionamento, podem ser divididas em repetição, semiautomática e automática. Nas armas de repetição, para que o atirador efetue um disparo, esse deve inserir na câmara uma nova munição manualmente. Já nas armas semiautomáticas, a alimentação da câmara é realizada utilizando somente a pressão proveniente do disparo anterior, sendo necessária somente a ação da tecla do gatilho. Armas automáticas são aquelas que, enquanto o gatilho estiver pressionado, é realizado o disparo, a ejeção do cartucho e a arma é realimentada, até que se esgote a munição de seu carregador ou cesse a pressão sobre o gatilho. 
Por fim, o tipo de ação consiste na relação entre o gatilho e o sistema de precursão da arma, sendo divido em:

- Ação Simples: ao apertar o gatilho, a arma realiza somente um movimento: o de liberar o cão, acionando o pino percursor efetuando o disparo da arma. Ou seja, é necessário que a arma esteja engatilhada para realizar o disparo.

- Ação Dupla: ao apertar o gatilho, a arma realiza dois movimentos, um de recuo e outro de aproximação do cano para percussão da espoleta, efetuando, assim, o disparo. Nesse tipo de arma, não é necessário engatilhar a arma para efetuar o disparo.

- Dupla Ação: consiste em armas que possuem ambos os tipos de ação: simples e dupla. Geralmente o primeiro disparo da arma é realizado com ação dupla, enquanto os demais disparos são realizados com ação simples.

- Ação Híbrida: são aquelas armas que não podem ser classificadas em ação simples ou dupla, como é o caso da Glock.

As diferentes classes de armas produzem diferentes padrões de dispersão de GSR. Em armas curtas, por exemplo, uma maior quantidade de resíduo é depositada nas mãos do atirador, tendo em vista que a nuvem de GSR é formada mais perto do cano da arma, enquanto em armas de tamanho longo, a maior parte dos resíduos se deposita principalmente no tórax e rosto do atirador e, em menor quantidade, nas mãos. ${ }^{37}$

\subsubsection{Estimativa da distância do disparo}

Para estimar a distância em que um disparo foi realizado, a aparência do orifício de entrada do projétil e a distribuição do resíduo de disparo são examinados. Observa-se se há um padrão característico que possa ser comparado a padrões de perfuração, obtidos com disparos realizados a partir de várias distâncias conhecidas, utilizando o mesmo tipo de arma. ${ }^{134,135}$ Quando o tiro é efetuado a uma distância próxima do alvo, a maior parte do GSR é depositada bem próxima ao orifício do projétil. À medida em que o atirador se distancia do alvo, o padrão de dispersão das partículas torna-se mais difuso. Tendo em vista os diferentes padrões que podem ser observados, a distância na qual uma arma foi disparada pode ser classificada da seguinte forma: contato, quase contato, intermediário e distante (Figura 16). Na maioria dos casos, são examinados pedaços de tecido, 
provenientes das roupas da vítima, contudo, testes podem ser realizados em outras superfícies. ${ }^{8}$

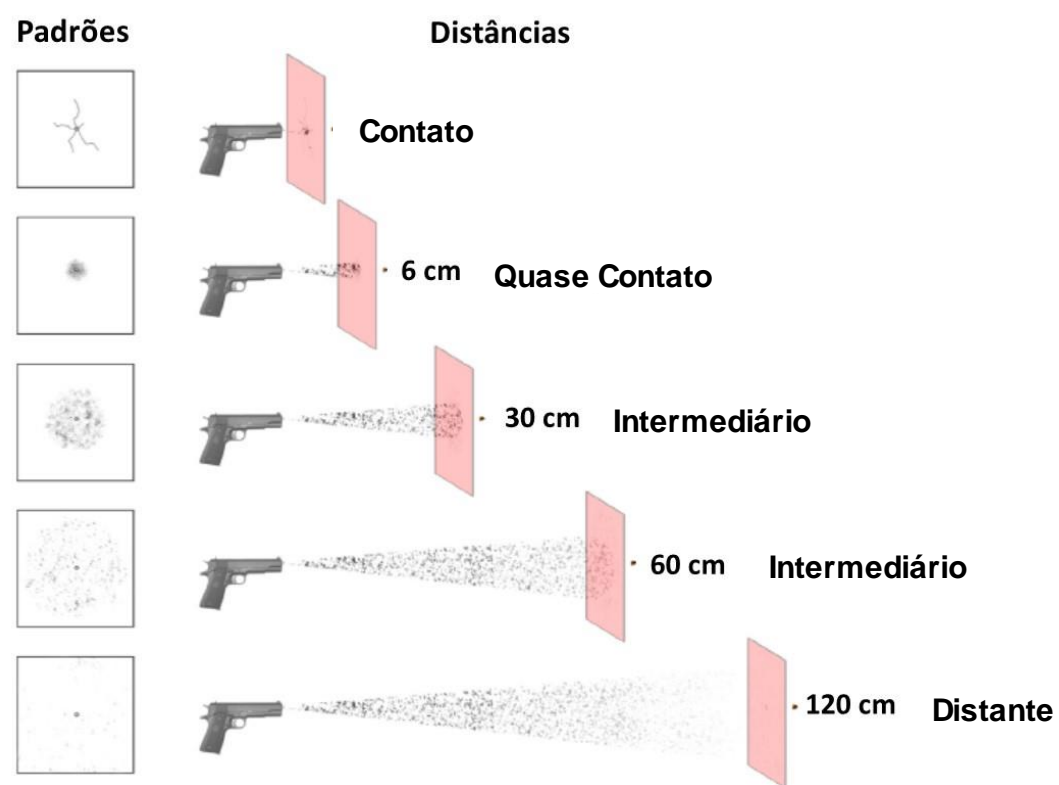

Figura 16. Padrões de dispersão do GSR obtidos de diferentes distâncias em que o disparo foi realizado. ${ }^{136}$

Os padrões formados são originados pelo GSR depositado na superfície de contato do projétil, sendo constituídos por partículas combustas ou incombustas, provenientes do propelente, do primer e do próprio corpo do projétil. O GSR depositado pode ser identificado visualmente ou com a utilização de microscópios ou lentes de aumento. ${ }^{30}$ Contudo, na maioria dos casos, é necessária a utilização de testes colorimétricos. ${ }^{29,31-33}$ O teste é realizado seguindo os seguintes passos, conforme proposto por Glattstein et al. ${ }^{134}$

1. Transferência dos GSR para uma fita adesiva.

2. Adição dos reagentes rodizonato de sódio, para revelar as partículas que contêm chumbo, e ácido rubeânico, para as partículas que contêm cobre.

3. Reação de hidrólise dos GSR, processo que aumenta a sensibilidade do método.

4. Aplicação do teste modificado de Griess para visualização dos resíduos de nitrito provenientes da pólvora.

O reagente de Griess consiste da mistura do ácido sulfanílico e $\alpha$-naftilamina em uma solução aquosa de ácido acético. A detecção dos íons nitritos livres é baseada na formação do íon diazônio decorrentes do ácido sulfanílico. O íon diazônio reage com a $\alpha$-naftilamina para formar um azo composto laranja. Apesar de apresentar uma toxicidade 
e um alto número de falsos positivos e negativos, o teste de Griess (Esquema 3) ainda é utilizado, principalmente no Brasil, para determinar a presença de GSR.

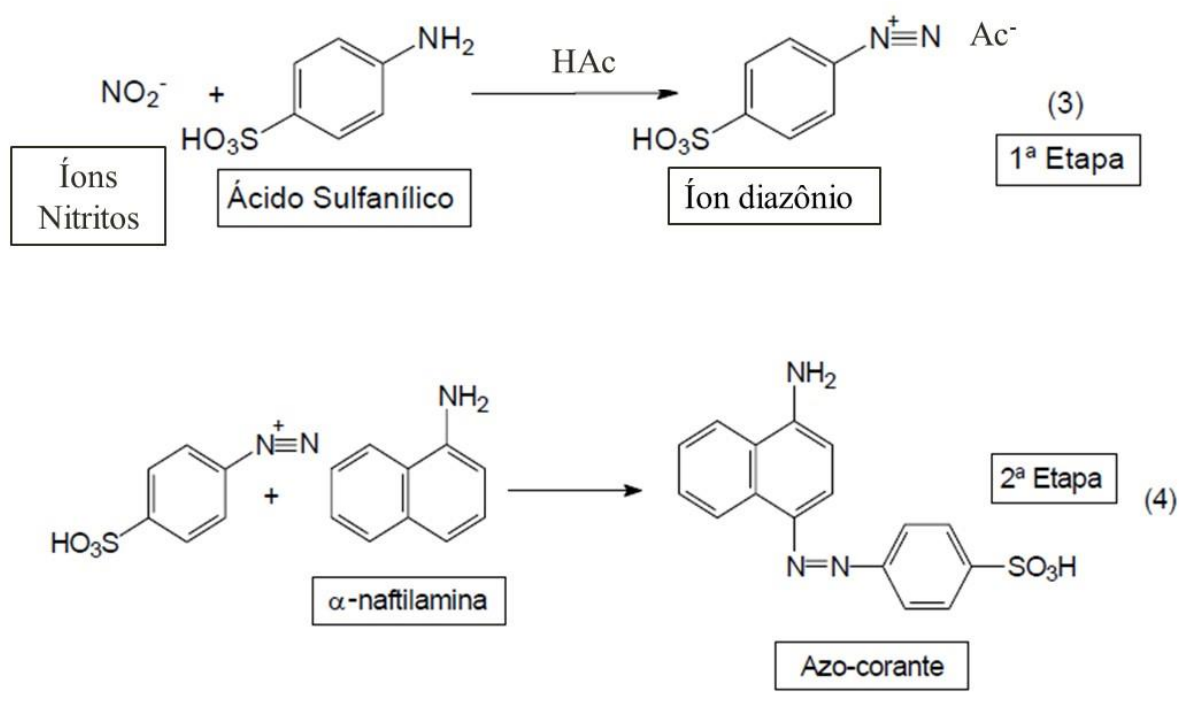

Esquema 3. Reação de Griess.

Os reagentes rodizonato de sódio e ácido rubeânico são utilizados na identificação do local de entrada do projétil, pois, nessa região, deposita-se maior número de partículas de chumbo e cobre, provenientes do material de fabricação do projétil. ${ }^{8}$ No caso da utilização de munições livres de chumbo, o uso do rodizonato de sódio torna-se ineficiente, tendo em vista que a massa iniciadora e a pólvora estão isentas deste metal. Para superar esse problema, foi proposta a utilização de um reagente capaz de revelar partículas com compostos de zinco e titânio, elementos presentes nesse tipo de munição. Contudo, os testes colorimétricos apresentam um taxa de erro muito elevada. ${ }^{137}$

Métodos de análises qualitativos instrumental também são descritos na literatura, tais como tomografia microcomputadorizada acoplada com software de análise de imagens, ${ }^{138}$ microscopia de força atômica com espectroscopia de infravermelho por transformada de Fourier ${ }^{139}$, espectroscopia de absorção atômica, ${ }^{140}$ fotografia digital com infravermelho ${ }^{141}$ e espectrometria de fluorescência de Micro Raios X (Micro-XRF). ${ }^{142,143}$

Outro método descrito na literatura é o uso de Vídeo comparador espectral, VSC (do inglês Video Spectral Comparator). O padrão de dispersão em tecidos escuros e roupas manchadas de sangue podem ser observados no VSC 2000. ${ }^{144}$ VSC é um equipamento amplamente utilizado em documentoscopia, ${ }^{145-147}$ que está presente na maioria dos laboratórios forenses, e, recentemente, tem sido utilizado como uma alternativa excelente em análise GSR. ${ }^{29,144}$ 


\subsubsection{Determinação da posição do atirador}

Determinar a posição do atirador em uma cena do crime é uma tarefa muito importante e árdua nas investigações de crimes por armas de fogo. Muitas vezes, ela envolve estimar a distância que a arma foi disparada (como o contato, quase contato, intermediário ou tiros distantes). No caso de tiros distantes, é muito difícil determinar com precisão.

A adição de marcadores na munição pode facilitar na análise de uma cena do crime. Weber et al. ${ }^{61}$ analisaram a dispersão de LGSR em uma cena do crime simulada em uma stand de tiro. No experimento, partículas foram encontradas ao longo da linha de fogo, sendo que não foram observadas partículas ao redor da linha de fogo. O padrão de dispersão observado indica uma possível localização do atirador no momento do disparo.

Nesse caso, o uso de LGSR abre uma nova perspectiva na análise da cena do crime, uma vez que o padrão de distribuição de LGSR no piso (ou qualquer outra superfície) pode ajudar a determinar a posição do atirador, a trajetória do projétil, bem como a distância de tiros distantes com excelente precisão.

\subsubsection{Transferência secundária e terciária de GSR}

A identificação de resíduos de disparo nos pertences de um suspeito pode ser uma evidência valiosa para relacionar uma pessoa a uma cena de crime. Por outro lado, a transferência de GSR pode levar a correlações errôneas entre pessoas e a cena do crime. Assim, um aspecto importante a ser considerado nas investigações criminais é a transferência de GSR para pessoas que não estão envolvidos com o crime.

$\mathrm{Na}$ área forense, o termo transferência secundária significa "movimento" de alguma evidência do seu local original para uma outra superfície, a qual não está relacionada com a fonte da transferência original (Esquema 4). ${ }^{148}$

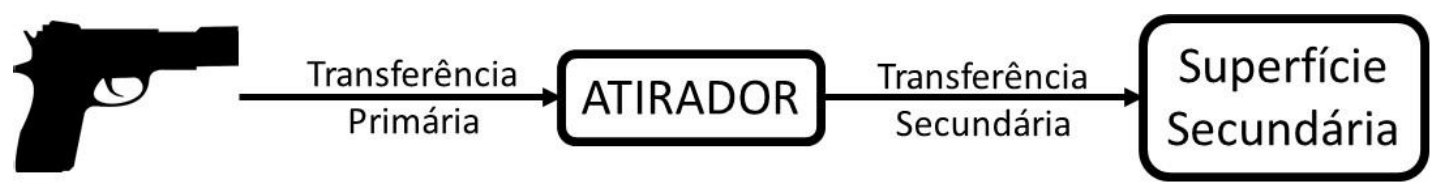

Esquema 4. Esquema representativo da transferência primária e secundária de GSR. 
Em 2014, French et al. ${ }^{148}$ realizaram um estudo acerca da transferência secundária do GSR por análise de MEV/EDS. O experimento teve como objetivo verificar a quantidade e o tamanho das partículas transferidas para um indivíduo que não estava presente no momento do disparo, assim como as devidas implicações desse fato na análise da evidencia. O grupo constatou que o resíduo pode sofrer transferência secundária por meio do aperto de mão com uma pessoa que não estava presente no momento do disparo, contundo o número de partículas encontradas no indivíduo foi consideravelmente menor do que o encontrado no atirador. Além disso, o grupo também avaliou o número de partículas transferidas a partir do manuseio da arma, na qual também foi observada a transferência de GSR. Tais resultados demonstram que um pequeno número de partículas depositadas em um suspeito não necessariamente indica que este realizou o disparo, podendo tais partículas serem provenientes de uma transferência.

Dando continuidade ao estudo realizado em 2014, French e Morgan ${ }^{149}$ publicaram em 2015 uma pesquisa acerca da transferência secundária e terciária do GSR. Novamente o grupo realizou uma série de experimentos com intuito de quantificar as partículas transferidas a indivíduos não presentes no momento do disparo após o aperto de mão e a contaminação de um indivíduo presente no momento do disparo sem que houvesse contato deste com o atirador ou com a arma. Em todos os casos experimentados, foram encontradas partículas de GSR em menor quantidade do que a recuperada do atirador.

Tendo em vista esses resultados, o estudo da dinâmica da transferência do GSR é de extrema importância, pois permite um maior entendimento e interpretação de uma cena do crime. 


\subsection{Objetivos}

Os objetivos deste trabalho foram sintetizar as MOFs ${ }_{\infty}[\mathrm{Eu}(\mathrm{DPA})-(\mathrm{HDPA})]$, ${ }_{\infty}\left[\mathrm{Eu}_{2}(\mathrm{BDC})_{3}\left(\mathrm{H}_{2} \mathrm{O}\right)_{2}\right]_{\mathrm{n}}, \mathrm{e} \infty_{\infty}[\mathrm{Eu}(\mathrm{BTC})]$ e aplicar esses compostos como marcadores de munições NTA. Também almejou-se estudar, preliminarmente, a toxicidade química do LGSR produzido pelo disparo de uma munição marcada a partir da análise dos subprodutos gerados após o disparo da arma, em específico a piridina e benzeno, e pela análise do tamanho das partículas produzidas.

Nesta etapa, os objetivos específicos consistiram no desenvolvimento de um método de análise por SPME e a aplicação deste método para verificar se os compostos benzeno e piridina foram formados no disparo da munição marcada, além de demais compostos com uma toxicidade conhecida. Também o trabalho teve como objetivo verificar o tamanho das partículas formadas no disparo das munições NTA marcadas, NTA e da munição comum, classificando-as em $\mathrm{MP}_{2,5}$ e $\mathrm{MP}_{10}$ e correlacionando esses valores com a possível toxicidade do material.

Além disso, o trabalho teve como objetivo o estudo da aplicação dos marcadores luminescente para resíduos de tiro contendo o íon $\mathrm{Eu}^{3+}$ em diversos cenários que simulassem rotinas forenses, como forma de identificar as potencialidades e as limitações destes marcadores.

Os objetivos específicos desta parte do trabalho consistiam em: (i) testar os marcadores em diferentes armas, que possuam mecanismos de disparos variados, verificando a influência destes na produção do resíduo luminescente; (ii) relacionar os padrões de dispersão dos LGSR em tecidos com a distância entre o atirador e o alvo, avaliando a possiblidade de identificar a distância na qual o disparo foi realizado, (iii) determinar a posição do atirador por meio da dispersão de LGSR no chão; e (iv) investigar se as partículas de LGSR podem ser transferidas das mãos dos atiradores por sucessivos apertos de mão. 
2. MATERIAIS E MÉTODOS 


\subsection{Síntese dos marcadores fluorescentes}

Três marcadores, os quais já foram previamente estudados por nosso grupo de pesquisa, foram sintetizados para a realização deste trabalho: ${ }_{\infty}[\mathrm{Eu}(\mathrm{DPA})-(\mathrm{HDPA})]$, ${ }_{\infty}\left[\mathrm{Eu}_{2}(\mathrm{BDC})_{3}\left(\mathrm{H}_{2} \mathrm{O}\right)_{2}\right]_{n}$ e ${ }_{\infty}[\mathrm{Eu}(\mathrm{BTC})]$, nomeados de EuDPA, EuBDC e EuBTC, respectivamente. Após a síntese e caracterização, os marcadores foram adicionados à munição NTA.

Para a síntese dos marcadores, primeiramente foi preparado o nitrato de európio e o sal do ligante BDC (NaBDC). Os demais ligantes foram utilizados como adquiridos.

\subsection{1 $\quad \mathrm{Eu}\left(\mathrm{NO}_{3}\right)_{3}$}

O nitrato de európio foi sintetizado a partir da reação de nitração do óxido de európio (Sigma Aldrich, 99,5\%). Incialmente, 10 mmols de $\mathrm{Eu}_{2} \mathrm{O}_{3}$ foram dissolvidos em água destilada. Em seguida, adicionou-se, lentamente, ácido nítrico até que a mistura ficasse transparente. A mistura foi aquecida e água foi adicionada até a neutralização do pH da solução. Com isso, a solução foi evaporada até a formação de um sólido branco.

\subsubsection{EuDPA}

O marcador denominado EuDPA foi sintetizado via hidrotermal assistida por micro-ondas (Monowave 300 Anton Paar) em um reator de vidro (Vial Glass) de $10 \mathrm{~mL}$, seguindo uma metodologia descrita por Rodrigues et al. ${ }^{71}$ Foram misturados 0,35 mmols de $\mathrm{Eu}\left(\mathrm{NO}_{3}\right)_{3}$ com 0,7 mmols do ligante ácido dipicolínico $\left(\mathrm{H}_{2} \mathrm{DPA}\right)$ (Aldrich, 95\%) em $5 \mathrm{~mL}$ de água destilada, sob agitação. A reação ocorreu durante 10 minutos a uma temperatura de $160{ }^{\circ} \mathrm{C}$, originando um pó branco. A potência utilizada foi de $400 \mathrm{~W}$. Após a síntese, o material foi filtrado e lavado com água e álcool etílico e seco em uma estufa por 24 horas à $100{ }^{\circ} \mathrm{C}$. A reação apresentou um rendimento de aproximadamente $72 \%$, em relação ao ligante.

\subsubsection{Na2BDC}

Para a síntese do sal de BDC, 20 mmol de $\mathrm{NaOH}$ foram dissolvidos em $10 \mathrm{~mL}$ de água destilada e adicionada lentamente a $10 \mathrm{mmol}$ de 1,4- $\mathrm{H}_{2} \mathrm{BDC}$ (Aldrich, 95\%) em 50 
$\mathrm{mL}$ de água, sob agitação magnética. Evaporou-se cerca de um terço do volume total de água e adicionou-se $20 \mathrm{~mL}$ de etanol até precipitação do sal. O sal obtido foi seco à temperatura ambiente, obtendo-se um rendimento de aproximadamente $75 \%$ com relação ao ligante.

\subsubsection{EuBDC}

Para o marcador EuBDC, foi utilizada uma adaptação da metodologia descrita por Reineke et al. ${ }^{150}$ Para tal, foram misturados 2,1 mmols de $\mathrm{Eu}\left(\mathrm{NO}_{3}\right)_{3}$ com 2,1 mmols do ligante benzeno-1,4-dicarboxílico de sódio ( $\left.\mathrm{Na}_{2} \mathrm{BDC}\right)$, em $15 \mathrm{~mL}$ de água destilada em um reator de $20 \mathrm{~mL}$, sob agitação magnética. Novamente, a reação foi realizada por via hidrotermal assistida por micro-ondas, na qual foi utilizada uma potência de $400 \mathrm{~W}$, durante 20 minutos e temperatura de $160{ }^{\circ} \mathrm{C}$. O produto obtido também é um pó branco., o qual foi filtrado e lavado com água e álcool etílico e seco em uma estufa por 24 horas à $100{ }^{\circ} \mathrm{C}$. A reação apresentou um rendimento de aproximadamente $80 \%$, em relação ao ligante.

\subsubsection{EuBTC}

O marcador intitulado EuBTC foi sintetizado por via hidrotermal assistida por micro-ondas com a adição de 1,05 mmols de $\mathrm{Eu}_{2} \mathrm{O}_{3}$ e 2,1 mmols do ligante ácido benzeno1,3,5-tricarboxílico ( $\mathrm{H}_{3} \mathrm{BTC}$ ) (Aldrich, 95\%) em $15 \mathrm{~mL}$ de água destila, conforme descrito por Lucena. ${ }^{63}$ A reação foi realizada em $160^{\circ} \mathrm{C}$, durante 20 minutos e com uma potência de $400 \mathrm{~W}$, sob agitação magnética. O material sintetizado (pó branco) foi filtrado e lavado com água e álcool etílico e seco em uma estufa por 24 horas à $100^{\circ} \mathrm{C}$. A reação apresentou um rendimento de aproximadamente $90 \%$, em relação ao ligante.

\subsection{Caracterização dos Marcadores}

\subsubsection{DRX}

Os padrões de difração dos marcadores foram obtidos em um difratômetro de raios X de pó (Bruker/Modelo D8 Discover) do Instituto Nacional de Criminalística da Polícia Federal (INC/PF). Foram utilizados os seguintes parâmetros: intervalos de $2 \theta$ de $5^{\circ}$ a 
$50^{\circ}$ com passo de $0,02^{\circ}$ e velocidade de $5 \%$ min e o mesmo porta-amostra para todos marcadores.

\subsubsection{FTIR}

Espectros na região do infravermelho foram obtidos com o espectrômetro da Termo IS-10 disponível no Laboratório do INC/PF utilizando a técnica de refletância total atenuada (ATR).

\subsubsection{Fotoluminescência}

Os espectros de emissão e excitação foram obtidos utilizando o Espectrofluorímetro Fluorolog da marca Horiba Scientific, disponível na central analítica do Instituto de Química da Universidade de Brasília. Para as análises, um suporte do equipamento para análise de materiais sólidos foi utilizando. Os espectros de emissão foram obtidos com varreduras na região de $550 \mathrm{~nm}$ à $750 \mathrm{~nm}$, com excitação da amostra em $293 \mathrm{~nm}$. Já os de excitação foram obtidos com uma varredura no comprimento de onda de excitação entre $200 \mathrm{~nm}$ e $550 \mathrm{~nm}$, monitorando a emissão em $610 \mathrm{~nm}$.

\subsubsection{VSC}

Para verificar a luminescência dos marcadores, foram obtidas imagens utilizando como fonte de irradiação a luz UV ( $\lambda=254$ nm) no VSC (VSC 6000 / HS Foster \& Freeman). Os equipamentos de VSC utilizados neste trabalho estão disponíveis no Setor de Documentoscopia do INC/PF.

\subsubsection{MEV/EDS}

A análise morfológica e elementar dos marcadores sintetizados foi realizada por Microscopia Eletrônica de Varredura acoplada à Espectroscopia por Dispersão de Energia (MEV/EDS) (FEI Modelo Quant 3d), disponível no Setor da Balística do INC/PF. O experimento foi realizado em alto vácuo, sem a necessidade de metalização da amostra. Além disso, foram adquiridos espectros EDS pontuais, sem varredura automática. Um detector de elétrons retroespalhados (BSE) foi utilizado nas análises, possibilitando 
identificar as variações na composição das partículas. A calibração foi realizada com os metais cobalto e ouro.

\subsection{Adição dos marcadores à pólvora}

Os marcadores foram adicionados à pólvora da munição NTA $9 \mathrm{~mm}$ da Companhia Brasileira de Cartuchos. O processo de adição é demonstrado no Esquema 5.

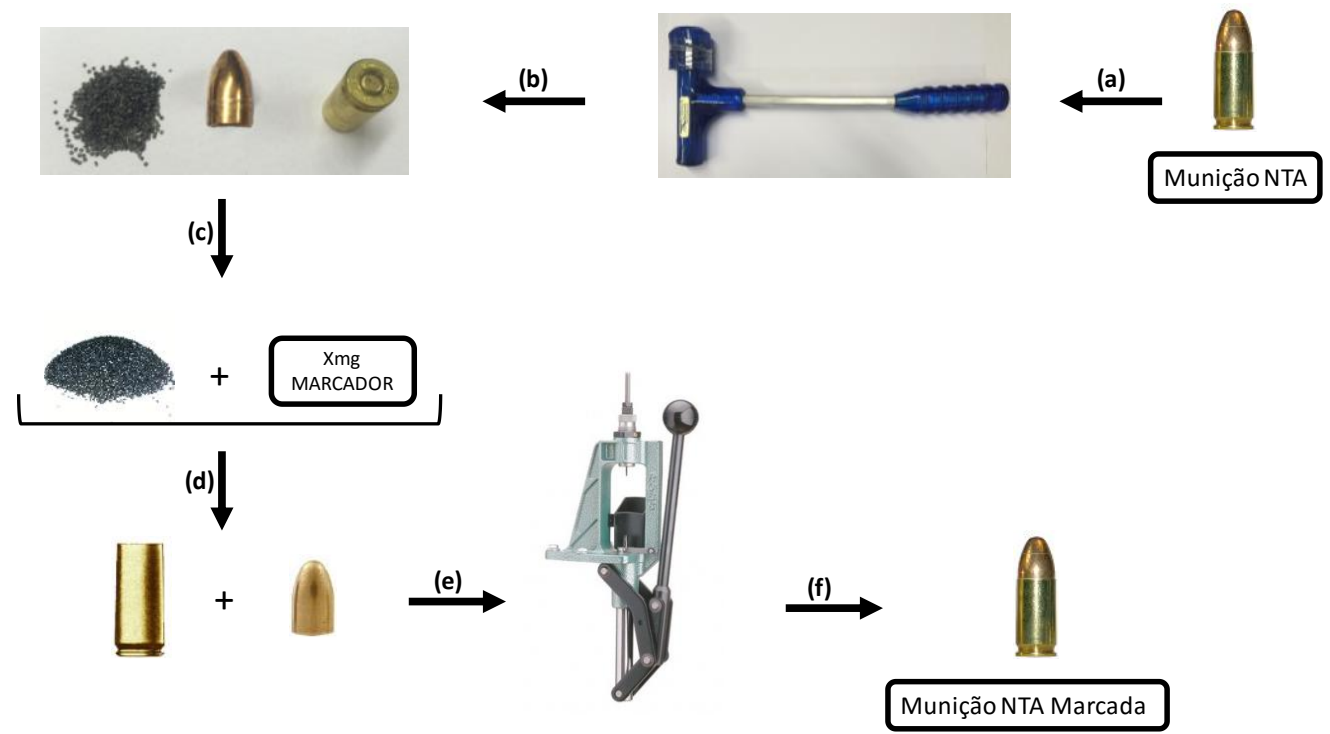

Esquema 5. Processo de adição dos marcadores à pólvora de uma munição NTA 9 mm.

Primeiramente, as munições NTA foram adicionadas ao martelo de inercia (processo a) onde os projéteis foram retirados dos cartuchos e a pólvora, cerca de $400 \mathrm{mg}$, foi recuperada (processo b). Após essa separação, a massa da pólvora foi pesada e misturada com quantidade pré-estabelecida do marcador (4-10\% em massa com relação à massa de pólvora, 16 a $40 \mathrm{mg}$ ) (processo c). A quantidade de marcador adicionada na munição variou de acordo com cada experimento, sendo que foi realizado um processo de otimização na realização dos experimentos visando reduzir o número de munições usadas, assim como o tempo de uso do stand de tiros do INC-DPF.

Além disso, em casos de análise exploratória onde se desejava obter grande quantidade de LGSR, optou-se por utilizar uma quantidade maior de marcador na munição. Em outros experimentos, nos quais não era necessário obter grande quantidade de LGSR ou ainda quando se pretendia avaliar o comportamento da arma, optou-se por uma menor quantidade. Conforme observado por Weber et al. ${ }^{61}$, o marcador pode ser identificado na cena do crime em quantidade maiores que $2 \%$, entretanto os melhores resultados (melhor visualização) ocorre quando são utilizados até 10\% de marcador. 
Após essa etapa, a mistura foi adicionada ao cartucho (processo d) e seu fechamento foi realizado utilizando uma prensa de recarga (crimping - processo e) obtendo, dessa forma, as munições NTA marcadas (processo f).

\subsection{Toxicidade Química dos Marcadores}

\subsubsection{Subprodutos gerados após o disparo}

Para análise dos subprodutos gerados após o disparo de uma arma, cartuchos foram coletados e os voláteis do cartucho foram extraídos por SPME. As amostras obtidas foram analisadas por CG/EM. As amostras foram geradas a partir de:

- Cartucho deflagrado com munição NTA;

- Cartucho deflagrado com munição NTA marcada com o marcador EuDPA;

- Cartucho deflagrado com munição NTA marcada com o marcador EuBDC;

- Cartucho deflagrado com munição NTA marcada com o marcador EuBTC;

As análises utilizando o equipamento de CG/EM foram realizadas utilizando nas condições experimentais descritas abaixo.

\section{Extração por SPME}

Após cada disparo, o cartucho foi inserido em uma capsula de SPME (CG vial de $20 \mathrm{~mL}$ ), conforme ilutrado no Esquema 6. Uma fibra $65 \mu \mathrm{m}$ PDMS/DVB (SUPELCO) foi utilizada para as extrações. Essa foi condicionada durante os experimentos conforme recomendações do fabricante (SUPELCO).

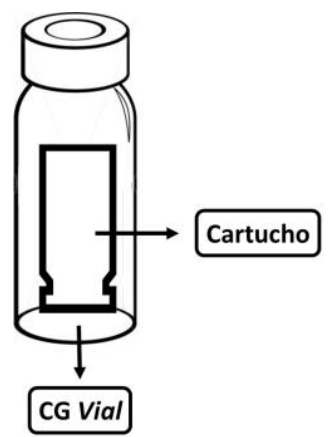

Esquema 6. Cartucho de uma munição $9 \mathrm{~mm}$ em um $C G$ vial para extração dos voláteis após o disparo. 
O experimento de SPME foi realizado na sequência: incubação à temperatura de $80{ }^{\circ} \mathrm{C}$ agitada à $600 \mathrm{rpm}$ durante $3 \mathrm{~min}$. O tempo de extração da fibra foi de 16 min e a dessorção no injetor ocorreu durante $20 \mathrm{~min}$.

\section{Condições de operação do Cromatógrafo}

Um espectrômetro de massas (Agilent modelo 5973 inert), acoplado a um cromatógrafo gasoso (Agilent modelo 6890N), com coluna capilar de fase 5\% metil-fenil polisiloxano/95\% polisiloxano, de dimensões 30m X 0,25 mm X 0,25 $\mu \mathrm{m}$ (Rtxi-5msda RESTEK), dotado de amostrador multipropósito CTC PAL, com módulo de SPME foi utilizado para realizar as análises.

As condições de operação cromatográficas foram as seguintes: temperatura do injetor foi mantida em $280{ }^{\circ} \mathrm{C}$, no modo Splitless com válvula de Split fechada durante 4 min. A coluna foi mantida em fluxo constante de Hélio de $1,3 \mathrm{~mL} / \mathrm{min}$. A programação de forno cromatográfico foi: temperatura inicial de $40{ }^{\circ} \mathrm{C}$, mantido por $1 \mathrm{~min}$, depois aquecimento à taxa de $10^{\circ} \mathrm{C} / \mathrm{min}$ até $120^{\circ} \mathrm{C}$, mantendo-se nesta temperatura por $1 \mathrm{~min}$. Depois foi aquecido na taxa de $5^{\circ} \mathrm{C} / \mathrm{min}$ até $180^{\circ} \mathrm{C}$, mantendo-se nesta temperatura por $1 \mathrm{~min}$, e por fim, o forno foi aquecido na taxa de $60{ }^{\circ} \mathrm{C} / \mathrm{min}$ até $315^{\circ} \mathrm{C}$, mantendo-se esta temperatura por $25 \mathrm{~min}$. O tempo total de análise foi de $50 \mathrm{~min}$ e $25 \mathrm{~s}$.

A interface do CG/EM foi mantida à $280{ }^{\circ} \mathrm{C}$, sendo o espectrômetro de massas operado no modo scan na faixa de varredura de 30 a $500 \mathrm{~m} / \mathrm{z}$. Os espectros de massa obtidos foram analisados pelo programa Chemstation Data Analysis e pelo programa NIST Search (versão 2.0).

\subsubsection{Tamanho das partículas}

Para esse experimento, quatro disparos foram realizados com a munição $9 \mathrm{~mm}$ NTA marcada com 10\% do marcador EuBTC. Após os disparos, partículas de LGSR foram coletadas nas mãos do atirador pressionando 50 vezes stubs metálicos cobertos com fita condutora de carbono, seguindo as instruções da $\mathrm{ASTM}^{35}$ e da Polícia Federal Brasileira. ${ }^{151} \mathrm{O}$ experimento foi repetido utilizando munição $9 \mathrm{~mm}$ NTA não marcada.

Além disso, partículas de LGSR também foram coletadas do cartucho após o disparo de uma munição NTA marcada com 10\% do marcador EuBTC. Novamente, a coleta também foi realizada com as munições 9 mm NTA não marcada. 
Os stubs contendo as partículas de LGSR e as partículas provenientes do disparo da munição NTA não marcada foram analisados por MEV/EDS, utilizando um software comercial automatizado, INCAGSR. Uma modificação no software foi realizada, através da criação de uma nova rotina que permitisse a identificação de todas as partículas que contêm algum elemento da família dos lantanídeos e actinídeos. Dessa forma, foi possível determinar o número de partículas luminescentes com o seu respectivo tamanho. No experimento, uma ampliação de 600x foi utilizada, sem foco automático. Nele, o stub foi dividido em cerca de 600 quadrículas, em cada uma, eram selecionados, no máximo, 25 pontos que apresentassem contraste similar ao padrão de Eu, nos quais o EDS era realizado.

Histogramas foram construídos utilizando o programa OriginPro (versão 8). Com isso, os gráficos obtidos da munição marcada foram comparados com os gráficos obtidos da munição NTA.

Todo o experimento foi realizado em triplicata.

\subsection{Testes Forenses}

Os marcadores sintetizados foram aplicados em experimento que simulam a rotina forense com intuito de avaliar a potencialidade e as limitações destes marcadores. Foram avaliados os seguintes aspectos relacionados à cena do crime e à utilização de marcadores de munição NTA: (i) influência do tipo de arma na produção e dispersão do LGSR; (ii) estimativa da distância do disparo; (iii) determinação da posição do atirador e (iv) transferência secundária e terciária.

Para todos os testes realizados, os disparos ocorreram no stand de tiro do Setor de Balística do INC/PF (Figura 17), sem circulação de ar. Para a coleta foram usados stubs metálicos de $1 / 2$ in recobertos com fita de carbono condutora, em que cada um foi pressionado 50 vezes nas mãos do atirador ou das pessoas de interesse, segundo recomendações da $\mathrm{ASTM}^{35}$ e da Polícia Federal. ${ }^{151}$ Coletas também foram realizadas nas armas utilizadas e no chão, quando necessário. As amostras coletadas foram analisadas usando VSC 40 e VSC 6000 (HS Foster \& Freeman) e por MEV/EDS (FEI Quant 3d), quando necessário. 


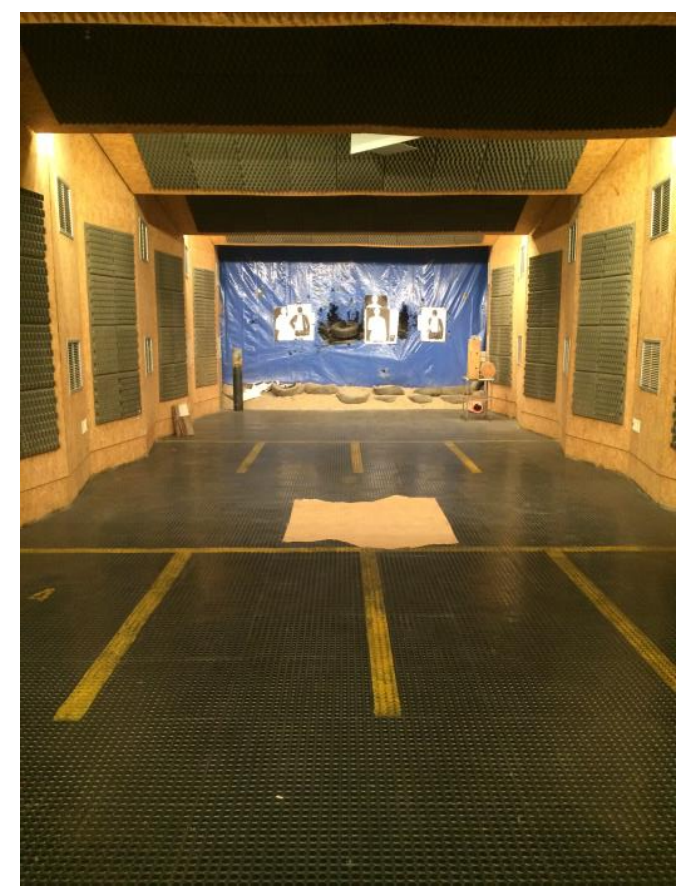

Figura 17. Stand de tiros do Setor de Balística do Instituto Nacional de Criminalística da Polícia Federal brasileira.

\subsubsection{Influência do tipo da arma na produção do LGSR}

Para este experimento, foram utilizados seis diferentes tipos de pistolas $9 \mathrm{~mm}$ : Glock G17, Glock G26, Smith \& Wesson 6906, Browning Hi-Power, Jericho 941F e Taurus PT 908 (Figura 18). Todas as armas usadas foram ou apreendidas pela Polícia Federal ou são de uso típico dos policiais (no caso das Glocks).

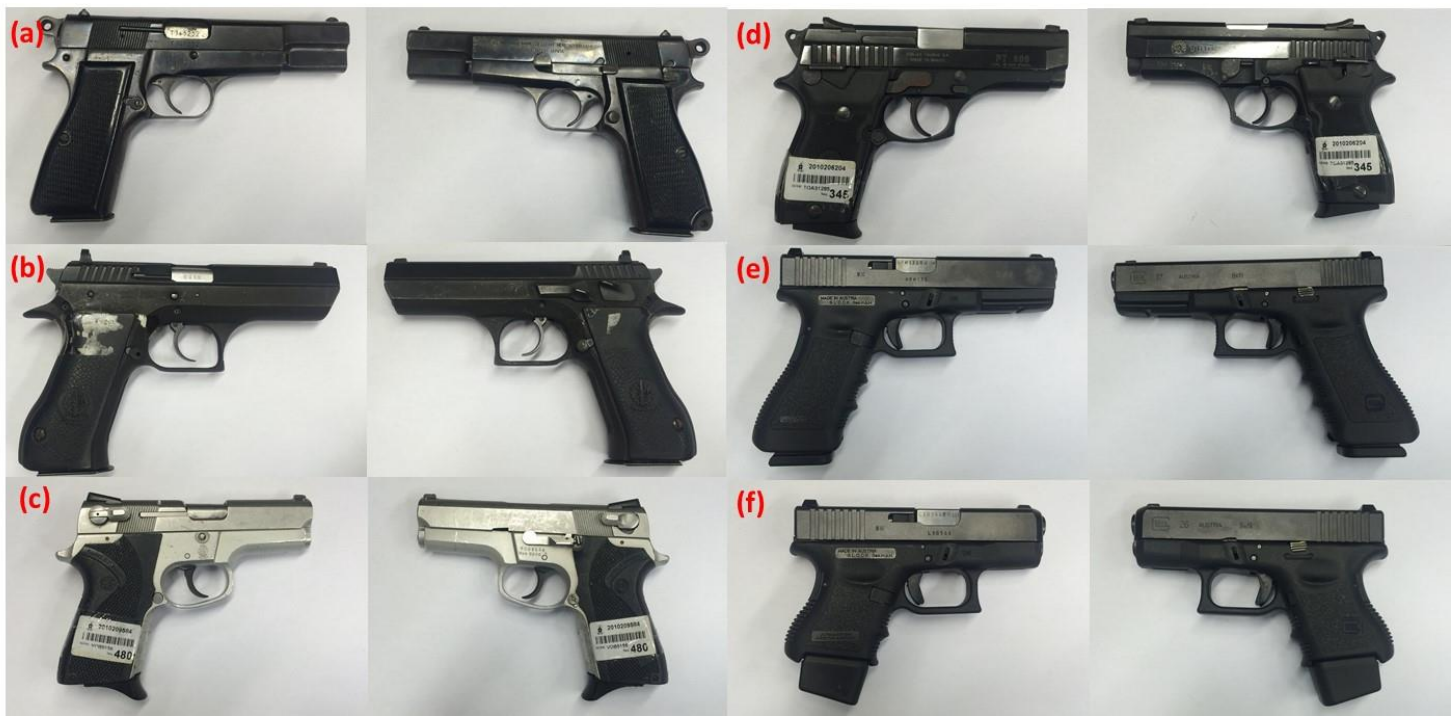

Figura 18. Armas testadas: (a) Browning, (b) Jericho (c) Smith \& Wesson, (d) Taurus, (e) Glock G17 e (f) Glock G26. 
Diferentes atiradores realizaram dois tiros cada, com munição NTA marcada com $10 \%$ do marcador EuBTC. Cada conjunto de disparos foram realizados em dias diferentes, para evitar interferências e contaminação. Além disso, as armas e mãos dos atiradores foram avaliadas antes de cada disparo com luz UV portátil $(\lambda=254 \mathrm{~nm})$ para verificar se elas estavam contaminadas com material luminescente.

Após os disparos, as mãos e armas dos atiradores foram analisadas e fotografadas sob radiação UV $(\lambda=254 \mathrm{~nm})$ no VSC. Após as fotos, partículas de LGSR foram coletados em stubs metálicos e analisados por MEV/EDS.

\subsubsection{Estimativa da distância do disparo}

Com intuito de estimar a distância entre o atirador e a vítima (ou alvo), pedaços de papelão $\left(30 \times 30 \mathrm{~cm}^{2}\right)$ foram cobertos com tecido de algodão preto e usados como alvos para simular as roupas das vítimas. Uma pistola Glock G17 com munição NTA 9 mm marcada com $6 \%$ dos marcadores EuDPA, EuBTC e EuBDC foi utilizada para realizar os disparos. Três conjuntos de disparos foram realizados, sendo que, em cada repetição, um marcador diferente foi utilizado. As seguintes distâncias foram testadas: $6 \mathrm{~cm}$ (quase contato), $30 \mathrm{~cm}$ (intermediário), $60 \mathrm{~cm}$ (intermediário) e $120 \mathrm{~cm}$ (distante). Após cada disparo, os alvos foram retirados do stand de tiro e mantidos na posição horizontal até análise, para evitar o desprendimento de partículas.

Cada pedaço de tecido foi examinado por VSC sob a luz UV $(\lambda=254 \mathrm{~nm})$, e os padrões de dispersão produzidos pelos LGSR depositados foram analisados em função da distância de tiro. Após a primeira avaliação no VSC, todos os pedaços de tecidos foram agitados a fim de avaliar o efeito do manuseio ou movimento da vítima. Cada pedaço de tecido foi segurado em suas extremidades e agitados verticalmente dez vezes. Em seguida, o tecido foi novamente analisado no $\operatorname{VSC}(\lambda=254 \mathrm{~nm})$.

Outro fator que pode influenciar no padrão de dispersão do LGSR é a presença de sangue. Neste caso, pedaços de tecidos de algodão preto $\left(30 \times 30 \mathrm{~cm}^{2}\right)$ contendo sangue de rato foram utilizados como alvo. O sangue utilizado no presente estudo foi doado pela Profa. Fabiane H. Veiga de Souza (Faculdade de Ceilândia - UnB). Esse sangue foi coletado como parte de outros experimentos, nos quais os animais foram anestesiados com uma mistura de cetamina e xilazina (60 mg/kg e $10 \mathrm{mg} / \mathrm{kg}$, respectivamente, i.p.) e, em seguida, $3 \mathrm{~mL}$ de sangue foram coletados do ventrículo direito com seringa 
heparinizada. Os experimentos animais foram aprovados pela Comissão de Ética no Uso Animal da UnB (UnBDoc n. 147474/2015).

O sangue coletado foi adicionado ao tecido segundos antes do disparo. Foram efetuados 4 disparos em tecidos distintos, nas distâncias de 6, 30, 60 e $120 \mathrm{~cm}$ do alvo. Após os disparos, os tecidos foram reservados na horizontal, em um lugar aberto durante 12 horas, para que os tecidos fossem analisados secos, situação comum nesse tipo de análise. Os padrões correspondentes à cada distância foram observados com auxílio do $\operatorname{VSC}(\lambda=254 \mathrm{~nm})$ e comparados com os padrões obtidos incialmente, sem a utilização do sangue. Amostras do LGSR foram coletadas em stubs e analisados por MEV/EDS. Diante disso, foi possível analisar a influência do sangue na luminescência do marcador e no padrão do marcador.

Para simular uma situação real, um conjunto de três testes cegos foram conduzidos. Três diferentes atiradores realizaram um disparo em uma das distâncias analisadas $(6,30,60$ e $120 \mathrm{~cm}$ do alvo), sem o conhecimento do responsável pela análise (analista). Cada atirador foi acompanhado por uma pessoa neutra, para auxiliar na montagem do teste e anotar a distância na qual o disparo foi realizado. Entretanto o analista não teve acesso ao stand de tiros. Ao final do teste, cada atirador anotou em um papel a distância a partir da qual realizou os disparos e colocou o papel em envelope lacrado.

Após a realização dos disparos de cada atirador, o analista investigou os pedaços de tecidos sob a luz VSC $(\lambda=254 \mathrm{~nm})$, comparando-os com os padrões obtidos anteriormente. A distância estimada pelo analista foi confrontada com a distância anotada pelo atirador e confirmada pela pessoa que acompanhou o disparo.

\subsubsection{Determinação da posição do atirador/teste cego}

Uma segunda série de testes cegos foi realizada a fim de se estimar a posição do atirador em uma cena de crime. Para tal, uma cena de crime simulada foi criada no stand de tiros, em que 12 posições foram demarcadas com papel pardo (cerca de 1 x 1,5 m² cada pedaço de papel), como representado na Figura 19. As posições 1A a 1D foram colocadas a $5 \mathrm{~m}$ do alvo, enquanto posições $3 \mathrm{~A}$ a $3 \mathrm{D}$ foram colocadas a até $10 \mathrm{~m}$ de alvo. 


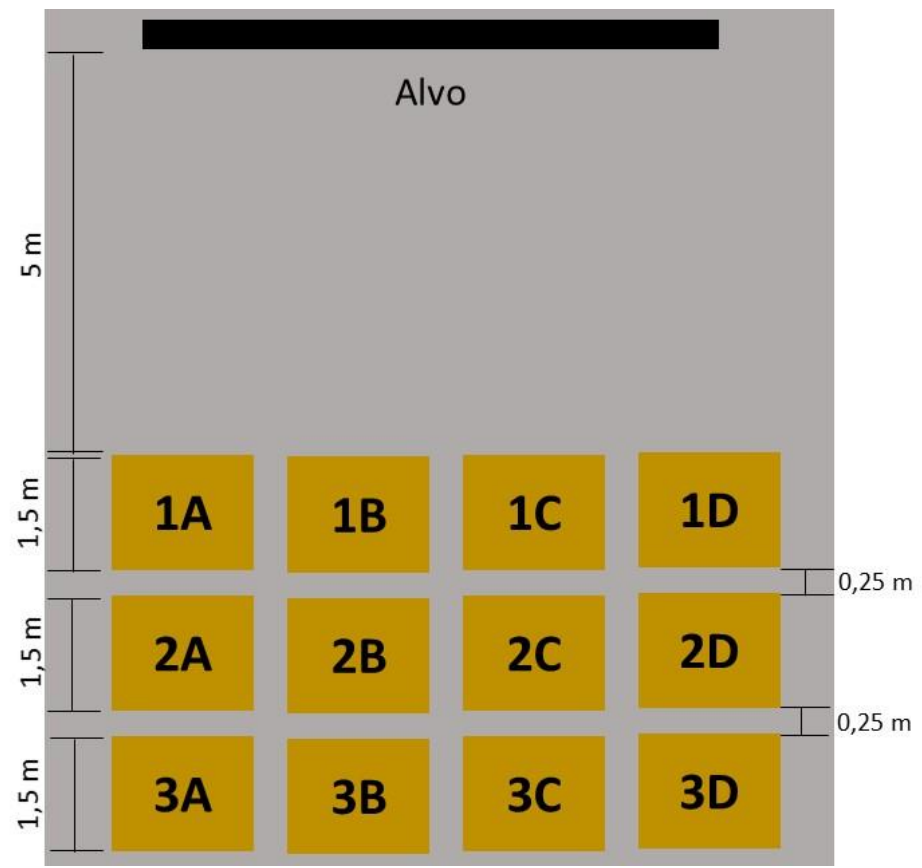

Figura 19. Layout da cena do crime simulada para realização do teste cego.

O atirador entrou sozinho no stand de tiro, escolheu uma das 12 posições, disparou 3 tiros, recolheu o cartucho (de modo que esse não poderia ser usado para inferir sobre a posição de tiro). Ainda dentro da sala, o atirador anotou a posição escolhida em um pedaço de papel, a qual foi selada no envelope.

Após os disparos, o analista entrou na cena do crime com uma lâmpada UV portátil $(\lambda=254 \mathrm{~nm})$ e tentou identificar a posição na qual disparo foi realizado e recolher amostras LGSR (usando stubs metálicos cobertos com fita de carbono). O analista também anotou a posição identificada em um pedaço de papel, que foi mantido em outro envelope lacrado. Os envelopes preenchidos foram mantidos por uma pessoa neutra e as posições foram confortadas posteriormente.

Oito séries de três tiros cada foram realizadas por oito atiradores diferentes, utilizando diferentes pistolas $9 \mathrm{~mm}$ NTA marcada com $4 \%$ do marcador luminescente EuBTC. Após cada série de tiro, todos os pedaços de papéis foram substituídos para a próxima série, evitando uma contaminação do disparo anterior.

\subsubsection{Transferência secundária e terciária}

Para este experimento, um atirador efetuou quatro tiros usando uma pistola Glock G17 com munição NTA 9 mm marcada com 10\% do marcador luminescente EuBTC. Logo após os disparos, o atirador (\#1) apertou a mão de um indivíduo (\#2), que não estava 
presente no momento do disparo. Em seguida, o primeiro indivíduo (\#2) apertou as mãos de uma terceira pessoa (\#3), que também não estava presente quando o tiro foi deflagrado. No final, uma cadeia de dois apertos de mão foi estabelecida, tal como descrito por French e Morgan ${ }^{149}$ e representada no Esquema 7. O teste foi realizado em triplicata.

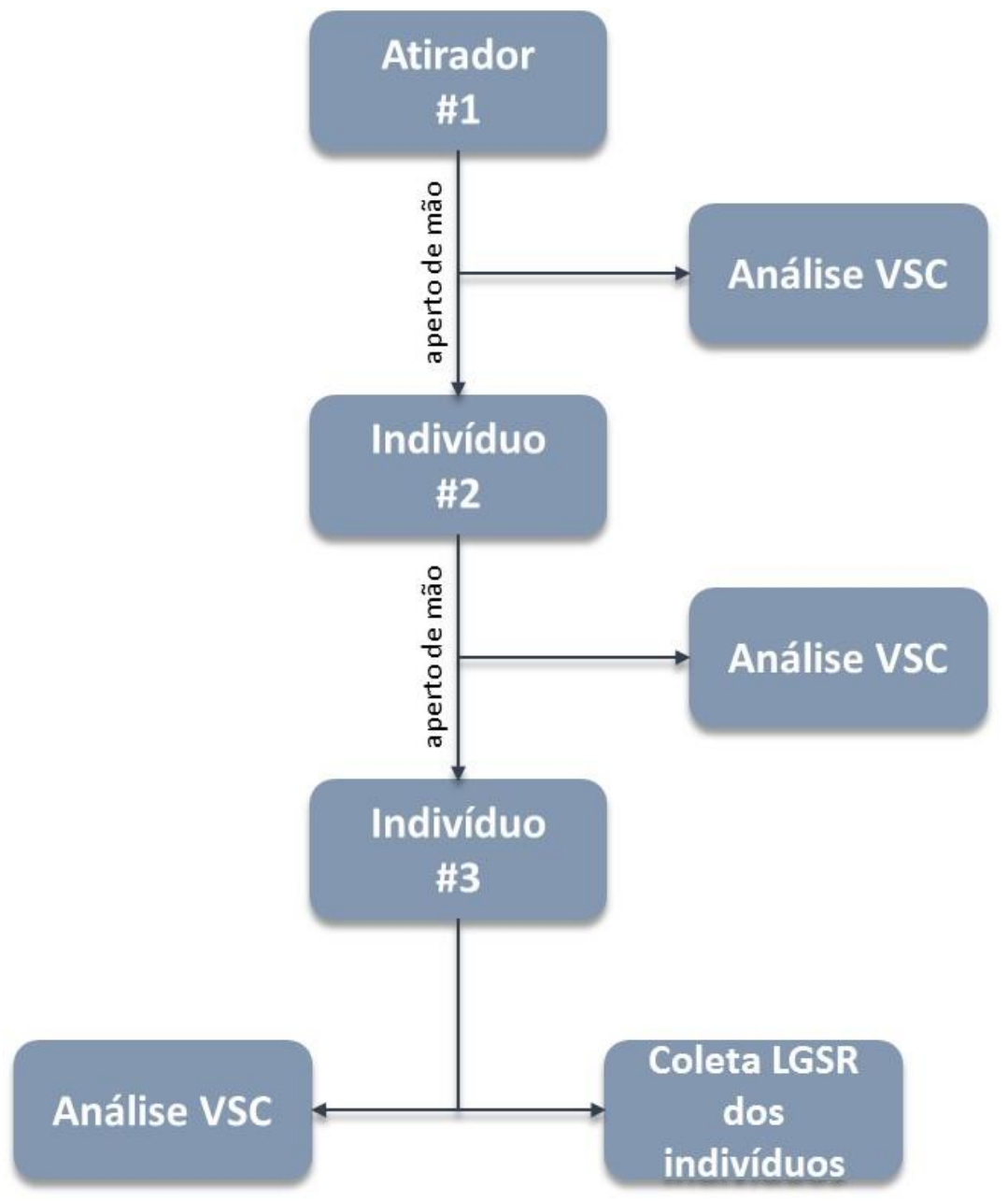

Esquema 7: Cadeia de apertos de mão e análises realizadas no experimento.

Antes e após cada aperto de mão, imagens VSC das mãos dos três participantes (\#1, \#2 e \#3) foram adquiridas utilizando irradiação UV $(\lambda=254 \mathrm{~nm})$. As mãos dos participantes foram amostradas 50 vezes, usando stubs metálicos cobertos com fita condutora de carbono, seguindo as instruções da $\operatorname{ASTM}^{35}$ e da Polícia Federal Brasileira. ${ }^{151}$ Durante a realização do experimento, nenhum dos indivíduos (\#1, \#2 e \#3) lavou as mãos.

Cada stub foi analisado por MEV/EDS, utilizando um software comercial automatizado, INCAGSR com a nova rotina desenvolvida descrita no item 2.4.2. Dessa forma, foi possível quantizar o número de partículas luminescente presentes nas mãos de cada participante do experimento. 
3. RESULTADOS E DISCUSSÃO 


\subsection{Caracterização dos Marcadores Luminescentes}

A primeira etapa do trabalho foi a síntese e caracterização dos três marcadores usados. Como já mencionado, estas estruturas já são conhecidas e estudas pelo grupo. ${ }^{61}$ Todas as três demonstraram potencial para marcar munições e auxiliar na identificação de resíduos de tiro.

Para a caracterização dos marcadores, os padrões de difração obtidos foram comparados com os padrões dos difratogramas contidos nos arquivos CIF (calculado), ${ }^{58,72,73}$ conforme demonstrado nas Figuras 20, 21 e 22.

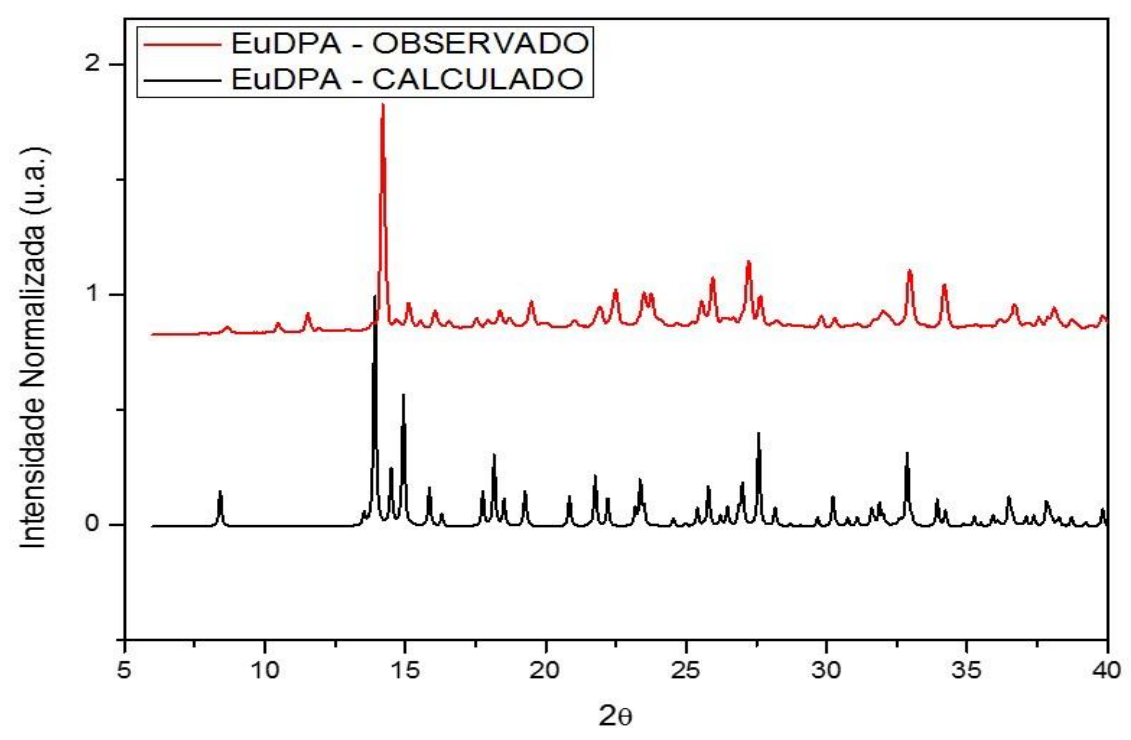

Figura 20. Difratograma de raios $X$ do marcador EuDPA.

O padrão de difração do marcador EuDPA (Figura 20) apresentou alguns picos não consistentes com o padrão calculado, indicando que a fase sintetizada não é a mesma do composto na referência utilizada ou que há uma mistura de fases. Apesar da diferença estrutural, a amostra EuDPA cumpriu os demais requisitos necessários ao uso como marcador de GSR, como alta estabilidade térmica (verificada mediante um teste preliminar de disparo com arma de fogo) e alta luminescência. É sabido que esta MOF apresenta alguns problemas de reprodutibilidade estrutural e que variações na estrutura podem ser observadas em função de variações na condição de síntese. No caso específico deste trabalho, observamos um problema com o micro-ondas, que não alcançava a potência desejada. Entretanto, como o objetivo deste trabalho não é fazer uma avaliação estrutural do material, e sim testar sua potencialidade como marcador de GSR em 
diferentes condições optou-se por utilizar a amostra como obtida. Diante disso, o estudo foi realizado utilizando o marcador com a fase sintetizada.

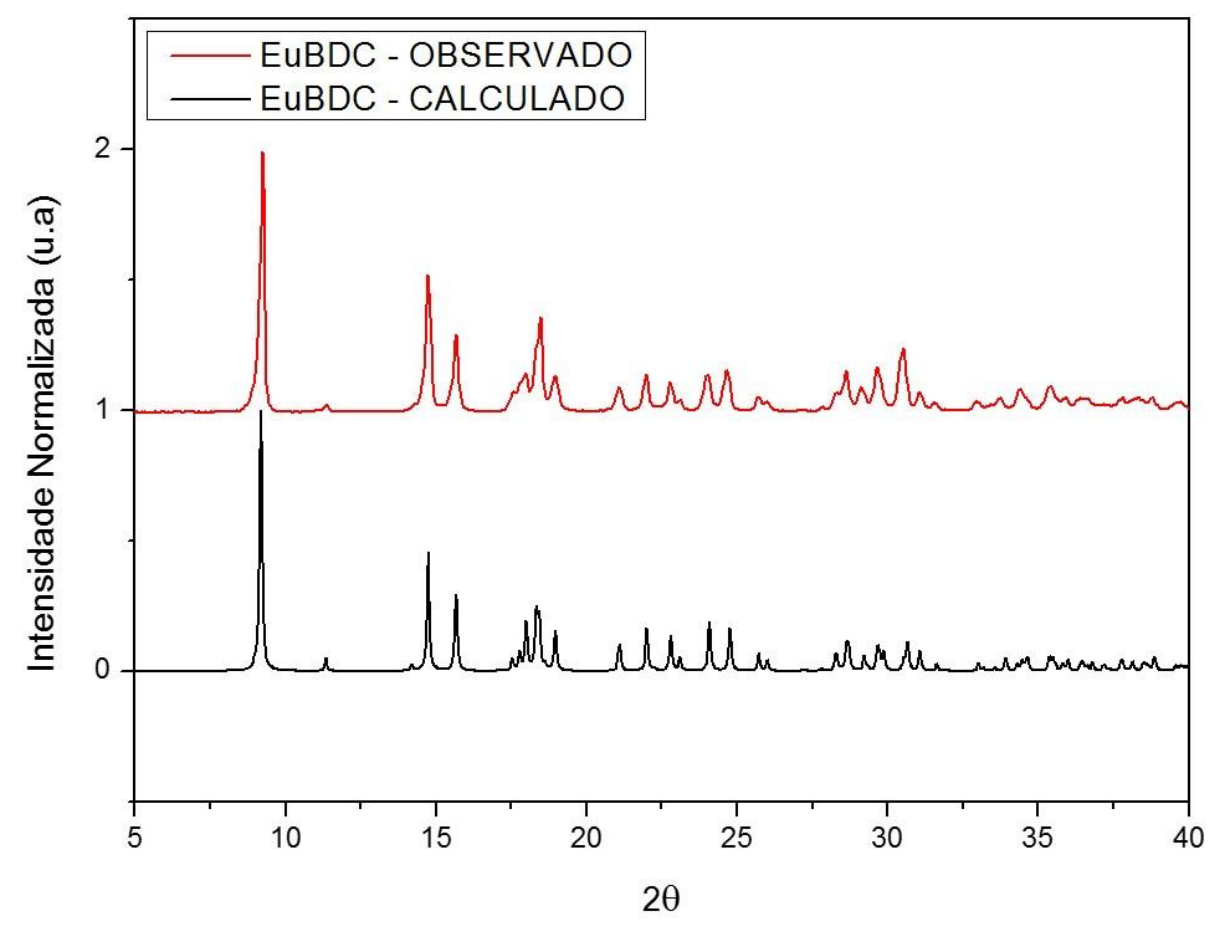

Figura 21. Difratograma de raios $\mathrm{X}$ do marcador EuBDC.

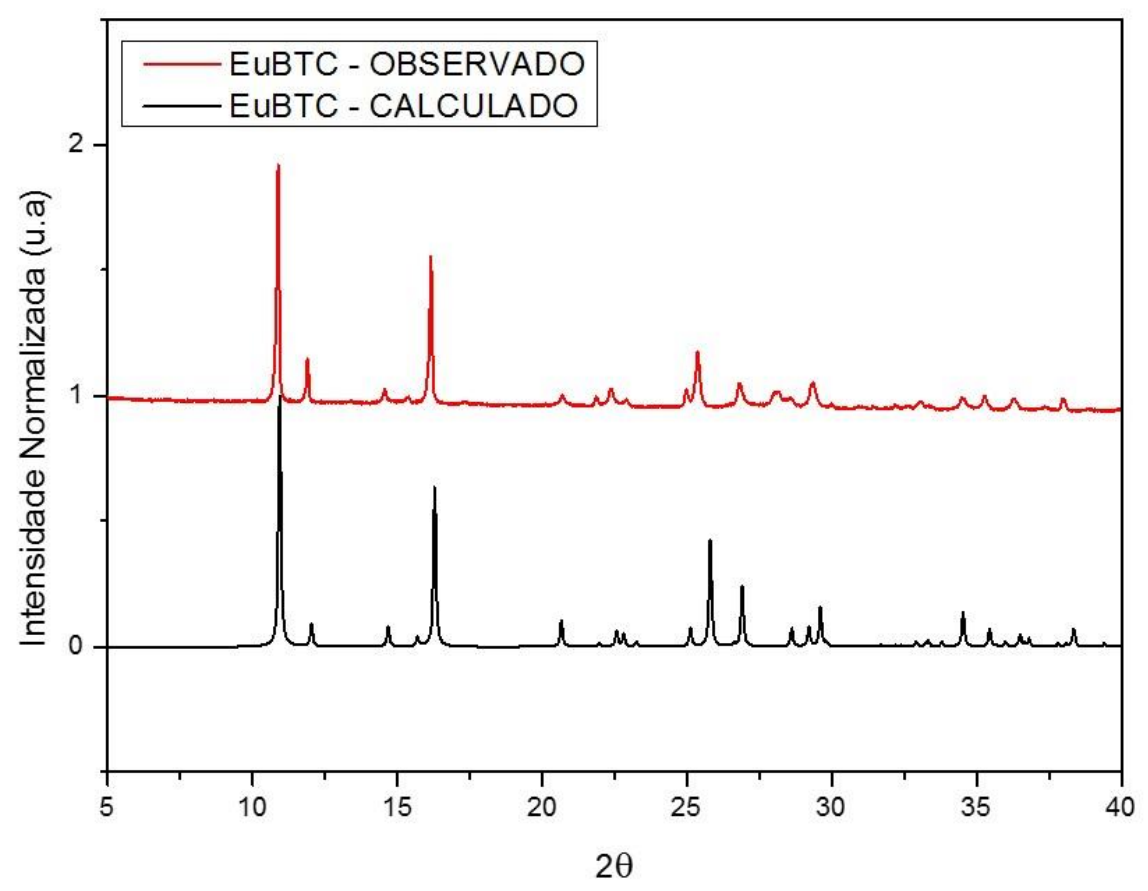

Figura 22. Difratograma de raios $X$ do marcador EuBTC. 
O padrão de difração do marcador EuBDC (Figura 21) está de acordo com o calculado assim como o do marcador EuBTC (Figura 22).

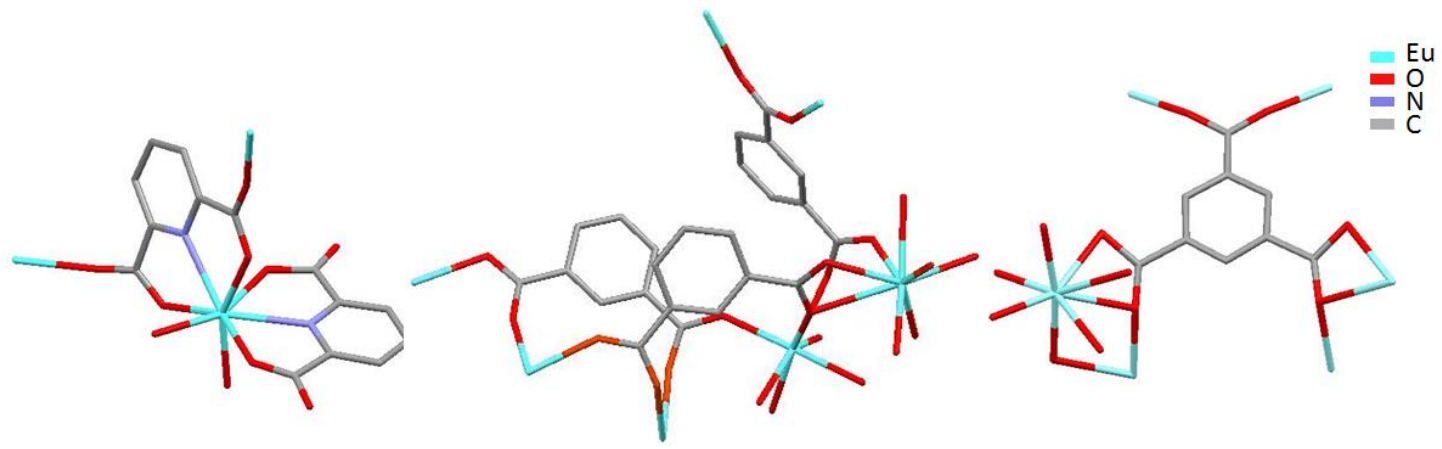

Figura 23. Estrutura dos marcadores $(\mathrm{a})_{\infty}[\mathrm{Eu}(\mathrm{DPA})-(\mathrm{HDPA})],(\mathrm{b})_{\infty}\left[\mathrm{Eu}_{2}(\mathrm{BDC})_{3}\left(\mathrm{H}_{2} \mathrm{O}\right)_{2}\right]_{\mathrm{n}}$, (c) $\infty[\mathrm{Eu}(\mathrm{BTC})]$.

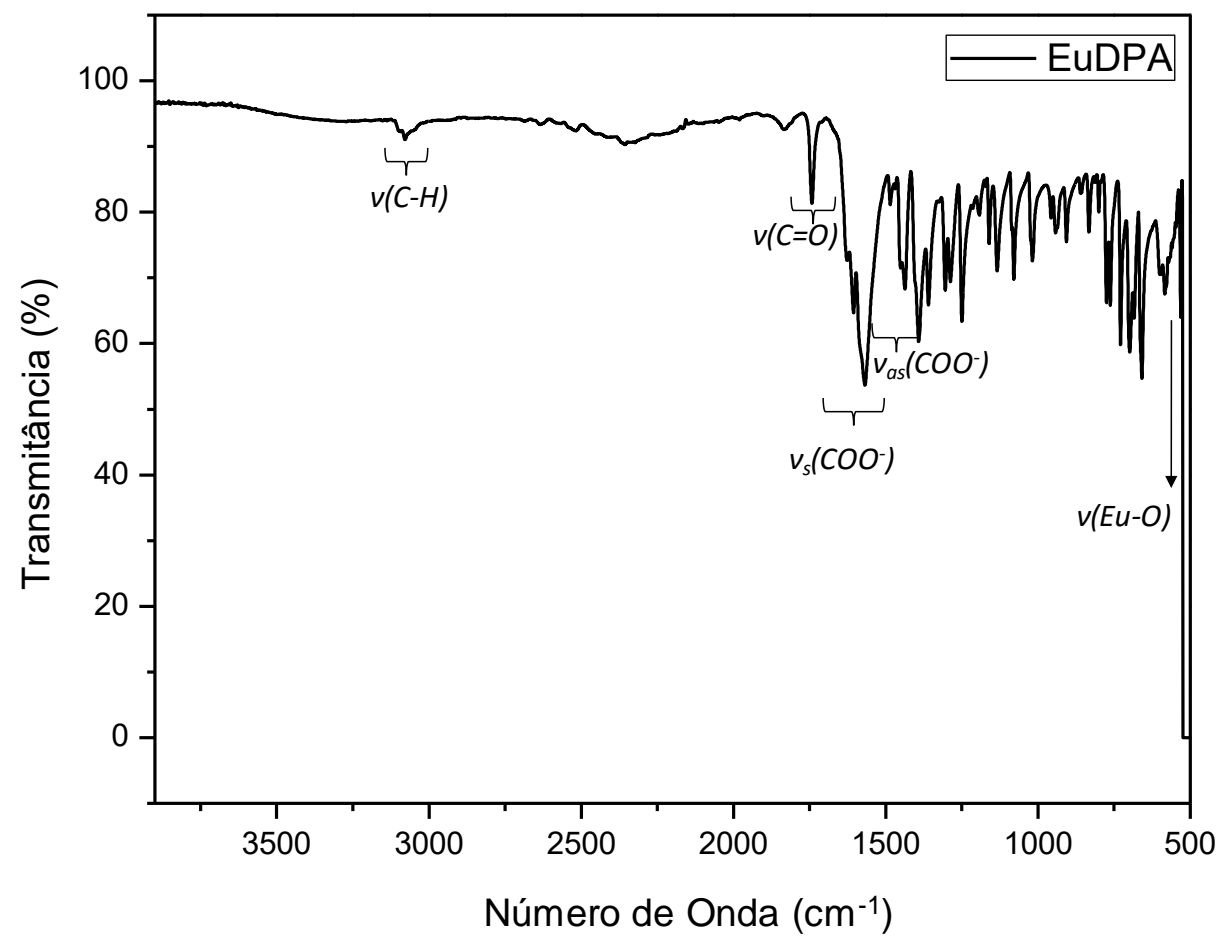

Figura 24. Espectro no Infravermelho do marcador EuDPA.

As figuras 24 a 26 apresentam os espectros FTIR para os 3 marcadores, Figura 23. Para o marcador EuDPA, a ausência da banda entre 3400 à $2400 \mathrm{~cm}^{-1}$, referente ao estiramento O-H, no espectro de infravermelho (Figura 24) indica a coordenação do íon $\mathrm{Eu}^{3+}$ pelo íon carboxilato. Tal fato não era esperado, tendo em vista que a estrutura da LMOF esperada para esta MOF é $\infty[\mathrm{Eu}(\mathrm{DPA})(\mathrm{HDPA})]^{69,71,152,153}$ a qual contém um ligante protonado (HDPA). Assim, era esperado observar uma banda atribuída à vibração da ligação $\mathrm{O}-\mathrm{H}$. Esta mudança de coordenação pode ser responsável pela variação estrutural observada no DRX. As demais bandas do espectro de infravermelho são 
compatíveis com o esperado. ${ }^{69,71,152,153}$. As bandas em 1605-1568 e 1485-1437 são referentes ao estiramento simétrico e assimétrico do grupo $\mathrm{COO}^{-}$, respectivamente. A banda em $1743 \mathrm{~cm}^{-1}$ está relacionada à vibração da dupla ligação $\mathrm{C}=\mathrm{O}$ do ácido carboxílico.

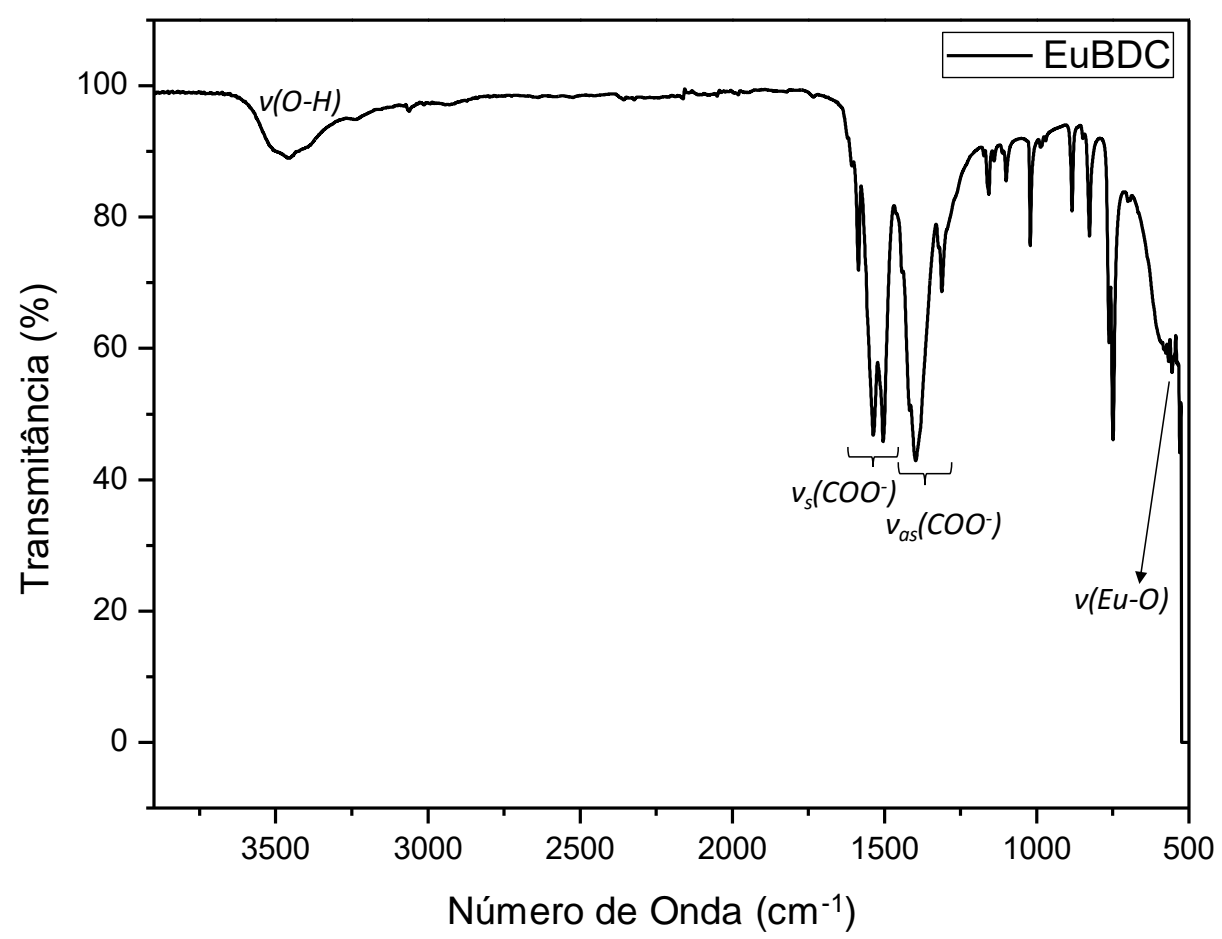

Figura 25. Espectro de Infravermelho do marcador EuBDC.

O espectro no infravermelho do marcador EuBDC, Figura 25, apresenta bandas características próximas a compostos similares descritos na literatura. ${ }^{72,154}$ Apresentou em $3457 \mathrm{~cm}^{-1}$ uma banda larga referente à molécula de água presente na estrutura. É importante salientar que a presença de moléculas de água na estrutura pode ser um eficiente canal de supressão de luminescência e portanto isto não é desejado. Em 1586 $1504 \mathrm{~cm}^{-1}$ e $1397 \mathrm{~cm}^{-1}$ bandas referentes ao estiramento simétrico e assimétrico dos grupos $\mathrm{COO}^{-}$, respectivamente. A presença da banda em $529 \mathrm{~cm}^{-1}$, correspondente ao estiramento da ligação do Eu-O são condizentes com a estrutura esperada. 


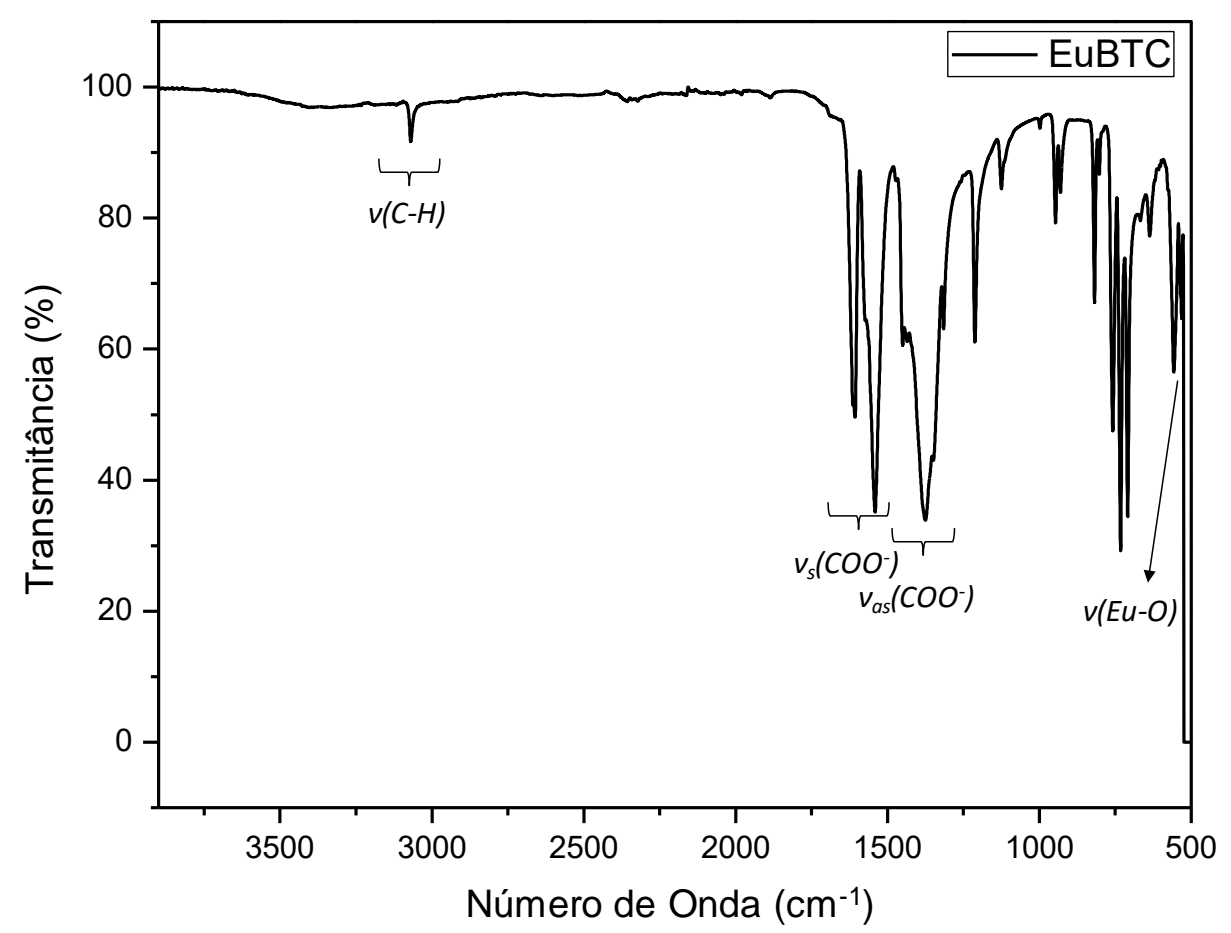

Figura 26. Espectro de Infravermelho do marcador EuBTC.

A MOF EuBTC apresentou um espectro de infravermelho semelhante ao descrito na literatura (Figura 26). ${ }^{154}$ A ausência de uma banda larga em torno de 3400 à $2400 \mathrm{~cm}^{-}$ ${ }^{1}$, referente ao estiramento $\mathrm{O}-\mathrm{H}$, indica a coordenação do ligante ao metal central pelo íon carboxílico. As bandas em torno de $1607-1541 \mathrm{~cm}^{-1}$ são correspondentes estiramento simétrico dos grupos $\mathrm{COO}^{-}$, já as bandas em torno de $1450-1374 \mathrm{~cm}^{-1}$ são referentes ao estiramento assimétrico dos grupos $\mathrm{COO}^{-}$. Novamente, observa-se a coordenação do ligante ao metal Eu através da presença da banda em $531 \mathrm{~cm}^{-1}$, referente ao estiramento Eu-O.

Os espectros de excitação dos marcadores (Figura 27) foram obtidos com uma varredura no comprimento de onda de excitação entre $200 \mathrm{~nm}$ e $550 \mathrm{~nm}$, monitorando a emissão em $610 \mathrm{~nm}$, correspondente ao comprimento de onda mais intenso do íon $\mathrm{Eu}^{+3}$. 

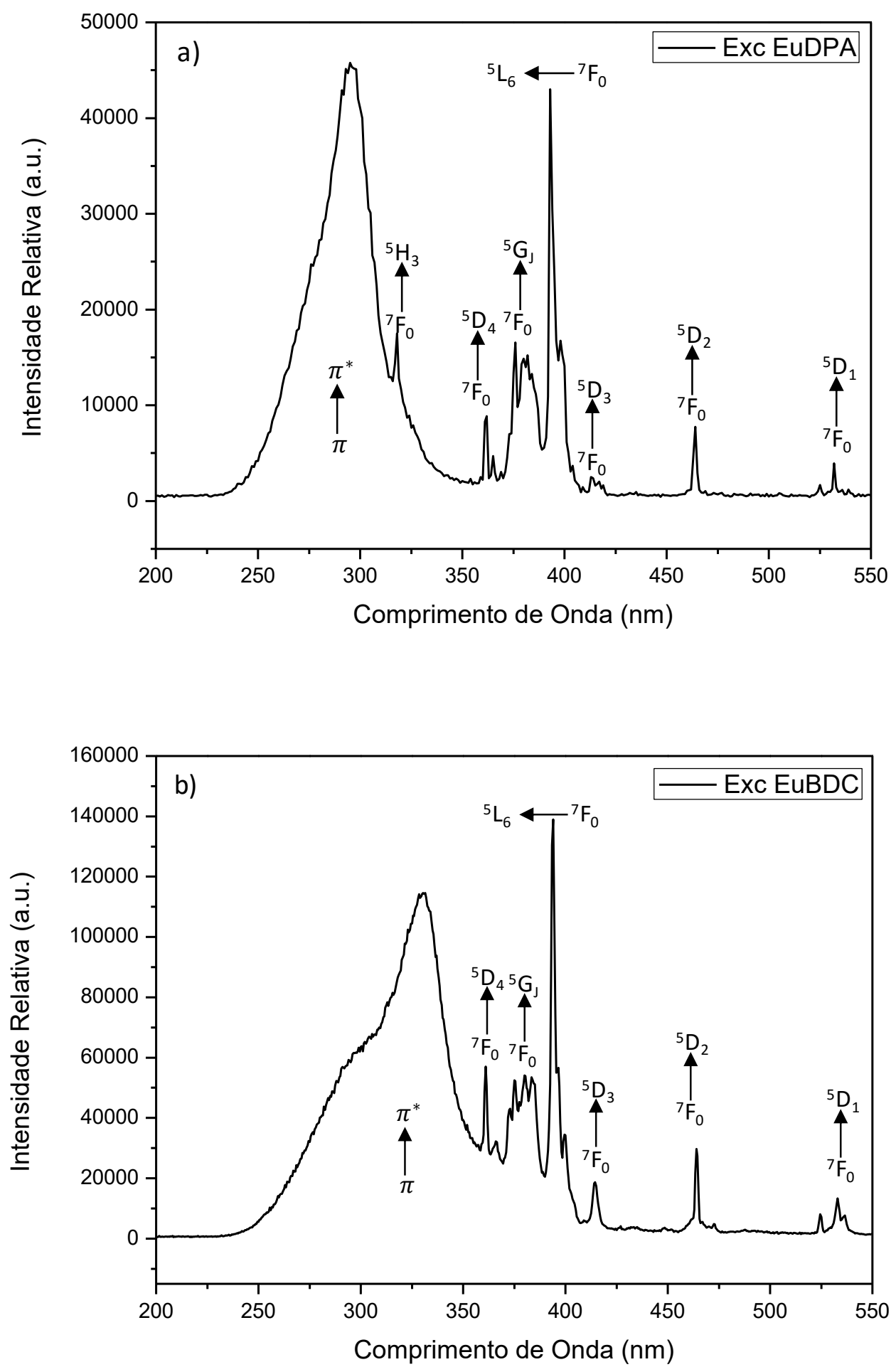


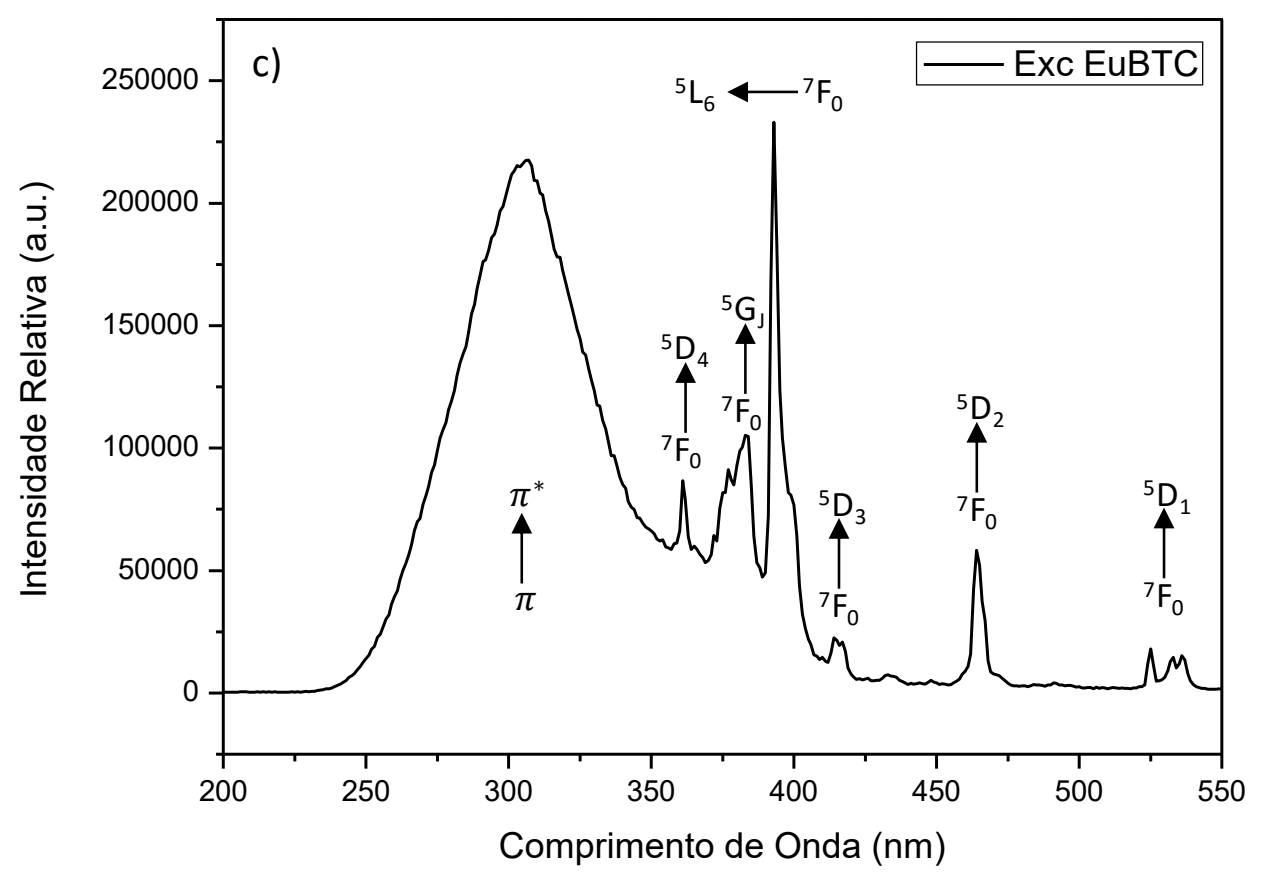

Figura 27. Espectros de excitação dos marcadores (a) EuDPA, (b) EuBDC e (c) EuBTC.

Nos espectros de excitação dos marcadores (Figura 27), além das transições características do íon $\mathrm{Eu}^{+3}$, é possível verificar uma banda larga, em torno de 250-350 $\mathrm{nm}$, referente ao efeito antena. Nesse caso, a radiação é absorvida pelo ligante, o qual transfere essa energia do estado excitado do ligante para os níveis "f” do íon lantanídeo, que emite sua radiação característica. Cabe ressaltar que esse efeito é desejável para os marcadores luminescentes, pois permite que os compostos apresentam uma maior eficiência quântica.

Os espectros de emissão dos marcadores EuDPA, EuBDC e EuBTC, foram obtidos a temperatura ambiente, com varreduras na região de $550 \mathrm{~nm}$ a $750 \mathrm{~nm}$, com excitação da amostra em $293 \mathrm{~nm}$, tendo em vista que esse comprimento é correspondente ao pico de maior intensidade nos espectros de excitação (Figura 27). 

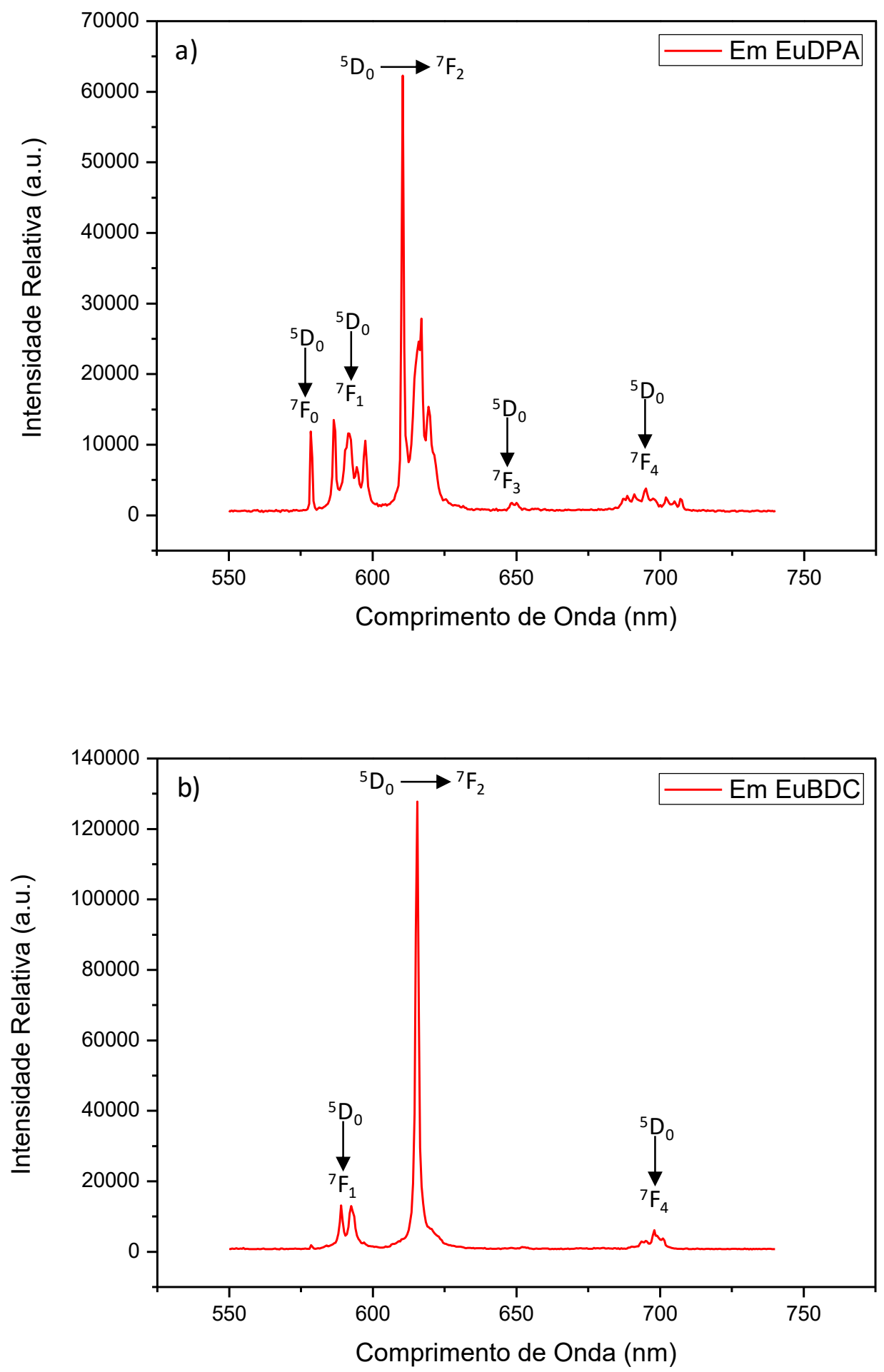


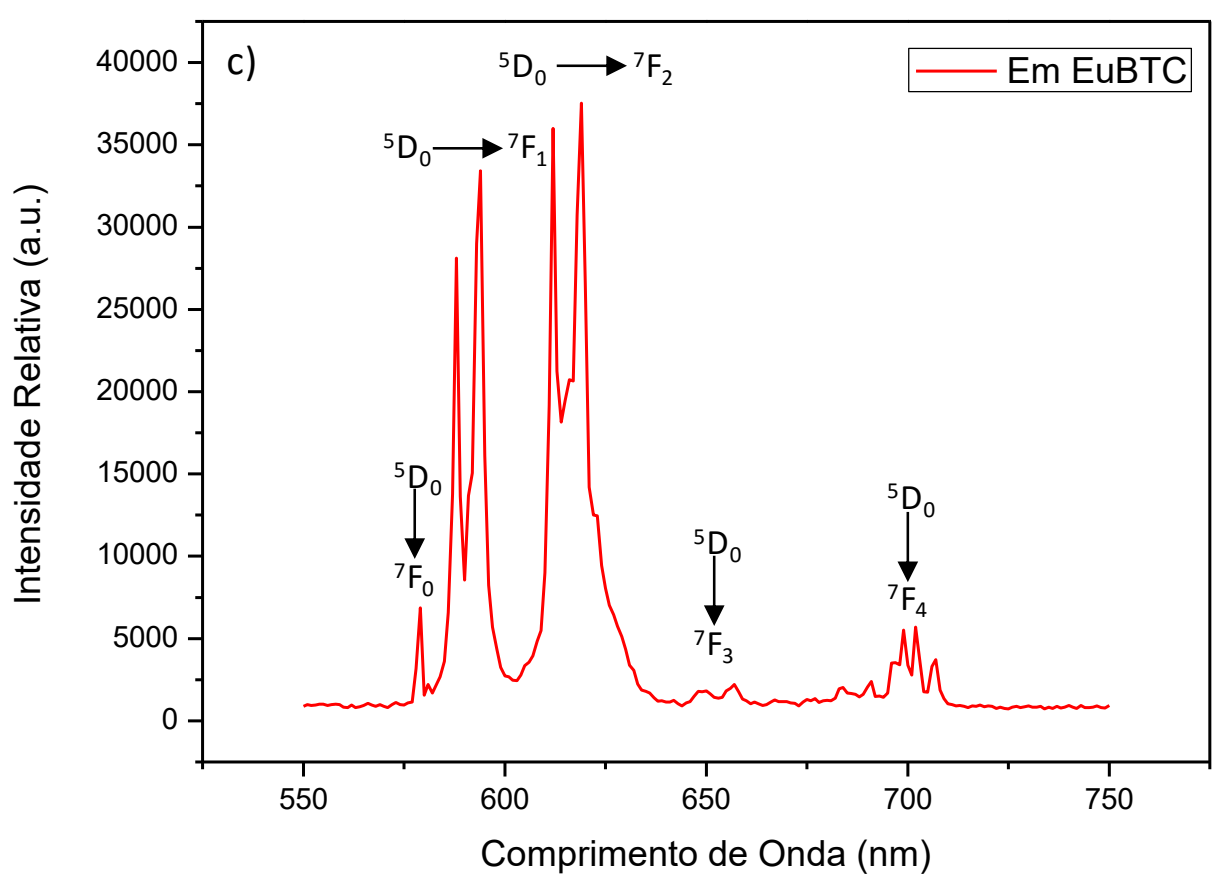

Figura 28. Espectros de emissão dos marcadores (a) EuDPA, (b) EuBDC e (c) EuBTC.

Nos espectros de emissão dos marcadores obtidos (Figura 28) é possível identificar que a emissão mais intensa ocorre na região do vermelho $(620-750 \mathrm{~nm})$. Além disso, é possível verificar as cinco transições características do íon $\mathrm{Eu}^{3+},{ }^{5} \mathrm{D}_{0} \rightarrow{ }^{7} \mathrm{~F}_{0}$, ${ }^{5} \mathrm{D}_{0} \rightarrow{ }^{7} \mathrm{~F}_{1},{ }^{5} \mathrm{D}_{0} \rightarrow{ }^{7} \mathrm{~F}_{2},{ }^{5} \mathrm{D}_{0} \rightarrow{ }^{7} \mathrm{~F}_{3},{ }^{5} \mathrm{D}_{0} \rightarrow{ }^{7} \mathrm{~F}_{4}$. Somente na MOF EuBDC as transições ${ }^{5} \mathrm{D}_{0} \rightarrow{ }^{7} \mathrm{~F}_{0}$ $\mathrm{e}^{5} \mathrm{D}_{0} \rightarrow{ }^{7} \mathrm{~F}_{3}$ não foram observadas. A ausência da transição ${ }^{5} \mathrm{D}_{0} \rightarrow{ }^{7} \mathrm{~F}_{0}$ indica que o íon $\mathrm{Eu}^{3+}$ encontra-se em um sitio o qual não possui uma simetria $\mathrm{Cnv}, \mathrm{Cn}$ ou $\mathrm{Cs}$, conforme expostos por Binnemans. ${ }^{78} \mathrm{~A}$ transição ${ }^{5} \mathrm{D}_{0} \rightarrow{ }^{7} \mathrm{~F}_{3}$ consiste em uma transição de baixa intensidade, e a sua ausência está relacionada ao baixo acoplamento spin-orbita ${ }^{78}$.

As imagens obtidas (Figura 29) obtidas com luz branca e luz UV $(\lambda=254 \mathrm{~nm})$ mostram que os marcadores possuem uma luminescência intensa e semelhante entre si, situada na região do vermelho, característica da emissão do $\mathrm{Eu}^{3}$, quando vistos a olho nu. 


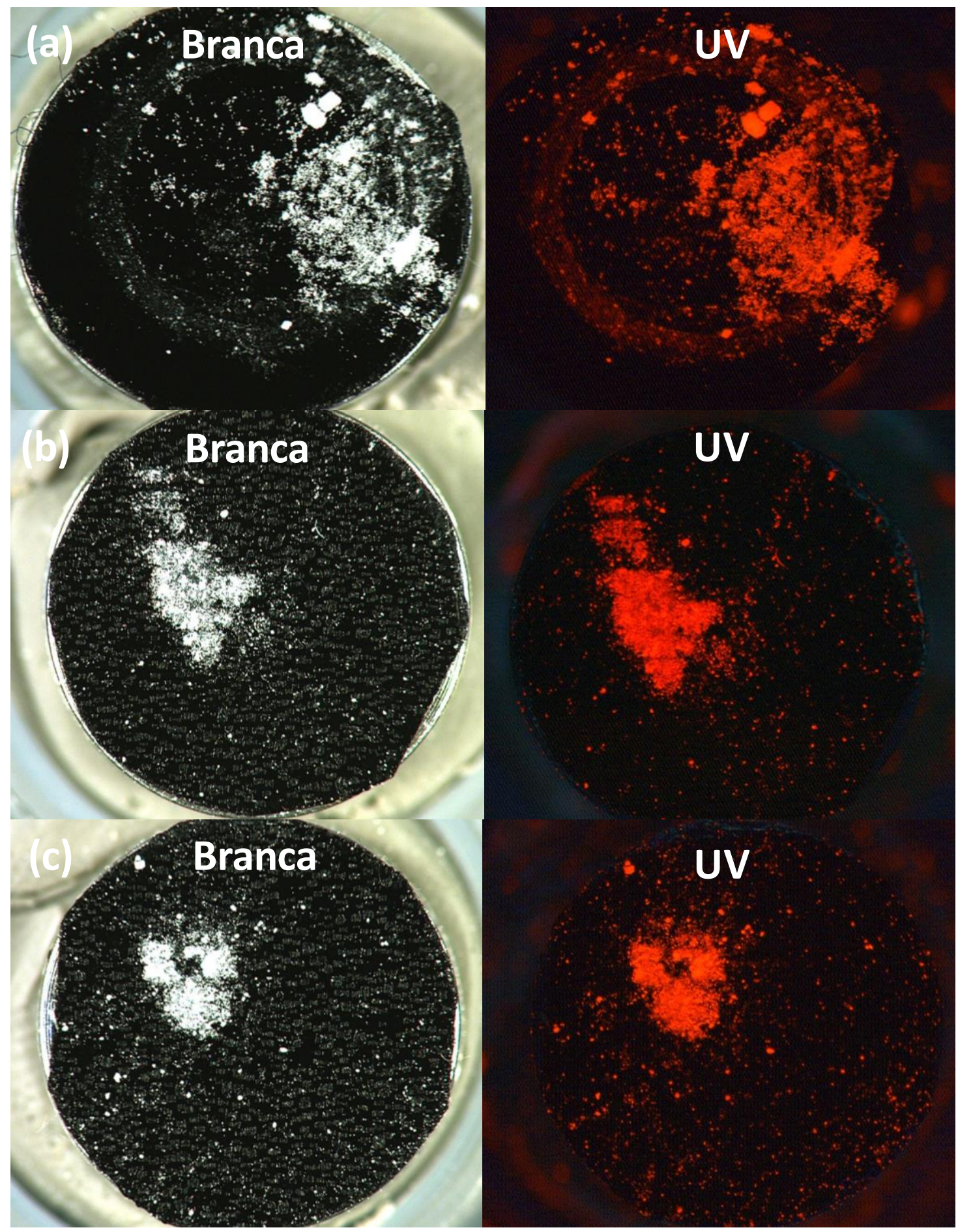

Figura 29. Imagens adquiridas por VSC dos marcadores (a) EuDPA, (b) EuBDC e (c) EuBTC com luz branca e luz UV $(\lambda=254 \mathrm{~nm})$. 


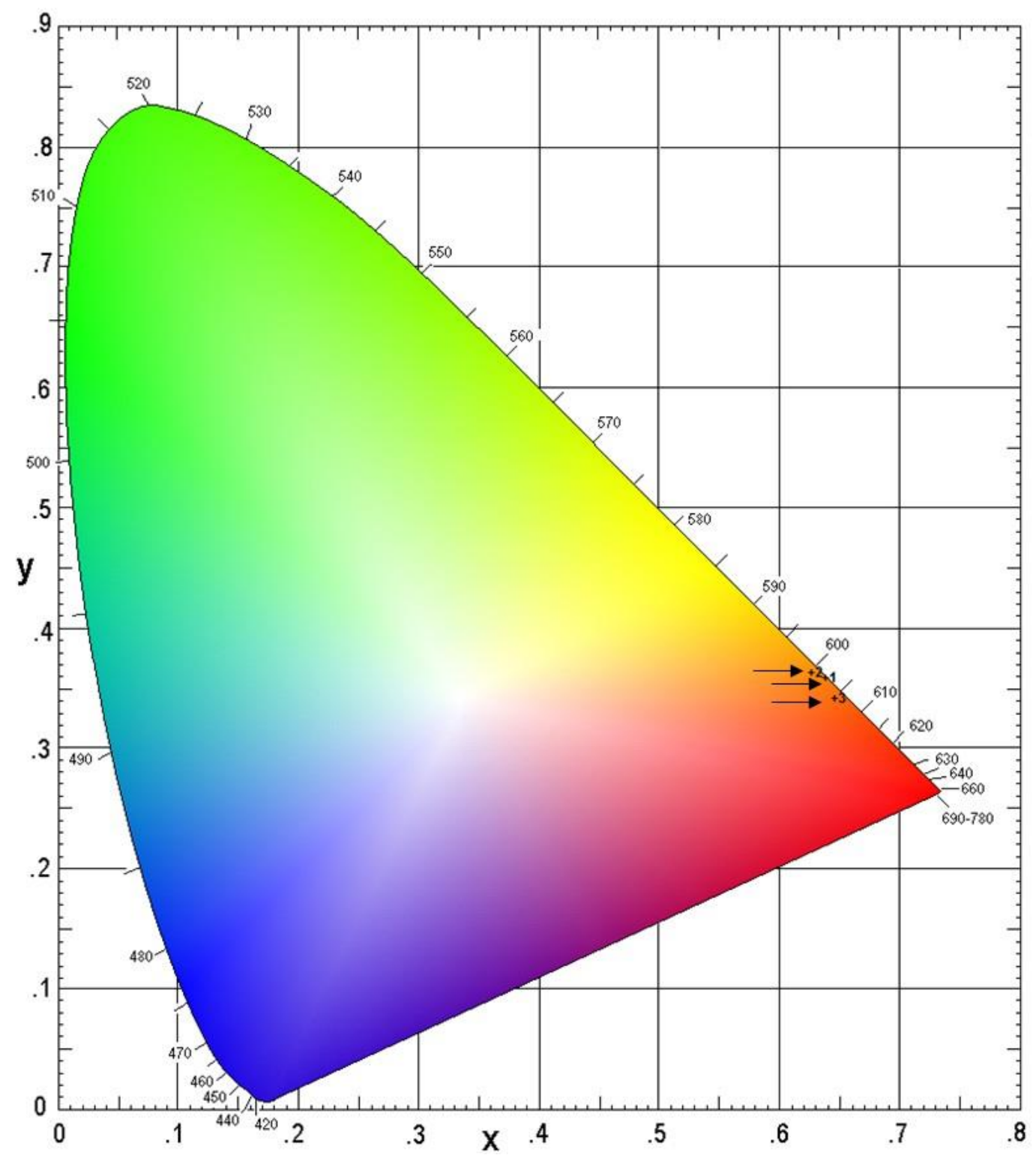

Figura 30. Diagrama de cromaticidade CIE 1931 obtido por VSC sob radiação UV $(\lambda=$ $254 \mathrm{~nm})$ dos marcadores $\operatorname{EuDPA}(+1), \operatorname{EuBDC}(+2)$ e $\operatorname{EuBTC}(+3)$.

As coordenadas cromáticas das amostras foram plotadas no diagrama de cromaticidade CIE 1931, Figura 30. O marcador EuDPA apresenta as coordenadas xy CIE 1931 (0,193, 0,108). Já os marcadores EuBDC e EuBTC apresentam as coordenadas $(0,191,0,110)$ e $(0,098,0,051)$, respectivamente. Diante disso, o marcador EuBTC apresenta uma cor de emissão mais próxima do vermelho, enquanto o marcador EuBDC uma cor de emissão mais amarelada, semelhante ao do marcador EuDPA, o qual apresentou uma coloração mais alaranjada. 


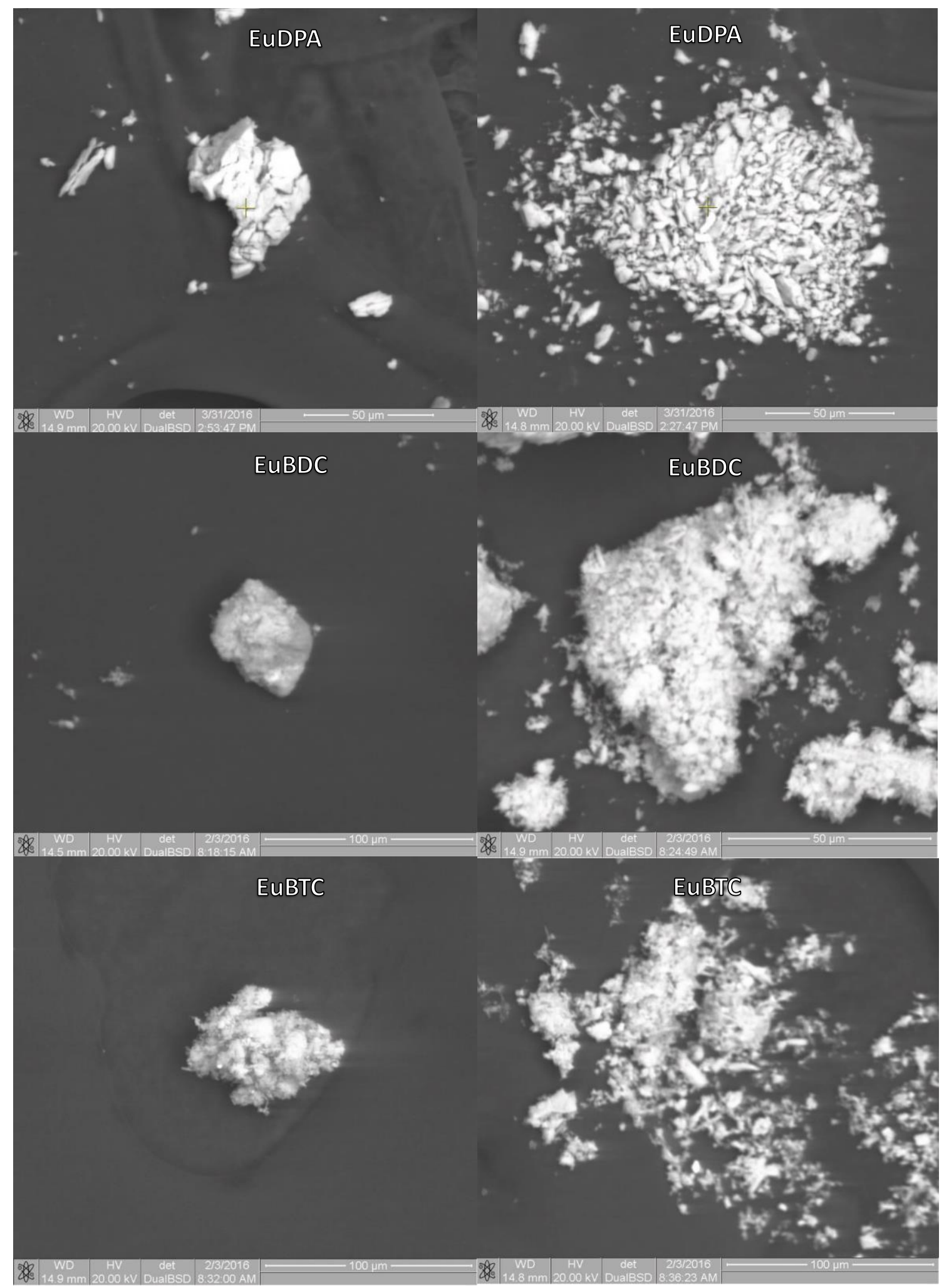

Figura 31. Micrografias dos marcadores EuDPA, EuBDC e EuBTC. 
A Figura 31 mostra as micrografias dos marcadores sintetizados. Eles apresentam uma morfologia irregular, formando aglomerados e agregados com forma e tamanho irregulares. Os espectros de dispersão de energia (EDS) dos marcadores, Figura 32, confirmado a presença do elemento európio como único metal presente na estrutura dos materiais preparados.
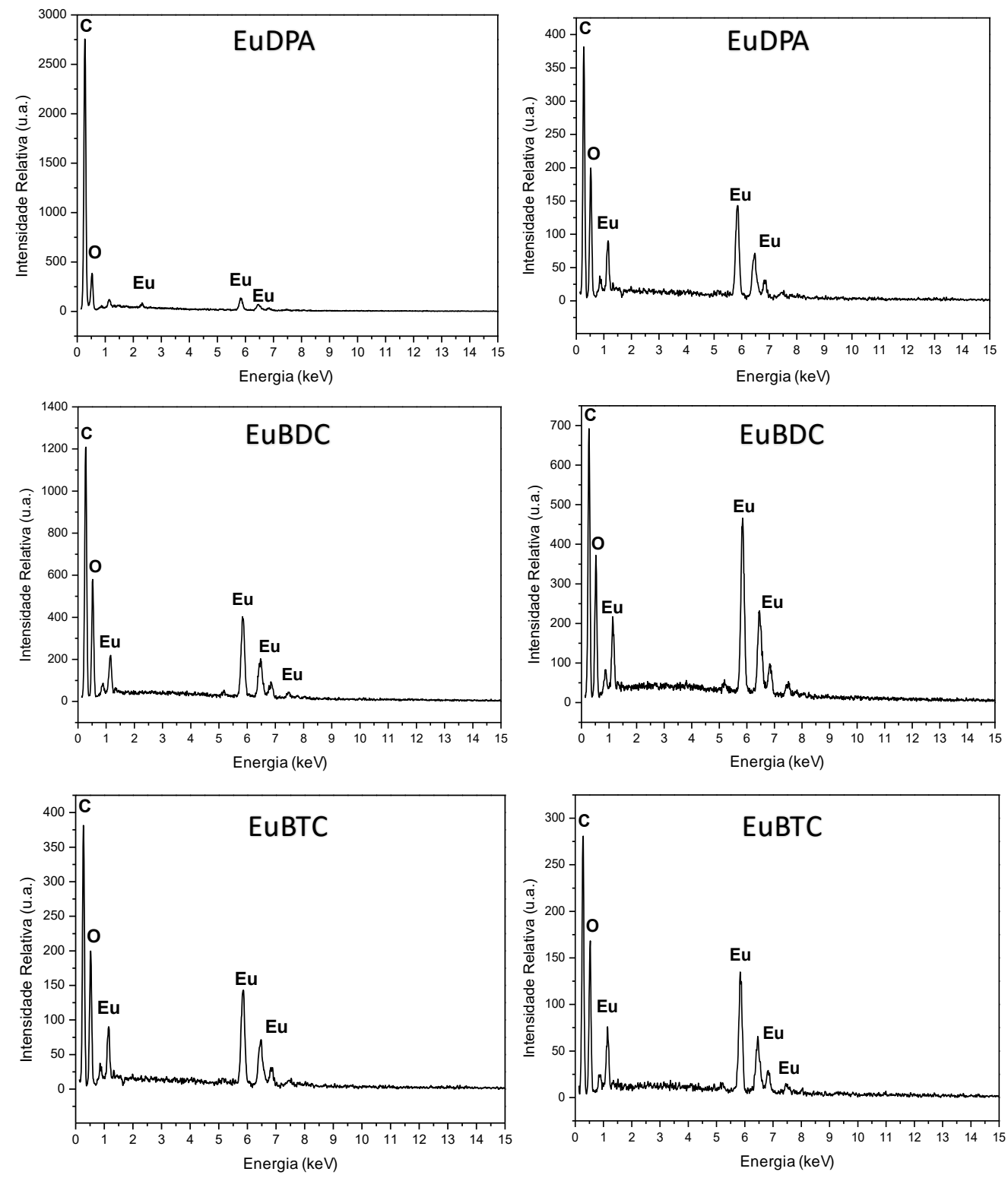

Figura 32. Espectros de dispersão de energia dos marcadores EuDPA, EuBDC e EuBTC

As MOFs sintetizadas e caracterizadas (EuDPA, EuBDC e EuBTC) foram então testadas em diferentes aspectos ligados à potencialidade de uso como marcador para identificação de resíduo de tiro. 


\subsection{Toxicidade química dos marcadores}

Um aspecto muito importante para a utilização dos marcadores luminescente em larga escala é a avaliação de sua toxicidade, pois caso apresente alta toxicidade pode por em risco a saúde de atiradores frequentes, especialmente policiais, militares e esportistas. A avaliação de toxicidade dos marcadores não é um processo simples e requer a análise de vários aspectos, como por exemplo toxicidade oral aguda, por inalação, etc. Neste trabalho, é apresentada como contribuição para a avaliação mais ampla da toxicidade dos marcadores luminescentes para GSR, fornecendo-se uma análise dos subprodutos gerados após o disparo e do tamanho de partículas contidas nos GSR.

\subsubsection{Subprodutos gerados após o disparo}

Com intuito de verificar a degradação do marcador após o disparo de uma munição marcada, os cartuchos deflagrados foram analisados por CG/EM, usando SPME como método de coleta. Incialmente, buscou-se um método de análise de OGSR descrito na literatura que permitisse a identificação de duas substâncias potencialmente tóxicas que poderiam ser formadas no momento do disparo. O foco principal de estudo foram os derivados de piridina e benzeno. Essa escolha foi feita devido ao fato de que os ligantes dos marcadores EuBDC e EUBTC serem derivados do benzeno, enquanto o ligante do marcador EuDPA apresentar um anel piridínico em sua estrutura.

Para determinação do método cromatográfico que seria utilizado no experimento, quatro técnicas reportadas na literatura foram selecionadas: os métodos descritos por Joshi et al,. ${ }^{101}$ Dalby e Birkett, ${ }^{107}$ Burleson et al, ${ }^{102}$ e o de Weyermann et al. ${ }^{100}$ (Tabela 4).

Tabela 4. Métodos de análise de OGSR descritos na literatura.

\begin{tabular}{ccc}
\hline Autor & Instrumentação & Fibra Utilizada \\
\hline Joshi et al. ${ }^{101}$ & CG/EM e IMS & $100 \mu \mathrm{m}$ de polidimetilsiloxano (PDMS) \\
\hline Dalby e Birkett ${ }^{107}$ & CG/EM & $65 \mu \mathrm{m} \mathrm{de}$ \\
& & polidimetilsiloxano/divinilbenzeno \\
Burleson et al. $^{102}$ & GC/NPD & $100 \mu \mathrm{m}$ de polidimetilsiloxano (PDMS) \\
\hline Weyermann et al. $^{100}$ & CG/EM & $85 \mu \mathrm{m}$ de Poliacrilato (PA) \\
\hline
\end{tabular}


Dos métodos selecionados, optou-se por utilizar o método de Weyermann et al., ${ }^{100}$ pois esse consistia na aplicação de um CG/EM com extrações por SMPE utilizando uma fibra de $85 \mu \mathrm{m}$ de Poliacrilato (PA), disponível no Laboratório de Análises do Instituto Nacional de Criminalística da Polícia Federal. Contudo, o método escolhido não era seletivo para os dois compostos de análises, piridina e benzeno, pois os métodos descritos na literatura são específicos para os compostos característicos do OGSR, e não necessariamente os subprodutos do marcador. Diante desse fato, desenvolvemos um método específico para os compostos alvos, utilizando uma fibra de SPME de $65 \mu \mathrm{m}$ PDMS/DVB, conforme descrito na metodologia deste trabalho.

Foram então obtidos cromatogramas das amostras coletadas nos cartuchos deflagrados contendo os marcadores EuDPA (Figura 33a), EuBDC (Figura 33b), EuBTC (Figura 33c) e da munição NTA (Figura 33d) foram obtidos. Observou-se que existe uma variabilidade na quantidade de compostos (picos) observados. Esta variabilidade já era esperada e pode ser associada à complexidade da matriz usada para a extração (cartucho de munição recém deflagrado) e à volatilidade de alguns compostos presentes nestes cartuchos. A munição não é uma "amostra" totalmente homogênea, assim como as armas não são instrumentos de precisão. Desta forma, pode-se obter variações no padrão de "queima", resultando em variabilidade dos subprodutos gerados. Além disso, pequenas variações no tempo de amostragem, temperatura do ambiente, umidade, etc, podem levar a que alguns compostos tenham sido volatilizados antes do cartucho ter sido colocado no vial. 

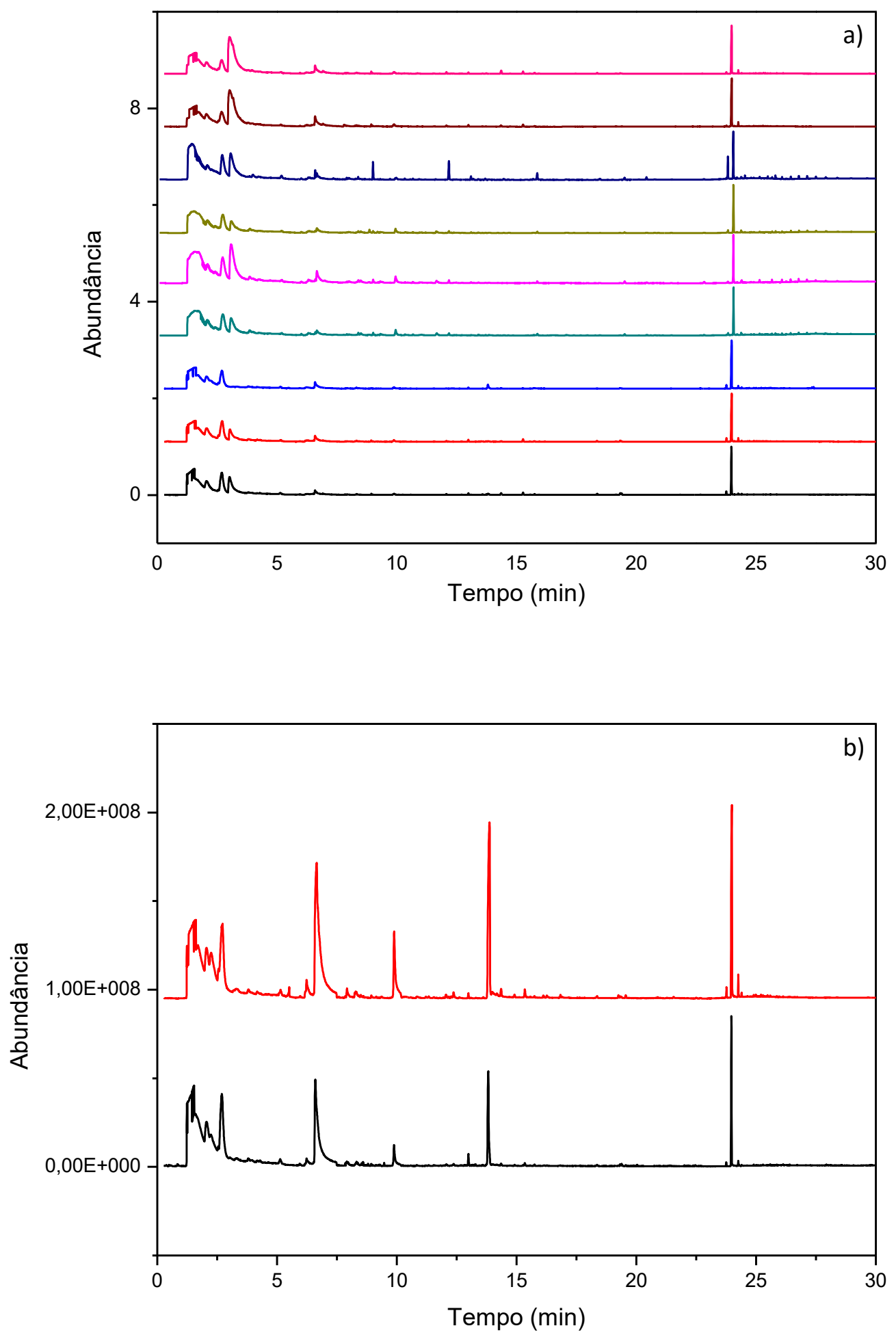

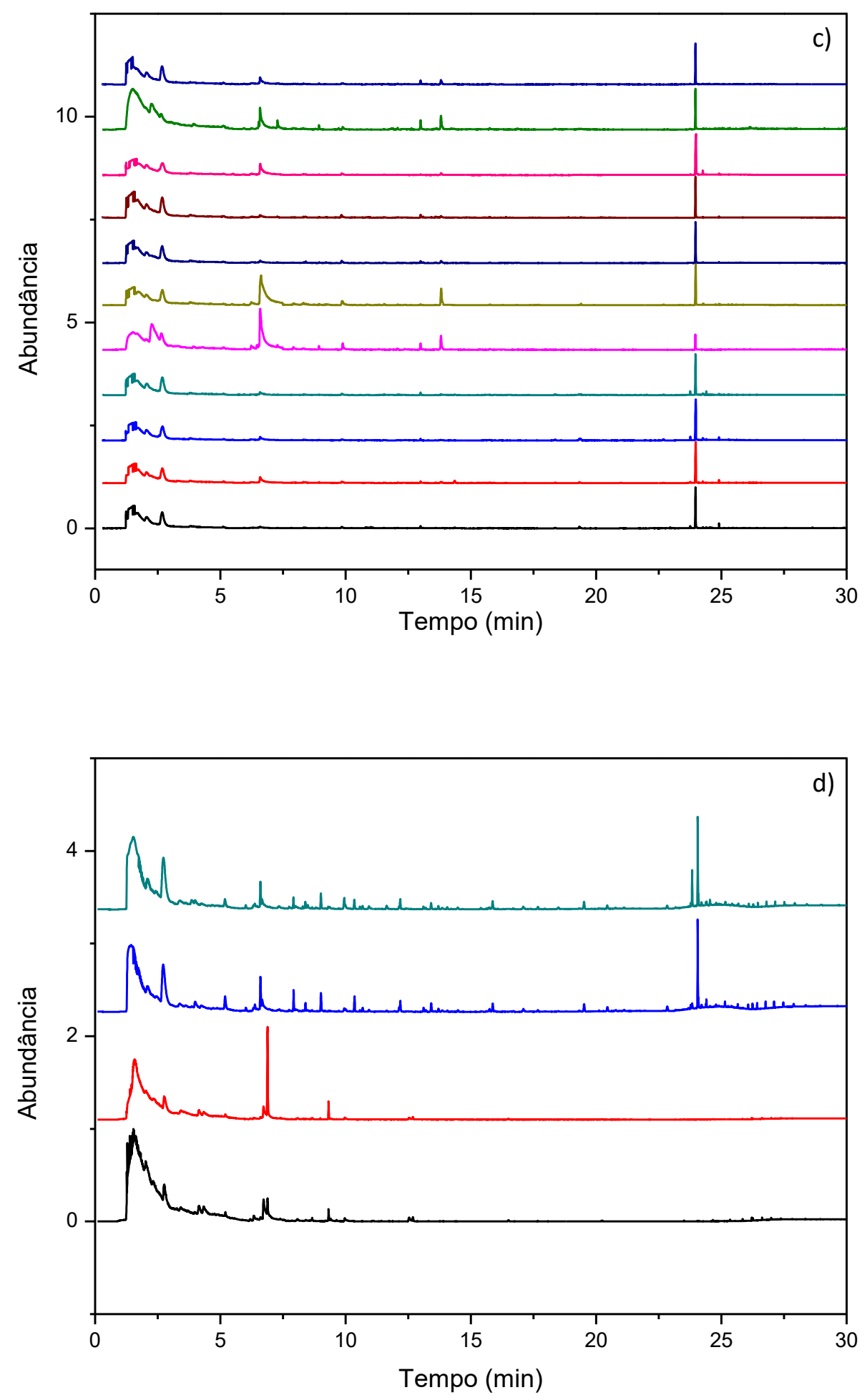

Figura 33. Cromatogramas dos cartuchos deflagrados com os marcadores EuDPA (a), EuBDC (b), EuBTC (c), e munição NTA.

Dentre os cromatogramas obtidos para cada cartucho com marcador deflagrado, foram selecionados aqueles que apresentavam uma maior quantidade de compostos, e 
comparados com o cromatogramas da munição NTA para identificar produtos que possam ser relacionados à degradação do marcador (Figura 34). Os picos que foram encontrados apenas na munição marcada (e, portanto, associados à degradação do marcador) foram identificados com $(*)$.
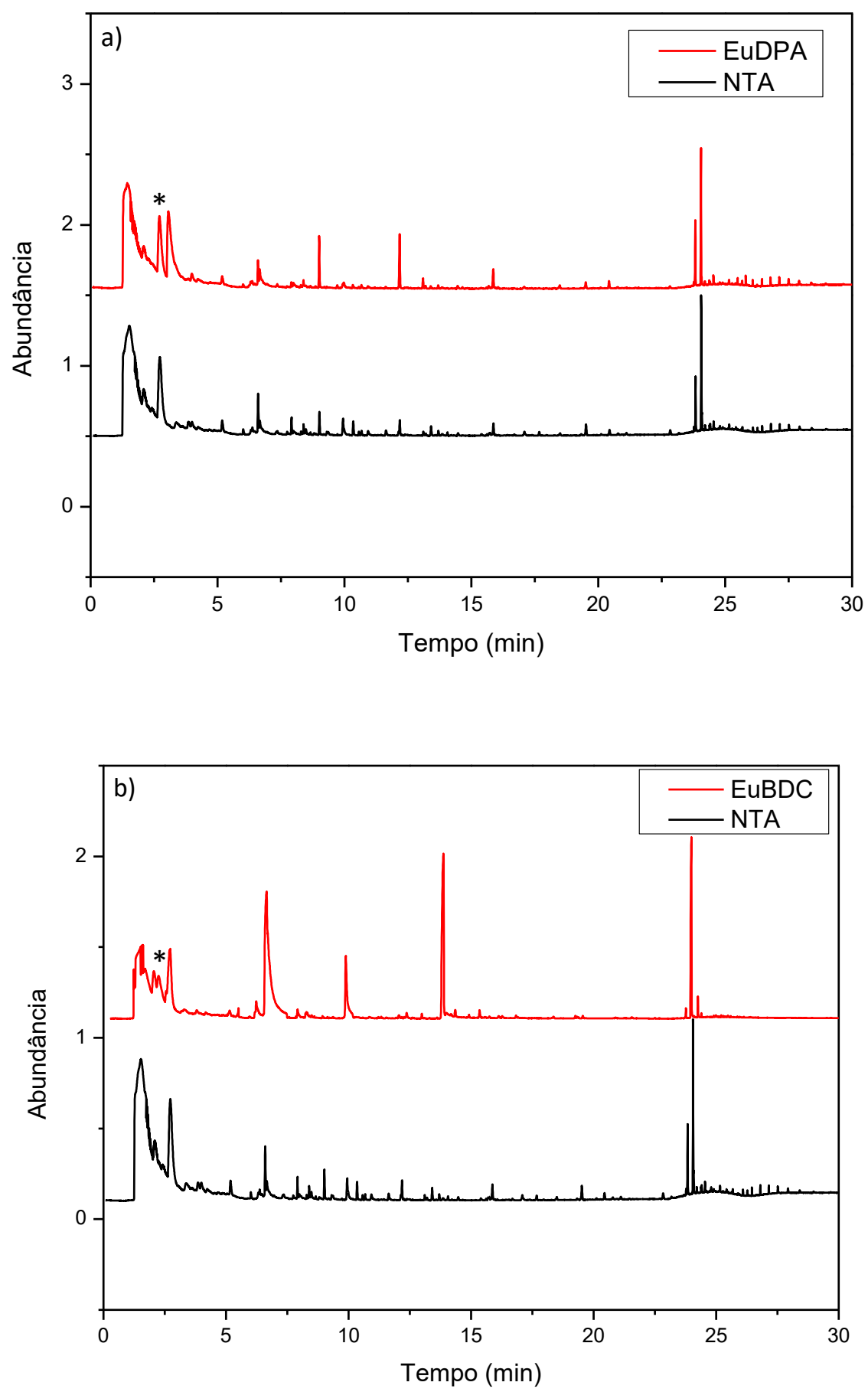


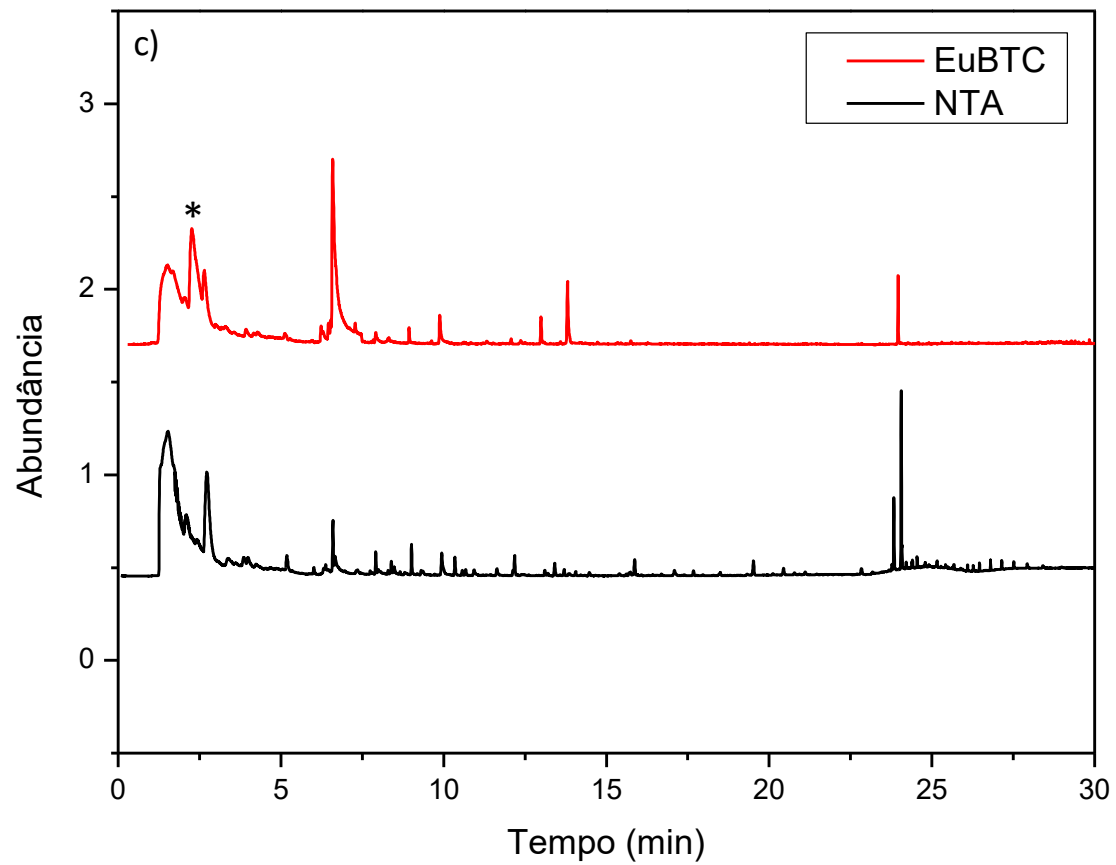

Figura 34. Comparação entre os cromatogramas dos marcadores (a) EuDPA, (b) EuBDC e (c) EuBTC com o cromatogramas da munição NTA. O tempo de retenção dos compostos piridina e benzeno estão demarcados com (*).

Ao comparar os espectros de massa obtidos para os picos assinalados com (*) com os dos bancos de dado (Figura 35), foi possível identificar alguns compostos. Para o marcador EuDPA, foi possível determinar, em 3,067 min, a presença de um pico referente à piridina. Já para os marcadores EuBDC e EuBTC, em 2,248 min e 2,268 min, respectivamente, a presença de um pico correspondente ao composto benzeno. Os picos apresentaram uma intensidade média, quando comparados com os demais, fato que indicaria uma quantidade relativamente alta destes compostos. Este resultado indicia que uma parte do marcador adicionado às munições é degradado durante a deflagração do tiro (embora uma parte significativa se mantenha inalterada como pode ser observado nas partículas de GSR e descrito na referência 58). A degradação da estrutura das MOFs gera pelo menos dois compostos que podem vir a representar algum risco à saúde de atiradores frequentes, se considerarmos uma exposição crônica por um período prolongado. Esta é a primeira vez que está sendo evidenciada a degradação parcial das MOFs e este fato faz com que seja necessário, no futuro, uma análise mais detalhada do processo de degradação das MOFs durante a deflagração de um tiro. Contudo, este estudo não é fácil, dada à complexidade da matriz, e requer o desenvolvimento de uma metodologia, dada a ausência de dados na literatura. 
Neste trabalho, como não foi realizado um procedimento de calibração interna, não foi possível quantificar tais compostos. Somente foi possível inferir a concentração relativa dos compostos encontrados. Por isto, nos estudos futuros será necessária uma quantificação destes compostos para que se tenha um panorama mais realista do risco associado ao uso das MOFs como marcadores de tiro. Além disso, não são conhecidos trabalhos que abordem o risco à saúde de atiradores envolvidos na exposição crônica aos resíduos orgânicos de um disparo. Apenas a intoxicação por Pb foi avaliada. ${ }^{45,47}$ Sendo assim, estudos adicionais são necessários não só para avaliar o risco associado ao uso do marcador quanto ao risco envolvido em uma exposição prolongada a resíduos de tiros de munições NTA, marcadas ou não.

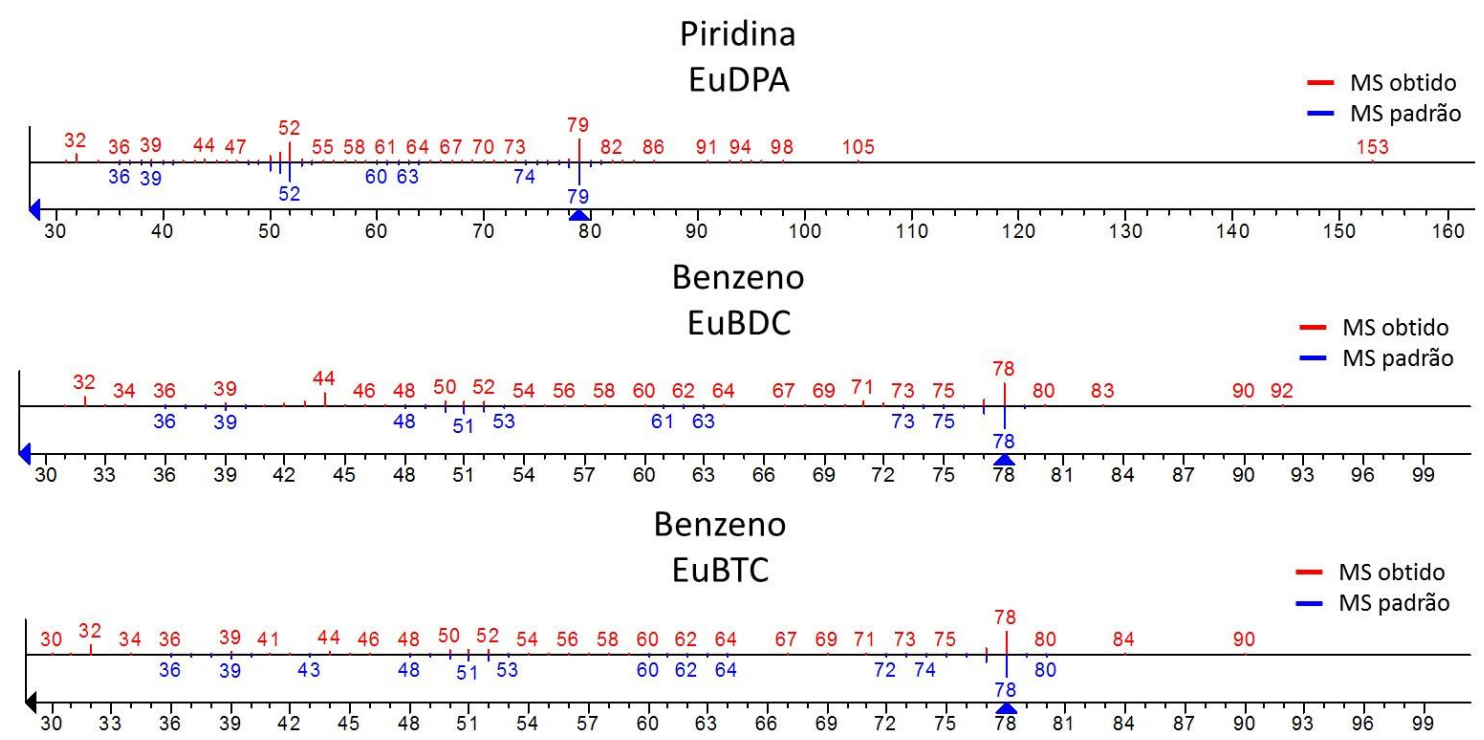

Figura 35. Comparação entre os espectros de massas dos compostos piridina e benzeno obtidos nos experimentos com os espectros de massas padrões fornecidos pela biblioteca digital.

Aproveitando o estudo realizado com GC/MS, procurou-se identificar mais alguns compostos presentes nos resíduos de tiro, que pudessem ser usados tanto para a identificação de OGSR como podem ser um ponto de partida de estudos futuros acerca do risco à saúde associado a exposição prolongada a estes. Estes compostos estão listados nas Tabelas A, B, C e D do apêndice foram encontrados.

Ao comparar as substâncias encontradas na munição NTA com as munições marcadas, foi possível identificar alguns compostos que estão presentes apenas nas munições marcadas. Estes compostos podem ser oriundos da degradação dos marcadores, da reação dos marcadores com componentes do propelente ou do primer (ou ainda com subprodutos da queima do propelente ou do primer), ou ainda, serem compostos oriundos 
da própria munição NTA, os quais não foi possível identificar nas amostras de munição não marcada devido à variabilidade e volatilidade dos compostos. Estes compostos estão listados na Tabela 5.

Tabela 5. Compostos encontrados apenas nos cartuchos das munições marcadas com EuDPA, EuBDC e EuBTC. Os compostos em negrito apresentaram uma área de integração maior que a do composto N,N'-Dietil-N,N'-difenilureia.

\begin{tabular}{|c|c|c|}
\hline EuDPA & EuBDC & EuBTC \\
\hline $\begin{array}{l}\text { 1-Formil-3-etil-6- } \alpha-\Delta \text { - } \\
\text { ribofuranosil-Pirazol[4,5- } \\
\beta] \text { imidazol }\end{array}$ & 1,2-Benzodicarbonitrila & 1,2-Benzodicarbonitrila \\
\hline $\begin{array}{l}\text { 1-Metil-2-(5-metil-1H- } \\
\text { pirazol-3)-Etilamina }\end{array}$ & 1-Etil-1H-Indeno & $\begin{array}{l}\text { 2,5-Bis(1-naftil)-1,5- } \\
\text { hexadieno }\end{array}$ \\
\hline $\begin{array}{l}\text { 2,4,4-Trimetil-3-(3- } \\
\text { metilbutil)ciclohex-2- } \\
\text { enona }\end{array}$ & 1-Isociano-16-Naftaleno & $\begin{array}{l}\text { 2-Fenil-1,3-dioxan-5-il } \\
\text { éster octadecanotrienóico }\end{array}$ \\
\hline 2-Aziridiniletil-amina & 1-Isopropildiaziridna & 2-Fenil-1-Benzopirilium \\
\hline 2-Formilhistamina & $\begin{array}{l}\text { 1-Metil-2-(5-metil-1H- } \\
\text { pirazo-3-il)-etilamina }\end{array}$ & 2-Hidroxi Propanamida \\
\hline 2-Hidroxi Propanamida & $\begin{array}{l}\text { 2,4,4-Trimetil-3-(3- } \\
\text { metilbutil)ciclohex-2- } \\
\text { anona }\end{array}$ & 2-Naftalenocarbonitrila \\
\hline 5- $\alpha$-Colestan-2-ona-oxima & 2-metil-1,1'-Bifenila & $\begin{array}{l}\text { 3-(3-Carboxi-4- } \\
\text { hidroxifenil)-D-alanina }\end{array}$ \\
\hline & 2-Metil-Naftaleno & 6-amino-2-metil-heptanol \\
\hline $\begin{array}{c}\text { Ácido } 1,2,3,4- \\
\text { Tetrahidroisoquinolin-6- } \\
\text { ol-1 }\end{array}$ & $\begin{array}{l}\text { 3-(3-Carboxi-4- } \\
\text { hidroxifenil)-D-alanina }\end{array}$ & $\begin{array}{c}\text { Acido 2,7,10- } \\
\text { tris(acetiloxi)- } \\
1,1 \alpha, 2,3,4,6,7,10,11,11 \alpha- \\
\text { decahidro-1,1,3,6,9- } \\
\text { pentametil-4-oxo-4 } \alpha, 7 \alpha- \\
\text { 3-Piridinacarboxílico }\end{array}$ \\
\hline & $\begin{array}{l}\text { 3-Fenil-(E)-2- } \\
\text { Propenonitrila }\end{array}$ & $\begin{array}{c}\text { Ácido 2- } \\
\text { Piridinacarboxílico }\end{array}$ \\
\hline \multirow{3}{*}{$\begin{array}{l}\text { Ácido 12,15- } \\
\text { Octadecadióico }\end{array}$} & $\begin{array}{l}\text { 4-hidroximetil- } \\
\text { benzonitrila }\end{array}$ & $\begin{array}{c}\text { Ácido 4-(1,5- } \\
\text { Dihidrobenzo[e][1,3,2]dio } \\
\text { xaborepin-3-il)benzoico }\end{array}$ \\
\hline & 6-amino-2-metil-heptanol & $\begin{array}{l}\text { Ácido pentadecil-2,2- } \\
\text { Dimetillpropiônico }\end{array}$ \\
\hline & $\begin{array}{c}\text { Ácido Ciclohexan-3-ona- } \\
\text { 1,4,5-triol }\end{array}$ & $\begin{array}{c}\text { Ácido } \\
\text { Triciclo[4.3.1.1 }(3,8)] \text { unde } \\
\text { cano-3-carboxílico }\end{array}$ \\
\hline
\end{tabular}


Continuação da Tabela 5.

\begin{tabular}{|c|c|c|}
\hline EuDPA & EuBDC & EuBTC \\
\hline \multirow{3}{*}{$\begin{array}{l}\text { Ácido 2-(3-acetoxi- } \\
\text { 4,4,14-trimetillandrost-8- } \\
\text { en-17-ona)-Propanóico }\end{array}$} & $\begin{array}{l}\text { Ácido } \alpha \text {-hidroxiimínico- } \\
\text { benzenopropanóico }\end{array}$ & Benzaldeído \\
\hline & Benzaldeído & Benzeno \\
\hline & Benzeno & Benzonitrila \\
\hline \multirow{2}{*}{$\begin{array}{c}\text { Ácido 2-metil-2,2-dimetil- } \\
\text { 1-(2-hidroxi-1-metiletil) } \\
\text { propanóico }\end{array}$} & Benzofenona & $\begin{array}{l}\text { Biciclo[4,4,1]undeca- } \\
\text { 1,3,5,7,9-pentano }\end{array}$ \\
\hline & Benzonitrila & Bifenila \\
\hline \multirow{2}{*}{ Borneol } & Bifenila & Fenol \\
\hline & Dibenzofurano & \multirow{3}{*}{$\begin{array}{c}\text { Metil-éster ácido-3- } \\
\text { Isopropopil-6 } \alpha, 7,10 \beta- \\
\text { trimetil-8-(2-oxo-2- } \\
\text { feniletil)dodecahidrobenz } \\
\text { o[f]benzopirano }\end{array}$} \\
\hline \multirow{2}{*}{ Naftaleno } & Fenantridina & \\
\hline & Naftaleno & \\
\hline \multirow[b]{2}{*}{ Piridina } & Nitrobenzeno & \multirow[b]{2}{*}{ Naftaleno } \\
\hline & $\begin{array}{l}\text { O-acetiloxima-(E)-3- } \\
\text { Piridinacarboxaldeído }\end{array}$ & \\
\hline \multirow[b]{2}{*}{ Topotecano } & Óxido Nitroso & \multirow{2}{*}{$\begin{array}{l}\alpha-(1 \text {-aminoetil })-(\mathrm{R}, \mathrm{R})- \\
\text { Benzometanol }\end{array}$} \\
\hline & $\begin{array}{c}\alpha-M e t i l- \\
\text { Benzenoetanamina }\end{array}$ & \\
\hline
\end{tabular}

Dentre os compostos listados na tabela acima, o naftaleno foi o único composto presente em todos os marcadores analisados, com um pico de intensidade média. Nos marcadores EuBDC e EuBTC, picos com intensidade alta foram observados, referente aos compostos bifenila e benzonitrila. Além desses, ambos os marcadores apresentaram picos com menor intensidade referente ao composto benzaldeído. Já os compostos piridina e benzeno apresentaram intensidade média. Os demais compostos listados na tabela apresentaram intensidades médias ou baixa.

Os compostos que apresentaram uma área integrada maior que a do composto N,N'-Dietil-N,N'-difenilureia, presente em todos os cromatogramas, foram selecionados 
e a sua toxicidade investigada. Os compostos investigados foram benzeno, piridina, naftaleno, fenol, benzonitrila, bifenila, benzaldeído.

O benzeno é um hidrocarboneto aromático inflamável, de odor adocicado, incolor, volátil, largamente empregado na indústria química em síntese de diversos produtos. ${ }^{155}$ A principal rota de exposição humana ao benzeno é o ar. A inalação de altas concentrações do composto por curto tempo pode causar sonolência, enjoo, aceleração do ritmo cardíaco, cefaleia, tremor, confusão mental e inconsciência. ${ }^{156} \mathrm{~A}$ ingestão de alimentos e bebidas contaminados com altos teores de benzeno pode produzir vômito, irritação no estômago, enjoo, sonolência, convulsão, aceleração do batimento cardíaco e morte. ${ }^{157}$ A exposição crônica pode causar vários transtornos no sangue, incluindo diminuição no número de glóbulos vermelhos e anemia aplástica (leucemia mielóide aguda de 1 grau), em ambientes ocupacionais. Efeitos reprodutivos têm sido relatados para as mulheres expostas por inalação a níveis elevados, e os efeitos adversos no feto em desenvolvimento têm sido observados em testes com animais. ${ }^{158,159}$

A piridina é um líquido amarelo a incolor, volátil e que produz vapores inflamáveis e tóxicos. É utilizada na indústria na preparação de muitos produtos, tais como medicamentos, vitaminas, aromas alimentares, tintas, corantes, produtos de borracha, adesivos, herbicidas e inseticidas. ${ }^{160}$ Os efeitos agudos incluem dores de cabeça, vertigem, sonolência e taquicardia. Leve irritação da pele e irritação dos olhos também são sintomas observados. ${ }^{160,161}$ Existem poucos estudos sobre os efeitos crônicos da piridina na saúde. Estudos em animais e alguns relatos de casos limitados em pessoas denotam danos ao fígado, nervosismo e dores abdominais. Até o momento, não existem estudos sobre a capacidade da piridina em afetar o sistema reprodutor feminino. ${ }^{161}$

O naftaleno é um hidrocarboneto aromático cuja molécula é constituída por dois anéis benzênicos condensados. O naftaleno é utilizado na fabricação de diversos produtos químicos, como corantes, inseticidas, fungicidas, solventes, ácido ftálico, plásticos, lubrificantes, explosivos, resinas sintéticas, entre outros. Pode ser utilizada também como repelente ao ataque de insetos. ${ }^{162,163}$ A exposição ao naftaleno pode ocorrer pelo ar, ingestão de alimentos ou bebidas contaminadas e pela pele. A principal via de exposição é o ar. Uma vez no organismo, o naftaleno é transportado para o fígado e outros órgãos, onde são metabolizados. ${ }^{164}$ Os efeitos agudos incluem náuseas, vômitos, diarreia, sangue na urina e icterícia. As exposições continuadas podem danificar algumas das células vermelhas do sangue, ocasionando anemia hemolítica. Outros efeitos incluem toxicidade 
materna durante a gravidez, diminuição do peso corporal, aumento da incidência de lesões não-neoplásicas e neoplásicas no nariz e pulmão. ${ }^{164,165}$

O fenol é considerado pela Agência de Proteção Ambiental (EPA) um dos resíduos mais perigosos. ${ }^{166}$ É um sólido esbranquiçado em sua forma pura e, na sua forma comercial, um líquido transparente. A exposição pode ocorrer pela inalação, ingestão de alimento e bebidas contaminadas ou através do contato com a pele. Estudos com animais provam que uma exposição crônica dessa substância causa danos no coração, rins, fígado e pulmões. ${ }^{166}$ A DL50 oral calculada para o fenol é de $500 \mathrm{mg} / \mathrm{kg} .{ }^{167}$ A DL50 dérmica obtida do composto é de $669 \mathrm{mg} / \mathrm{kg}$. ${ }^{168}$

A benzonitrila é um líquido incolor, com um odor característico, utilizando na indústria principalmente como solvente em reações para fabricação de resinas, plásticos e vernizes especiais, além de ser utilizado na fabricação de benzoguanamina e agente para borracha. ${ }^{169}$ A benzonitrila pode ser absorvida pelo corpo através da inalação, pela pele e ingestão. Com uma exposição de curto prazo, ela pode causar irritação nos olhos, pele e nas vias respiratórias, além de causar efeitos na respiração celular, resultando em cianose. ${ }^{170}$ A toxicidade aguda DL50 oral, em ratos, é de $971 \mathrm{mg} / \mathrm{kg}$. Já a CL50 inalação, em ratos, é de $1.800 \mathrm{mg} / \mathrm{m}^{3}$ e a DL50 dérmica, em coelhos é $1.250 \mathrm{mg} / \mathrm{kg}$. ${ }^{171}$

As bifenilas apresentam-se como cristais ou flocos brancos, com um odor fungicida característico. Em caso de contato com a pele e com os olhos causa irritações, vermelhidão e coceira. ${ }^{172} \mathrm{~A}$ exposição crônica pode causar efeitos no fígado e no sistema nervoso. Os sintomas mais característicos são náuseas, vômitos, tontura e irritação. ${ }^{173} \mathrm{~A}$ DL50 aguda, em ratos, é de $2400 \mathrm{mg} / \mathrm{kg} .{ }^{172}$

O benzaldeído pode ser encontrado em vários corantes e aromatizantes. Utilizado principalmente na preparação de perfumes, alimentos, cosméticos e produtos farmacêuticos. ${ }^{174}$ Consiste em um líquido amarelo, com um odor e gostos amendoados. Os efeitos agudos consistem em vermelhidão e irritação, quando em contato com os olhos, e tosse quando inalado. ${ }^{175}$ Em estudos de toxicidade aguda, a DL50 oral de benzaldeído em ratos variou entre 800 - $1600 \mathrm{mg} / \mathrm{kg}$. Além disso, benzaldeído não apresentou efeitos carcinogênico. ${ }^{176}$

Apesar de alguns subprodutos tóxicos terem sido gerados após o disparo, cabe ressaltar que somente uma parte do marcador sofre degradação, conforme observado em estudos anteriores do grupo. Estudos de espectroscopia de Raman ${ }^{61}$ e espectroscopia no infravermelho ${ }^{58}$ dos marcadores após o disparo provam que a rede da MOF permanece intacta após a ignição da pólvora, indicando que somente uma pequena parte do marcador 
adicionado sofre degradação. Com relação à toxicidade da estrutura da molécula do marcador, testes de toxicidade aguda e subaguda realizados por Lucena, ${ }^{63}$ demonstraram que a MOF $[\mathrm{Eu}(\mathrm{BTC})]$, de acordo com o protocolo utilizado na pesquisa, foi classificada na categoria menos tóxica da GHS (categoria 5), com uma DL50 estimada em 500 0mg. $\mathrm{kg}^{-1}$. Considerando os parâmetros avaliados na pesquisa (comportamento animal, evolução do peso, consumo de água e ração, parâmetros bioquímicos relacionados a função renal e hepática, avaliação macroscópica geral dos órgãos e peso do coração, fígado, baço e rins), nenhuma alteração ou efeito tóxico foi observado. Contudo, ainda é necessário avaliar o potencial toxicológico das demais redes.

Outro aspecto importante na análise da toxicidade dos subprodutos gerados após o disparo é o fato de que, apesar de não terem sido detectados pelo método de CG/EM desenvolvido, alguns compostos descritos na Tabela 5 são considerados como OGSR, conforme descrito por Goudsmits et al. ${ }^{94}$ Compostos tais como benzeno, benzaldeído, benzonitrila, bifenila, fenol e naftaleno foram encontrados em OGRS coletados de cartuchos deflagrados com um dessorvedor térmico com um cromatógrafo gasoso acoplado a um espectrômetro de massa. ${ }^{25,94}$ Com isso, apesar da munição NTA ser isenta de metais pesados e ser considera não-tóxica, ela possui compostos orgânicos que podem ser considerados tóxicos, fato ainda não descrito na literatura.

Além disso, o método desenvolvido mostrou-se viável para a identificação de OGSR, podendo ser aplicado na análise/identificação de resíduos advindos de cartuchos deflagrados.

Considerando esses dois fatores, apesar dos marcadores gerarem subprodutos considerados tóxicos, pode-se concluir que a toxicidade da munição NTA não é alterada de forma significativa.

\subsubsection{Tamanho da Partícula}

Para fins de análise acerca dos efeitos toxicológicos de materiais suspensos no ar, o estudo do tamanho da partícula é uma das características mais importantes e extensivamente estudada. ${ }^{177}$ Partículas micrométricas podem entrar no corpo causando efeitos nocivos à saúde. ${ }^{178}$ Trabalhos descritos na literatura que correlacionam toxicidade e tamanho de partículas são referentes ao estudo de nanopartículas e ao material particulado contido no ar (poluição). ${ }^{179-182}$ 
$\mathrm{Na}$ área forense, estudos foram realizados correlacionando a presença de chumbo nas partículas de GSR, encontradas em stands de tiro, da munição clássica (que contem mistura de Sb-Ba-Pb). ${ }^{49,53,183}$ Contudo, ainda não foi avaliada a toxicidade do resíduo de tiro relacionada ao seu tamanho. Apesar de não ter sido avaliado o potencial risco a saúde causado pela exposição às partículas de GSR, decidimos avaliar se a introdução dos marcadores altera o padrão de distribuição de tamanho e se isso pode ser associado a um possível aumento no risco à saúde por inalação de material particulado.

Diante disso, a proposta deste estudo consiste na análise da distribuição do tamanho das partículas formadas após o disparo de uma munição NTA marcada com os marcadores desenvolvidos e compará-la com o padrão encontrado para as partículas da munição NTA.

Nesta etapa do trabalho, procurou-se avaliar as variações na distribuição de tamanho de partículas de produzidas por munição NTA e por munição NTA marcada, buscando observar se a introdução do marcador levou à formação de uma maior quantidade de partículas com tamanho entre 0 e $5 \mu \mathrm{m}$. Partiu-se do pressuposto de que uma maior quantidade de partículas menores de $2,5 \mu \mathrm{m}$ pode vir a representar uma maior toxicidade do GSR. ${ }^{184}$ É importante ressaltar, entretanto, que este é um estudo exploratório e comparativo e não foi avaliada a toxicidade das partículas de GSR. Procurou-se determinar se há ou não uma mudança de perfil em função da introdução do marcador. É importante salientar também que não foi encontrado nenhum relato na literatura de uma avaliação semelhante, seja para munição convencional ou munição NTA, marcadas ou não. Portanto, não há uma metodologia de referência. Apesar de ser uma avalição preliminar, a motivação deste estudo é contribuir com a avaliação da segurança do uso dos marcadores para saúde ocupacional de atiradores frequentes (policiais, militares, esportistas, etc.).

Para realização deste estudo, uma série de histogramas com a distribuição de tamanho de partículas foi construída e analisada. Os tamanhos de partículas foram estimados por MEV-EDS com a utilização do programa comercial INCAGRS, com a nova configuração aplicada, as partículas eram classificadas (possuíam elementos do grupo lantanídeos e não possuíam) e analisadas. Inicialmente foram investigados os histogramas referentes às partículas produzidas pelo disparo da munição NTA.

Primeiramente, as partículas foram coletadas da mão do atirador, após esse ter efetuado 4 disparos com uma munição NTA não marcada. O procedimento foi realizado em triplicata e os histogramas obtidos podem ser observados na Figura A do apêndice. 
Com intuito de aumentar o número de partículas recolhidas, partículas provenientes de um cartucho deflagrado também foram coletadas. Novamente, o procedimento foi realizado em triplicata e os histogramas da Figura B do apêndice foram obtidas. Um histograma com os dados consolidados (Figura 36) foi elaborado com todas as partículas NTA coletadas e os dados de média e desvio padrão estão descritos na Tabela 6.

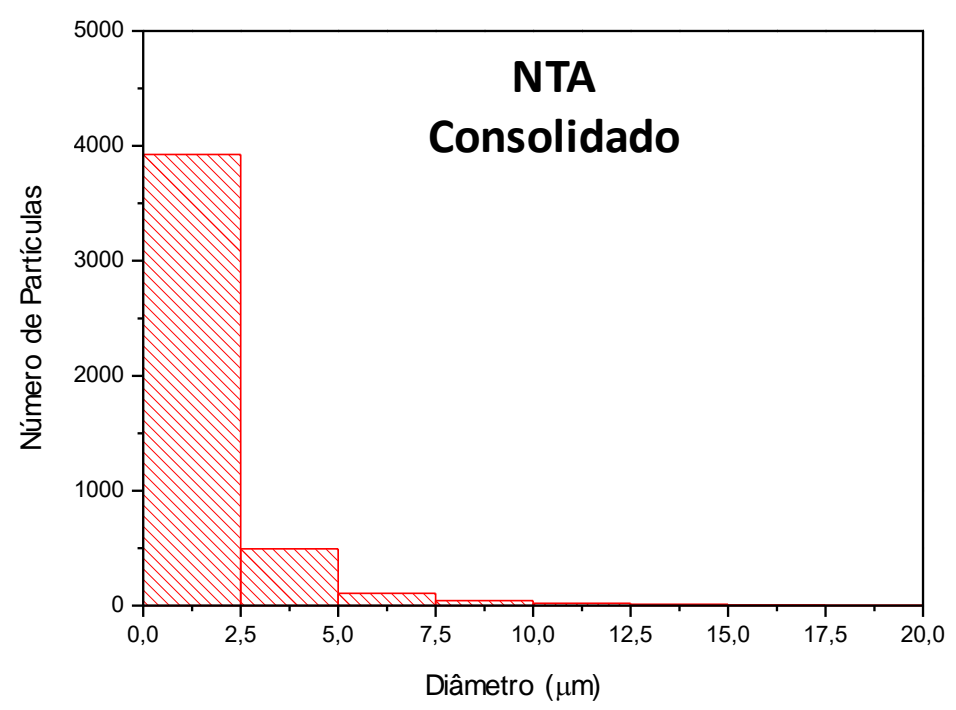

Figura 36. Histograma consolidado de todas as partículas coletadas da munição NTA.

Ao analisar os histogramas obtidos e o histograma consolidado para a munição NTA, é possível observar um padrão na distribuição do diâmetro das partículas, sendo uma maior quantidade encontram-se na faixa de $0-2,5 \mu \mathrm{m}$ (cerca de $85 \%$ ). À medida em que o tamanho aumenta, há um decaimento no número de partículas encontradas. Em tamanhos maiores do que $10 \mu \mathrm{m}$, a quantidade de partículas encontradas cai drasticamente, sendo que são observadas somente 1,19\% do total de partículas acima desta faixa.

O valor médio das partículas observadas no histograma consolidado é de aproximadamente $1,61 \mu \mathrm{m}$, estando na faixa de 0-2,5 $\mu \mathrm{m}$. Considerando o valor médio somado ao valor do desvio padrão, observa-se ainda uma prevalência de partículas que possuem diâmetros abaixo de $5,00 \mu \mathrm{m}$.

A predominância de partículas menores que $2,5 \mu \mathrm{m}, \mathrm{MP}_{2,5}$, pode gerar problemas para a saúde ocupacional de um atirador frequente, tendo em vista que essas partículas podem penetrar na corrente sanguínea e alcançar o pulmão e o coração. ${ }^{185}$ Altas concentrações de $\mathrm{MP}_{10}$ e $\mathrm{MP}_{2,5}$ estão relacionados com problemas de saúde, tais como asma, enfisema, bronquite, silicose e câncer de pulmão. ${ }^{177}$ Em crianças, existem indícios 
de que partículas finas em suspensão (menores que 2,5 $\mu \mathrm{m}$ ) causam efeitos deletérios no desenvolvimento pulmonar, doenças respiratórias, alergias, câncer e déficits no desenvolvimento neurocomportamental. ${ }^{186}$

Tabela 6. Dados das partículas coletadas da munição NTA.

\begin{tabular}{c|c} 
Faixa do Diâmetro $(\mu \mathrm{m})$ & Número de partículas \\
\hline $0-2,5$ & $3926(84,92 \%)$ \\
$2,5-5,0$ & $493(10,66 \%)$ \\
$5,0-7,5$ & $107(2,31)$ \\
$7,5-10,0$ & $42(0,91 \%)$ \\
$>10,00$ & $55(1,19 \%)$ \\
Número total de partículas analisadas & 4623 \\
Média do diâmetro & $1,61 \mu \mathrm{m}$ \\
Desvio Padrão & $3,30 \mu \mathrm{m}$
\end{tabular}

O mesmo procedimento foi aplicado às munições NTA marcadas. Incialmente, foram avaliadas todas as partículas (soma das classificadas e não classificadas) encontradas nas munições marcadas (Figura C, no apêndice). Na sequência, foi possível separar as partículas que contêm o elemento európio (classificadas) das partículas que não o contém (não classificadas). Esta separação foi feita com base nos espectros EDS adquiridos e foi possível graças à rotina introduzida no modo de varredura automático do MEV-EDS do INC-DPF. As Figura D e E do apêndice mostram os histogramas das partículas classificadas e não classificadas, respectivamente, recolhidas das mãos do atirador e do cartucho da munição. Novamente, as partículas coletadas da mão e do cartucho foram somadas e os histogramas consolidados da Figura 37 foram obtidos. Os dados da média e desvio padrão dos histogramas estão descritos na Tabela 7. 

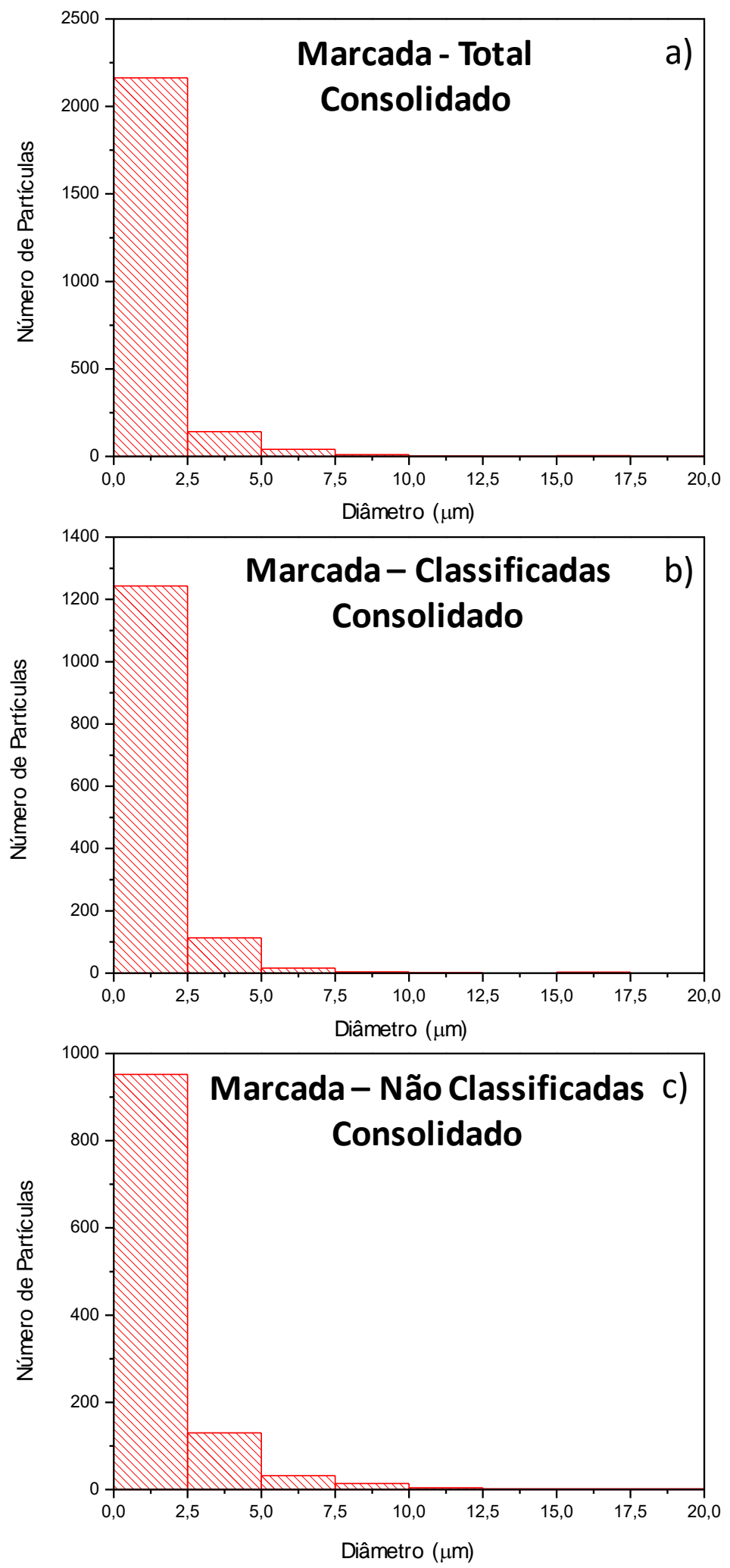

Figura 37. Histogramas consolidados das partículas coletadas da munição marcada, sendo: (a) todas as partículas, (b) partículas que contém európio (classificadas) e (c) partículas que não contem európio (não classificadas). 
Tabela 7. Dados das partículas coletadas da munição marcada.

\begin{tabular}{c|ccc|}
\cline { 2 - 4 } Faixa do Diâmetro $(\mu \mathrm{m})$ & \multicolumn{3}{|c|}{ Número de partículas } \\
\cline { 2 - 4 } & Total & Classificadas & $\begin{array}{c}\text { Não } \\
\text { Classificadas }\end{array}$ \\
\hline $0-2,5$ & $2163(90,84 \%)$ & $1243(89,68 \%)$ & $952(82,93 \%)$ \\
$2,5-5,0$ & $142(5,96 \%)$ & $113(8,15 \%)$ & $130(11,32 \%)$ \\
$5,0-7,5$ & $40(1,68 \%)$ & $16(1,15 \%)$ & $32(2,79 \%)$ \\
$7,5-10,0$ & $10(0,42 \%)$ & $4(0,29 \%)$ & $14(1,22 \%)$ \\
$>10,00$ & $26(1,09 \%)$ & $10(0,72 \%)$ & $20(1,74 \%)$ \\
Número total de & 2381 & 1386 & 1148 \\
partículas analisadas & & & $2,01 \mu \mathrm{m}$ \\
Média do diâmetro & $1,41 \mu \mathrm{m}$ & $1,42 \mu \mathrm{m}$ & $8,48 \mu \mathrm{m}$ \\
Desvio Padrão & $6,405 \mu \mathrm{m}$ & $3,41 \mu \mathrm{m}$ &
\end{tabular}

Novamente, a maior parte das partículas coletadas estão na faixa de $0-2,5 \mu \mathrm{m}$, sendo classificadas como $\mathrm{MP}_{2,5}$. Cerca de $90 \%$ das partículas que contêm o elemento európio são $\mathrm{MP}_{2,5}$ e $83 \%$ das partículas que não contem o elemento estão na mesma faixa de diâmetro. Assim como na munição NTA, o número de partículas diminui à medida que o diâmetro aumentou, sendo que, somente $0,72 \%$ das partículas classificadas e $1,74 \%$ das partículas não classificadas apresentam diâmetro maior que 10,00 $\mu \mathrm{m}$. As partículas que contêm európio apresentam tamanhos menores do que as que não contém o elemento, considerando que a última possui $1,74 \%$ das suas partículas com diâmetro maior que $10 \mu \mathrm{m}$, enquanto a primeira, apresenta $0,75 \%$ partículas. A média do diâmetro das partículas obtidas foram de 1,42 e 2,01 $\mu \mathrm{m}$ para as partículas classificadas e não classificadas, respectivamente. Já a média do diâmetro de todas as partículas provenientes do marcador (com e sem európio) foi de $1,41 \mu \mathrm{m}$.

Pode-se observar que as partículas classificadas apresentaram uma maior quantidade de partículas $\mathrm{MP}_{2,5}$ ao ser comparada com a NTA. O mesmo é observado ao analisar o número total de partículas do marcador (soma classificada e não classificadas), sendo que a munição NTA apresentou cerca de $85 \%$ das partículas como $\mathrm{MP}_{2,5}$ e a munição marcada apresentou $91 \%$. Os dados de desvio padrão confirmam esse padrão observado, um desvio de 6,4 $\mu$ m para o número total de partículas do marcador e 3,3 para a munição NTA, mostrando uma maior variabilidade no diâmetro da munição marcada. Contudo, essa diferença é pequena, e os padrões de dispersão obtidos entre a munição marcada e não marcada podem ser considerados semelhantes entre si.

Os dados de granulometria da MOF EuBTC, realizado por Talhari, A. L. R. ${ }^{187}$, demonstram que o marcador apresenta partículas com tamanhos entre 0,1-100 $\mu \mathrm{m}$, com uma maior quantidade de partículas com $10 \mu \mathrm{m}$. Além disso, considerando as 
micrografias dos marcadores obtidas, foi possível verificar que eles são compostos por grandes aglomerados, que, no momento do disparo, poderiam ser quebrados formando partículas de tamanhos menores, aumentando a quantidade de $\mathrm{MP}_{2,5}$ e $\mathrm{MP}_{10}$. Entretanto, tendo em vista os histogramas das Figuras 36 e 37, foi possível verificar que a fragmentação dos aglomerados não foi relevante. Por outro lado, é preciso considerar a possibilidade de uma fração do marcador ter sido pulverizada à nanopartículas tão pequenas que a metodologia desenvolvida seria incapaz de identificá-las. Para isso, sugere-se o refinamento da metodologia de análise.

Tendo em vista os dados expostos acima, apesar da maior parte das partículas encontradas estar na faixa de $0-2,5 \mu \mathrm{m}$, é possível concluir que a adição do marcador não aumenta a toxicidade relacionada ao tamanho das partículas formadas após os disparos. Essa conclusão é baseada no fato de que o padrão de dispersão de partículas encontrado para o marcador é semelhante ao padrão encontrado para a munição NTA.

\subsection{Testes Forenses}

Em paralelo ao estudo para avaliação da toxicidade dos marcadores, foi feito um estudo para avaliar potencialidades e limitações dos marcadores em situações de interesse de perícia forense. Este estudo teve como objetivo complementar uma pesquisa prévia do grupo que buscou também avaliar o desempenho dos marcadores em situações de interesse forense (a saber, velocidade do projetil e taxa de falha do disparo, coleta do LGSR, presença de LGSR após lavagem de mãos e em objetos manipulados, dispersão do LGSR em "cenas de crime" simuladas e distribuição do LGST na vítima). ${ }^{61}$ Neste trabalho, buscamos avaliar a influência do tipo da arma, a estimativa da distância do disparo, a identificação da posição do atirador e efeitos de transferência de LGSR para pessoas não envolvidas no disparo.

\subsubsection{Influência do tipo de arma na produção do LGSR}

Foi estudada a influência do tipo de arma na produção e distribuição de partículas LGSR. Seis tipos de pistolas $9 \mathrm{~mm}$ foram utilizadas neste experimento: Glock G17, Glock G26, Smith \& Wesson 6906, Browning Hi-Power, Jericho 941F e Taurus PT 908. Estas pistolas possuem diferentes tipos de sistema de acionamento, comprimentos de cano e formatos/local da janela de ejeção (Tabela 8). Estes parâmetros podem influenciar na nuvem gasosa formada no momento do disparo, que por sua vez pode influencia na 
produção e dispersão do LGSR. Estudos utilizando investigações cinematográficas de alta velocidade mostraram que a distribuição de partículas pode ser influenciada pela dinâmica da pluma após o disparo de um tiro. ${ }^{132}$

Tabela 8. Armas utilizadas no experimento e suas características.

\begin{tabular}{|c|c|c|c|c|c|c|}
\hline & $\begin{array}{l}\text { Browning } \\
\text { Hi-Power }\end{array}$ & $\begin{array}{l}\text { Jericho } \\
\text { 941F }\end{array}$ & $\begin{array}{c}\text { Smith \& } \\
\text { Wesson } \\
6906\end{array}$ & $\begin{array}{l}\text { Taurus } \\
\text { PT } 908\end{array}$ & $\begin{array}{c}\text { Glock } \\
\text { G17 }\end{array}$ & $\begin{array}{c}\text { Glock } \\
\text { G26 }\end{array}$ \\
\hline Tipo & Pistola & Pistola & Pistola & Pistola & Pistola & Pistola \\
\hline País de origem & Bélgica & Israel & $\begin{array}{l}\text { Estados } \\
\text { Unidos }\end{array}$ & Brasil & Áustria & Áustria \\
\hline Calibre & $\begin{array}{l}\text { 9x19 mm } \\
\text { (nove por } \\
\text { dezenove } \\
\text { milímetros) }\end{array}$ & $\begin{array}{l}9 \times 19 \mathrm{~mm} \\
\text { (nove por } \\
\text { dezenove } \\
\text { milímetros) }\end{array}$ & $\begin{array}{l}\text { 9x19 mm } \\
\text { (nove por } \\
\text { dezenove } \\
\text { milímetros) }\end{array}$ & $\begin{array}{l}\text { 9x19 mm } \\
\text { (nove por } \\
\text { dezenove } \\
\text { milímetros) }\end{array}$ & $\begin{array}{l}\text { 9x19 mm } \\
\text { (nove por } \\
\text { dezenove } \\
\text { milímetros) }\end{array}$ & $\begin{array}{l}\text { 9x19 mm } \\
\text { (nove por } \\
\text { dezenove } \\
\text { milímetros) }\end{array}$ \\
\hline $\begin{array}{l}\text { Capacidade de } \\
\text { munições }\end{array}$ & 13 & 16 & 12 & 8 & 17 & 10 \\
\hline $\begin{array}{c}\text { Peso não } \\
\text { carregada }\end{array}$ & $900 \mathrm{~g}$ & $1140 \mathrm{~g}$ & $751 \mathrm{~g}$ & $933 \mathrm{~g}$ & $710 \mathrm{~g}$ & $615 \mathrm{~g}$ \\
\hline $\begin{array}{c}\text { Comprimento } \\
\text { Total }\end{array}$ & $197 \mathrm{~mm}$ & $207 \mathrm{~mm}$ & $178 \mathrm{~mm}$ & $179 \mathrm{~mm}$ & $204 \mathrm{~mm}$ & $165 \mathrm{~mm}$ \\
\hline $\begin{array}{c}\text { Tamanho do } \\
\text { Cano }\end{array}$ & $118 \mathrm{~mm}$ & $112 \mathrm{~mm}$ & $88.9 \mathrm{~mm}$ & $98,55 \mathrm{~mm}$ & $114 \mathrm{~mm}$ & $87 \mathrm{~mm}$ \\
\hline $\begin{array}{c}\text { Sistema de } \\
\text { Funcionamento }\end{array}$ & $\begin{array}{l}\text { Semiauto- } \\
\text { mática }\end{array}$ & $\begin{array}{l}\text { Semiauto- } \\
\text { mática }\end{array}$ & $\begin{array}{l}\text { Semiauto- } \\
\text { mática }\end{array}$ & $\begin{array}{l}\text { Semiauto- } \\
\text { mática }\end{array}$ & $\begin{array}{l}\text { Semiauto- } \\
\text { mática }\end{array}$ & $\begin{array}{l}\text { Semiauto- } \\
\text { mática }\end{array}$ \\
\hline $\begin{array}{c}\text { Sistema de } \\
\text { Acionamento }\end{array}$ & $\begin{array}{c}\text { Ação } \\
\text { Simples }\end{array}$ & Dupla ação & Ação Dupla & Dupla ação & Híbrida & Híbrida \\
\hline
\end{tabular}




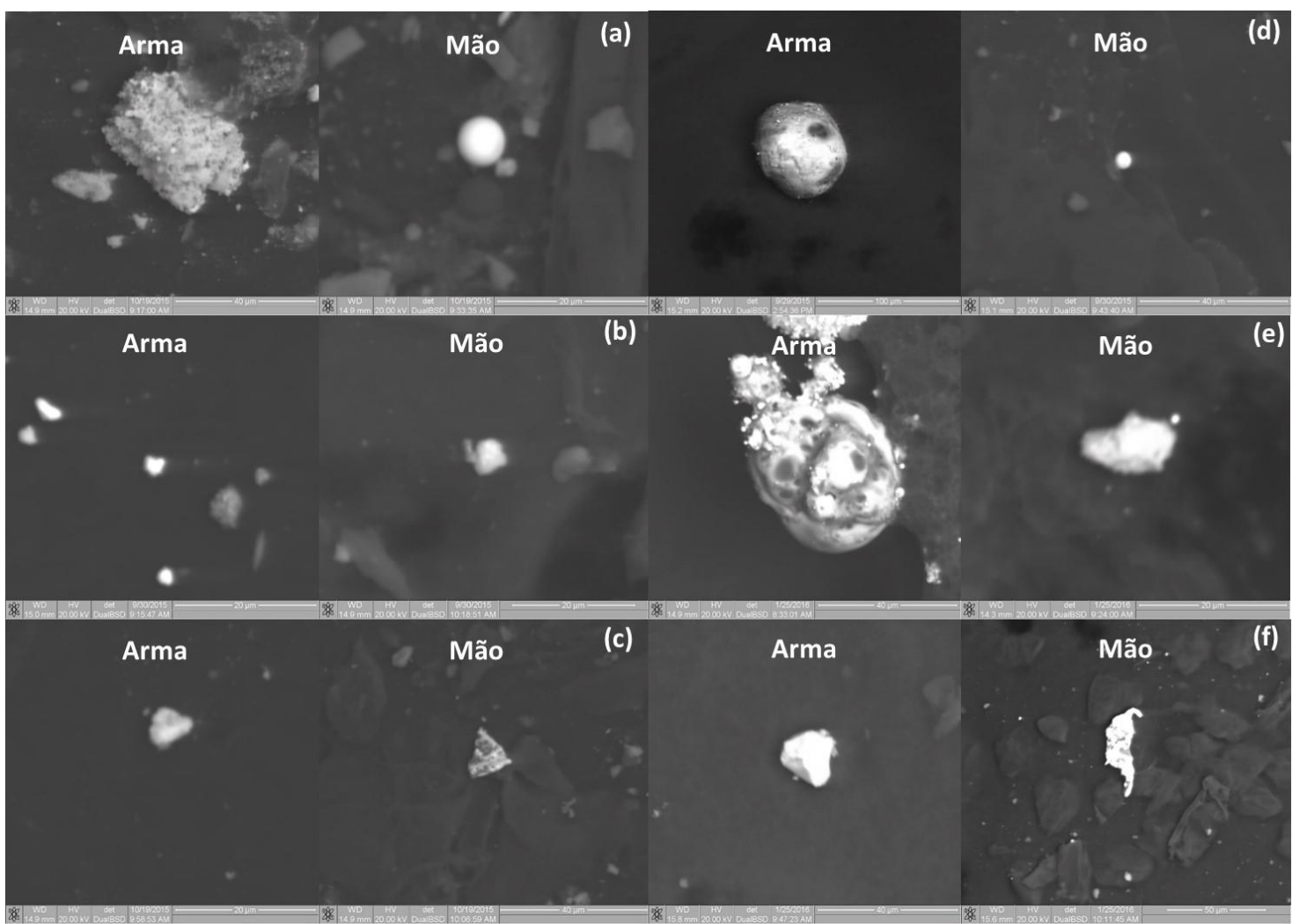

Figura 38. Micrografias dos resíduos encontrados nas mão e armas: (a) Browning, (b) Jericho (c) Smith \& Wesson, (d) Taurus, (e) Glock G17 e (f) Glock G26.

Com todas as pistolas investigadas, foi possível identificar visualmente, sob luz UV, as partículas de LGSR depositadas nas mãos do atirador e na arma. Também foi possível recolher partículas de LGSR produzidas por todas as pistolas testadas para análise por MEV/EDS, conforme demonstrado na Figura 38 (figura ampliada no apêndice). Nenhuma alteração no tamanho ou formato das partículas foi observada em função da arma usada. Todas as armas apresentaram partículas com morfologia irregulares e de tamanhos variados.

Com relação à composição (Figura 39), observou-se partículas com diversos elementos, de acordo com o descrito na literatura para as munições NTA, ${ }^{55}$ com exceção do európio, proveniente do marcador luminescente. 

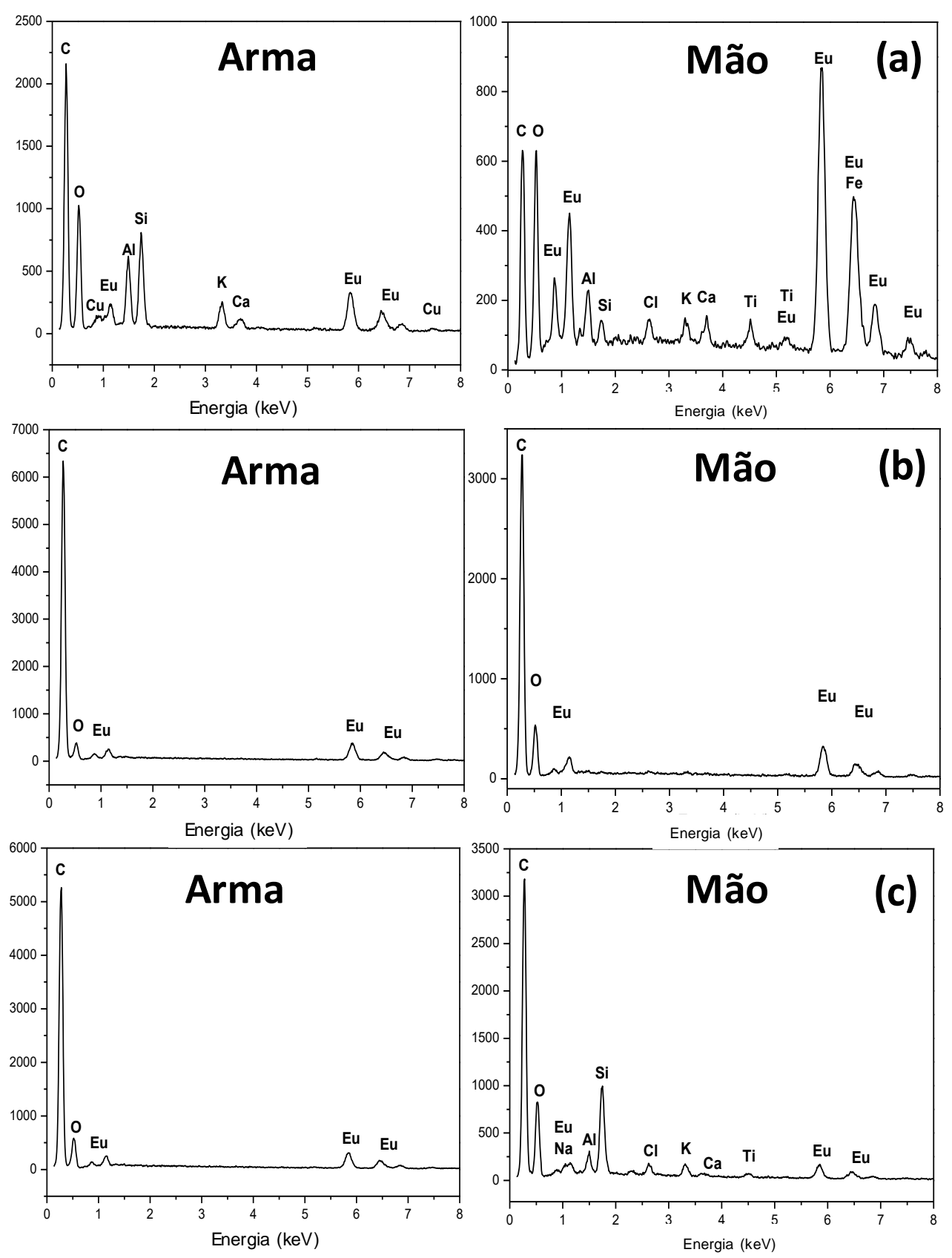

Figura 39. Espectros de dispersão de energia resíduos encontrados nas mão e armas: (a) Browning, (b) Jericho (c) Smith \& Wesson, (d) Taurus, (e) Glock G17 e (f) Glock G26. 


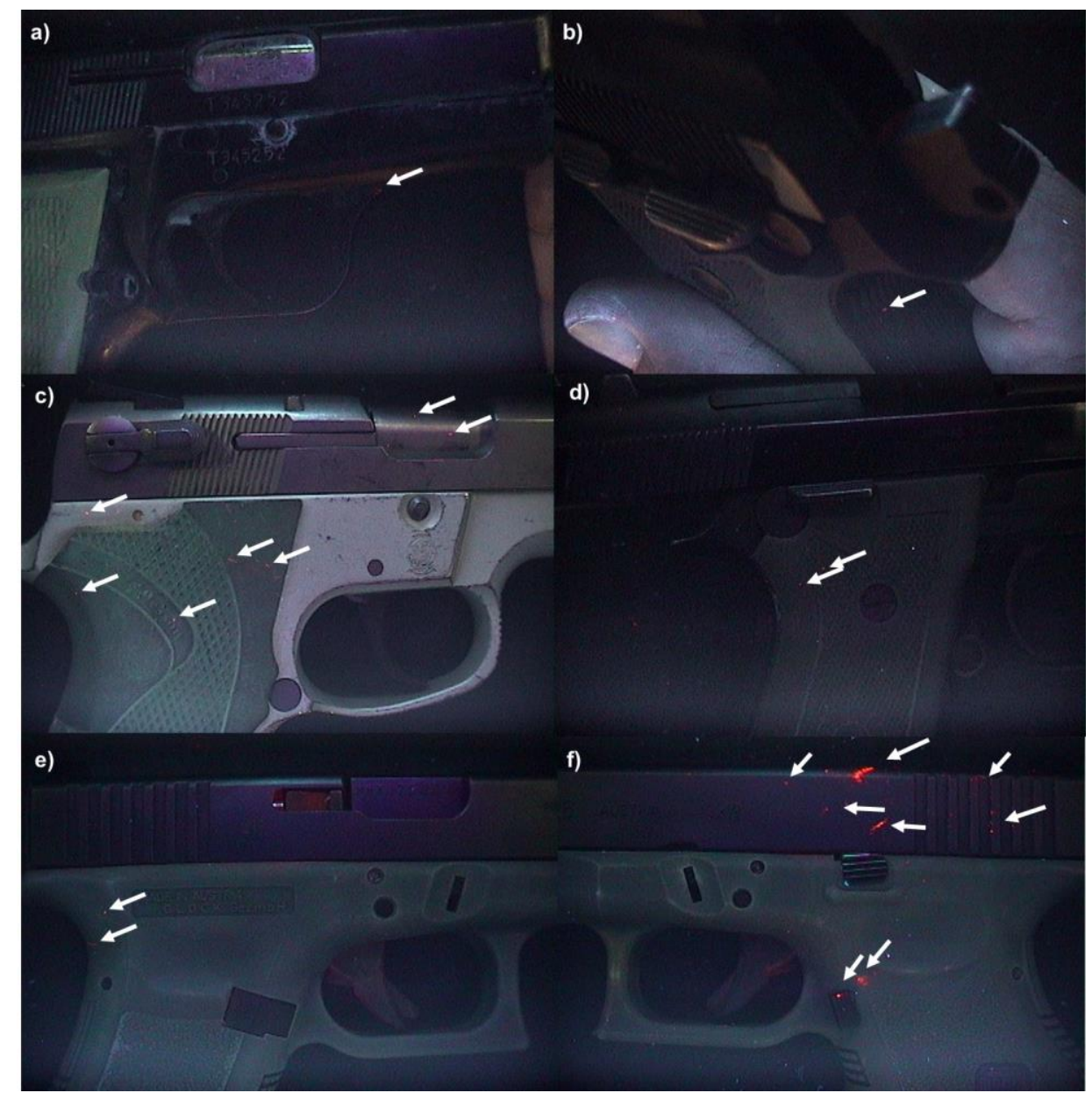

Figura 40 Imagens das partículas observadas sobre as armas obtidas no VSC sob radiação UV $(\lambda=254 \mathrm{~nm}$ ) após os disparos com NTA marcada: (a) Browning, (b) Jericho (c) Smith $\&$ Wesson, (d) Taurus, (e) Glock G17 e (f) Glock G26.

Após verificar que as diferentes características das armas não alteram a identificação visual do LGSR, e, portanto, em todos os casos foi possível fazer a coleta direcionada para realização de testes de confirmação. Procurou-se analisar o padrão de dispersão do LGSR, buscando avaliar se seria possível inferir sobre o tipo de pistola usada a partir dele. Usando as armas Browning (Figura 40a), Jericho (Figura 40b), Smith \& Wesson (Figura 40c) e Taurus (Figura 40d), não foram observadas diferenças na distribuição do LGSR na arma e na mão do atirador (Figuras 41a-d) de uma maneira que fosse possível distinguir qual arma foi utilizada, somente pela análise do padrão de dispersão. Dentre as armas estudadas, observou-se ainda que a arma Browning forneceu sistematicamente a menor quantidade de partículas do marcador depositada na arma e na mão do atirador. Isso se deve ao fato de que essa arma apresenta o maior tamanho do cano. O cano comprido faz com que o vórtice se forme mais longe da mão do atirador e consequentemente, menos partículas são depositas. As armas Jericho e Taurus, que 
apresentam o mesmo sistema de acionamento, apresentaram quantidades de LGSR semelhante. Todavia, a Jericho que apresentou um resultado menos satisfatório (menor quantidade de partícula), fato relacionado à essa possuir um cano maior. Contudo, apesar de algumas diferenças terem sido observadas, não foi não foi possível inferir sobre o tipo da arma com base no padrão de dispersão do LGSR.

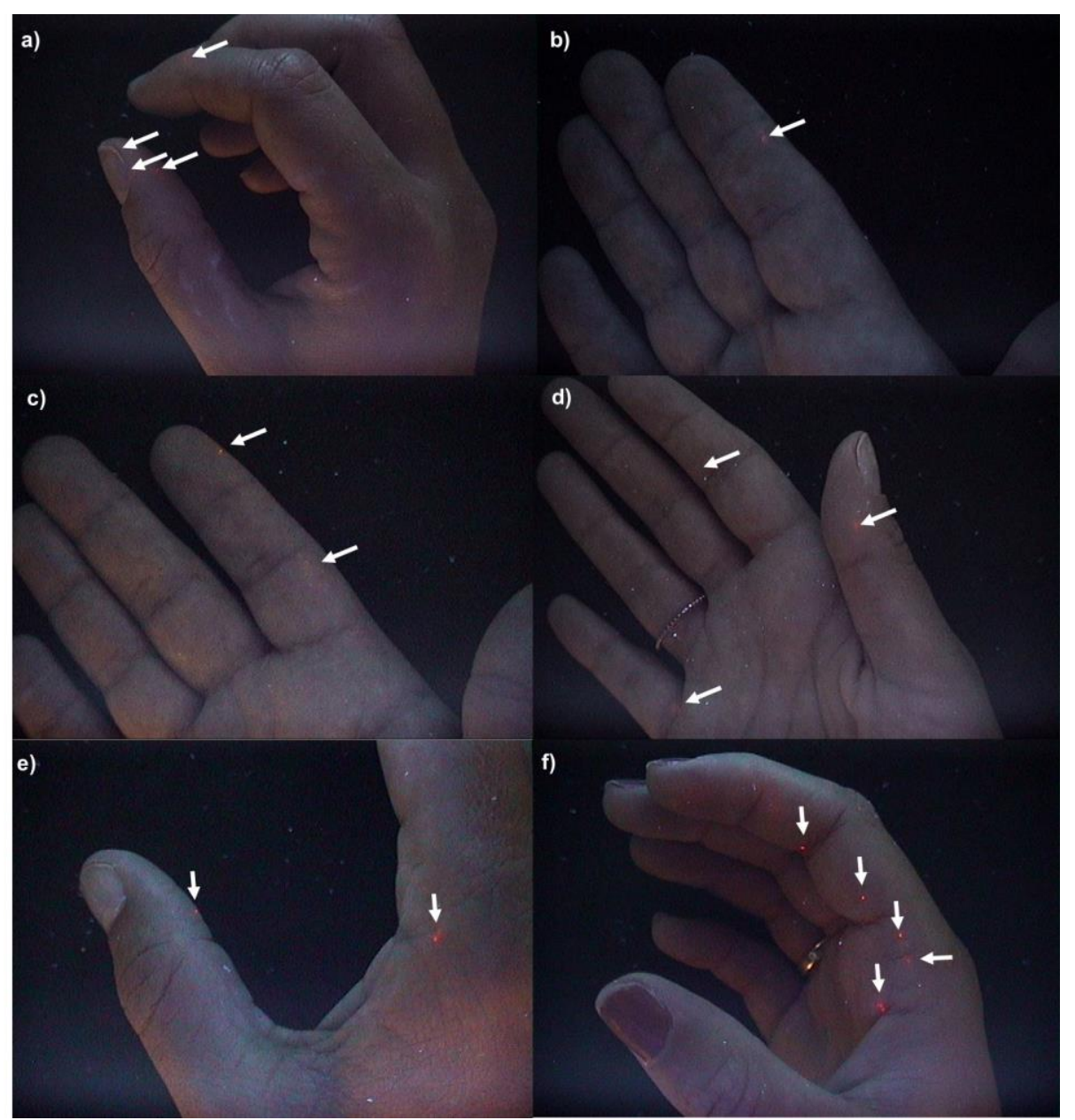

Figura 41. Imagens VSC das mãos dos atiradores obtido sob radiação UV $(\lambda=254 \mathrm{~nm})$ usando as armas: (a) de Browning, (b) Jericho (c) Smith \& Wesson, (d) Taurus, (e) Glock G17 e (f) Glock G26.

Além disso, com o uso das armas Browning, Jericho e Taurus, partículas luminescentes foram encontradas no rosto (Figura 42) e tórax do atirador. Essa observação pode ser explicada pelo fato das armas possuírem o cão exposto (Figura 18), região na qual pode ocorrer o escape das partículas que se depositam nos locais indicadas. Tal fato não foi visualizado com as armas da marca Glock, que possuem um mecanismo de disparo interno, e a Smith \& Wesson, que possui um sistema de acionamento de ação dupla. Saber destas nuances/variantes de comportamento pode auxiliar um perito em uma investigação na qual, por exemplo, não sejam encontrados GSR nas mãos do suspeito. 


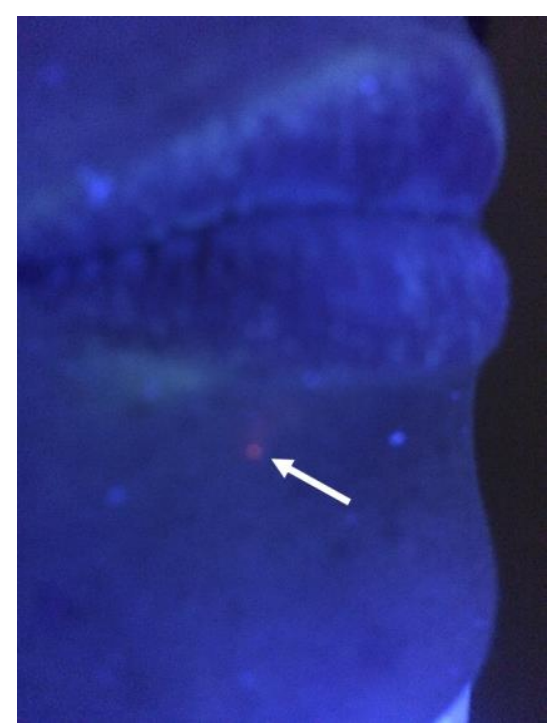

Figura 42. Imagem obtida sob radiação UV $(\lambda=254 \mathrm{~nm})$ da partícula de LGSR depositada no rosto do atirador utilizando a arma Taurus.

Comparando as duas pistolas Glock, as quais possuem um mecanismo de disparo interno, observou-se que a Glock G26 forneceu mais partículas LGSR nas mãos do atirador que a Glock G17. Isso pode ser explicado pelo diferente tamanho do cano de cada arma. A Glock G26, conhecida como "Baby Glock", tem um comprimento do cano de 87 mm, enquanto a Glock G17 tem um comprimento de $114 \mathrm{~mm}$. Portanto, como explicado para a Browning, o vórtice se forma mais longe da mão do atirador e consequentemente, menos partículas são depositadas sobre as mãos. Em ambos os casos, os LGSR foram encontrados na porta de ejecção e na abertura do gatilho, sendo que na Glock G26 uma grande quantidade de LGSR foi identificada no topo do cano (Figura 40e e 40f) e nas mãos do atirador (Figura. 41e e 41f). Assim como a Glock G26, a Smith \& Wesson 6906 apresenta um cano menor $(88,9 \mathrm{~mm})$, contudo, devido ao fato de a Glock possuir um sistema de acionamento híbrido, acredita-se que esse tenha influenciado no maior número de partículas depositas. O sistema de acionamento híbrido influência nas áreas de escape do LGSR, pois essa possui um mecanismo de acionamento interno, o que favorece o escape pelo cano.

Diante disso, foi possível concluir que todas as armas testadas apresentaram resultados positivos na identificação do LGSR, não havendo diferença significativa tanto na formação quanto na distribuição espacial do LGSR em função da pistola utilizada. Entretanto, detalhes como o tamanho do cano da arma e o mecanismo de acionamento podem influenciar na quantidade de partículas depositadas e em seu aparecimento em locais menos usais como rosto e tórax. 


\subsubsection{Estimativa da distância do disparo}

Uma segunda situação de interesse forense que foi investigada foi a estimativa da distância de disparo. Como descrito no item 1.7.2, a estimativa da distância do disparo é um fator de grande importância em rotinas forenses e se baseia na comparação do padrão de dispersão do GSR sobre o alvo. ${ }^{28}$ Contudo, tal análise requer, na maioria das vezes, utilização de reagentes (teste colorimétricos) e demandam de um expertise do perito. A introdução de marcadores luminescentes pode facilitar a rotina do perito, eliminando a necessidade da utilização de reagentes e/ou instrumentação complexas.

Para estimar a distância na qual o disparo foi efetuado, pedaços de tecido foram dispostos nas distâncias de $6 \mathrm{~cm}, 30 \mathrm{~cm}, 60 \mathrm{~cm}$ e $120 \mathrm{~cm}$ entre o atirador e o alvo. Foi observado que à medida em que a distância aumentava, os padrões de dispersão dos LGSR tornaram-se mais difusos em virtude da maior circunferência obtida na interseção do cone de dispersão dos gases e o alvo (Figuras 43, 44 e 45).

Quando o disparo foi efetuado a $6 \mathrm{~cm}$ do alvo, uma grande quantidade de partículas LGSR concentraram-se perto do orifício de entrada do projétil, enquanto que apenas algumas partículas foram depositadas perto da borda do tecido. Quando o disparo foi efetuado a $30 \mathrm{~cm}$, o tecido apresentou partículas mais dispersas, contudo, algumas partículas foram depositadas perto do local de entrada do projétil, formando uma espécie de "anel" difuso em volta do orifício. Quando o disparo foi efetuado a $60 \mathrm{~cm}$, as partículas apresentaram um padrão mais disperso, sendo encontradas em toda a extensão do tecido. Finalmente, quando o disparo foi efetuado a $120 \mathrm{~cm}$, poucas partículas foram encontradas no tecido. 


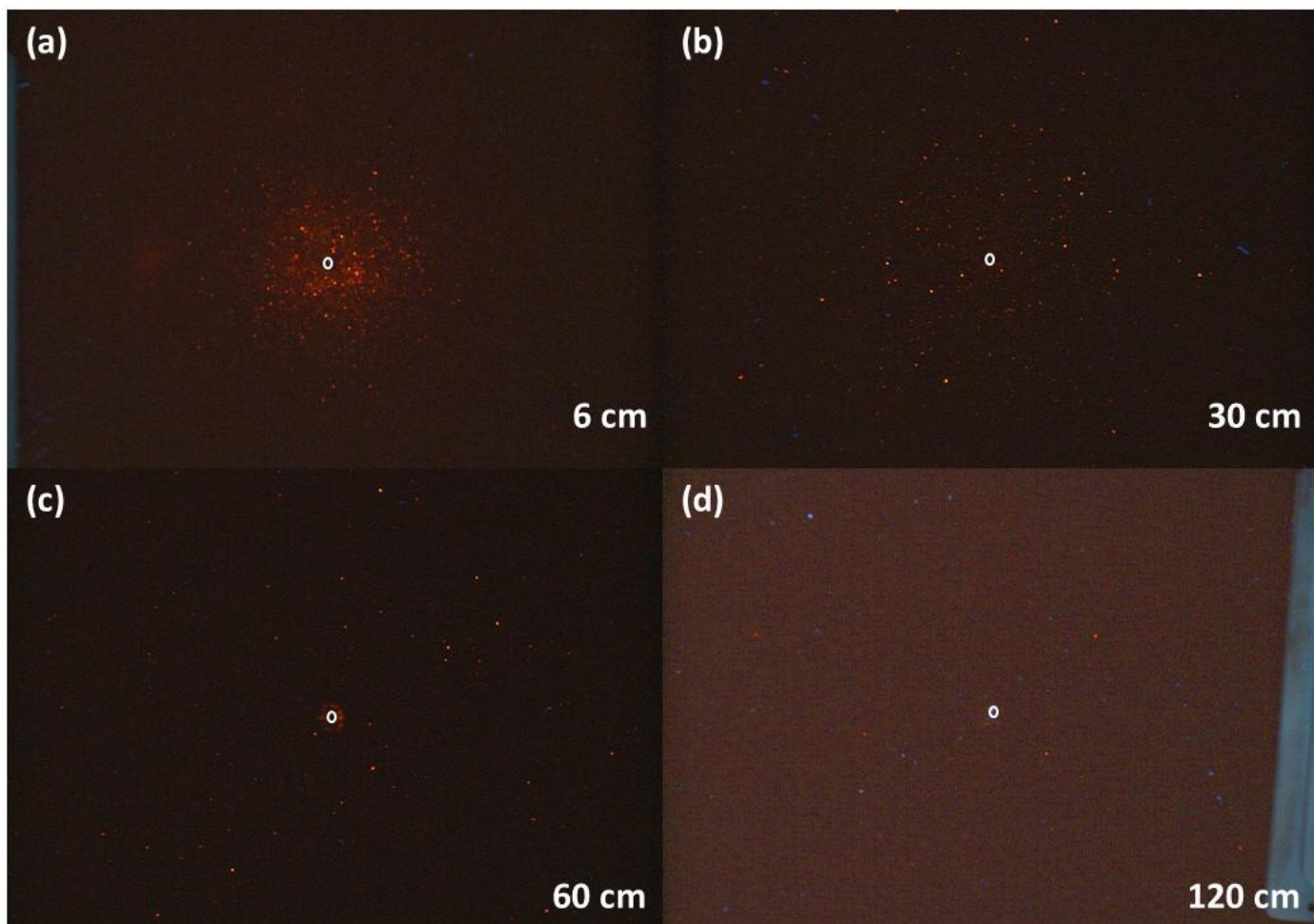

Figura 43. Imagens do alvo (tecido de algodão) obtidas no VSC sob irradiação UV ( $\lambda=$ $254 \mathrm{~nm}$ ) com o marcador EuDPA em função das distâncias do atirador: (a) de $6 \mathrm{~cm}$, (b) $30 \mathrm{~cm}$, (c) $60 \mathrm{~cm}$ e (d) $120 \mathrm{~cm}$. A localização do orifício de entrada do projétil foi marcada como um círculo branco na fotografia.

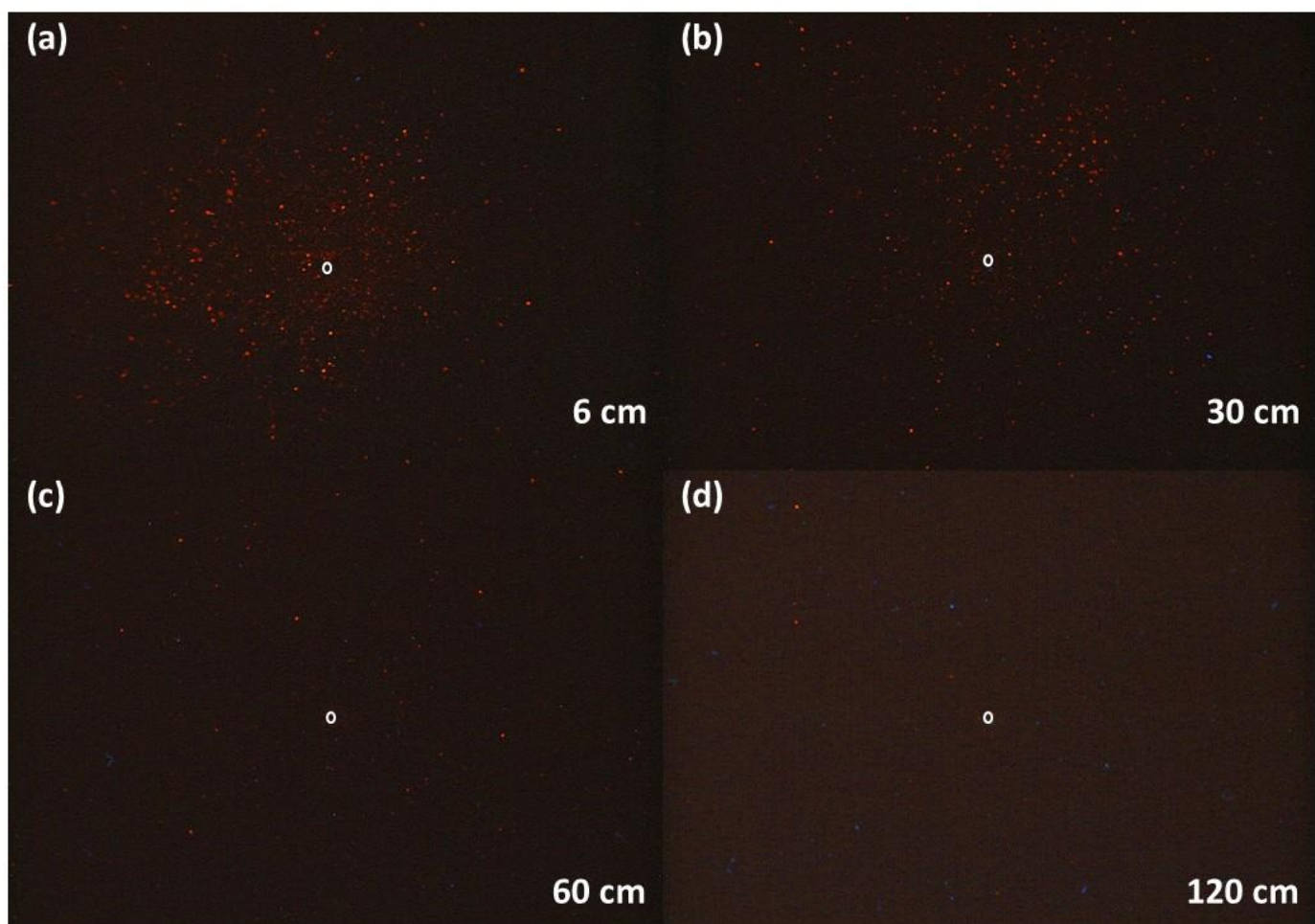

Figura 44 Imagens do alvo (tecido de algodão) obtidas no VSC sob irradiação UV ( $\lambda=$ $254 \mathrm{~nm}$ ) com o marcador EuBDC em função das distâncias do atirador: (a) de $6 \mathrm{~cm}$, (b) $30 \mathrm{~cm}$, (c) $60 \mathrm{~cm}$ e (d) $120 \mathrm{~cm}$. A localização do orifício de entrada do projétil foi marcada como um círculo branco na fotografia. 


\section{(a)}

(b)

0

o

$6 \mathrm{~cm}$

$30 \mathrm{~cm}$

(c)

(d)

0

0

$60 \mathrm{~cm}$

$120 \mathrm{~cm}$

Figura 45. Imagens do alvo (tecido de algodão) obtidas no VSC sob irradiação UV ( $\lambda=$ $254 \mathrm{~nm}$ ) com o marcador EuBTC em função das distâncias do atirador: (a) de $6 \mathrm{~cm}$, (b) $30 \mathrm{~cm}$, (c) $60 \mathrm{~cm}$ e (d) $120 \mathrm{~cm}$. A localização do orifício de entrada do projétil foi marcada como um círculo branco na fotografia.

O experimento foi realizado com os três marcadores estudados neste trabalho (Figuras 43, 44 e 45). Não foi observada nenhuma diferença no padrão de dispersão do LGSR em função do marcador utilizado. Esse resultado já era esperado, visto que o fator determinante para a formação do padrão de dispersão é o cone de gás formado no disparo e não os componentes da munição.

Estes padrões de dispersão são consistentes com os observados para GSR convencional, conforme descrito por Glattstein et al. ${ }^{28} \mathrm{~A}$ principal vantagem de utilizar LGSR é a sua fácil e rápida visualização, sendo somente necessária uma lâmpada UV para observá-lo. O contraste da imagem do LGSR com o tecido, que é muito maior que o observado com GSR convencional, permite ao analista fazer uma interpretação mais criteriosa do padrão de dispersão das partículas. Outra grande vantagem é ser uma análise não-destrutiva, não prejudicando a amostra, sem que seja necessário a utilização de métodos colorimétricos,

A etapa seguinte teve como objetivo avaliar a influência da agitação tecido. Em situações reais, muitas vezes o alvo pode ser agitado seja pelo caminhar da vítima, seja pela coleta de vestígios. Assim, buscou-se avaliar se as partículas de LGSR 
permaneceriam aderidas ao tecido mesmo após agitação e se haveria mudança no padrão de dispersão após agitação que pudesse influenciar na determinação da estimativa da distância de tiro. Após agitação, todas as amostras de tecido ainda apresentaram partículas LGSR suficientes para determinação do padrão e se relacionaram com a distância de disparo. A Figura 46 mostra as amostras de tecido antes e depois da agitação, para comparação.

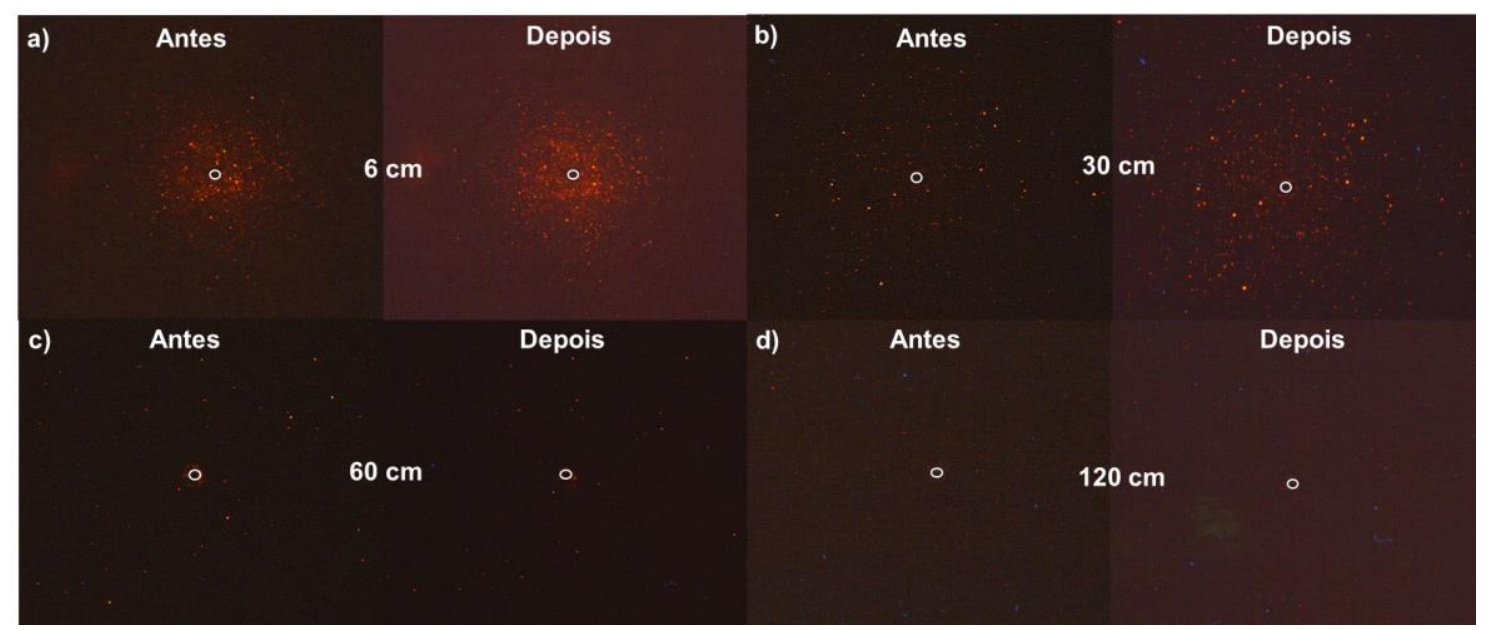

Figura 46. Imagens de $\operatorname{VSC}(\lambda=254 \mathrm{~nm})$ dos tecidos de algodão disparados antes e depois de serem chacoalhados, atirados nas distâncias: (a) $6 \mathrm{~cm}$ (b) $30 \mathrm{~cm}$ (c) $60 \mathrm{~cm}$ e (d) $120 \mathrm{~cm}$.

Outro aspecto importante na análise de crimes envolvendo armas de fogo é a identificação do local de entrada do projétil, tarefa que pode ser difícil ou mesmo impossível em alguns casos. ${ }^{8}$ A zona de enxugo pode ajudar na determinação do local do orifício do projétil. Segundo Tocchetto, ${ }^{188}$ quando o projétil passa através da pele, esta, por ser elástica, deforma-se e envolve o projétil, formando uma espécie de luva que se fricciona contra o projétil, limpando-o e retirando de sua superfície as impurezas. Formase, então, a zona ou orla de enxugo que se localiza ao redor do orifício de entrada. Além disso, a zona de enxugo pode auxiliar na determinação do ângulo e da trajetória do projétil. ${ }^{189,190}$ Testes colorimétricos são frequentemente usados para visualizar a zona de enxugo, por serem mais rápidos e baratos, contudo, tais testes apresentam um alto número de resultados incoerentes, além de danificarem a amostra. ${ }^{31}$

Utilizando a munição marcada, a zona de enxugo pôde ser claramente visualizada usando apenas a irradiação com UV (com exceção do tecido da Figura 48d, no qual foi necessário utilizar um aumento maior e alterar o contraste da imagem para visualizar). Assim, o reconhecimento do orifício do projétil torna-se mais fácil e mais confiável em 
comparação com testes colorimétricos. A Figura 47 mostra a zona de enxugo obtido em diferentes distâncias.

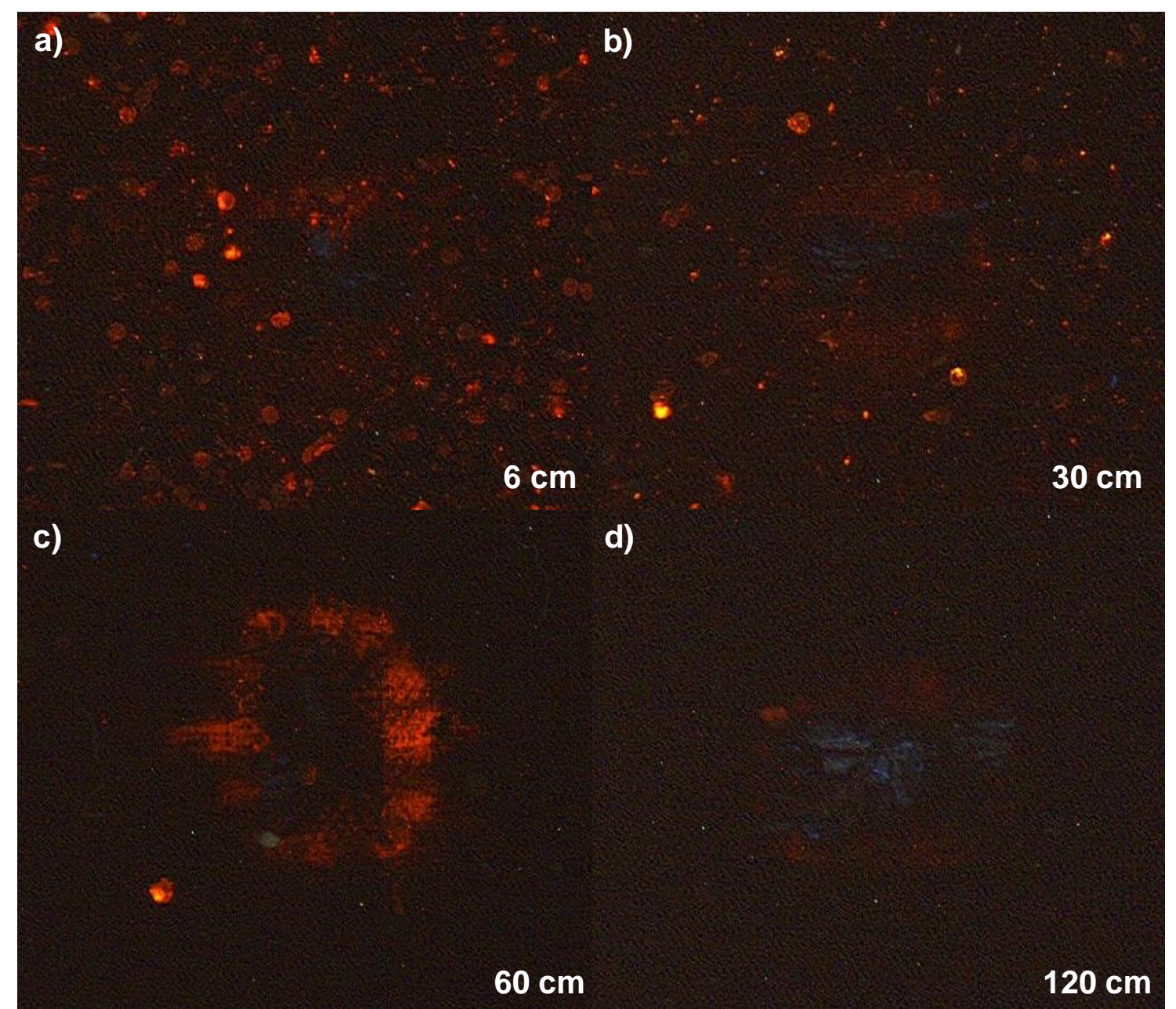

Figura 47. Imagens da zona de enxugo das amostras de tecido, obtidas por de VSC ( $\lambda=254 \mathrm{~nm}$ ), quando o disparo é realizado nas distâncias: (a) $6 \mathrm{~cm}$, (b) $30 \mathrm{~cm}$, (c) $60 \mathrm{~cm}$ e (d) $120 \mathrm{~cm}$ do alvo, utilizando o marcador EuDPA.

Além disso, avaliou-se o efeito da presença de sangue na luminescência do LGSR e na sua distribuição. Para tal, o tecido-alvo foi sujo com sangue de rato, Figura 48. 
(d)

Figura 48. Imagens do alvo (tecido de algodão com sangue) obtidos no VSC sob irradiação UV $(\lambda=254 \mathrm{~nm})$ com o marcador EuBDC em função das distâncias do atirador: (a) de $6 \mathrm{~cm}$, (b) $30 \mathrm{~cm}$, (c) $60 \mathrm{~cm}$ e (d) $120 \mathrm{~cm}$. A localização do orifício de entrada do projétil foi marcada como um círculo branco na fotografia.

Ao analisar as imagens obtidas foi possível verificar que os padrões de dispersão do LGSR no tecido ensanguentado não apresentaram nenhuma alteração significativa, quando comparados com os padrões obtidos nos tecidos sem sangue. Notou-se que uma maior quantidade de LGSR foi depositado na parte do tecido que estava com sangue, que ao secar, aderiu-se ao tecido. Devido a esse fato, a coleta do LGSR em stubs foi mais trabalhosa, contudo, ainda foi possível realizá-la, conforme observado nas Figuras 49 e 50. 


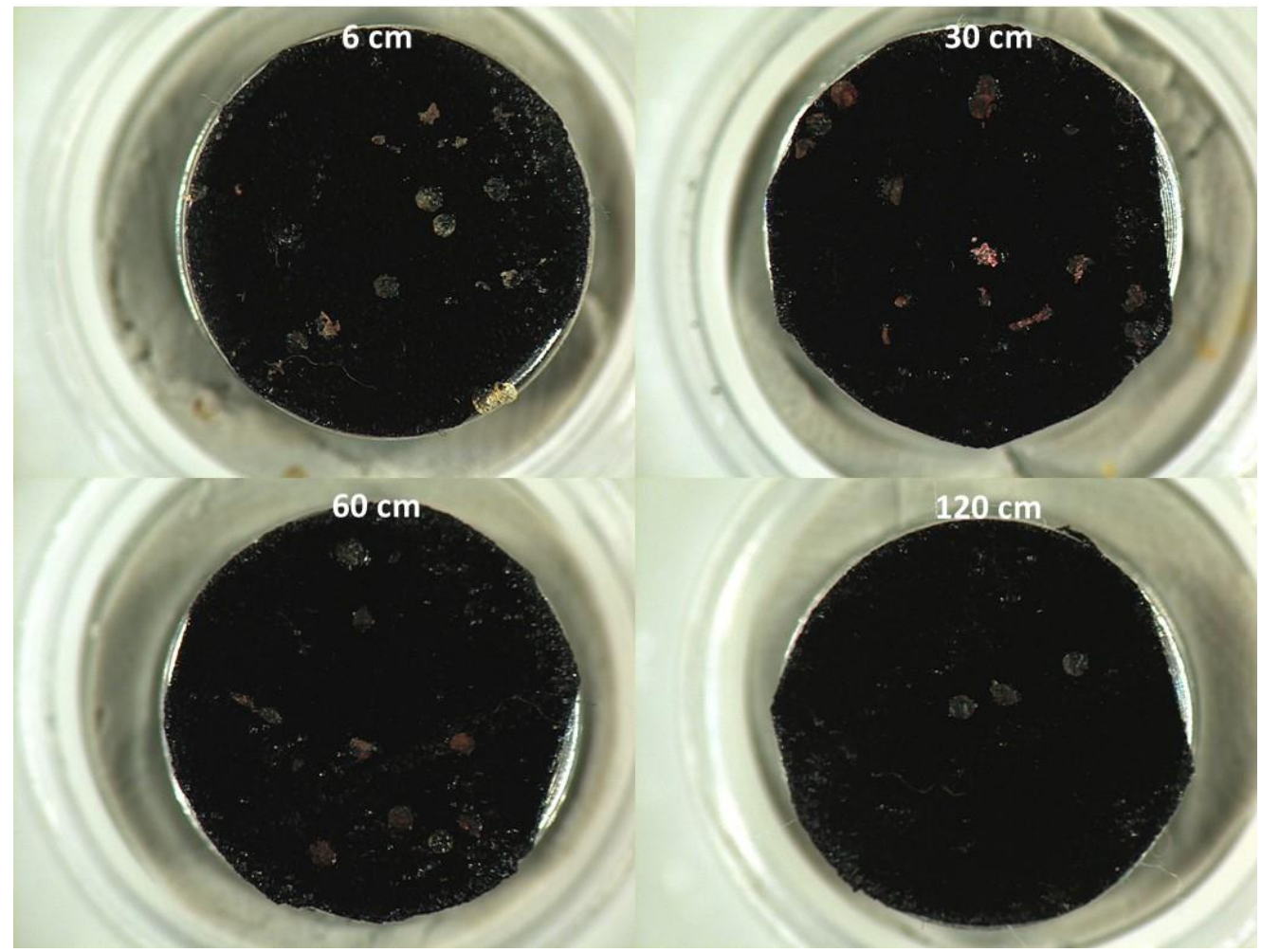

Figura 49. Imagens de VSC com luz branca das partículas luminescente coletadas dos tecidos ensanguentados disparados nas distâncias de 6, 30, 60 e $120 \mathrm{~cm}$ do alvo.

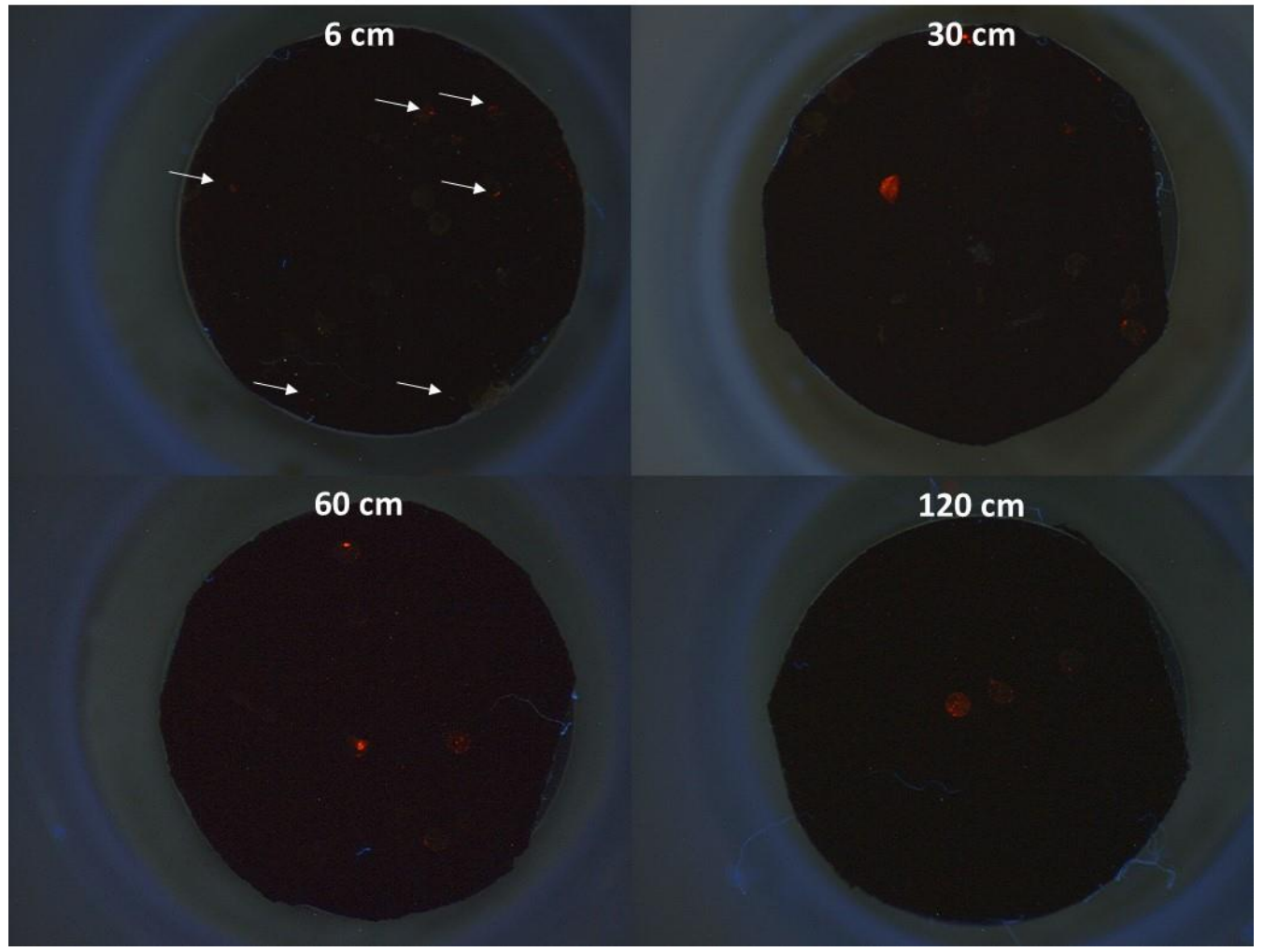

Figura 50. Imagens de $\operatorname{VSC}(\lambda=254 \mathrm{~nm})$ das partículas luminescente coletadas dos tecidos ensanguentados disparados nas distâncias de 6, 30, 60 e $120 \mathrm{~cm}$ do alvo. 
Devido a essa maior saturação da fita de carbono dos stubs, a análise de MEV/EDS demandou um tempo maior, fato já esperado para as análises desse tipo de material. Entretanto, em todos os stubs analisados, foi possível encontrar partículas contendo o metal európio, Figuras 51 e 52.

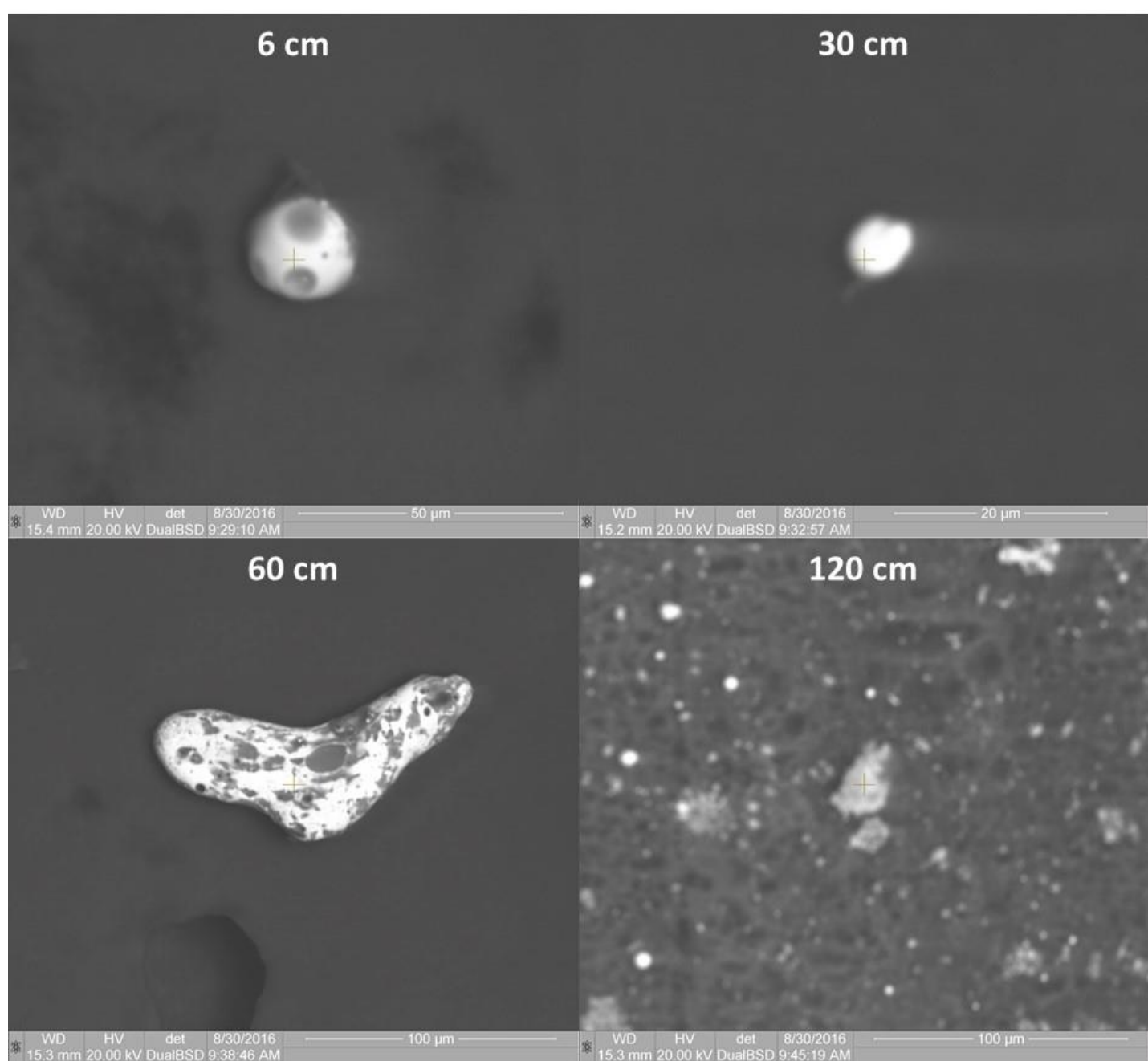

Figura 51. Micrografias dos resíduos depositados nos tecidos ensanguentados disparados nas distâncias de 6, 30, 60 e $120 \mathrm{~cm}$ do alvo. 

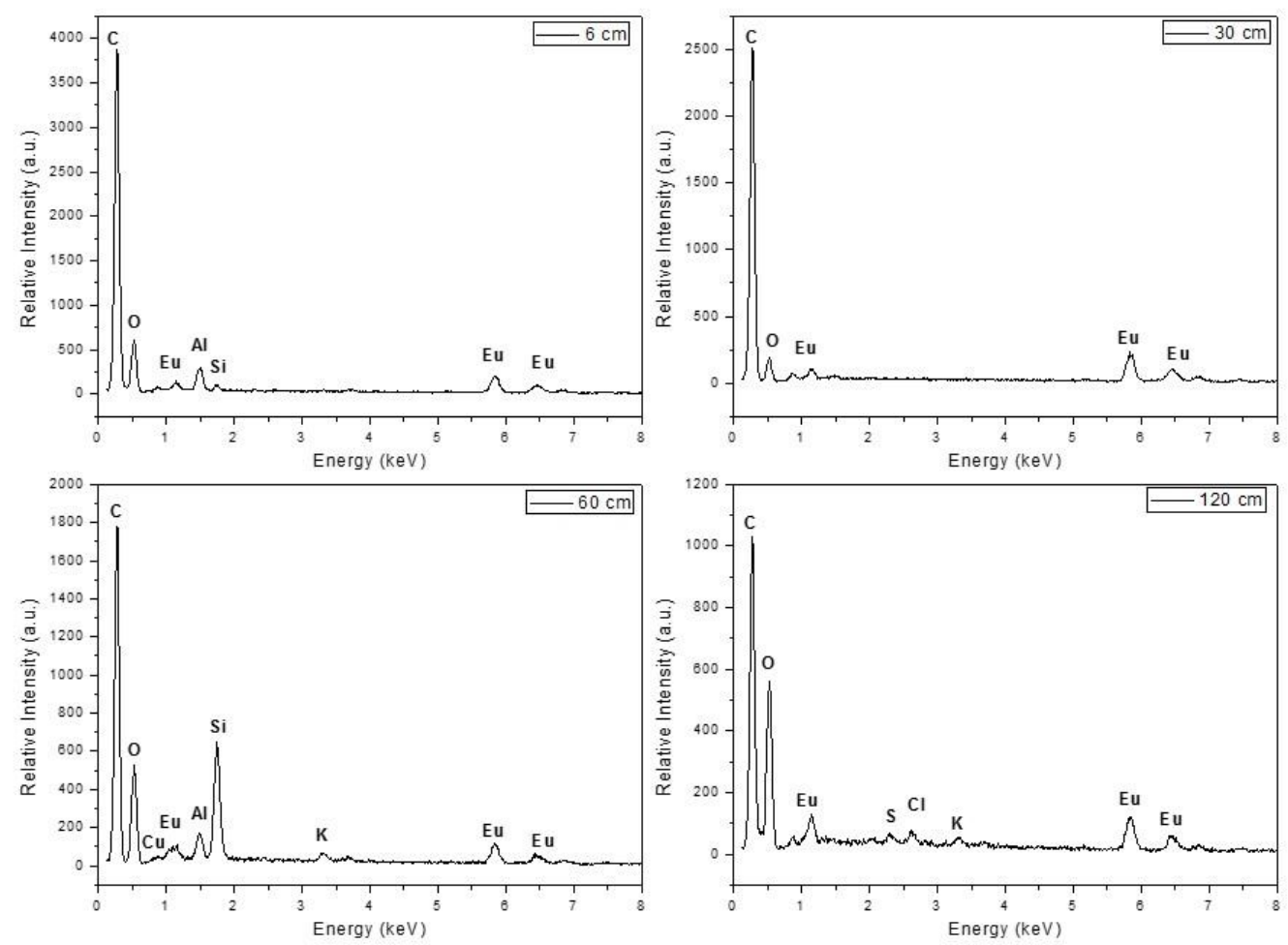

Figura 52. Espectros de dispersão de energia resíduos depositados nos tecidos ensanguentados disparados nas distâncias de 6, 30,60 e $120 \mathrm{~cm}$ do alvo.

Com isso, pode-se concluir que a presença de sangue nos tecidos não alterou a luminescência do marcador adicionado à pólvora da munição NTA e nem alterou o padrão de dispersão dos LGSR depositados no tecido, podendo ser utilizado para determinar a distância em que o disparo foi efetuado.

Por fim, uma série de 3 testes cegos foram realizados, com intuito de verificar a eficiência do marcador em uma situação que simulou uma situação real de estimativa da distância de disparo. Para tal, foi dado a um analista 3 tecidos contendo LGSR para que, usando como comparação os padrões de dispersão mostrados nas Figuras 43 a 45, ele estimasse a distância de disparo. Após a análise dos tecidos, o analista foi capaz de rapidamente determinar as distâncias do disparo em todos os 3 ensaios.

A Figura 53 mostra o padrão de dispersão do LGSR observado no teste cego (imagem da esquerda) e o padrão ao qual ela foi correlacionada pelo analista (imagem da direita). Na Figura 53 também é indicada a distância estimada pelo analista em função da comparação entre as imagens do teste cego e dos padrões. 


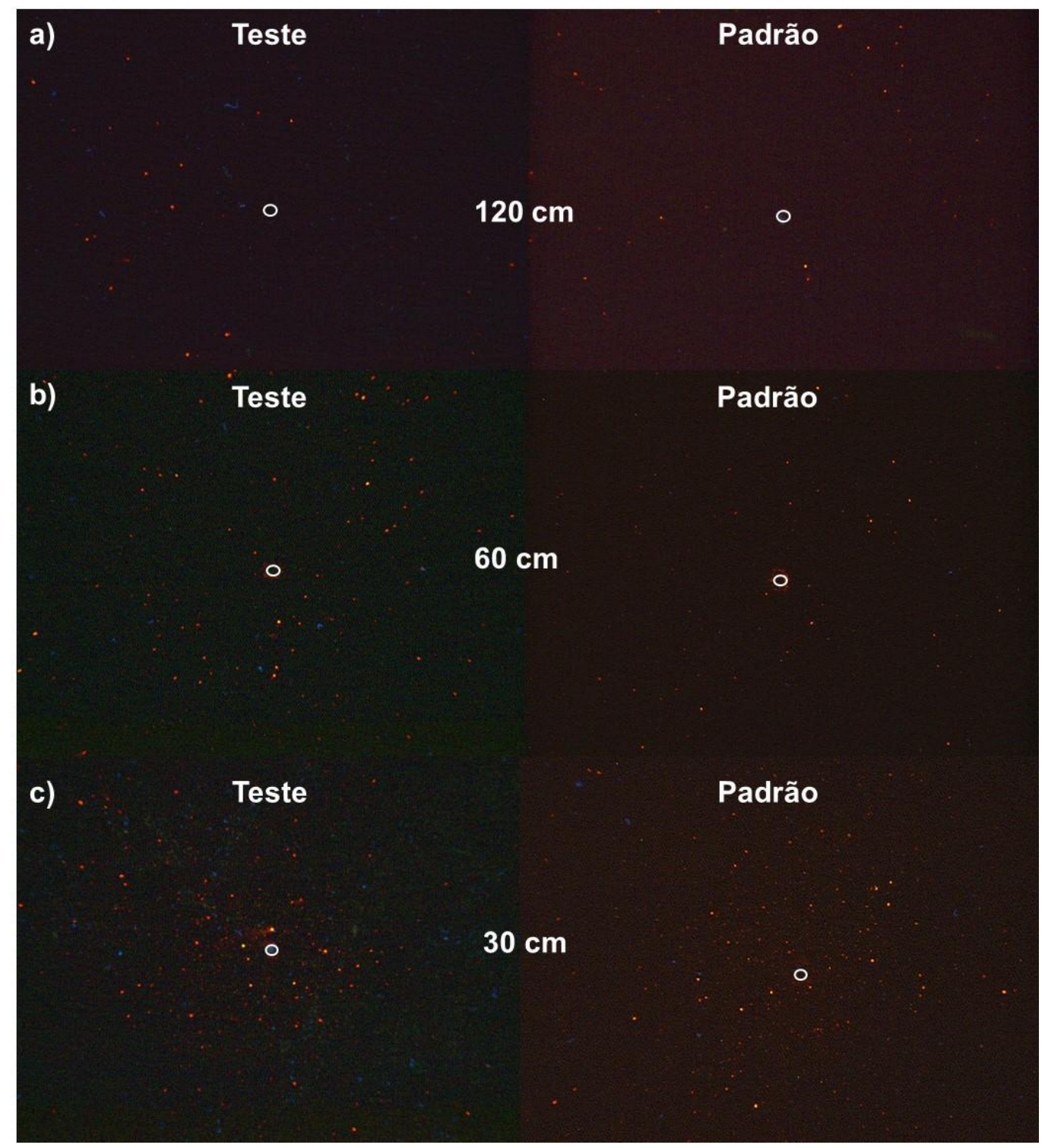

Figura 53. Imagens do alvo (tecido de algodão) disparado a uma distância desconhecida e uma distância conhecida do (a) primeiro, (b), segundo e (c) terceiro teste cego realizado, obtidos no VSC sob irradiação UV $(\lambda=254 \mathrm{~nm})$.

\subsubsection{Determinação da posição do atirador/teste cego}

Uma situação de grande interesse para a perícia forense é a determinação da posição do atirador no momento do disparo. Atualmente, determinar a posição do atirador é uma tarefa muito difícil. Já é sabido que o LGSR se deposita no chão próximo ao atirador e na trajetória até o alvo. ${ }^{58,61}$ Neste trabalho foi feito um estudo sistemático para avaliar se é possível determinar a posição do atirador em função da dispersão do LGSR no chão. Para tal foi realizado um conjunto de 8 disparos, nos quais o analista desconhecia a posição do atirador (teste cego - conforme descrito no item 1.7.3). O teste cego é uma 
estratégia comumente usada nas ciências forenses e tem como objetivo avaliar a capacidade de recuperação de uma informação independentemente da experiência do analista.

Analisando a cena do crime criada no teste cego, o analista buscou identificar corretamente a posição do atirador baseado apenas na distribuição de LGSR no solo (lembrando que os atiradores recolheram os cartuchos após cada disparo). Em todos os locais de disparos foram encontradas muitas partículas luminescentes. Além disso, foram encontradas partículas em direção ao alvo, indicando a trajetória do projétil. A Figura 54 mostra um exemplo das partículas luminescentes observadas pelo analista no piso.

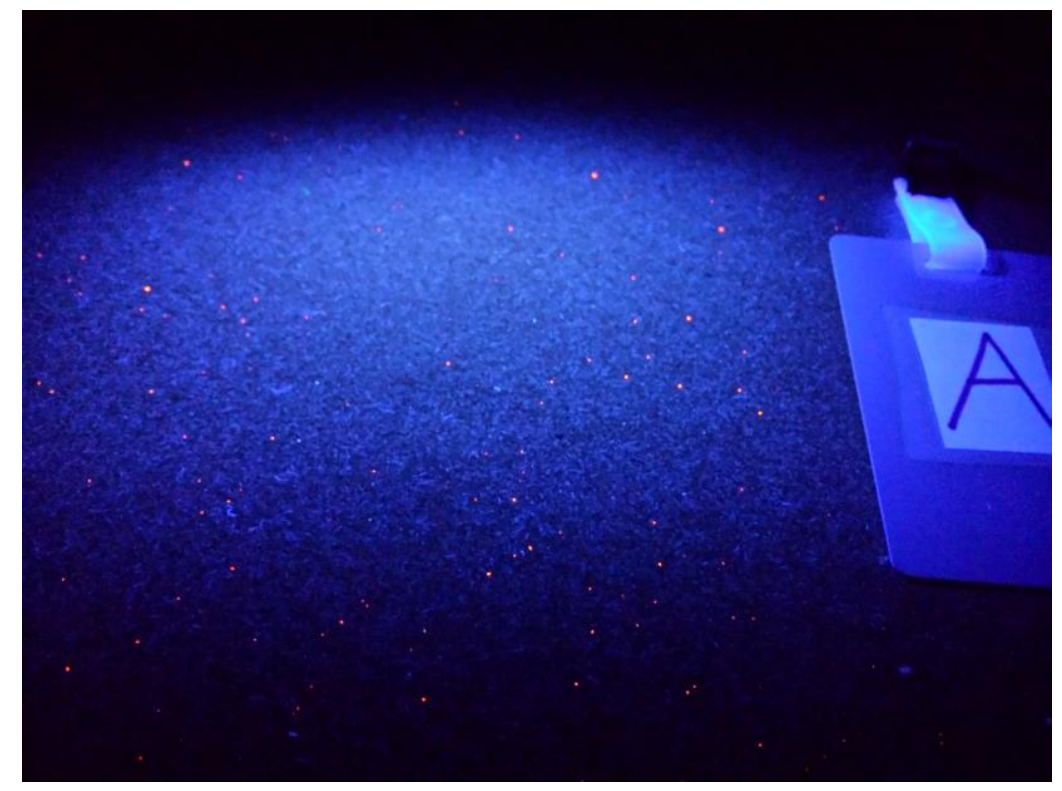

Figura 54. Imagem do LGSR encontrado no local do disparo na cena do crime simulada (posição 3B) visualizados com uma lâmpada UV portátil $(\lambda=254 \mathrm{~nm})$.

Após a finalização dos testes cegos, os envelopes contendo os formulários preenchidos pelo atirador foram abertos e confrontados com as estimativas do analista, conforme demonstrado nas figuras H-W do apêndice. A Tabela 9 mostra as posições escolhidas pelos atiradores e a posição estimada pelo analista. A posição do atirador foi identificada corretamente em todos os casos, sendo que a probabilidade de acertar a posição em um universo de 12 possibilidades seria de 0,083 . E acertar essa posição 8 vezes consecutivas seria de $2,36 \times 10^{-9}$. Isto implica em uma ferramenta muito forte que pode ser utilizada na análise da cena do crime, mesmo para tiros distantes. Com as ferramentas disponíveis hoje (munição não marcada) a identificação da posição do atirador, bem como da trajetória do projetil seria praticamente impossível considerando somente o resíduo de tiro encontrado na cena do crime. 
Tabela 9. Posições indicadas pelos atiradores e identificadas pelos peritos.

\begin{tabular}{|c|c|c|} 
Atirador & $\begin{array}{c}\text { Posição do } \\
\text { Atirador }\end{array}$ & $\begin{array}{c}\text { Posição indicada } \\
\text { pelo Perito }\end{array}$ \\
\hline$\# 1$ & $3 \mathrm{~B}$ & $3 \mathrm{~B}$ \\
\hline$\# 2$ & $1 \mathrm{C}$ & $1 \mathrm{C}$ \\
\hline$\# 3$ & $2 \mathrm{~B}$ & $2 \mathrm{~B}$ \\
\hline$\# 4$ & $1 \mathrm{~A}$ & $1 \mathrm{~A}$ \\
\hline$\# 5$ & $2 \mathrm{D}$ & $2 \mathrm{D}$ \\
\hline$\# 6$ & $1 \mathrm{~A}$ & $1 \mathrm{~A}$ \\
\hline$\# 7$ & $2 \mathrm{C}$ & $2 \mathrm{C}$ \\
\hline$\# 8$ & $1 \mathrm{C}$ & $1 \mathrm{C}$ \\
\hline
\end{tabular}

\subsubsection{Transferência secundária e terciária}

Finalmente, no último teste realizado, foi feita a avaliação da possibilidade das partículas de LGSR serem transferidas do atirador para outras pessoas não envolvidas no evento do disparo.

Em um estudo anterior, foi demonstrada a transferência de partículas LGSR aos objetos manipulados pelo atirador, como um estilete, um relógio, um distintivo e uma capa de livro, os quais podem ser usados para correlacionar um suspeito a um evento no caso de não serem encontradas partículas de LGSR nas mãos do suspeito. ${ }^{61}$ Com intuito de verificar a contaminação de indivíduos, foi verificada a quantidade de partículas transferidas em uma cadeia de apertos de mão (atirador $(\# 1) \rightarrow$ indivíduo \#2 $\rightarrow$ indivíduo \#3). Neste caso, o objetivo foi estudar os casos de falso positivo para LGSR nas mãos.

Constatou-se que as partículas luminescentes foram transferidas para indivíduos \#2 e \# 3, depois de cada aperto de mão. Entretanto, nas mãos do atirador foi possível visualizar as partículas de LGSR sob luz UV (seja com lâmpada portátil, seja no VSC). No caso dos indivíduos \#2 e \#3 não foi possível visualizar o LGSR diretamente sobre as mãos. Contudo, após a coleta com stubs, de acordo com o determinado pela $\operatorname{ASTM}^{35}$ e pela $\mathrm{PF},{ }^{151}$ a visualização no VSC utilizando luz UV foi possível (Figura 55), embora em quantidade muito menor. 


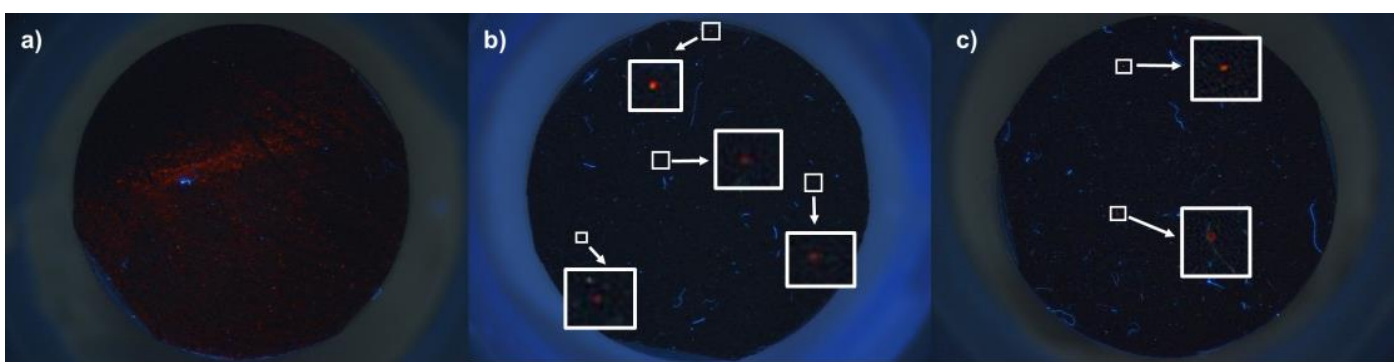

Figura 55. Imagens de VSC (254 nm) das partículas coletadas do (a) atirador (1), (b) indivíduo \#2 e (c) indivíduo \#3.

Após a coleta das partículas, cada stub foi analisado por MEV/EDS utilizando o software específico para análise de GSR, INCAGSR®. Usualmente o INCAGRS® identifica as partículas contendo $\mathrm{Sb}, \mathrm{Ba}$ e $\mathrm{Pb}$. Todavia, para que fosse feita a identificação do LGSR, uma modificação no programa foi realizada por meio da introdução de uma nova rotina de análise, em que as partículas contendo elementos do grupo das Terras Raras seriam marcadas e contabilizadas. A Figura 56 mostra a interface do programa, onde pode ser visualizada a partícula encontrada que contém o elemento alvo, o seu EDS, seu tamanho e demais informações.

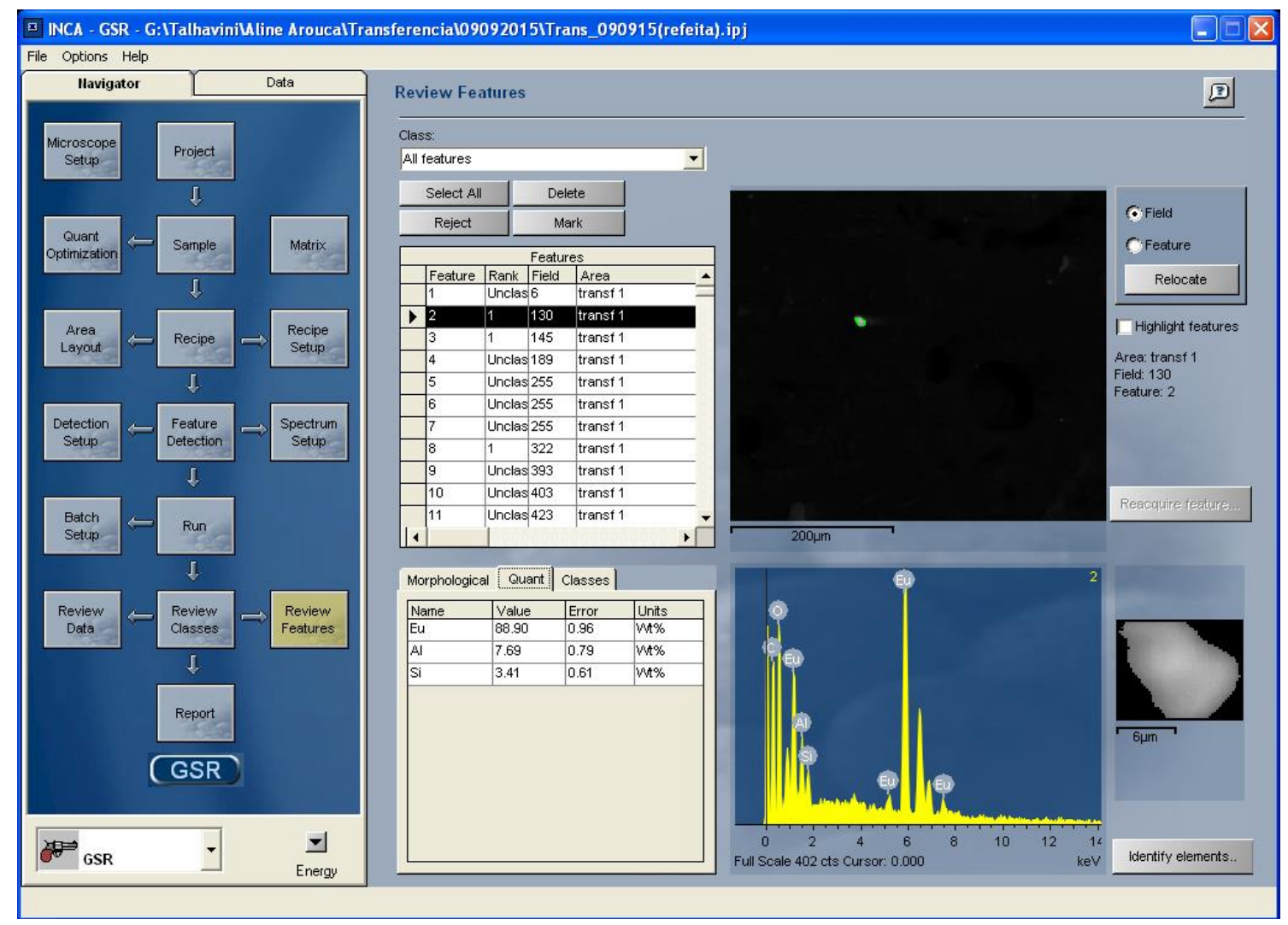

Figura 56. Interface do programa INCAGSR®. 
Diante disso, foi possível estimar o número de partículas luminescentes contidas em cada stub. O experimento foi realizado em triplicata e os resultados das análises quantitativas está descrito na Tabela 10.

Tabela 10. Número de partículas LGSR encontrados nas mãos após apertos de mão.

\begin{tabular}{c|cccc} 
Teste & $\begin{array}{c}\text { Partículas de } \\
\text { LGSR coletadas } \\
\text { do atirador }\end{array}$ & $\begin{array}{c}\text { Partículas de } \\
\text { LGSR coletadas } \\
\text { do indivíduo \#2 }\end{array}$ & $\begin{array}{c}\text { Partículas de } \\
\text { LGSR coletadas } \\
\text { do indivíduo \#3 }\end{array}$ & $\begin{array}{c}\text { Soma das } \\
\text { Partículas } \\
\text { Coletadas }\end{array}$ \\
\hline $\boldsymbol{1}$ & 175 & 38 & 34 & 247 \\
$\mathbf{2}$ & 198 & 19 & 4 & 221 \\
$\mathbf{3}$ & 637 & 72 & 2 & 711 \\
Média & 337 & 43 & 13 & 393 \\
Desvio & 260 & 27 & 18 & 276 \\
Padrão & & & &
\end{tabular}

No primeiro teste, foram depositadas 247 partículas no atirador, sendo que 72 foram transferidas para o indivíduo \#2 após o primeiro aperto de mão. Das 72 partículas transferidas para o indivíduo \#2, 34 foram para o indivíduo \#3 após o segundo aperto de mão (restando 38 partículas na mão de \#2). Dessa forma, observou-se uma eficiência de $29,2 \%$ para o primeiro aperto e de 47,2\% para o segundo aperto de mão. No segundo teste, foram depositadas 221 partículas na mão do atirador. Destas, 23 partículas foram transferidas para a mão do indivíduo \#2 após o primeiro aperto de mão. Das 23 partículas transferidas para \#2, 4 partículas foram transferidas para o no indivíduo \#3 com o segundo aperto de mão. Neste caso, observou-se uma eficiência da transferência primaria e secundária de $10,4 \%$ e $17,4 \%$ respectivamente. No último teste, observou-se um número muito maior de partículas depositadas sobre as mãos do atirador (711 partículas), das quais 72 foram transferidas para o \#2, resultando em uma eficiência de transferência secundária igual à do segundo teste (10,4\%). Após o segundo aperto de mão, 2 partículas foram transferidas do indivíduo \#2 para o indivíduo \#3, com uma eficiência de 2,70\%. A Tabela 11 apresenta uma estimativa de eficiência de transferência de partículas de LGSR em apertos de mão. 
Tabela 11. Eficiência da transferência secundária e terciária.

\begin{tabular}{|c|cc}
\multicolumn{1}{|c}{ Teste } & $\begin{array}{c}\text { Eficiência da } \\
\text { transferência secundária } \\
(\boldsymbol{\%})\end{array}$ & $\begin{array}{c}\text { Eficiência da } \\
\text { transferência terciária } \\
(\boldsymbol{\%})\end{array}$ \\
\hline $\boldsymbol{1}$ & 29,2 & 47,2 \\
$\mathbf{2}$ & 10,4 & 17,4 \\
$\mathbf{3}$ & 10,4 & 2,7 \\
Média & 17 & 22 \\
Desvio Padrão & 11 & 23 \\
\hline
\end{tabular}

Como o GSR convencional, ${ }^{149}$ o LGSR pode ser transferido por uma cadeia de apertos de mão sucessivos, embora se tenha uma incerteza muito grande associada tanto ao número de partículas depositadas quanto ao número de partículas transferidas. Uma grande quantidade de partículas encontradas no suspeito pode ser uma indicação de que esse efetuou o tiro, enquanto a baixa quantidade de partículas pode sugerir que o suspeito poderia estar próximo do atirador no momento do disparo ou ter sido contaminado por uma transferência.

Por outro lado, considerando os altos desvios padrão observados, um estudo mais detalhado é necessário para se obter um critério o que pode ser considerado 'um número elevado de partículas'. Outro resultado que chama atenção e que merece ser estudado com mais detalhes é que nas transferências do LGSR, este não foi observado diretamente nas mãos dos indivíduos (sendo observados apenas após uma "concentração" pelo procedimento de coleta). Um estudo com um número maior de amostras se faz necessário para verificar se este padrão se reproduz. Apesar disto, pode-se concluir que o LGSR é suscetível à transferência pelo aperto de mãos e que a quantidade de partículas encontradas na mão do indivíduo pode ser um indício de ele ter efetuado o disparo ou de contaminação/transferência. Em ambos os casos, evidências adicionais devem fundamentar a conclusão, pois falso positivos são possíveis. 


\section{CONCLUSÃO E}

\section{PERSPECTIVAS}


Neste trabalho foram sintetizados e caracterizados três marcadores luminescentes de munições ambientais e alguns aspectos relacionados à sua toxicidade química foram investigados. Os subprodutos formados com o disparo de uma munição marcada foram identificados com a técnica de SPME e um CG/EM. Além dos dois compostos alvos, piridina e benzeno, terem sido encontrados, outros compostos tóxicos foram detectados. Contudo, apesar da introdução do marcador na munição NTA gerar compostos tóxicos, somente uma parte do marcador sofre degradação, sendo que uma porção da rede da MOF permanece intacta após a ignição da pólvora. Além disso, apesar da munição NTA ser isenta de metais pesados e ser considera não-tóxica, ela possui compostos orgânicos que podem ser considerados tóxicos. Ainda é necessário realizar novos estudos acerca da degradação do marcador, utilizando outras rotinas cromatografias e outras fibras de SPME, permitindo a identificação de novos compostos. Outra perspectiva deste trabalho é o estudo dos LGSR também por Espectroscopia Raman, assim como a introdução de um padrão interno, possibilitando determinar a quantidade dos compostos formados com o disparo.

Outro aspecto relacionado à toxicidade química dos marcadores foi a análise das partículas formadas após o disparo de uma munição NTA marcada. Partículas muito pequenas $\left(<\mathrm{PM}_{2,5}\right)$ podem representar um problema para a saúde, pois essas, pelo seu reduzido tamanho, podem penetrar na corrente sanguínea. Ao examinar os histogramas advindos de munição NTA e os provenientes da munição NTA marcada, foi possível determinar que a adição do marcador luminescente não gera diferenças relevantes no tamanho das partículas do resíduo de tiro. É importante salientar que este é o primeiro estudo sobre o tamanho das partículas relacionados à toxicidade da munição e que novos testes devem ser realizados. Uma das perspectivas deste estudo é a utilização de amostradores da qualidade do ar, possibilitando a determinação da massa do material particulado $\left(\mu \mathrm{g} \cdot \mathrm{m}^{-3}\right)$.

Além dos estudos acerca da toxicidade, os marcadores sintetizados foram aplicados em situações de interesse forense com o intuito de investigar sua aplicação potencial em rotinas forenses. Quatro aspectos de interesse forense na investigação de eventos envolvendo armas de fogo foram analisados.

Primeiramente foi avaliada a influência da arma na produção e dispersão do LGSR. Seis tipos de pistolas $9 \mathrm{~mm}$ foram utilizadas neste experimento: Glock G17, Glock G26, Smith \& Wesson 6906, Browning Hi-Power, Jericho 941F e Taurus PT 908. Constatamos que a formação do resíduo luminescente não é alterada pelo uso de armas 
com diferentes tipos de mecanismo de disparo, tamanhos de cano, tipo de ação ou fabricante. Contudo, observou-se que há uma influência do tamanho do cano na quantidade de partículas de LGSR encontradas na mão do atirador e na deposição do LGSR em outras localidades, como rosto e tórax, fato relacionado ao sistema de acionamento da arma. Apesar destas diferenças, não foi possível distinguir qual arma foi realizada para efetuar o disparo com base na análise do LGSR. As partículas de LGSR coletadas foram identificadas como partículas sem morfologia específica e contendo o elemento európio, indicando que a formação da partícula não foi alterada com o uso de diferentes armas.

Foram realizados testes para estimar a distância em que o tiro foi deflagrado. Dentre as 4 distâncias utilizadas $(6,30,60$ e $120 \mathrm{~cm})$, foi possível observar diferentes padrões de dispersão dos LGSR sobre o alvo, o que permitiu inferir a respeito da distância entre o alvo e o atirador (baseado na comparação com padrões). A identificação dos padrões foi feita de forma rápida e sem utilização de reagentes (testes colorimétricos). A realização de testes cegos para a estimativa da distância confirmou a potencialidade do uso dos padrões de dispersão do GSR para este fim. Além disso, observamos que mesmo após uma agitação vigorosa do tecido, as partículas se mantiveram aderidas ao tecido e que o padrão de dispersão não foi alterado, mantendo possível a estimativa da distância. Além disso, verificou-se que a presença de sangue nos tecidos não interfere na luminescência dos marcadores e não modifica, de forma significativa, o padrão de dispersão formado a diferentes distâncias.

Por fim, testes cegos foram realizados com intuito de simular uma análise real realizado pelos peritos. Após a comparação dos tecidos do teste cego com o padrão obtido à uma distância conhecida, foi possível determinar qual distância o tiro foi deflagrado dos três testes cegos, demonstrando que o marcador pode ser utilizado na determinação da distância do disparo de forma fácil e rápida. Também foi avaliada a possibilidade de se determinar a posição do atirador numa cena de crime, por meio da análise da dispersão do GSR no solo. Para tal foi realizada uma série de 8 testes cegos e em todos eles a posição do atirador, bem como a direção do projetil, foi determinada de maneira rápida e inequívoca. Tal fato seria quase impossível de ser realizado sem o uso do marcador luminescente.

No último teste realizado, avaliou-se a possibilidade de falsos positivos para LGSR devido à transferência em uma sequência de apertos de mão. Verificou-se que o LGSR pode sofrer transferência secundária e terciária e que, portanto, a análise está 
sujeita a resultados falsos positivos. Este resultado evidencia que é necessário bastante cuidado na forma de interpretar a evidência "presença de resíduo de tiro no suspeito" no caso de uma investigação criminal.

Além disso, pôde-se constatar ao longo do trabalho que em todas as avalições realizadas, os três marcadores apresentaram comportamento semelhantes, aumentando a gama de marcadores que podem ser utilizados em rotinas forenses, possibilitando uma codificação no futuro.

Algumas outras perspectivas para este trabalho incluem a utilização de Espectroscopia Raman para identificar o LGSR em tecidos ensanguentados e a realização de novos estudos sobre a toxicidade dos marcadores sintetizados, utilizando outros métodos de CG/EM, assim como a análise dos espectros de massas obtidos no experimento descrito neste estudo. Além disso, tem como perspectiva a aplicação do método de CG/EM desenvolvido na determinação de OGSR provenientes do disparo de uma munição NTA. 


\section{REFERÊNCIAS}


(1) Waiselfisz, J. J. Mapa Da Violência 2015: Mortes Matadas Por Armas de Fogo. Mapa da Violência 2015 Mortes Matadas por Armas Fogo 2015, 112.

(2) ONU: Países da América Latina lideram índice de homicídios no mundo http://www.bbc.com/portuguese/noticias/2014/04/140410_homicidio_onu_mm, acessado em 30 de abril de 2016.

(3) Dreyfus, P. N. Small Arms Holdings in Brazil : Toward a Comprehensive Mapping of Guns and Their Owners; Rio de Janeiro: 7 Letras/Viva Rio/ISER, 2005.

(4) Dreyfus, P.; Lessing, B.; Nascimento, M. de S.; Purcena, J. C. Small Arms in Brazil : Production, Trade, and Holdings; Small Arms Survey/VIVA RIO/ISER: Geneva, 2010.

(5) Romolo, F. S.; Margot, P. Identication of Gunshot Residue : A Critical Review. Forensic Sci. Int. 2001, 119, 195-211.

(6) Dalby, O.; Butler, D.; Birkett, J. W. Analysis of Gunshot Residue and Associated Materials - A Review. J. Forensic Sci. 2010, 55 (4), 924-943.

(7) Chang, K. H.; Jayaprakash, P. T.; Yew, C. H.; Abdullah, A. F. L. Gunshot Residue Analysis and Its Evidential Values: A Review. Aust. J. Forensic Sci. 2013, 45 (1), $3-23$.

(8) Zeichner, A. Recent Developments in Methods of Chemical Analysis in Investigations of Firearm-Related Events. Anal. Bioanal. Chem. 2003, 376 (8), $1178-1191$.

(9) Rendle, D. F. Advances in Chemistry Applied to Forensic Science. Chem. Soc. Rev. 2005, 34 (12), 1021-1030.

(10) Basu, S. Formation of Gunshot Residues. J. Forensic Sci. 1982, 27 (1), 72-91.

(11) Taudte, R. V.; Beavis, A.; Blanes, L.; Cole, N.; Doble, P.; Roux, C. Detection of Gunshot Residues Using Mass Spectrometry. Biomed. Res. Int. 2014, 2014, 1-16.

(12) National Handgun Safety Course. Handgun informations.

(13) Wallace, J. S. Chemical Analysis of Firearms, Ammunition and Gunshot Residue; CRC Press: Boca Raton, 2008.

(14) Paubel, E. Casus Belli: História Militar e assuntos relacionados http://epaubel.blogspot.com.br/2012/06/arm-armas-de-infantaria-municao.html, acessado em 23 de fevereio de 2016.

(15) Companhia Brasileira de Cartucho (CBC). Munição NTA.

(16) Kirk-Othmer. X Kirk-Othmer Encyclopedia of Chemical Technology. Encyclopedia of Chemical Technology V.8; Wiley-Interscience: New York, 2004; 
p 659.

(17) Guanaes, D.; Bittencourt, E. Propelentes Sólidos: Uma História Ligada À Evolução Dos Polímeros. Rev. Mil. Ciência e Tecnol. 2008, 71-80.

(18) Sanghavi, R. R.; Pillai, A. G. S.; Velapure, S. P.; Singh, A. Studies on Different Types of Nitrocellulose in Triple Base Gun Propellant Formulations. J. Energ. Mater. 2003, 21 (2), 87-95.

(19) Druet, L.; Asselin, M. A Review of Stability Test Methods for Gun and Mortar Propellants, I: The Chemistry of Propellant Ageing. J. Energ. Mater. 2006, 6 (12), 27-43.

(20) Ghosh, K.; Pant, C. S.; Sanghavi, R.; Adhav, S.; Singh, A.; Shekher Pant, C. Studies on Triple Base Gun Propellant Based on Two Energetic Azido Esters. $J$. Energ. Mater. 2008, 27 (1), 40-50.

(21) Chemello, E. Ciência Forense: Balística. Química Virtual 2007, 1-10.

(22) Wolten, G. M.; Nesbitt, A. R.; Calloway, G. L.; Loper, P. F. J. Particle Analysis for the Detection of Gunshot Residue I. Scanning Electron Microscopy/energy Dispersive X-Ray Characterisation of Hand Deposits from Firing. Forensic Sci. Int. 1979, 24, 409-422.

(23) Taudte, R. V.; Roux, C.; Bishop, D.; Blanes, L.; Doble, P.; Beavis, A. Development of a UHPLC Method for the Detection of Organic Gunshot Residues Using Artificial Neural Networks. Anal. Methods 2015.

(24) Laza, D.; Nys, B.; Kinder, J. De; Kirsch-De Mesmaeker, A.; Moucheron, C. Development of a Quantitative LC-MS/MS Method for the Analysis of Common Propellant Powder Stabilizers in Gunshot Residue. J. Forensic Sci. 2007, 52 (4), 842-850.

(25) Gallidabino, M.; Romolo, F. S.; Bylenga, K.; Weyermann, C. Development of a Novel Headspace Sorptive Extraction Method to Study the Aging of Volatile Compounds in Spent Handgun Cartridges. Anal. Chem. 2014, 86 (9), 4471-4478.

(26) Tarifa, A.; Almirall, J. R. Fast Detection and Characterization of Organic and Inorganic Gunshot Residues on the Hands of Suspects by CMV-GC-MS and LIBS.pdf. Sci. Justice 2015, 55, 168-175.

(27) Tocaia Dos Reis, E. L.; De Souza Sarkis, J. E.; Rodrigues, C.; Neto, O. N.; Viebig, S. Identificação de Resíduos de Disparos de Armas de Fogo Por Meio Da Técnica de Espectrometria de Massas de Alta Resolução Com Fonte de Plasma Indutivo. Quim. Nova 2004, 27 (3), 409-413. 
(28) Glattstein, B.; Vinokurov, A.; Levin, N.; Zeichner, A. Improved Method for Shooting Distance Estimation . Part 1 . Bullet Holes in Clothing Items. J. Forensic Sci. 2015, 45 (4), 801-806.

(29) Bailey, J. a.; Casanova, R. S.; Bufkin, K. A Method for Enhancing Gunshot Residue Patterns on Dark and Multicolored Fabrics Compared with the Modified Griess Test. J. Forensic Sci. 2006, 51 (4), 812-814.

(30) Muller, D.; Levy, A.; Vinokurov, A.; Ravreby, M.; Shelef, R.; Wolf, E.; Eldar, B.; Glattstein, B. A Novel Method for the Analysis of Discharged Smokeless Powder Residues. J. Forensic Sci. 2007, 52 (1), 75-78.

(31) Andreola, S.; Gentile, G.; Battistini, A.; Cattaneo, C.; Zoja, R. Forensic Applications of Sodium Rhodizonate and Hydrochloric Acid: A New Histological Technique for Detection of Gunshot Residues. J. Forensic Sci. 2011, 56 (3), 771774.

(32) Marty, W.; Sigrist, T.; Wyler, D. Determination of Firing Distance Using the Rhodizonate Staining Technique. Int. J. Legal Med. 2002, 116 (1), 1-4.

(33) Tugcu, H.; Yorulmaz, C.; Karslioglu, Y.; Uner, H. B.; Koc, S.; Ozdemir, C.; Ozaslan, A.; Celasun, B. Image Analysis as an Adjunct to Sodium Rhodizonate Test in the Evaluation of Gunshot Residues: An Experimental Study. Am. J. Forensic Med. Pathol. 2006, 27 (4), 296-299.

(34) Vanini, G.; Destefani, C. A.; Merlo, B. B.; Tereza, M.; Carneiro, W. D.; Filgueiras, P. R.; Poppi, R. J.; Romão, W. Forensic Ballistics by Inductively Coupled PlasmaOptical Emission Spectroscopy: Quanti Fi Cation of Gunshot Residues and Prediction of the Number of Shots Using Different Fi Rearms. Microchem. J. 2015, $118,19-25$.

(35) ASTM Standart E1588-10e1, Standard Guide for Gunshot Residue Analysis by Scanning Electron Microscopy/Energy Dispersive X-Ray Spectrometry. ASTM Stand. E1588-10e1, Stand. Guid. Gunshot Residue Anal. by Scanning Electron Microsc. Dispersive X-ray Spectrom. 2008.

(36) Brozek-Mucha, Z. Scanning Electron Microscopy and X-Ray Microanalysis for Chemical and Morphological Characterisation of the Inorganic Component of Gunshot Residue : Selected Problems. Biomed Res. Int. 2014, 2014, 1-11.

(37) Martiny, A.; Pinto, L. Aplicação Da Microscopia Eletrônica de Varredura À Análise de Resíduos de Tiro. Rev. Mil. Ciência e Tecnol. 3 Q 2008 2008, 24-35.

(38) Berk, R. E.; Rochowicz, S. a.; Wong, M.; Kopina, M. a. Gunshot Residue in 
Chicago Police Vehicles and Facilities: An Empirical Study. J. Forensic Sci. 2007, $52(4), 838-841$.

(39) Schoeble, A. J.; Exline, D. L. Current Methods in Forensic Gunshot Resideu Analysis; CRC Press: Boca Raton, 2000.

(40) Andrasko, J.; Pettersson, S. A Simple Method for Collection of Gunshot Residues from Clothing. J. Forensic Sci. Soc. 1991, 31 (3), 321-330.

(41) MacCrehan, W. A.; Layman, M. J.; Secl, J. D. Hair Combing to Collect Organic Gunshot Residues (OGSR). Forensic Sci. Int. 2003, 135 (2), 167-173.

(42) Zeichner, A.; Eldar, B. A Novel Method for Extraction and Analysis of Gunpowder Residues on Double-Side Adhesive Coated Stubs. J. Forensic Sci. 2004, 49 (6), 113.

(43) Degaetano, D.; Siegel, J. A.; Klomparens, K. L. A Comparison of 3 Techniques Developed for Sampling and Analysis of Gunshot Residue by Scanning ElectronMicroscopy / Energy Dispersive X-Ray Analysis (SEMEDX). J. Forensic Sci. 1992, 37 (1), 281-300.

(44) Wrobel, H. A.; Millar, J. J.; Kijek, M. Comparison of Properties of Adhesive Tapes, Tabs, and Liquids Used for the Collection of Gunshot Residue and Other Trace Materials for SEM Analysis. J. Forensic Sci. 1998, 43 (1), 178-181.

(45) Center for Disease Control/CDC; National Institute for Occupational Safety and Health/NIOSH. Preventing Occupational Exposures to Lead and Noise at Indoor Firing Ranges; 2009; Vol. 139.

(46) Center for Disease Control/CDC; National Institute for Occupational Safety and Health/NIOSH. Lead Exposure and Design Considerations for Indoor Firing Ranges; 1975.

(47) Center for Disease Control/CDC; National Institute for Occupational Safety and Health/NIOSH. Reducing Exposure to Lead and Noise at Outdoor Firing Ranges; 2009.

(48) Center for Disease Control/CDC; National Institute for Occupational Safety and Health/NIOSH. Reducing Exposure to Lead and Noise at Indoor Firing Ranges; 2010.

(49) Occupational Safety and Health Administration. Lead Management and OSHA Compliance for Indoor Shooting Ranges. Facility Development Series no. 15, National Shooting Sports Foundation Inc.,. 2005, pp 1-40.

(50) Silveira, A. M. Atenção a Saúde Dos Trabalhadores Expostos Ao Chumbo 
Metálico. Ministério da Saúde. Série A. Normas e Manuais Técnicos. Editora do Ministério da Saúde 2006, pp 1-44.

(51) Gelberg, K. H.; Depersis, R. Lead Exposure among Target Shooters. Arch. Environ. Occup. Health 2009, 64 (2), 115-120.

(52) Ministério do Trabalho e do Emprego - Brasil. Norma Regulamentadora 7 Do Programa De Controle Médico De Saúde Ocupacional. 1983.

(53) Rocha, E. D.; Sarkis, J. E. S.; Carvalho, M. D. F. H.; Santos, G. V. Dos; Canesso, C. Occupational Exposure to Airborne Lead in Brazilian Police Officers. Int. J. Hyg. Environ. Health 2014, 217 (6), 702-704.

(54) Oommen, Z.; Pierce, S. M. Lead-Free Primer Residues: A Qualitative Characterization of Winchester WinClean, Remington/UMC LeadLess, Federal BallistiClean, and Speer Lawman CleanFire Handgun Ammunition. J. Forensic Sci. 2006, 51 (3), 509-519.

(55) Martiny, A.; Campos, A. P. C.; Sader, M. S.; Pinto, M. A. L. SEM/EDS Analysis and Characterization of Gunshot Residues from Brazilian Lead-Free Ammunition. Forensic Sci. Int. 2008, 177 (1), e9-e17.

(56) Niewoehner, L.; Buchholz, N.; Merkel, J. New Ammunitions for the German Police. Proceedings of SCANNING; 2005 April 5-7; Monterey, CA.FAMS, Inc.:. $2005, \mathrm{p} 69$.

(57) Brandone, A.; De Ferrari, F.; Pelizza, P.; Signori, M. The Labeling of Gunpowder: An Approach to Improve Gunshot Residues Determination. Forensic Sci. Int. 1990, 47, 289-295.

(58) Weber, I. T.; Geber de Melo, A. J.; Lucena, M. a. D. M.; Rodrigues, M. O.; Junior, S. A. High Photoluminescent Metal À Organic Frameworks as Optical. Anal. Chem. 2011, 83, 4720-4723.

(59) Weber, I. T.; Terra, I. A. A.; Melo, A. J. G. De; Lucena, M. a. D. M.; Wanderley, K. a.; Paiva-Santos, C. D. O.; Antônio, S. G.; Nunes, L. a. O.; Paz, F. a. a.; Sá, G. F. De; et al. Up-Conversion Properties of Lanthanide-Organic Frameworks and How to Track Ammunitions Using These Materials. RSC Adv. 2012, 2 (7), 30833087.

(60) Lucena, M. a M.; De Sá, G. F.; Rodrigues, M. O.; Alves, S.; Talhavini, M.; Weber, I. T. ZnAl2O4-Based Luminescent Marker for Gunshot Residue Identification and Ammunition Traceability. Anal. Methods 2013, 5 (3), 705-709.

(61) Weber, I. T.; Melo, a. J. G.; Lucena, M. a. M.; Consoli, E. F.; Rodrigues, M. O.; 
de Sá, G. F.; Maldaner, a. O.; Talhavini, M.; Alves, S. Use of Luminescent Gunshot Residues Markers in Forensic Context. Forensic Sci. Int. 2014, 244, 276284.

(62) Melo Lucena, M. a; Rodrigues, M. O.; Gatto, C. C.; Talhavini, M.; Maldaner, A. O.; Alves Jr, S.; Weber, I. T. Synthesis of [Dy(DPA)(HDPA)] and Its Potential as Gunshot Residue Marker. J. Lumin. 2015, 1-4.

(63) Lucena, M. A. de M. Tese de Doutorado: Marcadores Luminescentes Para Identificação de Resíduos de Tiro: Síntese, Avaliação Da Toxicidade E Aplicação Da Rede Metal-Orgânica [Ln(BTC)], Universidade Federal de Pernambuco, 2016.

(64) Hu, Z.; Deibert, B. J.; Li, J. Luminescent Metal-Organic Frameworks for Chemical Sensing and Explosive Detection. Chem. Soc. Rev. 2014, 43 (16), 5815-5840.

(65) Cui, Y.; Yue, Y.; Qian, G.; Chen, B. Luminescent Functional Metal À Organic Frameworks. Chem. Rev. 2012, 112, 1126-1162.

(66) Allendorf, M. D.; Bauer, C. A.; Bhakta, R. K.; Houk, R. J. T. Luminescent Metalorganic Frameworks. Chem. Soc. Rev. 2009, 38 (5), 1330.

(67) Cui, Y.; Chen, B.; Qian, G. Lanthanide Metal-Organic Frameworks for Luminescent Sensing and Light-Emitting Applications. Coord. Chem. Rev. 2014, 273-274, 76-86.

(68) Dhakshinamoorthy, A.; Garcia, H. Metal-Organic Frameworks as Solid Catalysts for the Synthesis of Nitrogen-Containing Heterocycles. Chem. Soc. Rev. 2014, 43 (16), 5750-5765.

(69) Fernandes, A. Study of New Lanthanide Complexes of 2,6-Pyridinedicarboxylate: Synthesis, Crystal Structure of Ln(Hdipic)(dipic) with Ln=Eu, Gd, Tb, Dy, Ho, Er, $\mathrm{Yb}$, Luminescence Properties of Eu(Hdipic)(dipic). Polyhedron 2001, 20 (18), $2385-2391$.

(70) Dantas Ramos, A. L.; Tanase, S.; Rothenberg, G. Redes Metalorgânicas E Suas Aplicações Em Catálise. Quim. Nova 2014, 37 (1), 123-133.

(71) Rodrigues, M. O.; Brito-Silva, A. M.; Júnior, S. A.; De Simone, C. a.; Adriano Antunes, S. A.; De Carvalho, P. H. V; Santos, S. C. G.; Aragão, K. A. S.; Freire, R. O.; Mesquita, M. E. Estudos Espectroscópicos E Estruturais Dos Polímeros de coordenaçãO 2D, $\infty[\mathrm{Tb}(\mathrm{DPA})(\mathrm{HDPA})] \mathrm{E} \infty[\mathrm{Gd}(\mathrm{DPA})(\mathrm{HDPA})]$. Quim. Nova 2009, 32 (2), 286-291.

(72) Qu, Y.; Ke, Y.; Lu, S.; Fan, R.; Pan, G.; Li, J. Hydrothermal Synthesis, Structures and Spectroscopy of 2D Lanthanide Coordination Polymers Built from Helical 
Chains: [Ln2(BDC) 3(H2O)2]n $\quad(\mathrm{Ln}=\mathrm{Sm}, \quad 1 ; \quad \mathrm{Ln}=\mathrm{Eu}, \quad 2 ; \quad \mathrm{BDC}=1,3$ Benzenedicarboxylate). J. Mol. Struct. 2005, 734 (1-3), 7-13.

(73) Serre, C.; Millange, F.; Thouvenot, C.; Gardant, N.; Pelle, F.; Férey, G. Synthesis, Characterisation and Luminescent Properties of a New Three-Dimensional Lanthanide Trimesate: $\{\mathrm{M}((\mathrm{C} 6 \mathrm{H} 3)-(\mathrm{CO} 2) 3))(\mathrm{M}=\mathrm{Y}, \mathrm{Ln})$ or MIL-78 $\}$. J. Mater. Chem. 2004, 14 (10), 1540-1543.

(74) Valeur, B. Molecular Fluorescence: Principles and Applications; Wiley-VCH: Weinheim, 2002.

(75) Gonçalves, P. Dissertação de Mestrado: Síntese E Caracterização de Novas Iminas Fluorescentes E Suas Aplicações Como Sensores Ópticos, Universidade Federal do Rio Grande do Sul, 2008.

(76) Housecroft, C. E.; Sharpe, A. G. Inorganic Chemistry; Pearson Eduacation Limited: Essex.

(77) Moeller, T. The Chemistry of the Lanthanides. In Comprehensive Inorganic Chemistry; Pergamon Press: New York, 1975; p 101.

(78) Binnemans, K. Interpretation of Europium ( III ) Spectra. Coord. Chem. Rev. 2015, $295,1-45$.

(79) Tanner, P. A. Some Misconceptions Concerning the Electronic Spectra of TriPositive Europium and Cerium. Chem. Soc. Rev. 2013, 42 (12), 5090.

(80) Martins, T. S.; Isolani, P. C. Terras Raras: Aplicações Industriais E Biológicas. Quim. Nova 2005, 28 (1), 111-117.

(81) Weissman, S. I. Intramolecular Energy Transfer. The Fluorescence of Complexes of Europium. Jounal Chem. Phys. 1942, 10 (1942), 214-217.

(82) Baek, N. S.; Nah, M. K.; Kim, Y. H.; Roh, S.; Kim, H. K. Efficient Energy Transfer Pathways for the Sensitization of Lanthanide Ions by Luminescent Ligands in Luminescent Lanthanide Complexes. Bull. Korean Chem. Soc. 2004, 25 (4), 443444.

(83) Ingle, J. D. Spectrochemical Analysis; Prentice Hall: New Jersey, 1998.

(84) Lima, P. P. Dissertação de Mestrado: Estudo Espectroscópico de Complexos de Íons Lantanídeos Com Ligantes de Ácidos Dicarboxílicos, Universidade Federal de Pernambuco, 2003.

(85) Lacowicz, J. R. Principles of Fluorescence Spectroscopy; Kluwer Academic: New York, 1999.

(86) Bettencourt-dias, A. De. Luminescence of Lanthanide Ions in Coordination 
Compounds and Nanomaterials; Wiley: Wes Sussex, 2014.

(87) Mauricio, F. G. B. Dissertação de Mestrado: Marcação de Explosivos Baseado Em Fotoluminescência Para Codificar E Identificar Resíduos de Pós-Explosão, Universidade de Brasília, 2015.

(88) Carvalho, M. A. Dissertação de Mestrado: Utilização Da Análise de Imagem Hiperespectral No Infravermelho Próximo Para Identificação de Marcadores Luminescentes a Base de Redes Metalorgânicas MOF, Universidade Federal de Pernambuco, 2015.

(89) Destefani, C. A. Dissertação de Mestrado: Síntese, Aplicação E Avaliação Da Toxicidade Aguda de Complexo Orgânico À Base de Európio Proposto Como Marcador Fotoluminescente Para a Identificação de Resíduos de Tiro, Universidade Federal do Espírito Santo, 2014.

(90) Horcajada, P.; Chalati, T.; Serre, C.; Gillet, B.; Sebrie, C.; Baati, T.; Eubank, J. F.; Heurtaux, D.; Clayette, P.; Kreuz, C.; et al. Porous Metal-Organic-Framework Nanoscale Carriers as a Potential Platform for Drug Delivery and Imaging. Nat. Mater. 2010, 9 (2), 172-178.

(91) Horcajada, P.; Serre, C.; Vallet-Regí, M.; Sebban, M.; Taulelle, F.; Férey, G. Metal-Organic Frameworks as Efficient Materials for Drug Delivery. Angew. Chemie - Int. Ed. 2006, 45 (36), 5974-5978.

(92) McKinlay, A. C.; Morris, R. E.; Horcajada, P.; Férey, G.; Gref, R.; Couvreur, P.; Serre, C. BioMOFs: Metal-Organic Frameworks for Biological and Medical Applications. Angew. Chemie - Int. Ed. 2010, 49 (36), 6260-6266.

(93) Benito, S.; Abrego, Z.; Sánchez, A.; Unceta, N.; Goicolea, M. A.; Barrio, R. J. Characterization of Organic Gunshot Residues in Lead-Free Ammunition Using a New Sample Collection Device for Liquid Chromatography-quadrupole Time-ofFlight Mass Spectrometry. Forensic Sci. Int. 2015, 246, 79-85.

(94) Goudsmits, E.; Sharples, G. P.; Birkett, J. W. Recent Trends in Organic Gunshot Residue Analysis. TrAC Trends Anal. Chem. 2015, 74, 46-57.

(95) López-López, M.; Delgado, J. J.; García-Ruiz, C. Ammunition Identification by Means of the Organic Analysis of Gunshot Residues Using Raman Spectroscopy. Anal. Chem. 2012, 84 (8), 3581-3585.

(96) Arndt, J.; Bell, S.; Crookshanks, L.; Lovejoy, M.; Oleska, C.; Tulley, T.; Wolfe, D. Preliminary Evaluation of the Persistence of Organic Gunshot Residue. Forensic Sci. Int. 2012, 222 (1-3), 137-145. 
(97) López-López, M.; Delgado, J. J.; García-Ruiz, C. Analysis of Macroscopic Gunshot Residues by Raman Spectroscopy to Assess the Weapon Memory Effect. Forensic Sci. Int. 2013, 231 (1-3), 1-5.

(98) López-López, M.; de la Ossa, M. a F.; Galindo, J. S.; Ferrando, J. L.; Vega, A.; Torre, M.; García-Ruiz, C. New Protocol for the Isolation of Nitrocellulose from Gunpowders: Utility in Their Identification. Talanta 2010, 81 (4-5), 1742-1749.

(99) Moran, J. W.; Bell, S.; Bennett, C. E.; Room, O. H. Skin Permeation of Organic Gunshot Residue: Implications for Sampling and Analysis. Anal. Chem. 2014, 86, 6071-6079.

(100) Weyermann, C.; Belaud, V.; Riva, F.; Romolo, F. S. Analysis of Organic Volatile Residues in 9 Mm Spent Cartridges. Forensic Sci. Int. 2009, 186 (1-3), 29-35.

(101) Joshi, M.; Rigsby, K.; Almirall, J. R. Analysis of the Headspace Composition of Smokeless Powders Using GC-MS, GC-??ECD and Ion Mobility Spectrometry. Forensic Sci. Int. 2011, 208 (1-3), 29-36.

(102) Burleson, G. L.; Gonzalez, B.; Simons, K.; Yu, J. C. C. Forensic Analysis of a Single Particle of Partially Burnt Gunpowder by Solid Phase Micro-ExtractionGas Chromatography-Nitrogen Phosphorus Detector. J. Chromatogr. A 2009, 1216 (22), 4679-4683.

(103) Gilchrist, E.; Jongekrijg, F.; Harvey, L.; Smith, N.; Barron, L. Characterisation of Gunshot Residue from Three Ammunition Types Using Suppressed Anion Exchange Chromatography. Forensic Sci. Int. 2012, 221 (1-3), 50-56.

(104) López-Ĺopez, M.; Bravo, J. C.; Garciá-Ruiz, C.; Torre, M. Diphenylamine and Derivatives as Predictors of Gunpowder Age by Means of HPLC and Statistical Models. Talanta 2013, 103, 214-220.

(105) Thomas, J. L.; Lincoln, D.; McCord, B. R. Separation and Detection of Smokeless Powder Additives by Ultra Performance Liquid Chromatography with Tandem Mass Spectrometry (UPLC/MS/MS),. J. Forensic Sci. 2013, 58 (3), 609-615.

(106) Kabir, A.; Holness, H.; Furton, K. G.; Almirall, J. R. Recent Advances in MicroSample Preparation with Forensic Applications. TrAC Trends Anal. Chem. 2013, $45,264-279$.

(107) Dalby, O.; Birkett, J. W. The Evaluation of Solid Phase Micro-Extraction Fibre Types for the Analysis of Organic Components in Unburned Propellant Powders. J. Chromatogr. A 2010, 1217 (46), 7183-7188.

(108) Chang, K. H.; Yew, C. H.; Abdullah, A. F. L. Optimization of Headspace Solid- 
Phase Microextraction Technique for Extraction of Volatile Smokeless Powder Compounds in Forensic Applications. J. Forensic Sci. 2014, 59 (4), 1100-1108.

(109) Skoog, D. A.; West, D. M.; Holler, F. J.; Crouch, S. R. Fundamentos de Química Analítica; Thomson: São Paulo, SP, 2006.

(110) Harris, C. D. Análise Química Quantitativa; LTC - Livros Técnicos e Científicos Editora S.A.: Rio de Janeiro, RJ, 1999.

(111) Pawliszyn, J. Solid-Phase Microextraction. In Extraction; Academic Press, 2000; pp 1416-1424.

(112) Arthur, C. L.; Pawliszyn, J. Solid Phase Microextraction with Thermal Desorption Using Fused Silica Optical Fibers. Anal. Chem. 1990, 62 (19), 2145-2148.

(113) Jain, R.; Singh, R. Microextraction Techniques for Analysis of Cannabinbids. Trac-Trends Anal. Chem. 2016, 80, 156-166.

(114) Fucci, N.; Gambelunghe, C.; Aroni, K.; Rossi, R. A Direct Immersion Solid-Phase Microextraction Gas Chromatography/Mass Spectrometry Method for the Simultaneous Detection of Levamisole and Minor Cocaine Congeners in Hair Samples From Chronic Abusers. Ther. Drug Monit. 2014, 36 (6), 789-795.

(115) Denmana, J. A.; Skinnera, W. M.; Kirkbrideb, K. P.; Kempson, I. M. Organic and Inorganic Discrimination of Ballpoint Pen Inks by ToF-SIMS and Multivariate Statistics. Appl. Surf. Sci. 2010, 256 (7), 2155-2163.

(116) Curran, A. M.; Rabin, S. I.; Prada, P. A.; Furton, K. G. Comparison of the Volatile Organic Compounds Present in Human Odor Using Spme-GC/MS. J. Chem. Ecol. 2005, 31 (7), 1607-1619.

(117) Prada, P. A.; Curran, A. M.; Furton, K. G. The Evaluation of Human Hand Odor Volatiles on Various Textiles: A Comparison Between Contact and Noncontact Sampling Methods. J. Forensic Sci. 2011, 56 (4), 866-881.

(118) Lovestead, T. M.; Bruno, T. J. Trace Headspace Sampling for Quantitative Analysis of Explosives with Cryoadsorption on Short Alumina Porous Layer Open Tubular Columns. Anal. Chem. 2010, 82 (13), 5621-5627.

(119) Stefan, A. R.; Dockery, C. R.; Nieuwland, A. A.; Roberson, S. N.; Baguley, B. M.; Hendrix, J. E.; Morgan, S. L. Forensic Analysis of Anthraquinone, Azo, and Metal Complex Acid Dyes from Nylon Fibers by Micro-Extraction and Capillary Electrophoresis. Anal. Bioanal. Chem. 2009, 394 (8), 2077-2085.

(120) Bodle, E. S.; Hardy, J. K. Multivariate Pattern Recognition of Petroleum-Based Accelerants by Solid-Phase Microextraction Gas Chromatography with Flame 
Ionization Detection. Anal. Chim. Acta 2007, 589 (2), 247-254.

(121) Bravo-Linares, C. M.; Mudge, S. M.; Loyola-Sepulveda, R. H. Occurrence of Volatile Organic Compounds (VOCs) in Liverpool Bay, Irish Sea. Mar. Pollut. Bull. 2007, 54 (11), 1742-1753.

(122) Parreira, F. V.; De Lourdes Cardeal, Z. Amostragem de Compostos Orgânicos Voláteis No AR Utilizando a Técnica de Microextração Em Fase Sólida. Quim. Nova 2005, 28 (4), 646-654.

(123) Ulrich, S. Solid-Phase Microextraction in Biomedical Analysis. J. Chromatogr. A 2000, 902 (1), 167-194.

(124) Chang, K. H.; Yew, C. H.; Abdullah, A. F. L. Study of the Behaviors of Gunshot Residues from Spent Cartridges by Headspace Solid-Phase Microextraction-Gas Chromatographic Techniques. J. Forensic Sci. 2015, 60 (4), 869-877.

(125) Wang, B.; Feng, W. Y.; Wang, T. C.; Jia, G.; Wang, M.; Shi, J. W.; Zhang, F.; Zhao, Y. L.; Chai, Z. F. Acute Toxicity of Nano- and Micro-Scale Zinc Powder in Healthy Adult Mice. Toxicol. Lett. 2006, 161, 115-123.

(126) Brown, D. M.; Wilson, M. R.; MacNee, W.; Stone, V.; Donaldson, K. Size Dependent Proinflammatory Effects of Ultrafine Polystyrene Particles: A Role for Surface Area and Oxidative Stress in the Enhanced Activity of Ultrafines. Toxicol. Appl. Pharmacol. 2001, 175, 191-199.

(127) Midander, K.; Cronholm, P.; Karlsson, H. L.; Elihn, K.; Moller, L.; Leygraf, C.; Wallinder, I. O. Surface Characteristics, Copper Release, and Toxicity of Nanoand Micrometer-Sized Copper and copper(II) Oxide Particles: A CrossDisciplinary Study. Small 2009, 5 (389-399).

(128) EPA (U.S. Environmental Protection Agency). Air Quality Index (AQI) - A Guide to Air Quality and Your Health; 2009.

(129) Governo Federal. CONAMA Nº 003/1990 - Qualidade Do Ar. Publicada no DOU, 22 agosto 1990, Seção 1, páginas 15937-15939.

(130) Pacheco-Blandino, I.; Vanner, R.; Buzea, C. Toxicity of Nanoparticles. Toxic Build. Mater. 2012, 427-475.

(131) Chen, S.; Zhang, C.; Jia, G.; Duan, J.; Wang, S.; Zhang, J. Size-Dependent Cytotoxicity of Europium Doped NaYF4 Nanoparticles in Endothelial Cells. Mater. Sci. Eng. C 2014, 43, 330-342.

(132) Ditrich, H. Distribution of Gunshot Residues - The Influence of Weapon Type. Forensic Sci. Int. 2012, 220 (1-3), 85-90. 
(133) Instituto de Defesa http://www.defesa.org/, acessado em 03 de maio de 2016.

(134) Glattstein, B.; Vinokurov, A.; Levin, N.; Zeichner, A. Improved Method for Shooting Distance Estimation. Part III. Bullet Holes in Cadavers. J. Forensic Sci. 2000, 45 (6), 1243-1249.

(135) Glattstein, B.; Zeichner, A.; Vinokurov, A.; Shoshani, E. Improved Method for Shooting Distance Determination. Part 2-Bullet Holes in Objects That Cannot Be Processed in the Laboratory. J Forensic Sci 2000, 45 (5), 1000-1008.

(136) López-López, M.; García-Ruiz, C. Recent Non-Chemical Approaches to Estimate the Shooting Distance. Forensic Sci. Int. 2014, 239, 79-85.

(137) Beijer, R. Experience with Zincon, a Useful Reagent for the Determination of Firing Range with Respect to Leadfree Ammunition. J. Forensic Sci. 1994, 39 (4), 981-986.

(138) Cecchetto, G.; Giraudo, C.; Amagliani, A.; Viel, G.; Fais, P.; Cavarzeran, F.; Feltrin, G.; Ferrara, S. D.; Montisci, M. Estimation of the Firing Distance through Micro-CT Analysis of Gunshot Wounds. Int. J. Legal Med. 2011, 125 (2), 245251.

(139) Mou, Y.; Lakadwar, J.; Rabalais, J. W. Evaluation of Shooting Distance by AFM and FTIR/ATR Analysis of GSR. J. Forensic Sci. 2008, 53 (6), 1381-1386.

(140) Gagliano-Candela, R.; Colucci, A. P.; Napoli, S. Determination of Firing Distance. Lead Analysis on the Target by Atomic Absorption Spectroscopy (AAS). $J$. Forensic Sci. 2008, 53 (2), 321-324.

(141) Bailey, J. A. Digital Infrared Photography to Develop GSR Patterns. Aust. J. Forensic Sci. 2007, 39 (1), 33-40.

(142) Latzel, S.; Neimke, D.; Schumacher, R.; Barth, M.; Niewöhner, L. Shooting Distance Determination by M-XRF--Examples on Spectra Interpretation and Range Estimation. Forensic Sci. Int. 2012, 223 (1-3), 273-278.

(143) Berendes, A.; Neimke, D.; Schumacher, R.; Barth, M. A Versatile Technique for the Investigation of Gunshot Residue Patterns on Fabrics and Other Surfaces: MXRF. J. Forensic Sci. 2006, 51 (5), 1085-1090.

(144) Atwater, C. S.; Durina, M. E.; Durina, J. P.; Blackledge, R. D. Visualization of Gunshot Residue Patterns on Dark Clothing. J. Forensic Sci. 2006, 51 (5), 10911095.

(145) Verônica, A. G.; Talhavini, M.; Peixoto, I. C. F.; Zacca, J. J.; Maldaner, A. O.; Braga, J. W. B. Non-Destructive Identi Fi Cation of Different Types and Brands 
of Blue Pen Inks in Cursive Handwriting by Visible Spectroscopy and PLS-DA for Forensic Analysis. Microchem. J. 2014, 116, 235-243.

(146) Kaur, R.; Saini, K.; Sood, N. C. Application of Video Spectral Comparator (Absorption Spectra) for Establishing the Chronological Order of Intersecting Printed Strokes and Writing Pen Strokes. Sci. Justice 2013, 53 (2), 212-219.

(147) Silva, V. A. G.; Talhavini, M.; Zacca, J. J.; Trindade, B. R.; Braga, J. W. B. Discrimination of Black Pen Inks on Writing Documents Using Visible Reflectance Spectroscopy and PLS-DA. 2014, 25 (9), 1552-1564.

(148) French, J.; Morgan, R.; Davy, J. The Secondary Transfer of Gunshot Residue: An Experimental Investigation Carried out with SEM-EDX Analysis. X-Ray Spectrom. 2014, 43 (1), 56-61.

(149) French, J.; Morgan, R. An Experimental Investigation of the Indirect Transfer and Deposition of Gunshot Residue: Further Studies Carried out with SEM-EDX Analysis. Forensic Sci. Int. 2015, 247, 14-17.

(150) Reineke, T. M.; Eddaoudi, M.; Fehr, M.; Kelley, D.; Yaghi, O. M. From Condensed Lanthanide Coordination Solids to Microporous Frameworks Having Accessible Metal Sites. J. Am. Chem. Soc. 1999, 121, 1651-1657.

(151) Ministério da Justiça/Departamento de Polícia Federal/Diretoria TécnicoCientífica. Instrução Técnica $N^{o}$. 001/2010-GAB/DITEC, DE 18 de Fevereiro de 2010 .

(152) de Carvalho, P. H. V.; Barreto, A. S.; Rodrigues, O. M.; Prata, V. de M.; Alves, P. B.; de Mesquita, M. E.; Alves, S.; Navickiene, S. Two-Dimensional Coordination Polymer Matrix for Solid-Phase Extraction of Pesticide Residues from Plant Cordia Salicifolia. J. Sep. Sci. 2009, 32 (12), 2132-2138.

(153) Rodrigues, M. O. Tese de Doutorado: Estudos Espectroscópicos de Materiais Metal-Orgânicos Baseados Em Íons Lantanídeos, Universidade Federal de Pernambuco, 2010.

(154) Liu, K.; You, H.; Zheng, Y.; Jia, G.; Zhang, L.; Huang, Y.; Yang, M.; Song, Y.; Zhang, H. Facile Shape-Controlled Synthesis of Luminescent Europium Benzene1,3,5-Tricarboxylate Architectures at Room Temperature. CrystEngComm 2009, 11 (12), 2622-2628.
Química
Nova
Interativa
Benzeno
http://qnint.sbq.org.br/novo/index.php?hash=molecula.70, acessado em 01/10/2016. 
(156) Morales, D. L. Biodegradação Da Fração BTX E Etanol Da Gasolina Comercial E Da Gasolina Pura Por Microorganismos Isolados de Locais Impactados, Universidade Federal do Rio Grande do Sul, 2008.

(157) Agency for Toxic Substances and Diseasw Registry (ATSDR). ToxFAQs http://www.atsdr.cdc.gov/toxfaqs/tfacts3.pdf, acessado em 01 de outubro de 2016.

(158) Wena, H.; Yuana, L. W.; Weia, C.; Zhaoa, Y.; Qianb, Y.; Mac, P.; Dinga, S. Effects of Combined Exposure to Formaldehyde and Benzene on Immune Cells in the Blood and Spleen in Balb/c Mice. Environ. Toxicol. Pharmacolo 2016, 45, $265-273$.

(159) Zanga, L.; McHalea, C. M.; Rothmanb, N.; Lic, G.; Jia, Z.; Vermeulend, R.; Hubbarda, A. E.; Rena, X.; Shenb, M.; Rappaporta, S. M.; et al. Systems Biology of Human Benzene Exposure. Chem. Biol. Interact. 2010, 184 (1-2), 89-93.

(160) CETESB. Ficha de Informação de Produto Químico: Piridina http://sistemasinter.cetesb.sp.gov.br/produtos/ficha_completa1.asp?consulta=PIR IDINA, acessado em 08 de novembro de 2016.

(161) Agency for Toxic Substances and Diseasw Registry (ATSDR). Toxicological Profile for Pyridine http://www.atsdr.cdc.gov/toxprofiles/tp52.pdf, acessado em 08 de outubro de 2016.

(162) Comissão Interna de Segurança Química (CISQ). Ficha de Segurança Química http://www.qca.ibilce.unesp.br/prevencao/produtos/naftaleno.html, acessado em 08 de outubro de 2016.

(163) CETESB. Ficha de Informação Toxicológica: Naftaleno http://laboratorios.cetesb.sp.gov.br/wpcontent/uploads/sites/47/2013/11/Naftaleno.pdf, acessado em 08 de outrubro de 2016.

(164) Agency for Toxic Substances and Diseasw Registry (ATSDR). Toxicological Profile for Naphthalene, 1-Methylnaphthalene and 2-Methylnaphthalen http://www.atsdr.cdc.gov/toxprofiles/tp67.pdf, acessado em 08 de outubro de 2016.

(165) Griegoa, F. Y.; Bogenb, K. T.; Pricea, P. S.; Weed, D. L. Exposure, Epidemiology and Human Cancer Incidence of Naphthalene. Regul. Toxicol. Pharmacol. 2008, $51(2), 22-26$.

(166) Agency for Toxic Substances and Diseasw Registry (ATSDR). Toxicologival Profile for Phenol http://www.atsdr.cdc.gov/ToxProfiles/tp115.pdf, acessadp e, 28 
de outubro de 2016.

(167) Deichmann, W. B. Phenol Studies. V. The Distribution, Detoxification, and Excretion of Phenol in the Mammalian Body. Arch. Biochem. Biophys. 1944, 3, $345-355$.

(168) Conning, D. M.; Hayes, M. J. The Dermal Toxicity of Phenol: An Investigation of the Most Effective First-Aid Measures. Br. J. Ind. Med. 1970, 27, 155-159.

(169) CETESB. Ficha de Informação Toxicológica: Benzonitrila http://sistemasinter.cetesb.sp.gov.br/produtos/ficha_completa1.asp?consulta=BE NZONITRILA, acenssado em 28 de outubro de 2016.

(170) The National Institute for Occupational Safety and Health (NIOSH). International Chemical Safety Cards

(ICSC) http://www.cdc.gov/niosh/ipcsneng/neng1103.html, acessado em 28 de outubro de 2016.

(171) Sigma-Aldrich. Ficha de dados de segurança: Benzonitrila http://sites.ffclrp.usp.br/cipa/fispq/Benzonitrila.pdf, acessado em 28 de outubro de 2016.

(172) Science

Material Safety

Data

Sheet http://www.sciencelab.com/msds.php?msdsId=9927456, acessado em 28 de outubro de 2016.

(173) The National Institute for Occupational Safety and Health (NIOSH). International Chemical Safety Cards (ICSC). http://www.cdc.gov/niosh/ipcsneng/neng0106.html, acessado em 28 de novembro de 2016.

$\begin{array}{lllll}\text { PubChem. Compound } & \text { Summary } & \text { CID } & \end{array}$ https://pubchem.ncbi.nlm.nih.gov/compound/benzaldehyde\#section=Top, acessado em 28 de outubro de 2016.

(175) The National Institute for Occupational Safety and Health (NIOSH). International Chemical Safety Cards (ICSC) http://www.cdc.gov/niosh/ipcsneng/neng0102.html, acessado em 28 de outubro de 2016.

(176) Fiume, M. Final Report on the Safety Assessment of Benzaldehyde. Int. J. Toxicol. 2003, 25 (Suppl. 2), 11-27.

(177) Xie, R. K.; Seip, H. M.; Leinum, J. R.; Winje, T.; Xiao, J. S. Chemical Characterization of Individual Particles (PM10) from Ambient Air in Guiyang 
City, China. Sci. Total Environ. 2005, 343 (1-3), 261-272.

(178) Dockery, D. W.; Pope, C. a. Acute Respiratory Effects of Particulate Air Pollution. Annu. Rev. Public Health 1994, 15, 107-132.

(179) Li, X.; Liu, W.; Sun, L.; Aifantis, K. E.; Yu, B.; Fan, Y.; Feng, Q.; Cui, F.; Watari, F. Effects of Physicochemical Properties of Nanomaterials on Their Toxicity. $J$. Biomed. Mater. Res. Part A 2015, 103 (7), 2499-2507.

(180) Soenen, S. J.; Rivera-Gil, P.; Montenegro, J. M.; Parak, W. J.; De Smedt, S. C.; Braeckmans, K. Cellular Toxicity of Inorganic Nanoparticles: Common Aspects and Guidelines for Improved Nanotoxicity Evaluation. Nano Today 2011, 6, 446465.

(181) Campelo, V. Efeitos Das Partículas Totais Em Suspensão ( Pts ) Na Saúde Da População Dos Bairros De Benfica, Bonsucesso, Ramos E Manguinhos - Rio De Janeiro / Rj 1 Health Effect of Total Particulate Matter Air Sampling At Benfica, Bonsucesso, Ramos and Manguinhos. Rev. Bras. Geogr. 2009, 5 (9), 99-114.

(182) Jantunen, M.; Hänninen, O.; Koistinen, K.; Hashim, J. H. H. Fine PM Measurements: Personal and Indoor Air Monitoring. Chemosphere 2002, 49 (9), 993-1007.

(183) Valway, S. E.; Martyny, J. W.; Miller, J. R.; Cook, M.; Mangione, E. J. Lead Absorption in Indoor Firing Range Users. Am. J. Public Health 1989, 79 (8), 10291032.

(184) Schlesinger, R. B. The Health Impact of Common Inorganic Components of Fine Particulate Matter (PM2.5) in Ambient Air: A Critical Review. Inhal. Toxicol. 2007, 19 (10), 811-832.

(185) Kelly, F. J.; Fussell, J. C. Size, Source and Chemical Composition as Determinants of Toxicity Attributable to Ambient Particulate Matter. Atmos. Environ. 2012, 60, 504-526.

(186) Binková, B.; Bobak, M.; Chatterjee, A.; J., C. A.; J., D.; Dokery, D. W.; Everad, M.; Forastiere, F.; Fililand, F.; Jolgate, S.; et al. Effects of Air Pollution on Children' S Health and Development a Review of the Evidence Special Programme on Health and Environment. WHO Reg. Off. Eur. 2005, 1-183.

(187) Talhari, A, L. R. Qualificação de Mestrado: Estudo Da Toxicidade de Marcadores Luminescêntes Para Resíduos de Tiro: Avaliação Da Citotoxicidade E Da Toxicidade Aguda Por Inalação Das MOFs $\infty[E u(D P A)(H D P A)]$, $\infty[\mathrm{Eu} 2(\mathrm{BDC}) 3(\mathrm{H} 2 \mathrm{O}) 2] \mathrm{E} \infty[\mathrm{Eu}(\mathrm{BTC})] \mathrm{E}$ Em Doses Repetidas Por 28 Dias Da, 
Universidade de Brasília, 2016.

(188) Tochetto, D. Balística Forense: Aspectos Técnicos E Jurídicos, 6. ed.; MILLENNIUM: Campinas, 2011.

(189) Bailey, J. a. Analysis of Bullet Wipe Patterns on Cloth Targets. J Forensic Indent 2005, 55, 448-460.

(190) Kieser, D. C.; Carr, D. J.; Girvan, L.; Leclair, S. C. J.; Horsfall, I.; Theis, J. C.; Swain, M. V; Kieser, J. a. Identifying the Source of Bullet Wipe: A Randomised Blind Trial. Int. J. Legal Med. 2013, 127 (5), 951-955. 
6. APÊNDICE 
Tabela A. Compostos encontrados na munição NTA deflagrada.

Tempo de Retenção (min)

\begin{tabular}{|c|c|}
\hline 1,532 & Dihidro-5-hidroxi-2,4-(1H,3H)-Pirimidinadiona \\
\hline $\begin{array}{c}1,757 ; 1,784 ; 1,811,1,863 ; \\
1,883 ; 1,912\end{array}$ & 2-Amino-1-propanol \\
\hline 1,$932 ; 1,984 ; 3,866$ & 4-Amino-1-pentanol \\
\hline 2,$029 ; 2,057 ; 2,078 ; 2,099$ & Hidroxi[(1-oxo-2-propenil)amino]-acético \\
\hline 2,423 & 4-Fluorohistamina \\
\hline 2,727 & Glicidiol \\
\hline 3,365 & Fenilmetil éster ácido hidrazinacarboxílico \\
\hline 5,184 & Metoxi-fenil oxima \\
\hline 6,319 & 2,8-Decadieno \\
\hline 6,666 & Benzonitrila \\
\hline 7,326 & $\delta$-Glicero- $\delta$-heptose \\
\hline 7,357 & 1-Gala-1-ido-octose \\
\hline 7,994 & 3-Benzoilmetil-3-hidroxi-5-nitro-2-indolinona \\
\hline 8,069 & 2-(1-fenil-etilamina)-2-tioxo-acetamida \\
\hline 8,295 & 3-Isopropil-2-fenil-pent-4-em-2ol \\
\hline 13,11 & $\begin{array}{c}\text { 2,2,6,7-Tetrametil-10-oxatriciclo[4,3,0,1(1,7)]decan-5- } \\
\text { ona }\end{array}$ \\
\hline 13,209 & $\begin{array}{l}\text { Ácido propanóico 2-metil-2,2-dimetil-1-(2-hidroxi-1- } \\
\text { metiletil)propil ester }\end{array}$ \\
\hline 14,479 & 2,4,7,9-Tetrametil-5-decin-4,7-diol \\
\hline 15,4 & 1-trimetilsilil-3-nitro-benzeno \\
\hline 15,618 & $\begin{array}{l}\text { 7-Metoxi-2,2,4,8- } \\
\text { tetrametiltriciclo[5.3.1.0(4,11)]undecano }\end{array}$ \\
\hline 15,703 & 2,6-bis(1,1-dimetiletil)-2,5-Ciclohexadieno-1,4-diona- \\
\hline 15,$995 ; 24,004 ; 24,908$ & Etil iso-alocolato \\
\hline 20,445 & 2,4-di-t-butil-6-nitro-Fenol \\
\hline 23,178 & 2-Metil-E,E-3,13-octadecadien-1-ol \\
\hline 23,$685 ; 24,133 ; 24,586$ & 1-Heptatrioctanol \\
\hline $\begin{array}{c}23,776 ; 24,796 ; 25,16 \\
25,681\end{array}$ & $\begin{array}{c}\text { Ácido 2-(3-acetoxi-4,4,14-trimetilandrost-8-en-17-il)- } \\
\text { propanóico }\end{array}$ \\
\hline
\end{tabular}


Continuação da Tabela A.

\begin{tabular}{|c|c|}
\hline Tempo de Retenção (min) & Composto \\
\hline 23,835 & Ácido bis(2-metilpropil)-1,2-Benzenodicarboxílico \\
\hline 24,059 & N,N'-Dietil-N,N'-difenilureia \\
\hline 24,211 & 7,9-Di-t-butil-1-oxaspiro(4,5)deca-6,9-dieno-2,8-diona \\
\hline 24,549 & Ácido 1,2-Benzenodicarboxilico-butil-octil éster \\
\hline
\end{tabular}

Tabela B. Compostos encontrados no cartucho contendo munição NTA marcada com EuDPA após deflagração.

\begin{tabular}{|c|c|}
\hline Tempo de Retenção (min) & Composto \\
\hline 1,4 & 2-Aziridiniletil-amina \\
\hline 1,596 & Topotecano \\
\hline 1,$702 ; 1,866$ & 2-Formilhistamina \\
\hline $\begin{array}{c}1,755 ; 1,802 ; 1,82 ; 1,939 \\
1,966\end{array}$ & 2-Hidroxi Propanamida \\
\hline 2,094 & Hidroxi [(1-oxo-2-propenil)amino]-acético \\
\hline 2,714 & Glicidiol \\
\hline 3,067 & Piridina \\
\hline 4,236 & 1-Metil-2-(5-metil-1H-pirazol-3)-Etilamina \\
\hline 5,183 & Metoxi-fenil oxima \\
\hline 6,309 & N-fenil-1H-Benzotriazol-1-metanamina \\
\hline 6,468 & Ácido 12,15-Octadecadióico \\
\hline 6,$661 ; 6,764$ & Benzonitrila \\
\hline 7,353 & 1-Gala-1-ido-octose \\
\hline 7,989 & 3-Benzoilmetil-3-hidroxi-5-nitro-2-indolinona \\
\hline 8,286 & 3-Isopropil-2-fenil-pent-4-em-2ol \\
\hline 9,718 & Borneol \\
\hline 9,978 & Naftaleno \\
\hline 13,098 & 2,4,4-Trimetil-3-(3-metilbutil)ciclohex-2-enona \\
\hline 13,197 & $\begin{array}{c}\text { Ácido 2-metil-2,2-dimetil-1-(2-hidroxi-1-metiletil) } \\
\text { propanóico }\end{array}$ \\
\hline 13,696 & 5- $\alpha$-Colestan-2-ona-oxima \\
\hline 14,464 & 2,4,7,9-Tetrametil-5-decin-4,7-diol \\
\hline
\end{tabular}


Continuação da Tabela B.

\begin{tabular}{|c|c|}
\hline Tempo de Retenção $(\mathbf{m i n})$ & Composto \\
\hline 15,685 & 2,6 -bis(1,1-dimetiletil)-2,5-Ciclohexadieno-1,4-diona \\
\hline 18,485 & 1-Formil-3-etil-6- $\alpha$ - $\Delta$-ribofuranosil-Pirazol[4,5- \\
& $\beta]$ imidazol \\
\hline 20,426 & $2,4-$-di-t-butil-6-nitro-Fenol \\
\hline 23,$767 ; 26,811 ; 26,26$ & Etil iso-alocolato \\
\hline 23,824 & Ácido bis(2-metilpropil)-1,2-Benzenodicarboxílico \\
\hline 24,049 & N,N'-Dietil-N,N'-difenilureia \\
\hline 24,202 & 7,9-Di-t-butil-1-oxaspiro(4,5)deca-6,9-dieno-2,8- \\
& diona \\
\hline 24,377 & Ácido 1,2,3,4-Tetrahidroisoquinolin-6-ol-1 \\
\hline 24,$404 ; 24,789 ; 26,085$ & Ácido 2-(3-acetoxi-4,4,14-trimetillandrost-8-en-17- \\
\hline 24,54 & Ácido 1,2-Benzenodicarboxilico-butil-octil éster \\
\hline
\end{tabular}

Tabela C. Compostos encontrados no cartucho contendo munição NTA marcada com EuBDC após deflagração.

\begin{tabular}{|c|c|}
\hline Tempo de Retenção (min) & Composto \\
\hline 1,234 & Óxido Nitroso \\
\hline 1,$514 ; 1,59 ; 1,692$ & 6-amino-2-metil-heptanol \\
\hline 2,057 & 1-Isopropildiaziridna \\
\hline 2,248 & Benzeno \\
\hline 2,558 & Ácido Ciclohexan-3-ona-1,4,5-triol \\
\hline 2,$725 ; 3,801$ & Glicidiol \\
\hline 3,303 & $\alpha$-Metil-Benzenoetanamina \\
\hline 4,167 & 1-Metil-2-(5-metil-1H-pirazo-3-il)-etilamina \\
\hline 5,088 & O-acetiloxima-(E)-3-Piridinacarboxaldeído \\
\hline 5,152 & 3-(3-Carboxi-4-hidroxifenil)-D-alanina \\
\hline 5,84 & Ácido N'-[3-(1-hidroxi-1-pheniletil)fenil]hidrazida \\
\hline 6,235 & Benzaldeído \\
\hline 6,$657 ; 7,921$ & Benzonitrila \\
\hline 8,249 & Nitrobenzeno \\
\hline
\end{tabular}


Continuação da Tabela C.

\begin{tabular}{|c|c|}
\hline Tempo de Retenção (min) & Composto \\
\hline 8,289 & Ácido $\alpha$-hidroxiimínico-benzenopropanóico \\
\hline 9,15 & 4-hidroximetil-benzonitrila \\
\hline 9,889 & Naftaleno \\
\hline 11,215 & 3-Fenil-(E)-2-Propenonitrila \\
\hline 11,35 & 1,2-Benzodicarbonitrila \\
\hline 12,054 & 2-Metil-Naftaleno \\
\hline 12,372 & 1-Etil-1H-Indeno \\
\hline 12,99 & 2,4,4-Trimetil-3-(3-metilbutil)ciclohex-2-anona \\
\hline 13,$872 ; 13,985 ; 14,183$ & Bifenila \\
\hline 14,$916 ; 16,121$ & 2-metil-1,1'-Bifenila \\
\hline 16,267 & 1-Isociano-16-Naftaleno \\
\hline 16,834 & Dibenzofurano \\
\hline 19,255 & Benzofenona \\
\hline 19,561 & Fenantridina \\
\hline 23,768 & Ácido bis(2-metilpropil)-1,2-Benzenodicarboxílico \\
\hline 23,$991 ; 24,257$ & N,N'-Dietil-N,N'-difenilureia \\
\hline 24,397 & Ácido 1,2-Benzenodicarboxilico-butil-octil éster \\
\hline
\end{tabular}

Tabela D. Compostos encontrados no cartucho contendo munição NTA marcada com EuBTC após deflagração.

\begin{tabular}{|c|c|}
\hline Tempo de Retenção $(\mathbf{m i n})$ & Composto \\
\hline 1,52 & 6-amino-2-metil-heptanol \\
\hline 1,681 & 2-Hidroxi Propanamida \\
\hline 2,039 & Ácido hidroxi[(1-oxo-2-propenil)amina] acético \\
\hline 2,268 & Benzeno \\
\hline 2,649 & Glicidiol \\
\hline 3 & Ácido 2-Piridinacarboxílico \\
\hline 3,178 & $\alpha-(1-a m i n o e t i l)-(R, R)-B e n z o m e t a n o l$ \\
\hline 3,301 & Fenilmetil éster ácido hidrazinacarboxílico \\
\hline 3,557 & Ácido Triciclo[4.3.1.1(3,8)]undecano-3-carboxílico \\
\hline 4,285 & $2-F e n i l-1-B e n z o p i r i l i u m, ~$ \\
\hline
\end{tabular}


Continuação da Tabela D.

\begin{tabular}{|c|c|}
\hline Tempo de Retenção (min) & Composto \\
\hline 5,126 & 3-(3-Carboxi-4-hidroxifenil)-D-alanina \\
\hline 5,281 & 2-Fenil-1,3-dioxan-5-il éster octadecanotrienóico \\
\hline 6,237 & Benzaldeído \\
\hline 6,46 & Fenol \\
\hline 6,$595 ; 7,107 ; 7,464 ; 7,918$ & Benzonitrila \\
\hline 7,283 & Ácido pentadecil-2,2-Dimetillpropiônico \\
\hline 7,$918 ; 8,319$ & $\begin{array}{l}\text { Ácido 4-(1,5-Dihidrobenzo[e][1,3,2]dioxaborepin- } \\
\text { 3-il)benzoico }\end{array}$ \\
\hline 8,777 & Etil iso-alocolato \\
\hline 9,886 & Naftaleno \\
\hline 12,993 & $\begin{array}{l}\text { 2,2,6,7-Tetrametil-10- } \\
\text { oxatriciclo[4,3,0,1(1,7)]decan-5-ona }\end{array}$ \\
\hline 13,$809 ; 14,018$ & Bifenila \\
\hline 14,212 & 2,5-Bis(1-naftil)-1,5-hexadieno \\
\hline 15,347 & Acenaphthylene \\
\hline 15,448 & $\begin{array}{l}\text { Metil-éster ácido-3-Isopropopil-6 } \alpha, 7,10 \beta \text {-trimetil-8- } \\
\text { (2-oxo-2-feniletil)dodecahidrobenzo[f]benzopirano }\end{array}$ \\
\hline 16,27 & 2-Naftalenocarbonitrila \\
\hline 23,963 & N,N'-Dietil-N,N'-difenilureia \\
\hline 24,908 & $\begin{array}{c}\text { Acido } 2,7,10 \text {-tris(acetiloxi)- } \\
1,1 \alpha, 2,3,4,6,7,10,11,11 \alpha \text {-decahidro-1,1,3,6,9- } \\
\text { pentametil-4-oxo-4 } \alpha, 7 \alpha \text {-3-Piridinacarboxílico }\end{array}$ \\
\hline
\end{tabular}



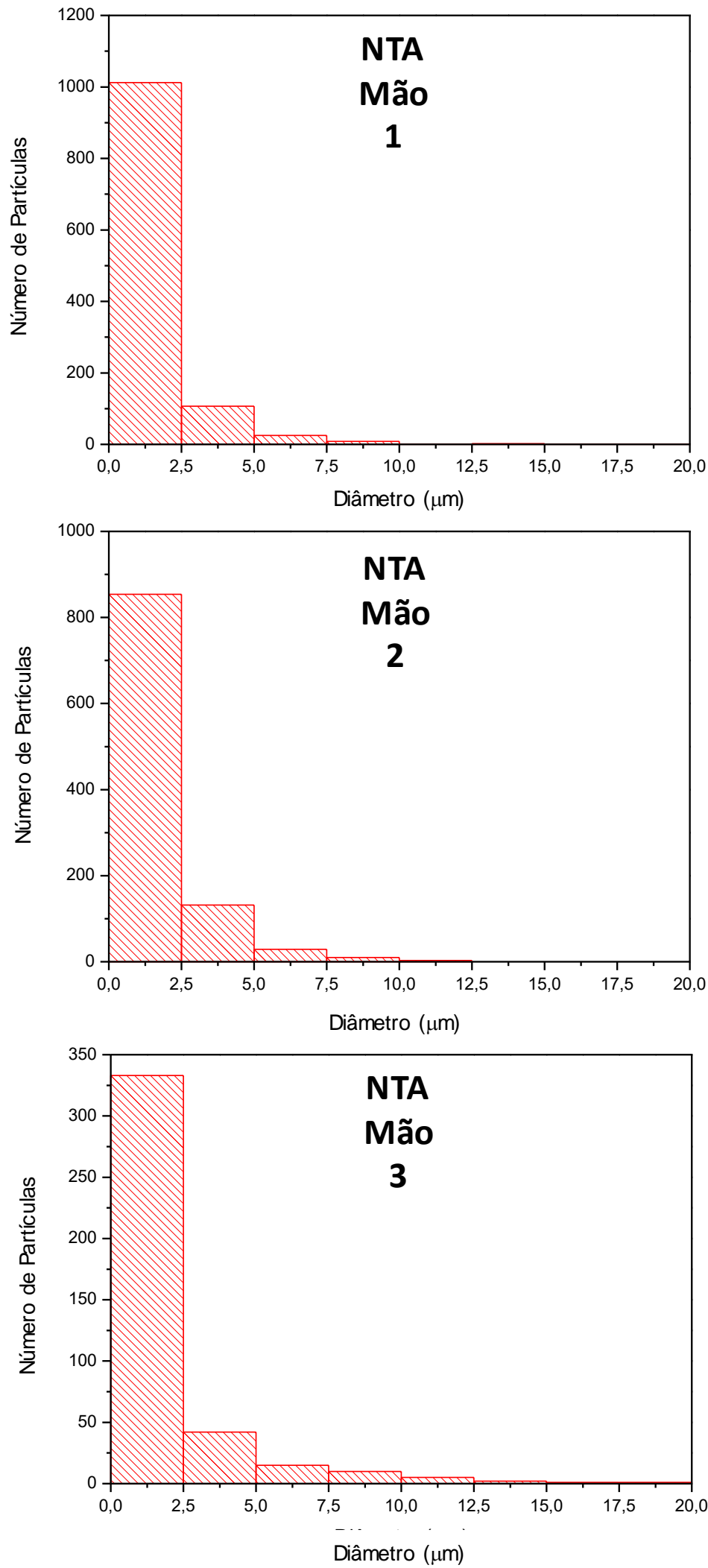

Figura A. Histogramas das partículas coletadas da mão do atirador após 4 disparos com munição NTA. 

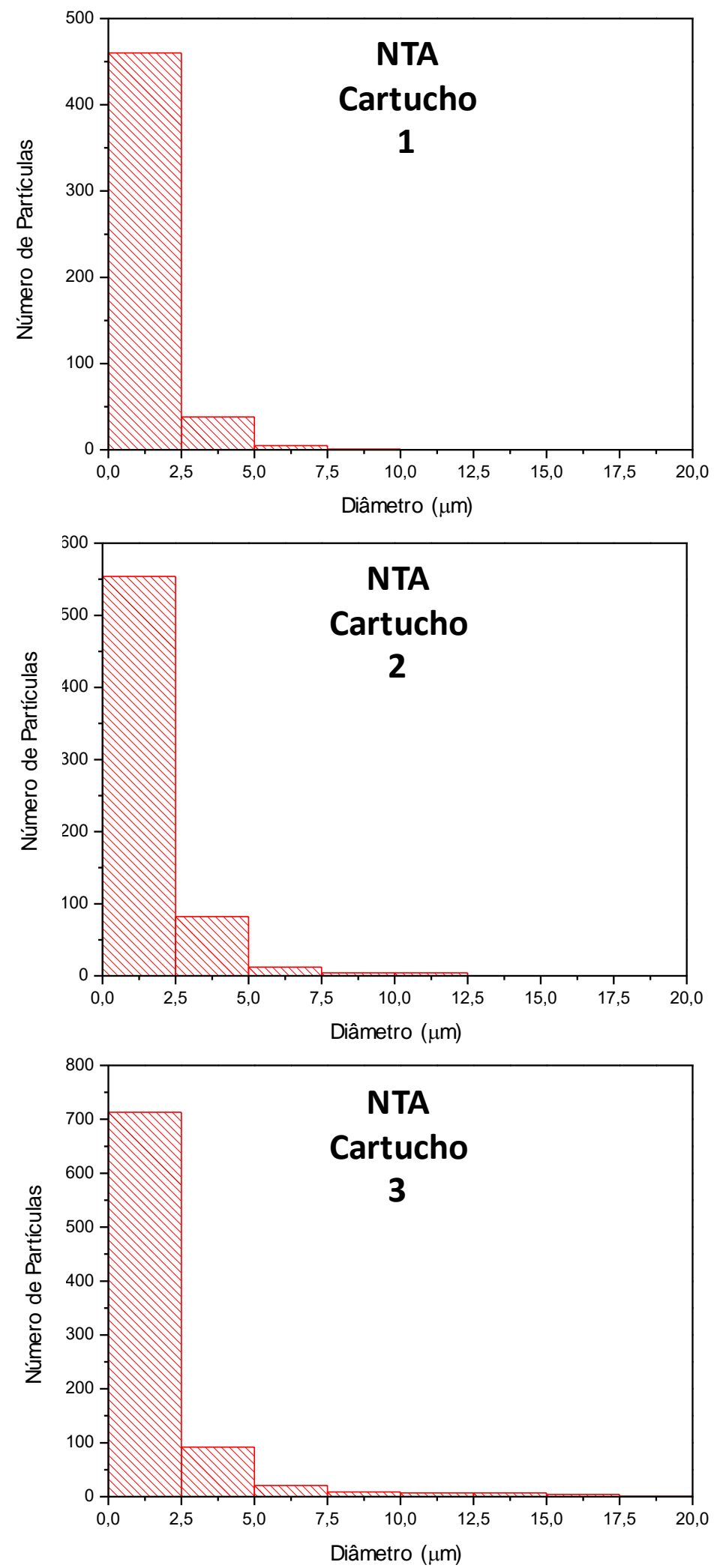

Figura B. Histogramas das partículas coletadas de um cartucho NTA deflagrado. 

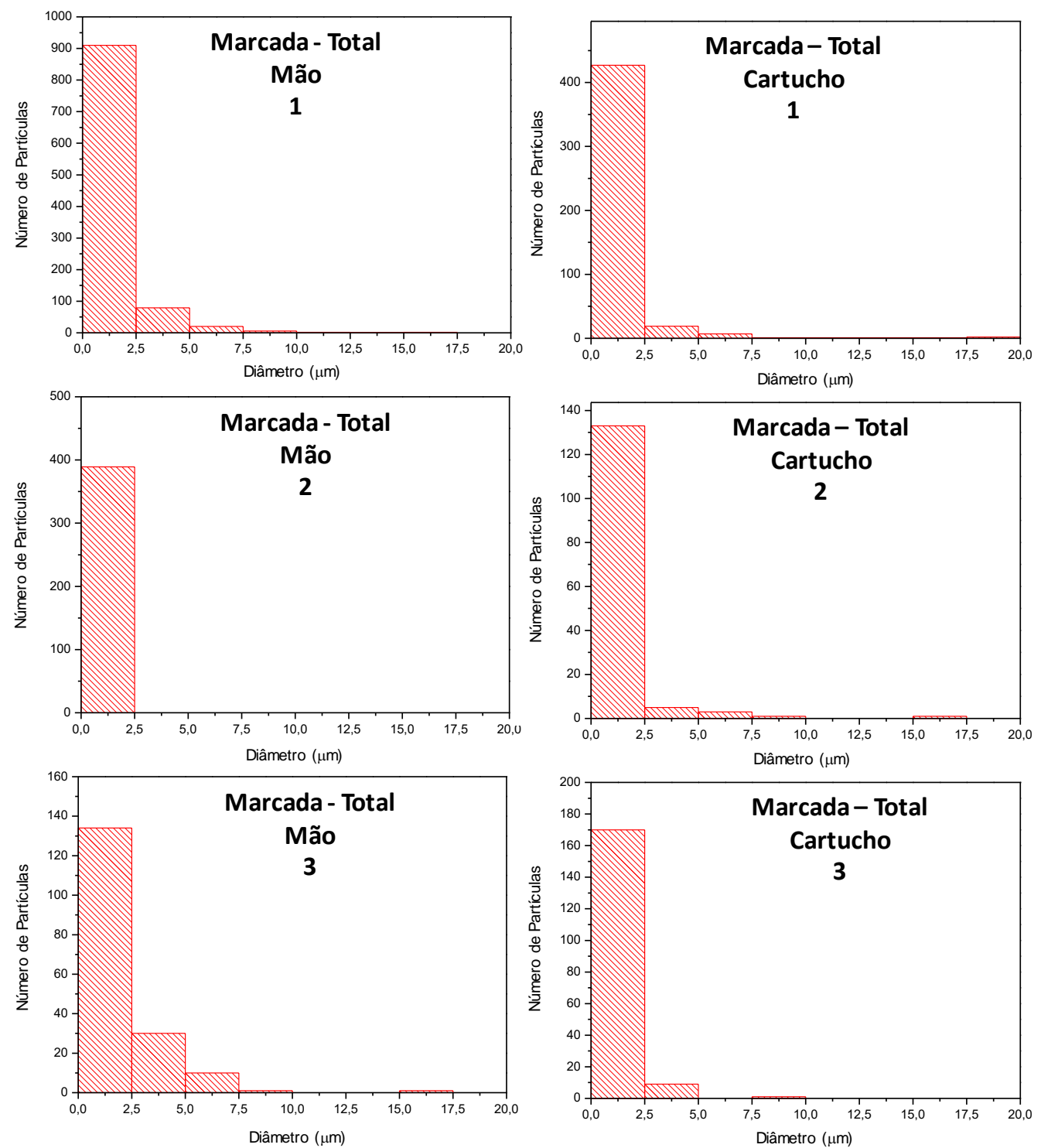

Figura C. Histogramas todas as partículas da munição marcada (soma das classificadas e não classificadas) coletadas da mão do atirador após 4 disparos e de um cartucho NTA marcado deflagrado. 

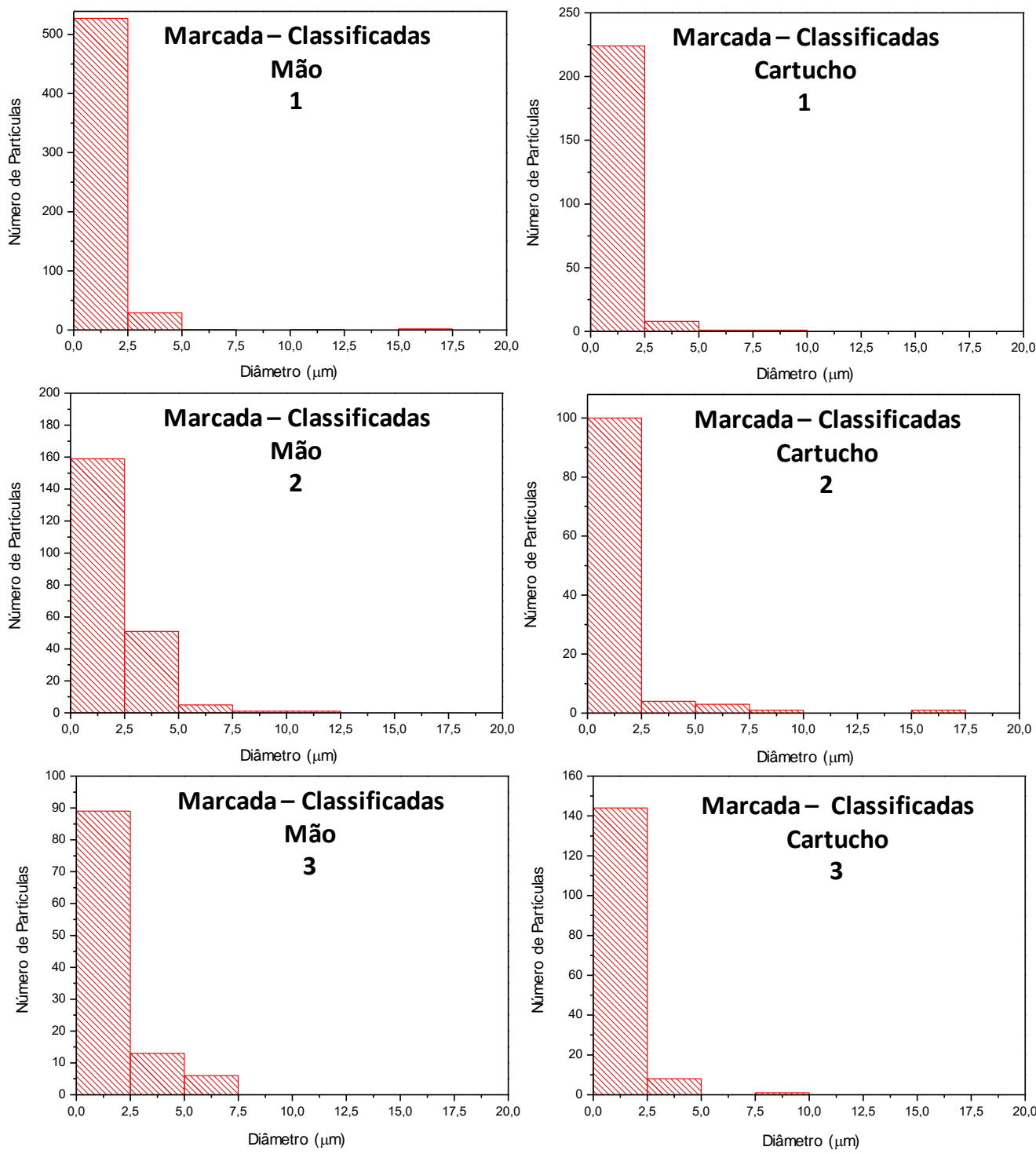

Figura D. Histogramas das partículas classificadas da munição marcada coletadas da mão do atirador após 4 disparos e de um cartucho NTA marcado deflagrado. 

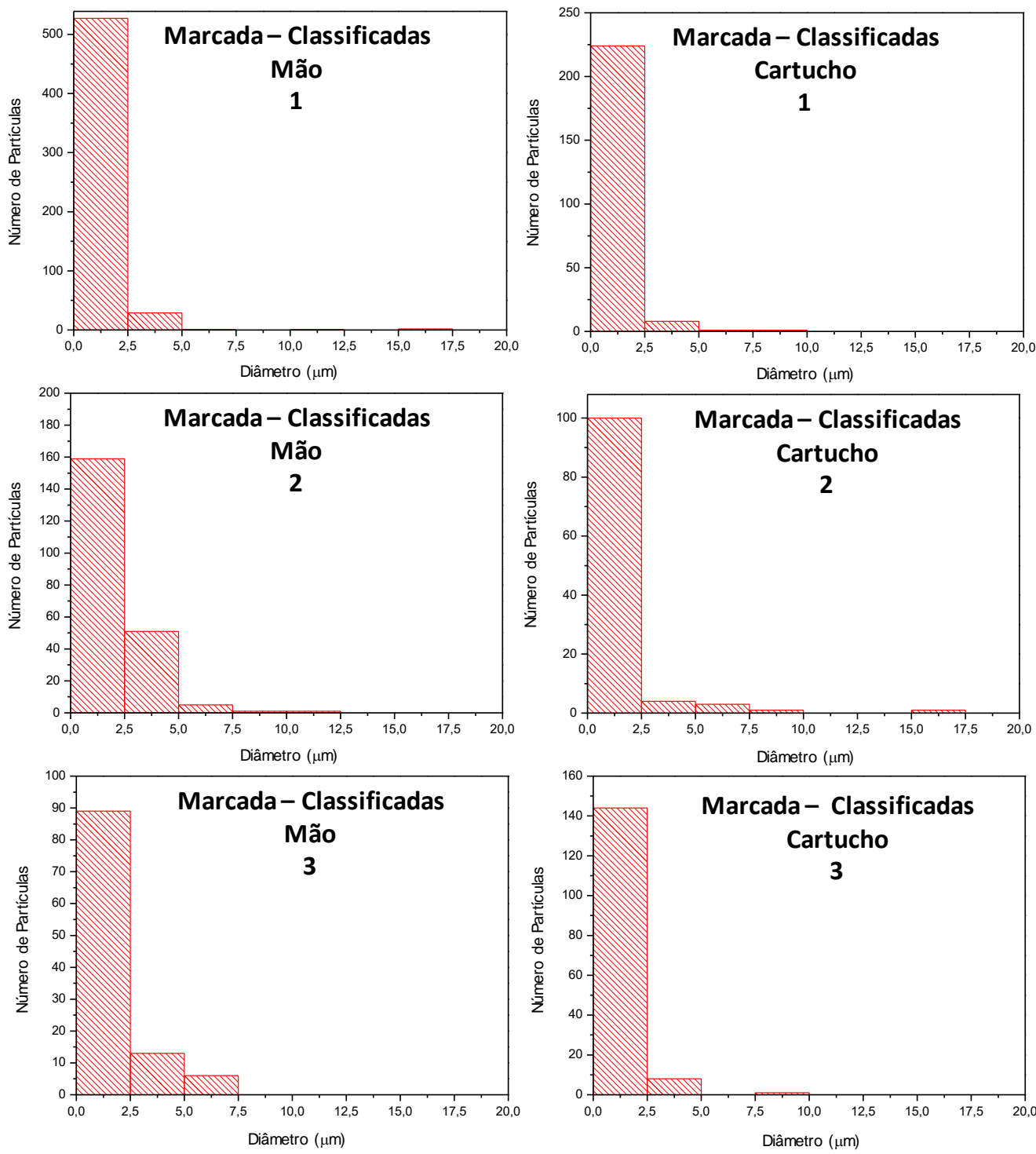

Figura E. Histogramas das partículas não classificadas da munição marcada coletadas da mão do atirador após 4 disparos e de um cartucho NTA marcado deflagrado. 

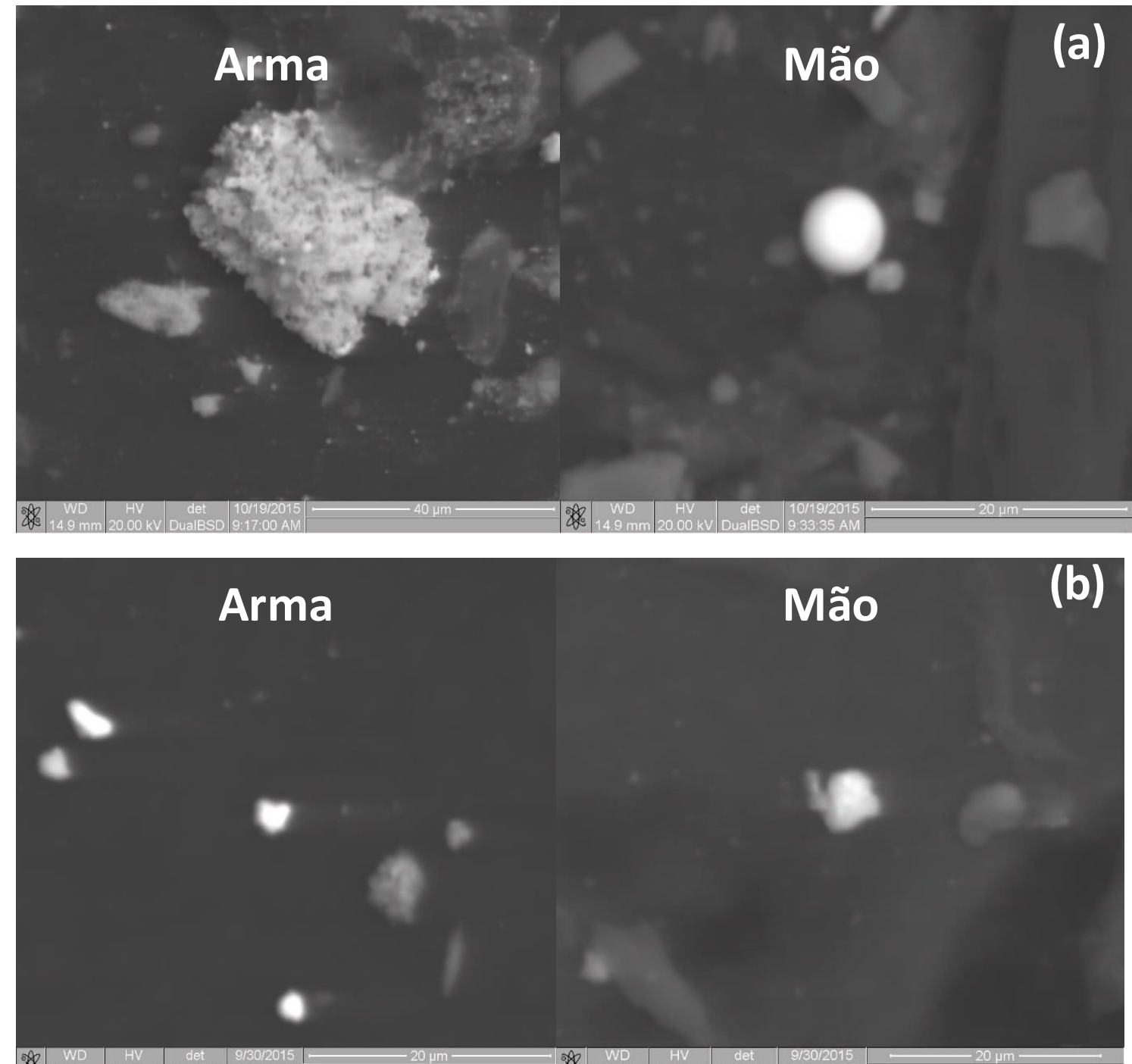

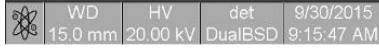

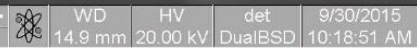

\section{Arma}

Mão

(c)

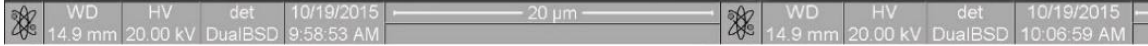



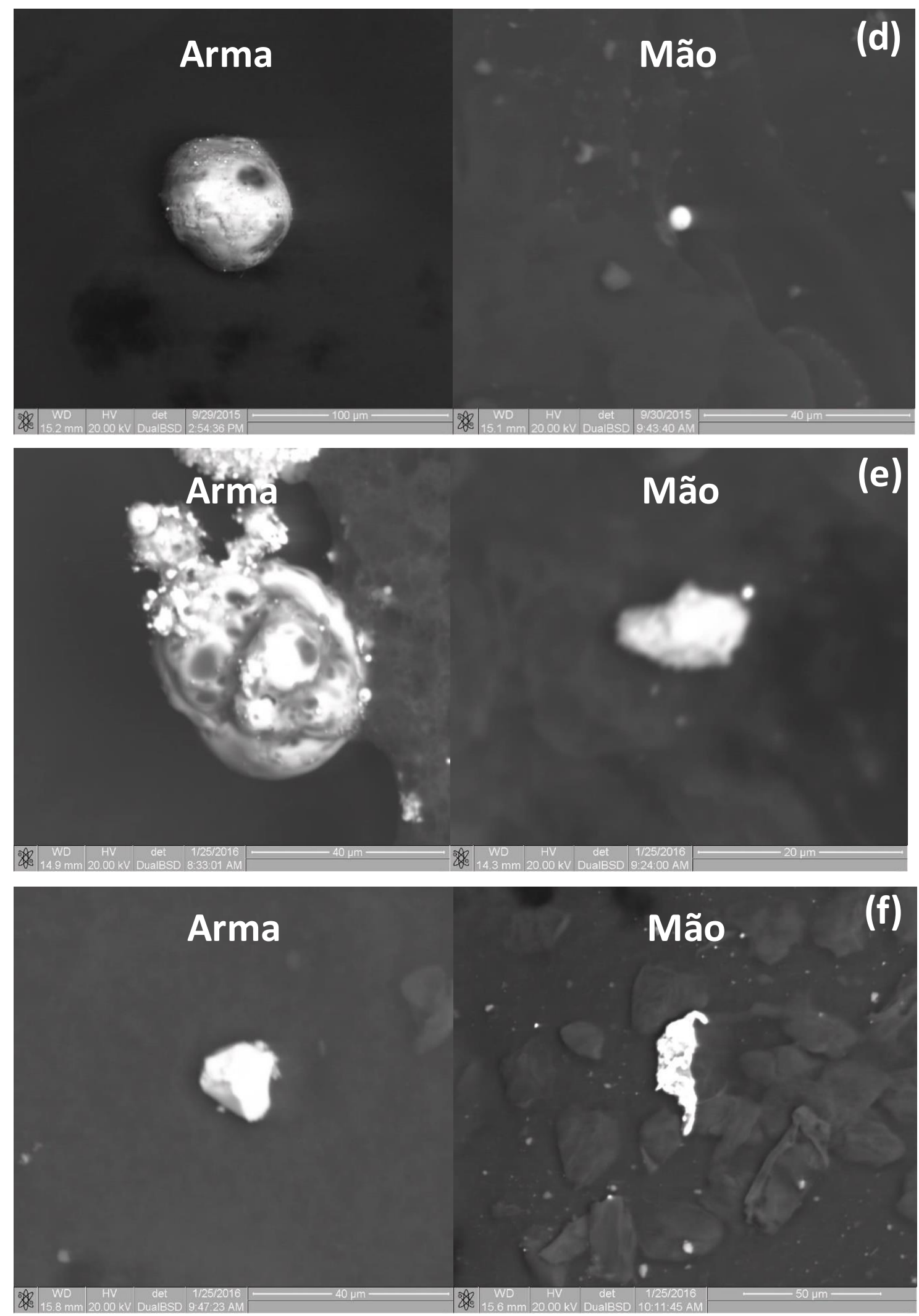

Figura F. Micrografias dos resíduos encontrados nas mão e armas: (a) Browning, (b) Jericho (c) Smith \& Wesson, (d) Taurus, (e) Glock G17 e (f) Glock G26. 


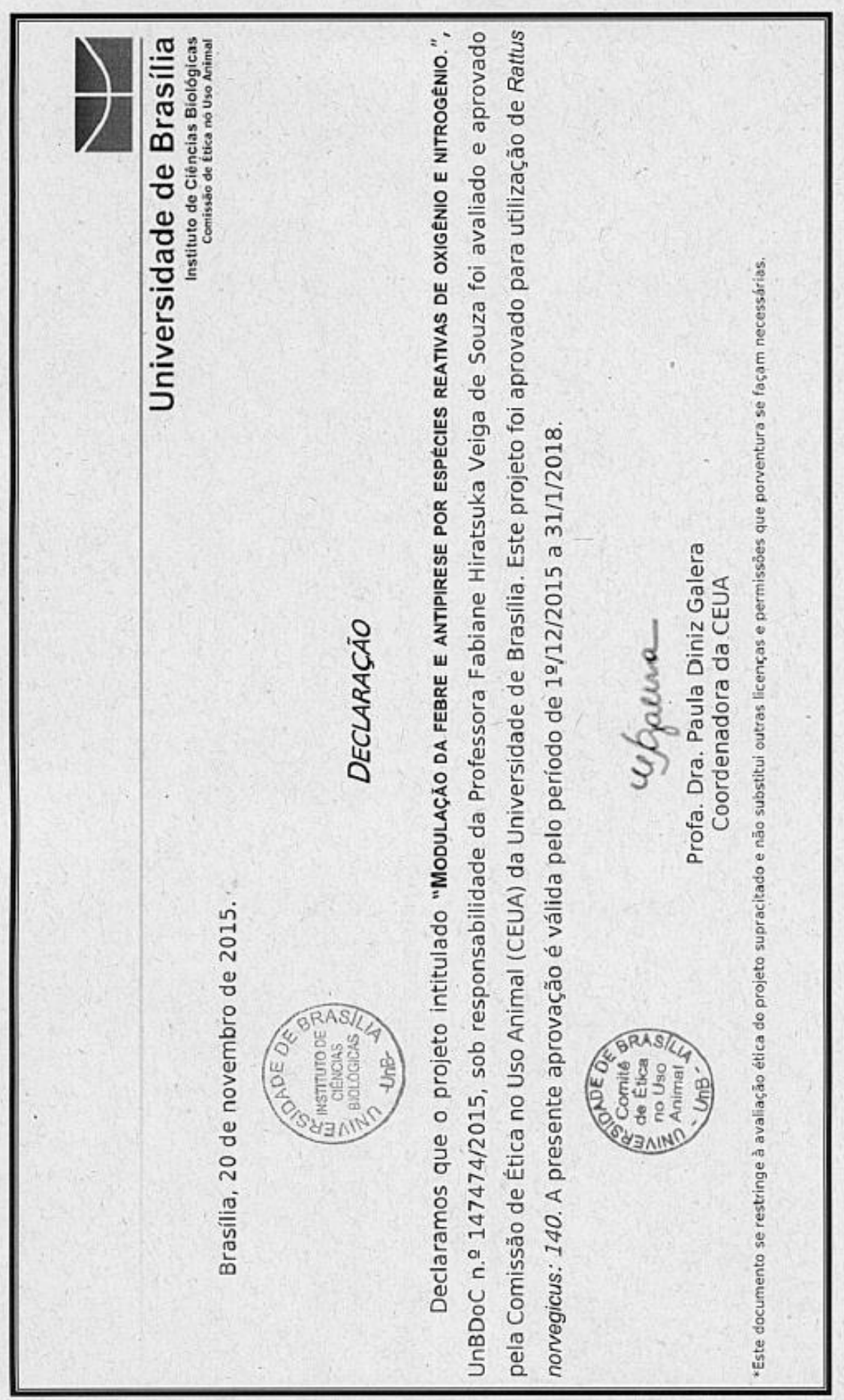

Figura G. Declaração de aprovação do projeto UnBDoc n. 147474/2015) pela Comissão de Ética no Uso Animal da UnB. 


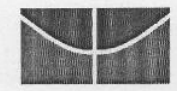

UnB/Universidade de Brasilia

IQ/Instituto de Química
Laboratório Interdisciplinar de

Materiais - Prof. Gilberto Sá

Formulário para Teste à Cegas

Atirador

\begin{tabular}{l}
\hline Nome: \\
\hline Data do disparo: $07-\mathrm{Jn}-15$ \\
\hline Hora do disparo: $17: 00$ \\
\hline Local: $A P B \Omega$ \\
\hline Arma: GLCA 19 \\
\hline Proprietário da Arma: \\
\hline
\end{tabular}

Marcador utilizado: $\square \mathrm{A} \square \mathrm{B} \quad \square \mathrm{C} \square \mathrm{D} \square \mathrm{E}$ F $\square \mathrm{G} \square \mathrm{H}$

Marque a posição na qual o tiro foi deflagrado (posicione-se no centro do quadrado).

\begin{tabular}{|l|l|l|l|}
\hline $1 A$ & $1 B$ & $1 C$ & $1 D$ \\
\hline $2 A$ & $2 B$ & $2 C$ & $2 D$ \\
\hline $3 A$ & $3 B$ & $3 C$ & $3 D$ \\
\hline
\end{tabular}

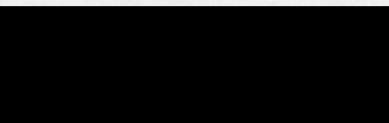

Assinatura do atirador

Figura H. Formulário preenchido no teste cego pelo primeiro atirador. 


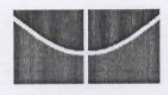

UnB/Universidade de Brasilia

IQ/Instituto de Química

Formulário para Teste à Cegas

Atirador

Nome:

Data do disparo: $9 / 7 / 15$

Hora do disparo: $15: 00$

Local:

Arma:

Proprietário da Arma:

Marcador utilizado: $\square \mathrm{A} \square \mathrm{B} \triangle \mathrm{C} \quad \square \mathrm{D} \quad \square \mathrm{E} \square \mathrm{F} \square \mathrm{G} \square \mathrm{H}$

Marque a posição na qual o tiro foi deflagrado (posicione-se no centro do quadrado).

\begin{tabular}{|c|c|c|c|}
\hline $1 A$ & $1 B$ & $1 D$ \\
\hline $2 A$ & $2 B$ & $2 C$ & $2 D$ \\
\hline $3 A$ & $3 B$ & $3 C$ & $3 D$ \\
\hline
\end{tabular}

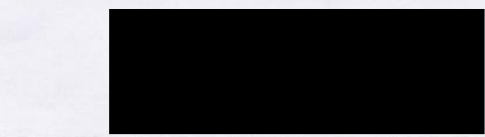

Assinatura do atirador

Figura I. Formulário preenchido no teste cego pelo segundo atirador. 


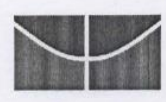

UnB/Universidade de Brasilia

IQ/Instituto de Quimica
Laboratório Interdisciplinar de

Materiais - Prof. Gilberto Sa

Formulário para Teste à Cegas

Atirador

Nome:

Data do disparo: $09 / 071 / 5$

Local:

Arma: $\quad 226$

Proprietário da Arma:

Marcador utilizado: $\square \mathrm{A} \square \mathrm{B} \quad \square \mathrm{C} \square \mathrm{D} \quad \square \mathrm{F} \quad \square \mathrm{G} \square \mathrm{H}$

Marque a posição na qual o tiro foi deflagrado (posicione-se no centro do quadrado).

\begin{tabular}{|l|l|l|l|}
\hline $1 \mathrm{~A}$ & $1 \mathrm{~B}$ & $1 \mathrm{C}$ & $1 \mathrm{D}$ \\
\hline $2 \mathrm{~A}$ & $2 \mathrm{~B}$ & $2 \mathrm{C}$ & $2 \mathrm{D}$ \\
\hline $3 \mathrm{~A}$ & $3 \mathrm{~B}$ & $3 \mathrm{C}$ & $3 \mathrm{D}$ \\
\hline
\end{tabular}

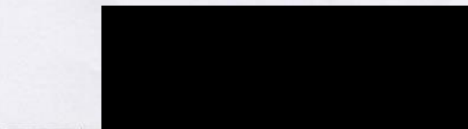

Assinatura do atirador

Figura J. Formulário preenchido no teste cego pelo terceiro atirador. 


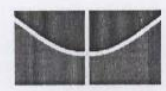

UnB/Universidade de Brasilia

IQ/Instituto de Química

Formulário para Teste à Cegas

Nome:

Data do disparo: $14 / 07 / 15$

Hora do disparo: L1:0 D

Local:

Arma: JCnCluo - SUYA

Proprietário da Arma: $P_{n Y n / \cap}$ onto APBL

Marcador utilizado: $\square \mathrm{A} / \mathrm{B} \quad \square \mathrm{C} \square \mathrm{D} \quad \square \mathrm{E} \quad \square \mathrm{F} \square \mathrm{G} \square \mathrm{H}$

Marque a posição na qual o tiro foi deflagrado (posicione-se no centro do quadrado).

\begin{tabular}{|l|l|l|l|}
\hline 1B & $1 \mathrm{~B}$ & $1 \mathrm{C}$ & $1 \mathrm{D}$ \\
\hline $2 \mathrm{~A}$ & $2 \mathrm{~B}$ & $2 \mathrm{C}$ & $2 \mathrm{D}$ \\
\hline $3 \mathrm{~A}$ & $3 \mathrm{~B}$ & $3 \mathrm{C}$ & $3 \mathrm{D}$ \\
\hline
\end{tabular}

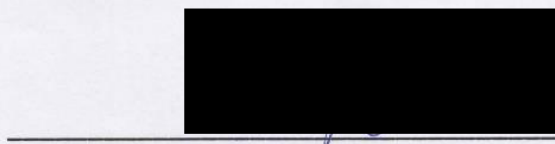

Assinatura do atirador

Figura K. Formulário preenchido no teste cego pelo quarto atirador. 


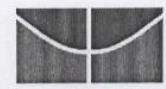

UnB/Universidade de Brasilia

IQ/Instituto de Química

Formulário para Teste à Cegas
Laboratório Interdisciplinar de

Materiais - Prof. Gilberto Sá

\section{Atirador}

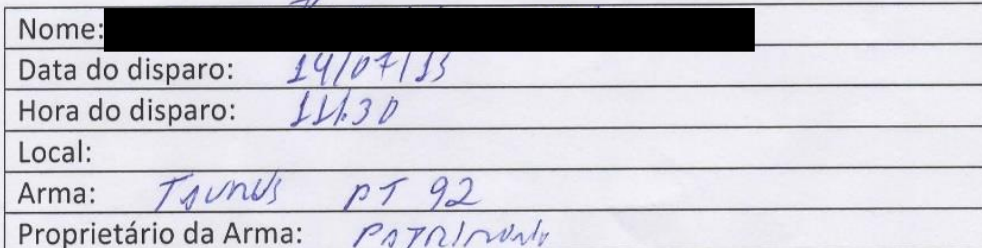

Marcador utilizado: $\square \mathrm{A} \quad \square \mathrm{B} \quad \square \mathrm{C} \quad \square \mathrm{D} \quad \square \mathrm{E} \quad \square \mathrm{F} \square \mathrm{G} \not \mathrm{H}$

Marque a posição na qual o tiro foi deflagrado (posicione-se no centro do quadrado).

\begin{tabular}{|c|c|c|c|}
\hline $1 \mathrm{~A}$ & $1 \mathrm{~B}$ & $1 \mathrm{C}$ & $1 \mathrm{D}$ \\
\hline $2 \mathrm{~A}$ & $2 \mathrm{~B}$ & $2 \mathrm{C}$ & $2 \mathrm{D}$ \\
\hline $3 \mathrm{~A}$ & $3 \mathrm{~B}$ & $3 \mathrm{C}$ & $3 \mathrm{D}$ \\
\hline
\end{tabular}

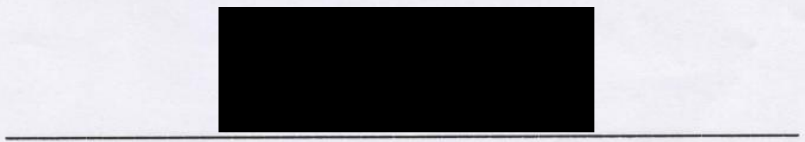

Assinatura do atirador

Figura L. Formulário preenchido no teste cego pelo quinto atirador. 


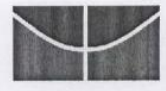

UnB/Universidade de Brasilia

IQ/Instituto de Química

Formulário para Teste à Cegas

Atirador

\section{Nome:}

Data do disparo: $14 / 7 / 15$

Hora do disparo: $12: 11$

Local: INC

Arma: Nourinco modelo 1775

Proprietário da Arma: PF/INC

Marcador utilizado: $\quad$ A $\square \mathrm{B} \quad \square \mathrm{C} \square \mathrm{D} \quad \square \mathrm{E} \quad \square \mathrm{F} \square \mathrm{G} \square \mathrm{H}$

Marque a posição na qual o tiro foi deflagrado (posicione-se no centro do quadrado).

\begin{tabular}{|c|c|c|c|}
\hline & $1 B$ & $1 C$ & $1 D$ \\
\hline $2 A$ & $2 B$ & $2 C$ & $2 D$ \\
\hline $3 A$ & $3 B$ & $3 C$ & $3 D$ \\
\hline
\end{tabular}

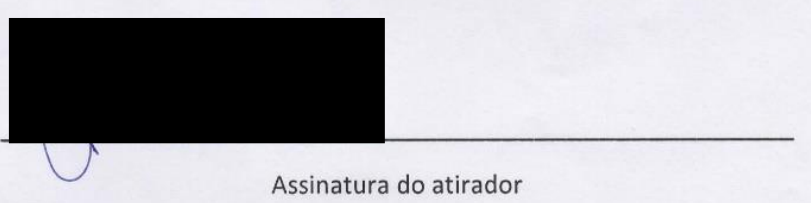

Figura M. Formulário preenchido no teste cego pelo sexto atirador. 


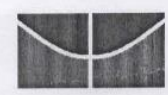

UnB/Universidade de Brasilia

IQ/Instituto de Química

Formulário para Teste à Cegas
Laboratório Interdisciplinar de

Materiais - Prof. Gilberto Sá

Atirador

Nome:

Data do disparo:

Hora do disparo:

Local:

Arma: $J \& R / \angle H D$

Proprietário da Arma:

PPTRIITANa

Marcador utilizado: $\square \mathrm{A} \square \mathrm{B} \quad \square \mathrm{C}$ D $\square \mathrm{E} \square \mathrm{F} \square \mathrm{G} \square \mathrm{H}$

Marque a posição na qual o tiro foi deflagrado (posicione-se no centro do quadrado).

\begin{tabular}{|c|c|c|c|}
\hline $1 A$ & $1 B$ & $1 C$ & $1 D$ \\
\hline $2 A$ & $2 B$ & $2 C$ & $2 D$ \\
\hline $3 A$ & $3 B$ & $3 C$ & $3 D$ \\
\hline
\end{tabular}

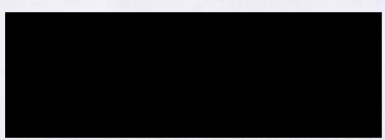

Assinatura do atirador

Figura N. Formulário preenchido no teste cego pelo sétimo atirador. 


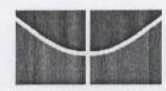

UnB/Universidade de Brasilia

IQ/Instituto de Química

Formulário para Teste à Cegas
Laboratório Interdisciplinar de

Materiais - Prof. Gilberto Sá

Atirador

\begin{tabular}{|l|}
\hline Nome \\
\hline Data do disparo: $14107 / 15$ \\
\hline Hora do disparo: \\
\hline Local: SEPLAB/INC \\
\hline Arma: TAN 9 MS PT 92 \\
\hline Proprietário da Arma: PATR/NPN/D \\
\hline
\end{tabular}

Marcador utilizado: $\square \mathrm{A} \square \mathrm{B} \square \mathrm{C} \square \mathrm{D} \quad \square \mathrm{E} \square \mathrm{F} \otimes \mathrm{G} \square \mathrm{H}$

Marque a posição na qual o tiro foi deflagrado (posicione-se no centro do quadrado).

\begin{tabular}{|c|c|c|c|}
\hline $1 \mathrm{~A}$ & $1 \mathrm{~B}$ & $\mathrm{BC}$ & $1 \mathrm{D}$ \\
\hline $2 \mathrm{~A}$ & $2 \mathrm{~B}$ & $2 \mathrm{C}$ & $2 \mathrm{D}$ \\
\hline $3 \mathrm{~A}$ & $3 \mathrm{~B}$ & $3 \mathrm{C}$ & $3 \mathrm{D}$ \\
\hline
\end{tabular}

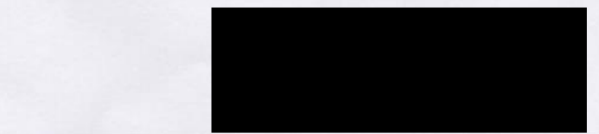

Assinatura do atirador

Figura O. Formulário preenchido no teste cego pelo oitavo atirador. 


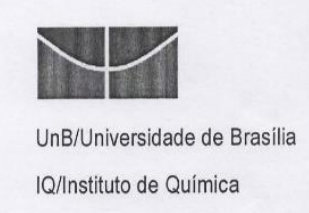

Laboratório Interdisciplinar de Materiais - Prof. Gilberto Sá

Formulário para Teste à Cegas

Analista

TA

\begin{tabular}{|l|l|}
\hline Nome: \\
\hline Data do disparo: $07 / 07 / 15$ & ThRO TA \\
\hline Hora do dispares:? $17: 25$ & \\
\hline Local: inC \\
\hline
\end{tabular}

Posição estimada do atirador e trajetória do projétil.

\begin{tabular}{|l|l|l|l|}
\hline $1 A$ & $1 B$ & $1 C$ & $1 D$ \\
\hline $2 A$ & $2 B$ & $2 C$ & $2 D$ \\
\hline $3 A$ & $3 B$ & $3 C$ & $3 D$ \\
\hline
\end{tabular}

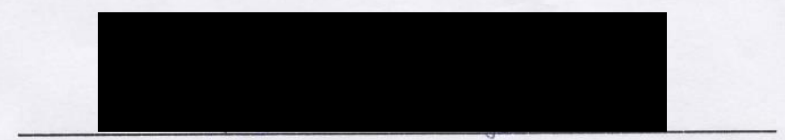

Assinatura do analista

Figura P. Formulário preenchido no teste cego pelo analista responsável pela análise da cena do crime após o disparo do primeiro atirador. 


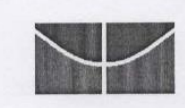

UnB/Universidade de Brasilia

IQ/Instituto de Química
Laboratório Interdisciplinar de

Materiais - Prof. Gilberto Sá

Formulário para Teste à Cegas

Analista

Nome:

Data do disparo: $09 / 07 / 15$

Hora do disparo: AnÁl SE $=16: 00$

Local: INC

Posição estimada do atirador e trajetória do projétil.

\begin{tabular}{|c|c|c|c|}
\hline $1 A$ & $1 B$ & $1 C$ & $1 D$ \\
\hline $2 A$ & $2 B$ & $2 C$ & $2 D$ \\
\hline $3 A$ & $3 B$ & $3 C$ & $3 D$ \\
\hline
\end{tabular}

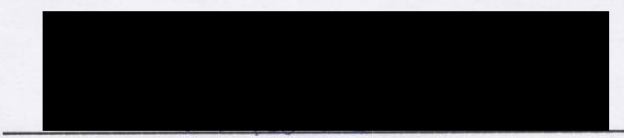

Assinatura do analista

Figura Q. Formulário preenchido no teste cego pelo analista responsável pela análise da cena do crime após o disparo do segundo atirador. 


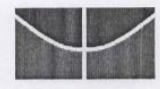

UnB/Universidade de Brasilia

IQ/Instituto de Quimica
Laboratório Interdisciplinar de

Materiais - Prof. Gilberto Sá

Formulário para Teste à Cegas

Analista

Nome:

Data do disparo: $0910+115$

Hora do disparo: 17.30

Local:

Posição estimada do atirador e trajetória do projétil.

\begin{tabular}{|c|c|c|c|}
\hline $\begin{array}{r}1 A \\
\times \quad \\
\end{array}$ & + & $\begin{array}{r}16 \\
\times \quad \\
\end{array}$ & 1D \\
\hline x & $\pi$ & $2 C$ & 20 \\
\hline $3 A$ & 3B & $3 C$ & $3 D$ \\
\hline
\end{tabular}

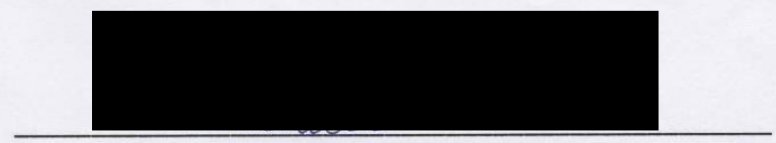

Assinatura do analista

Figura R. Formulário preenchido no teste cego pelo analista responsável pela análise da cena do crime após o disparo do terceiro atirador. 


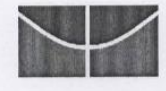

UnB/Universidade de Brasilia

IQ/Instituto de Quimica
Laboratório Interdisciplinar de

Materiais - Prof. Gilberto Sá

Formulário para Teste à Cegas

Analista

T4

\begin{tabular}{|l|}
\hline Nome \\
\hline Data do disparo: $14 / 07 / 2015$ \\
\hline Hora do Litspafo: $11: 15$ \\
\hline Local: I.N.C \\
\hline JERICHO
\end{tabular}

Posição estimada do atirador e trajetória do projétil.

\begin{tabular}{|c|c|c|c|}
\hline (1A) & $\begin{array}{r}1 B \\
\times \quad \\
\end{array}$ & $1 \mathrm{C}$ & 10 \\
\hline $2 A$ & $2 B$ & $2 C$ & $2 D$ \\
\hline $3 A$ & 3B & $3 c$ & 3D \\
\hline
\end{tabular}

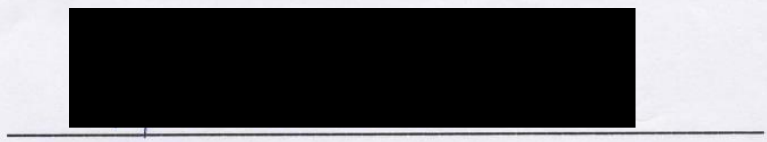

Assinatura do analista

Figura S. Formulário preenchido no teste cego pelo analista responsável pela análise da cena do crime após o disparo do quarto atirador. 


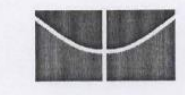

UnB/Universidade de Brasilia

IQ/Instituto de Química
Laboratório Interdisciplinar de Materiais - Prof. Gilberto Sá

Formulário para Teste à Cegas

Analista

Nome:

Data do disparo: 14/07/2015

Hora do disparo: 11:50

Local: INC

TAURUS

Posição estimada do atirador e trajetória do projétil.

\begin{tabular}{|c|c|c|c|}
\hline $1 \mathrm{~A}$ & $1 \mathrm{~B}$ & $1 \mathrm{C}$ & $1 \mathrm{D} \times$ \\
\hline $2 \mathrm{~A}$ & $2 \mathrm{~B}$ & $2 \mathrm{C}$ & $2 \mathrm{D}$ \\
\hline $3 \mathrm{~A}$ & $3 \mathrm{~B}$ & $3 \mathrm{C}$ & $\times 3 \mathrm{D}$ \\
\hline
\end{tabular}

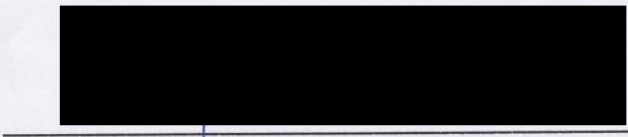

Assinatura do analista

Figura T. Formulário preenchido no teste cego pelo analista responsável pela análise da cena do crime após o disparo do quinto atirador. 


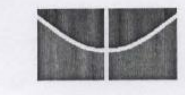

UnB/Universidade de Brasilia

IQ/Instituto de Quimica
Laboratório Interdisciplinar de Materiais - Prof. Gilberto Sá

Formulário para Teste à Cegas

Analista

Nome:

Data do disparo: 14/07/2015

Hora do 13:00

Local: INC

Posição estimada do atirador e trajetória do projétil.

\begin{tabular}{|c|c|c|c|}
\hline IA & $1 B$ & $1 C$ & $1 D$ \\
\hline $2 A$ & $2 B$ & $2 C$ & $2 D$ \\
\hline $3 A$ & $3 B$ & $3 C$ & $3 D$ \\
\hline
\end{tabular}

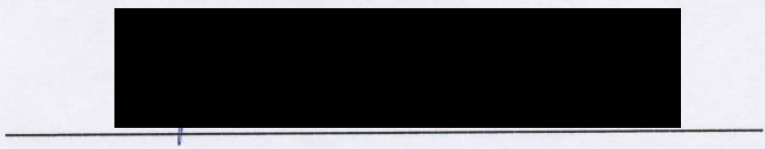

Assinatura do analista

Figura U. Formulário preenchido no teste cego pelo analista responsável pela análise da cena do crime após o disparo do sexto atirador. 


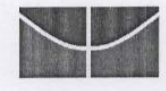

UnB/Universidade de Brasilia

IQ/Instituto de Quimica
Laboratório Interdisciplinar de

Materiais - Prof. Gilberto Sá

Formulário para Teste à Cegas

Analista

Nome:

Data do disparo: $147 / 15$

Hora do disparo: 15:51

Local: INC/PF

Posição estimada do atirador e trajetória do projétil.

\begin{tabular}{|c|c|c|c|}
\hline $1 \mathrm{~A}$ & $1 \mathrm{~B}$ & $1 \mathrm{C}$ & $1 \mathrm{D}$ \\
\hline $2 \mathrm{~A}$ & $2 \mathrm{~B}$ & $2 \mathrm{C}$ & $2 \mathrm{D}$ \\
\hline $3 \mathrm{~A}$ & $3 \mathrm{~B}$ & $3 \mathrm{C}$ & $3 \mathrm{D}$ \\
\hline
\end{tabular}

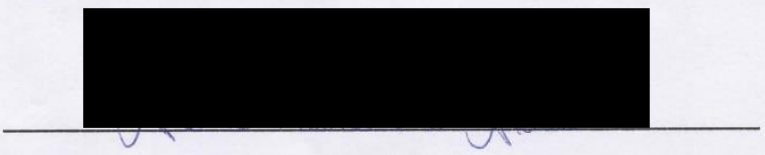

Assinatura do analista

Figura V. Formulário preenchido no teste cego pelo analista responsável pela análise da cena do crime após o disparo do sétimo atirador. 


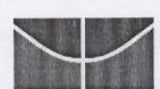

UnB/Universidade de Brasilia

IQ/nstituto de Quimica
Laboratório Interdisciplinar de Materiais - Prof. Gilberto Sá

Formulário para Teste à Cegas

Analista

\section{Nome:}

Data do disparo: $14 / 7 / 15$

Hora do disparo: 16:36

Local: INC

Posição estimada do atirador e trajetória do projétil.

\begin{tabular}{|l|l|l|l|}
\hline $1 A$ & $1 B$ & $1 D$ \\
\hline $2 A$ & $2 B$ & $2 C$ & $2 D$ \\
\hline $3 A$ & $3 B$ & $3 C$ & $3 D$ \\
\hline
\end{tabular}

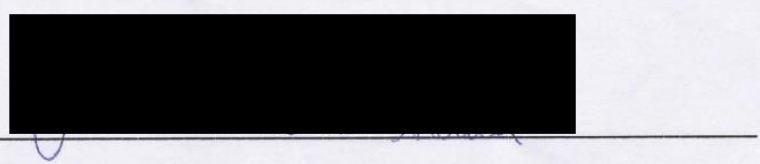

Assinatura do analista

Figura W. Formulário preenchido no teste cego pelo analista responsável pela análise da cena do crime após o disparo do oitavo atirador. 